\title{
Wastewater Triad Project: Final Summary Report
}

\section{December 2001}

\author{
Prepared by \\ J. F. Walker, Jr. \\ T. E. Kent \\ Oak Ridge National Laboratory
}

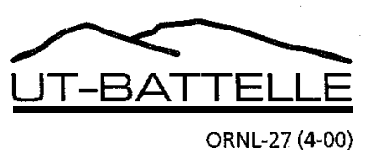




\title{
DOCUMENT AVAILABILITY
}

Reports produced after January 1, 1996, are generally available free via the U.S. Department of Energy (DOE) Information Bridge.

\section{Web site http://www.osti.gov/bridae}

Reports produced before January 1, 1996, may be purchased by members of the public from the following source.

\author{
National Technical Information Service \\ 5285 Port Royal Road \\ Springfield, VA 22161 \\ Telephone 703-605-6000 (1-800-553-6847) \\ TDD 703-487-4639 \\ Fax 703-605-6900 \\ E-mail omfp@mtos/fedwpr;d/apv \\ Web site http://www.ntis.gov/support/ordemowabout.htm
}

Reports are available to 'DOE employees, DOE contractors, Energy Technology Data Exchange (ETDE) representatives, and International Nuclear Information System (NIS) representatives from the following source.

Office of Scientific and Technical Information

P.O. Box 62

Oak Ridge, TN 37831

Telephone 865-576-8401

Fax 865-576-5728

E-mail reports@adonis.osti.gov

Web site http://www. osti.gov/contact.html

\footnotetext{
This report was prepared as an account of work sponsored by an agency of the United States Government. Neither the United States government nor any agency thereof, nor any of their employees, makes any warranty, express or implied, or assumes any legal liability or responsibility for the accuracy, completeness, or usefulness of any information, apparatus, product, or process disclosed, or represents that its use would not infringe privately owned rights. Reference herein to any specific commercial product, process, or service by trade name, trademark, manufacturer, or otherwise, does not necessarily constitute or imply its endorsement, recommendation, or favoring by the United States Government or any agency thereof. The views and opinions of authors expressed herein do not necessarily state or reflect those of the United States Government or any agency thereof.
} 
Nuclear Science and Technology Division

\title{
WASTEWATER TRIAD PROJECT: FINAL SUMMARY REPORT
}

\author{
J. F. Walker, Jr. \\ T. E. Kent
}

Manuscript Completed: September 2001

Date Published: December 2001

Prepared by the

OAK RIDGE NATIONAL LABORATORY

P.O. Box 2008

Oak Ridge, Tennessee 37831-6285

Managed by

UT-BATTELLE, LLC

For the U.S. DEPARTMENT OF ENERGY

Under contract DE-AC05-00OR22725 


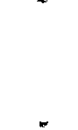




\section{CONTENTS}

\section{Page}

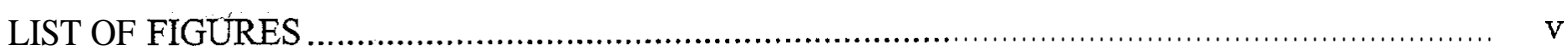

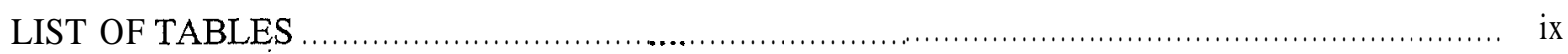

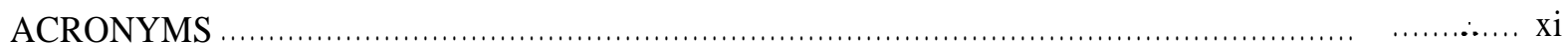

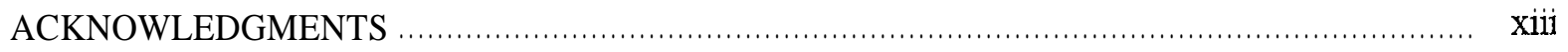

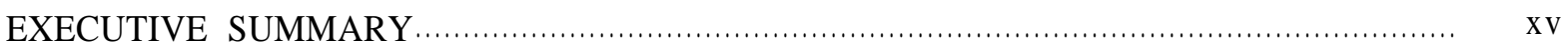

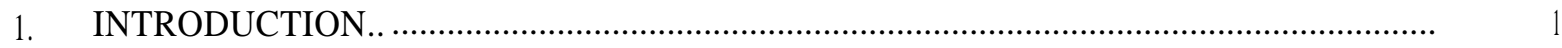

2. INTEGRATED TANK WASTE MANAGEMENT PLAN …................................................... 2

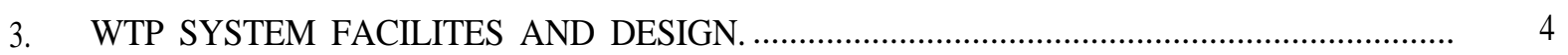

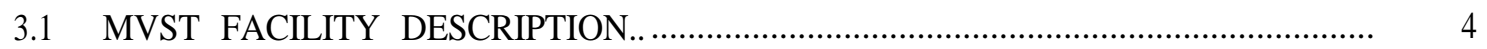

3.1.1 Waste Composition ................................................................................................

3.2 WTP SYSTEM DESIGN AND DEMONSTRATION OPERATIONS............................ 6

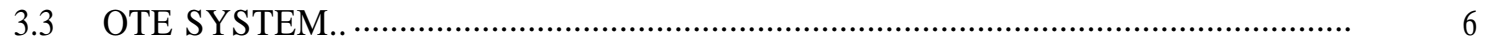

3.3.1 Heating Loop ……................................................................................... 8

3.3.2 Cooling Loop........................................................................................ 8

3.3.3 Distillate Loop ....................................................................................... 8

3.3.4 Concentrate Loop.............................................................................................. 10

3.3.5 OTE Demonstration Operations .................................................................... 11

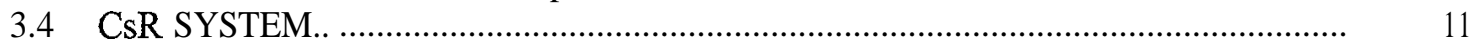

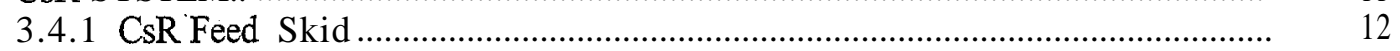

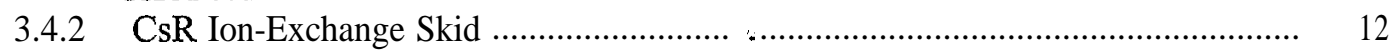

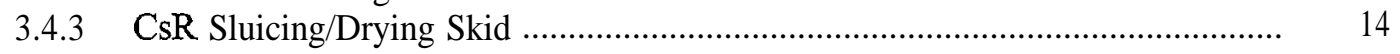

3.4.4 CsR Demonstration Operations..................................................................... 17

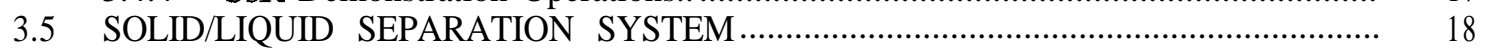

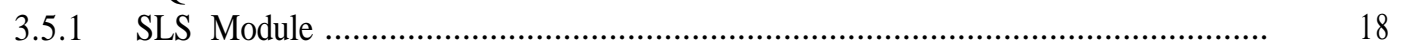

3.5.2 Backpulse System ..................................................................................... 21

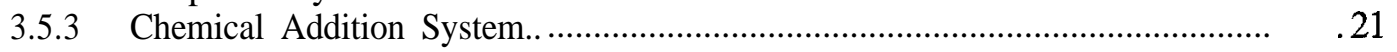

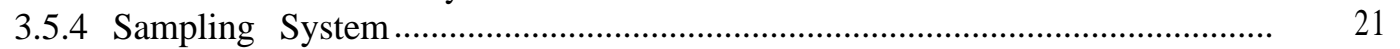

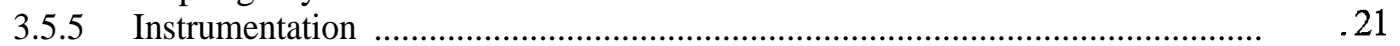

3.5.6 Waste Feed System ............................................................................ 22

3.5.7 SLS Demonstration Operations ...................................................................... 23

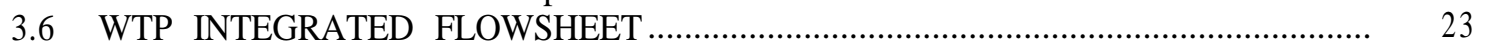

3.7 PERFORMANCE REQUIREMENTS AND OPERATING PLANS................................ . . 23

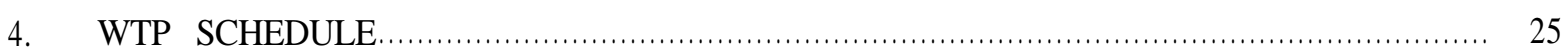

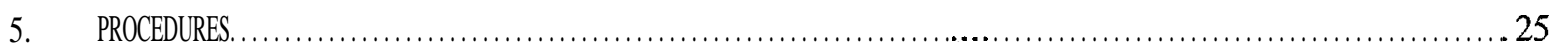

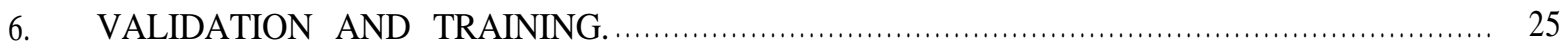


7. DOCUMENT REQUIREMENTS AND READINESS SELF-ASSESSMENT ........................ 26

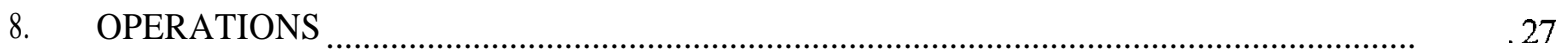

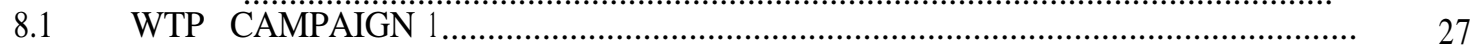

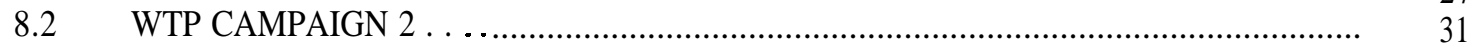

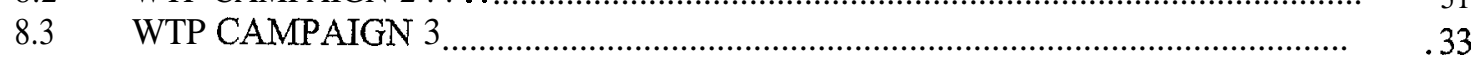

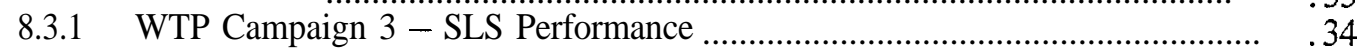

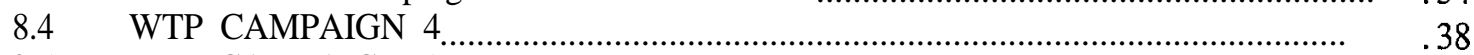

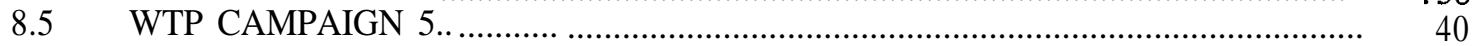

8.5.1 WTP Campaign 5 - SLS Performance .......................................................... . .42

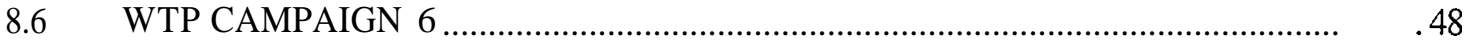

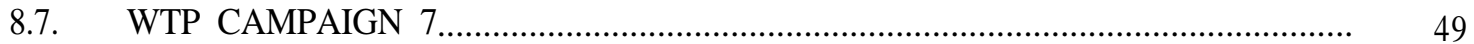

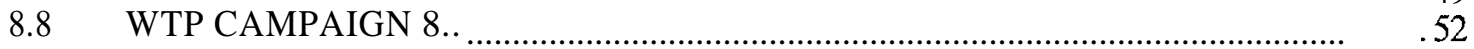

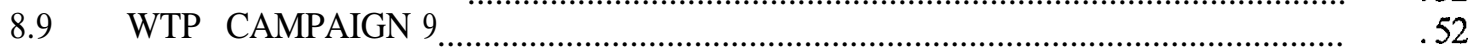

8.9.1 WTP Campaign 9 - SLS Performance …….................................................. .52

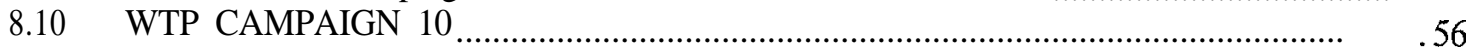

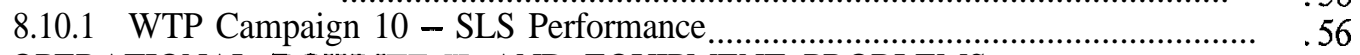

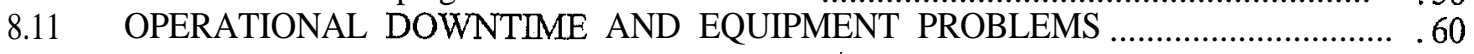

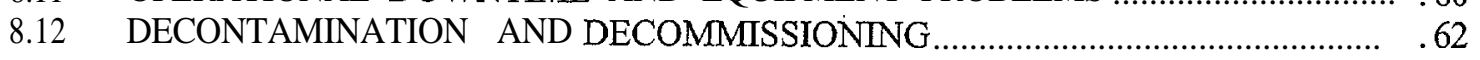

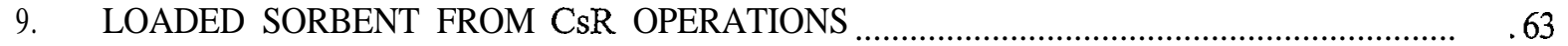

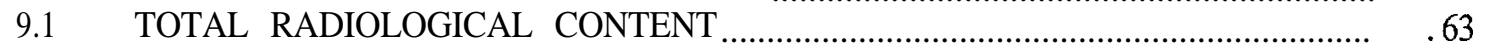

9.2 TRANSURANICS AND HAZARDOUS WASTE COMPONENTS............................... 64

9.3 HIGH-INTEGRITY CONTAINER CONTENTS ....................................................... . 64

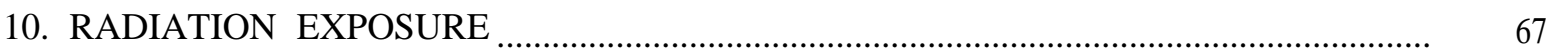

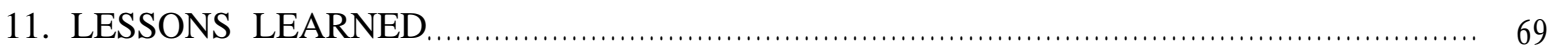

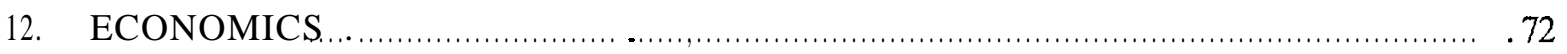

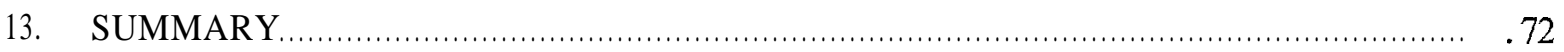

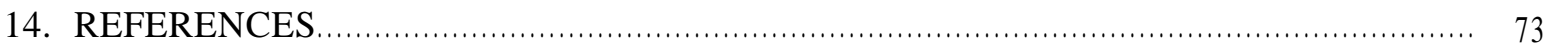

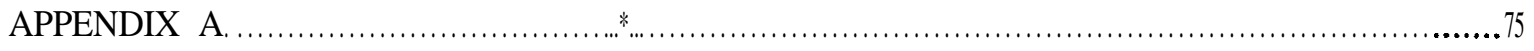

APPENDIX B 


\section{LIST OF FIGURES}

F i g u r e $\quad$ Page

1 Inventory of sludge and supematant in the Bethel Valley watershed prior to the implementation of the integrated tank waste management plan. .......................................................... 4

2 Aerial photograph of the MVST facilities during construction for the capacity increase tanks.... 5

3 Photograph of the OTE skid prior to the placement of the concrete shields $\ldots \ldots \ldots \ldots \ldots \ldots \ldots \ldots \ldots \ldots \ldots$

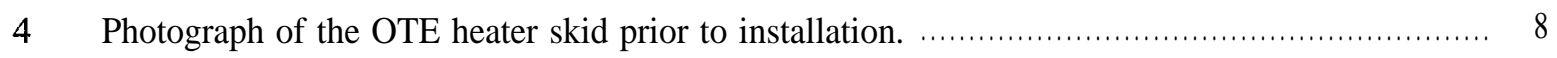

5 Overhead view of the OTE evaporator skid, OTE feed skid, CsR feed skid, and CsR ion-exchange skid after installation had been completed................................................ 9

6 Schematic diagram showing the four basic loops for the OTE system: the heating loop, the cooling loop, the distillate loop, and the concentrate loop. ...................................................... 10

$7 \quad$ Photograph of the CsR feed skid during installation of the feed tank shielding........................ 13

$8 \quad$ Photograph of the feed tank skid with all shielding installed. ................................................. 13

9 Photograph of the ion-exchange skid showing the shielded ion-exchange columns during

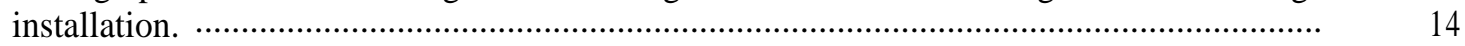

10 Photograph of the sorbent-sluicing/drying skid. ................................................................. 15

11 Photograph of the fill head installed on the shielded high-integrity container. .......................... 16

12 Photograph taken during remote operations with the overhead crane.................................. 16

13 Photograph of the concrete cask used to shield the high-integrity container containing the

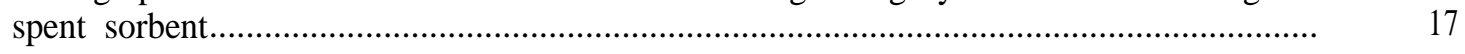

14 SLS system during acceptance testing at the NUMET facility. ......................................... 19

15 SLS components prior to installation of shie Ming. ................................................................ 19

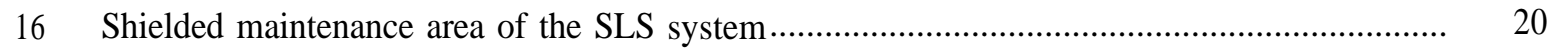

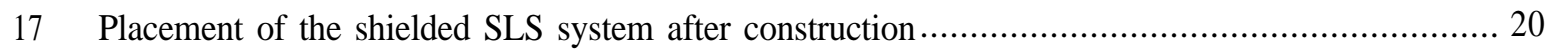

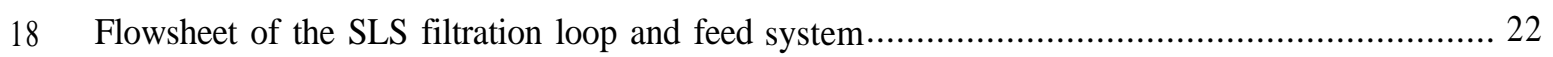

19 Schematic drawing of the WTP system ............................................................ 24

20 Graph of the decontamination factors for the CsR system for the WTP operational campaigns. . . 29

21 Flow rate for the WTP system as a function of time for the first WTP operational campaign. ..... 30 
22 Pressure drop through the CsR prefilter and ion-exchange columns during the first WTP operational campaign

23 Flow rate through the WTP system as a function of time for the second WTP campaign. . . . . . . 32

24 Pressure drop through the CsR prefilter and ion-exchange columns during the second WTP

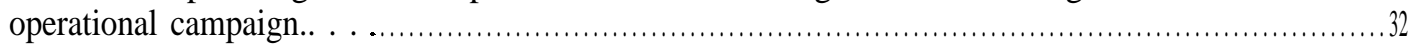

25 Flow rate through the WTP system as a function of time for the third WTP operational campaign

26 Filtrate flow, transmembrane pressure, and axial flow as a function of time during the third WTP Campaign (Series 1, tests 1-7, tank W31). *............ 35

27 Filtrate flow, transmembrane pressure, and axial flow as a function of time during the third WTP Campaign (Series 1, tests 8-12, tank W31)

28 Filtrate flow, feed TSS, and feed mass flow as a function of time during the third WTP Campaign (Series 1, tests 1-7, tank W31).

29 Filtrate flow, feed TSS, and feed mass flow as a function of time during the third WTP Campaign (Series 1, tests 8-12, tank W31),.... 37

30 Feed TSS, filtrate flow, and feed mass flow as a function of time near the end of processing tank W31 for the third WTP Campaign.

31 Filtrate flow, axial flow, and transmembrane pressure as a function of time near the end of processing for tank W3 1 during the third WTP Campaign.

32 Flow rate through the WTP system as a function of time for the fourth WTP operational campaign.

33 Flow through the WTP system as a function of time for the fifth WTP Campaign. . . . . . . . ...... 41

34 Filtrate flow, transmembrane pressure, and axial flow as a function of time during the fifth WTP campaign (Test Series 2, tank W26)

35 Feed mass flow and TSS as a function of time during the fifth WTP Campaign (Series 2, tank W26)

36 Average filtrate flux as a function of transmembrane pressure during the fifth WTP Campaign (Test Series 2, tank W26).

37 Average filtrate flux as a function of axial velocity during the fifth WTP Campaign (Test Series 2, tank W26).

38 Feed mass flow, feed TSS, and filtrate flow as a function of time during the fifth WTP Campaign (Test Series 3, tank W26).

39 Filtrate flow, axial flow, and transmembrane pressure as a function of time during the fifth WTP Campaign (Test Series 3, tank W26)..... 
40 Average filtrate flux as a function of transmembrane pressure during the fifth WTP Campaign

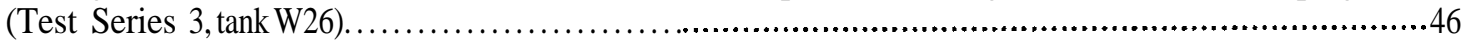

41 Average filtrate flux as a function of axial velocity during the fifth WTP Campaign

(Test Series 3, tank W26).................................................................................. 47

42 Average filtrate flux as a function of test chronological order for tank W26 during the fifth WTP Campaign.

43 Pressure drop across the prefilter and ion-exchange columns during the sixth WTP campaign. . . 48

44 Front view of the OTE evaporator skid showing the location of the standpipe containing the instrument for monitoring the OTE shell level

45 End view of the OTE evaporator skid showing the location of the standpipe containing the instrument for monitoring the OTE shell level.

46 Drawing showing the design of the new spool piece to change the location of the OTE shell level instrument from a standpipe to a location within the shell. ..................................... 51

47 Solids content of the SLS feed as a function of time for the ninth WTP campaign. . . . . . . . . . 54

48 Filtrate flow rate as a function of time for the ninth WTP operational campaign. . . . . . . . . . . 54

49 Feed flow rate to the SLS system as a function of time for the ninth WTP operational

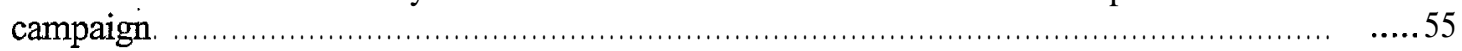

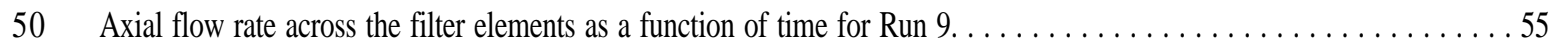

51 Transmembrane pressure as a function of time for the ninth WTP operational campaign. ...........56

52 Solids content of the SLS feed as a function of time for the tenth WTP campaign. .57

53 Flow rate of the feed to the SLS system as a function of time during the tenth WTP operational campaign.

54 Axial flow rate across the filter elements as a function of time for the tenth WTP operational campaign.

Filtrate flow rate as a function of time for the tenth operational campaign .

Transmembrane pressure as a function of time for the tenth WTP operational campaign.. . . . . . . 59

57 Pressure drop across the filters as a function of time for the tenth WTP operational campaign. . . . 60

59 Total radiation exposure received during the WTP during the various operational periods. . . . . . 68

60 Radiation levels received by WTP individuals during the 1999 calendar year broken down by organization (includes only personnel whose exposure exceeded $10 \mathrm{mR}$ for the calendar year). . 69 


\section{.}

. 


\section{LIST OF TABLES}

$\begin{array}{lll}\text { Table } & \text { Page }\end{array}$

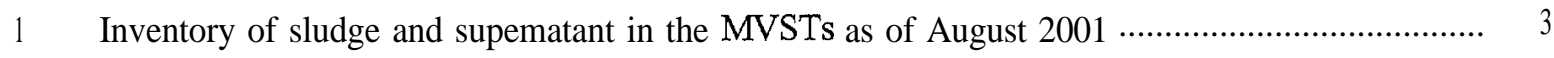

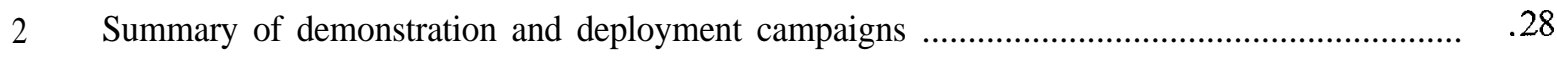

3 Summary of operational problems and time requirements for each operational run .................... .61

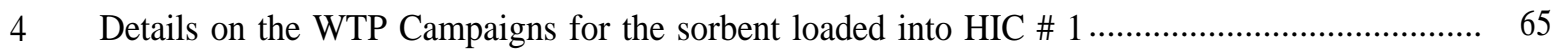

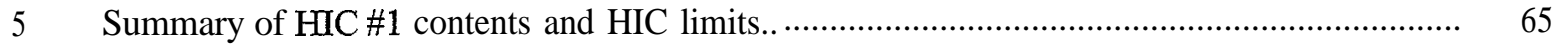

6 Details on the WTP Campaigns for the sorbent loaded into HIC \# $2 \ldots \ldots \ldots \ldots \ldots \ldots \ldots \ldots \ldots \ldots \ldots \ldots \ldots \ldots . . . . .66$

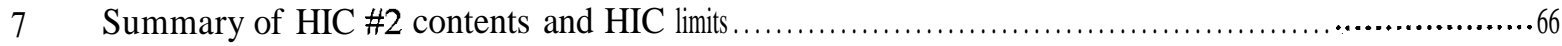




\section{ACRONYMS}

\begin{tabular}{|c|c|}
\hline ALARA & as low as reasonably achievable \\
\hline ASTD & Accelerated Site Technology Development \\
\hline BJC & Bechtel Jacobs Company LLC \\
\hline BVEST & Bethel Valley Evaporator Service Tank \\
\hline CERCLA & Comprehensive Environmental Response, Compensation, and Liability Act \\
\hline CFR & Code of Federal Regulation \\
\hline CI & capacity increase (tank) \\
\hline CIP & Capacity Increase Project \\
\hline CsR & cesium removal \\
\hline CST & crystalline silicotitanate \\
\hline CTD & Chemical Technology Division (ORNL) \\
\hline D\&D & decontamination and decommissioning \\
\hline $\mathrm{D} / \mathrm{D}$ & double diaphragm \\
\hline DOE & U.S. Department of Energy \\
\hline DOE-ORO & U.S. Department of Energy Oak Ridge Operations \\
\hline DOT & U. S . Department of Transportation \\
\hline DWPF & Defense Waste Processing Facility \\
\hline ESP & Efficient Separations and Crosscutting Program (DOE) \\
\hline FCV & flow control valve \\
\hline GAAT & Gunite and Associated Tanks \\
\hline GUI & graphical user interface \\
\hline HEPA & high-efficiency particulate air \\
\hline HIC & high-integrity container \\
\hline $\mathrm{I} \& \mathrm{C}$ & Instrumentation and Controls Division (ORNL) \\
\hline $\mathrm{I} / \mathrm{O}$ & input/output \\
\hline IFE & Internal Field Evaluation \\
\hline INEEL & Idaho National Engineering and Environmental Laboratory \\
\hline LDR & Land Disposal Restriction \\
\hline LGWOP & Liquid and Gaseous Waste Operations Project \\
\hline LLLW & low-level liquid waste \\
\hline LMER & Lockheed Martin Energy Research Corp. \\
\hline MLDUA & modified light-duty utility arm \\
\hline MVST & Melton Valley Storage Tank \\
\hline JTS & Nevada Test Site \\
\hline
\end{tabular}




$\begin{array}{ll}\text { OHF } & \text { Old Hydrofracture Facility } \\ \text { ORNL } & \text { Oak Ridge National Laboratory } \\ \text { ORR } & \text { Oak Ridge Reservation } \\ \text { OST } & \text { Office of Science and Technology (DOE) } \\ \text { OTE } & \text { Out-of-Tank-Evaporator } \\ & \\ \text { P\&E } & \text { Plant and Equipment Division (ORNL) } \\ \text { P\&ID } & \text { piping and instrument diagram } \\ \text { PCB } & \text { polychlorinated biphenyl } \\ \text { PDC } & \text { Performance Document Checklist } \\ \text { PID } & \text { proportionalintegralderivative (loop) } \\ \text { PLC } & \text { programmable logic controller } \\ \text { PUE } & \text { Procedure User Examination } \\ \text { PWTP } & \text { Process Waste Treatment Plant } \\ \text { PVV } & \text { pump-and-valve vault } \\ & \\ \text { RCRA } & \text { Resource Conservation and Recovery Act } \\ \text { RH-TRU } & \text { remote-handled transuranic (waste) } \\ \text { RWP } & \text { Radiation Work Permit } \\ & \\ \text { SAP } & \text { sampling and analysis plan } \\ \text { SLS } & \text { solid/liquid separation } \\ \text { SME } & \text { subject matter expert } \\ \text { SNL } & \text { Sandia National Laboratories } \\ \text { SRS } & \text { Savannah River Site } \\ \text { SRTC } & \text { Savannah River Technology Center } \\ \text { SWSA } & \text { Solid Waste Storage Area } \\ & \text { Toxicity Characteristic Leaching Procedure } \\ \text { TCLP } & \text { Tanks Focus Area } \\ \text { TFA } & \text { transuranic } \\ \text { TRU } & \text { total suspended solids } \\ \text { TSS } & \text { Wasdissolved solids } \\ \text { UDS } & \text { Waste Acceptance Criteria } \\ \text { WAC } & \text { Waste Isolation Pilot Plant } \\ \text { WIPP } & \\ \text { WTP } & \end{array}$




\section{ACKNOWLEDGMENTS}

The successful completion of this project was made possible through a dedicated team effort involving many individuals and organizations over the span of several years. The U.S. Department of Energy (DOE) Tanks Focus Area (TFA) was the major provider of funding for the project and made possible the integration of technical support from several different DOE sites where state-of-the-art ion-exchange and filtration technologies were being developed and evaluated. The TFA recognized that the support of this project would benefit environmental management activities at Oak Ridge and across the DOE complex by providing local processing capability and evaluating the performance of full-scale volume reduction, ion-exchange, and solid/liquid separation (SLS) systems for potential application in tank waste pretreatment at other DOE sites. The program contributions of C. S. Mims and J. N. Dial, of DOE-Oak Ridge Operations (DOE-ORO), were vital to the project. Their vision of the Wastewater Triad Project (WTP) system as an integral part of the remediation activity associated with the Bethel Valley Watershed was critical. S. M. Robinson and C. P. McGinnis, of the ORNL Chemical Technology Division, provided dedicated support through their coordination of the project with TFA, DOE-ORO, and Waste Operations since the inception of the project in 1996. A. J. Lucero led the effort for the initial installation and demonstration of the Out-of-Tank Evaporator (OTE). J. H. Wilson and J. R. Farmer, of the ORNL Engineering Division, led the development of design specifications for the SLS system and selected NUMET Engineering, Ltd., as the design and fabrication subcontractor for the full-scale SLS system. J. R. Farmer and R. D. Gray, Quality Engineering, performed thorough quality assurance inspections during fabrication of the SLS system by NUMET. The Bechtel Jacobs Company LLC Waste Operations Project team under the management of C. E. Frye and C. B. Scott provided excellent field operations and maintenance support for the project. The field operations shift leaders from the Radiochemical Technology Section of the ORNL Chemical Technology Division, provided outstanding, dedicated support of the operation. This team included R. L. Cummins, B. S. Evans, L. L. Farr, J. D. Hewitt, H. L. Jennings, S. A. Richardson, and P. A. Taylor. 'Installation and evaluation of the dual Coriolis meter system for monitoring on line suspended solids concentrations were provided by T. D. Hylton, of the Radiochemical Technology Section of the ORNL Chemical Technology Division. 


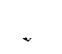

.

. 


\section{E X E C U T I V E S U M M A R Y}

The Wastewater Triad Project (WTP) was part of the integrated tank waste management plan at Oak Ridge National Laboratory (ORNL) involving the development, demonstration, and deployment of three treatment processes for reducing the volume and radioactivity of ORNL liquid low-level waste (LLLW) stored in the Melton Valley Storage Tanks (MVSTs). These processes were designed for deployment as modular processing units and included evaporation, ion-exchange, and solid/liquid separation technologies. Each processing unit was developed and demonstrated separately, followed by modification for deployment as an integrated processing system. The deployment of these three treatment units together as the WTP made it possible to (1) reduce the volume of of LLLW being generated from tank remediation, (2) reduce the radioactivity of LLLW being generated from typical R\&D and reactor operations, (3) accelerate the schedule for clean-out and remediation of underground storage tanks, and (4) evaluate the performance of treatment technologies that are likely to be deployed at other U.S. Department of Energy (DOE) sites.

During the period from December 1997 though April 2000, the WTP processes were successfully deployed and 14 operational campaigns were completed A total of $-268,000$ gal of LLLW was processed, reducing the volume by $-117,000 \mathrm{gal}$ and removing $7700 \mathrm{Ci}$ of ${ }^{137} \mathrm{Cs}$. The performance of the systems generally met expectations, and the secondary wastes produced (distillate and cesium-loaded ion exchanger) met the requirements for final disposal.

The deployment of these treatment systems as modular units within existing containment facilities was an important concept that was demonstrated successfully for this project. The ability to use existing containment facilities near the tank systems and have the treatment units designed and fabricated off-site can translate into significant cost savings compared with on-site "greenfield" construction of large processing facilities. Both the evaporator and ion-exchange systems were installed in existing Building 7877, adjacent to the MVSTs. Modular shield walls were used to reduce the general area radiation dose within the building, and the existing ventilation and spill containment systems were adequate for environmental protection. The filtration system was designed to include ventilation and spill containment and was installed separately as a stand-alone unit adjacent to the MVST vault. Hands-on maintenance and repairs were performed successfully on all three processing units without exceeding the planned radiation dose limits for workers. The ability to drain and flush the systems and to shield individual components were key factors in facilitating hands-on work and reducing radiation dose to personnel

In most cases, the performance of the systems met expectations and the requirements defined in the project plans. The evaporator system (also referred to as the Out-of-Tank Evaporator, or OTE) was designed to produce $90 \mathrm{gal} / \mathrm{h}$ of distillate with purity that met the waste acceptance criteria (WAC) for onsite wastewater treatment and discharge. The evaporator usually produced from 30 to $60 \mathrm{gal} / \mathrm{h}$, and the distillate produced met the criteria for treatment at the ORNL Process Waste Treatment Plant (PWTP) and discharge to the environment.

A crystalline silicotitanate-based sorbent, Ionsiv IE-911, manufactured by UOP Molecular Sieves, LLC, was used in the cesium removal (CsR) ion-exchange system to remove $7700 \mathrm{Ci}$ of ${ }^{137} \mathrm{Cs}$ from the supematant. 'The system successfully removed greater than $90 \%$ of the cesium from the feed liquid and concentrated the cesium on 540 gal of IE-9 11. The IE-91 1 was successfully dewatered and packaged to meet the WAC for the Nevada Test Site (NTS). A portion of the cesium-loaded IE-911 was also shipped to the Savannah River Technology Center (SRTC) in Aiken, South Carolina, and unloaded into a hot cell facility for use in vitrification demonstrations. The SRTC developed a glass formulation for the IE-911 
that could incorporate up to $65 \mathrm{wt} \%$ of the cesium-loaded sorbent into the glass matrix without crystal formation. Ion exchange with IE-911 is one of the alternative technologies being pursued at both Savannah River and Hanford for treatment of their tank wastes.

A modular Solid/Liquid Separation (SLS) system, based on cross-flow filtration technology, was used to provide solids-free feed liquid to the CsR and OTE systems for processing. The SLS system used 0.5- $\mu \mathrm{m}$ stainless steel sintered-metal filter units with a total filter surface of $50 \mathrm{ft}^{2}$ and was designed to provide filtrate at a rate of 1 to $5 \mathrm{gal} / \mathrm{min}$ (flux range of 0.02 to $0.1 \mathrm{gal} \mathrm{min}^{-1} \mathrm{ft}^{-2}$ ). During operations in four campaigns, the actual filtrate production ranged between 0.6 and $8.0 \mathrm{gal} / \mathrm{min}$ (flux range of 0.012 to $0.16 \mathrm{gal} \mathrm{min}^{-1} \mathrm{ft}^{-2}$ ). The performance of the system was excellent, and the quality of filtrate consistently met the requirements for feed to the downstream ion-exchange and evaporator systems.

All systems performed successfully during the demonstrations and deployments; however, some modifications were required to correct operational deficiencies, and maintenance activities became more frequent in later operations. The OTE system was sometimes difficult to operate due to the buildup of scale on heat transfer surfaces. Problems with instrumentation and valve actuators were also fairly common. The primary difficulty encountered with the CsR system was brought on by a design limitation that caused buildup of IE-911 fines in the CsR piping system. This buildup led to unplanned downtime to clear flow restrictions and repair pump damage. Problems with CsR instrumentation in high-radiation fields were also encountered. The SLS system encountered minor problems with the feed system installed in the MVST pump and valve vault. The two double-diaphragm feed pumps operated erratically at times but were able to maintain the flow and pressure necessary for adequate filtrate production.

The WTP was beneficial to both ORNL and the DOE complex. The reduction in volume and radioactivity of the ORNL tank waste translates into significant cost savings compared with the baseline plan for direct grouting of untreated tank waste. However, the baseline plan was modified during the WTP to accommodate a new privatization contract for treatment of tank waste liquids and sludges. The actual cost benefit for the WTP will not be quantifiable until the treatment method and estimated costs are known. All three of the technologies used in the WTP are in the baseline planning flowsheets for treatment of tank waste at Hanford, Savannah River, and Idaho. The information gained and lessons learned from the ORNL deployments will be extremely valuable for similar deployments at these sites. 


\section{INTRODUCTION}

The U.S. Department of Energy (DOE) facilities have performed nuclear energy research and radiochemical production since the early 1940s. Currently, millions of gallons of legacy radioactive liquid and sludge wastes are contained in over 300 large underground storage tanks, located primarily at Hanford, the Savannah River Site (SRS), Idaho National Engineering and Environmental Laboratory (INEEL), and Oak Ridge National Laboratory (ORNL). Plans for tank waste retrieval, treatment, and immobilization are being developed and implemented throughout the DOE complex In order to meet regulatory requirements for remediation of underground storage tanks, ORNL has developed an integrated approach to the management of its waste that has applications across the DOE complex. The integrated approach consolidates plans for remediation of inactive tanks; upgrade of the active waste collection, storage, and treatment systems; and treatment of transuranic (TRU) tank waste for disposal. ${ }^{1}$ Important elements of this integrated approach to tank waste management include waste retrieval of sludges fi-om tanks, conditioning and transport of retrieved waste to active storage tanks or treatment facilities, solid/liquid separations for supematant recycle and/or waste treatment, removal of cesium from the supernatant, volume reduction of the supematant, and solidification of sludges and supematant for disposal. Each unit operation of the flowsheet is interconnected and impacts the overall efficiency of the entire flowsheet. ORNL has implemented innovative but proven technologies for each of the major unit operations to to accelerate clean-up.

ORNL used the integrated plan to determine where developing technologies were required to create an optimized flowsheet to (1) accelerate clean-out and remediation of underground storage tanks; (2) provide significant cost avoidance and schedule reductions; (3) consolidate wastes for private-sector immobilization; (4) facilitate regulatory compliance with the Comprehensive Environmental Response, Compensation, and Liability Act (CERCLA), Resource Conservation and Recovery Act (RCRA), and Land Disposal Restrictions (LDR) regulations; and (5) deploy state-of-the art technologies that have applications across the DOE complex. Partnerships were developed with DOE technology development agencies, private-sector companies, and other DOE sites to accomplish implementation of these technologies.

The Wastewater Triad Project (WTP), an integral part of the integrated waste management plan, was developed and implemented through the DOE Tanks Focus Area (TFA) technology development program and two Accelerated Site Technology Development (ASTD) projects to support the ORNL remediation plan. The processes included the Out-of-Tank Evaporator (OTE), the Cesium Removal (CsR) ionexchange system, and the Solid/Liquid Separation (SLS) system. Each process was deployed through co-funded EM-30/50 projects at ORNL using skid-mounted, modular systems installed in existing facilities. The ion-exchange and evaporation unit operations were implemented through the Modular Evaporator and Ion Exchange Systems for Waste Reduction in Tanks ASTD project, while the SLS system was implemented through the Tanks Sludge Retrieval, Conditioning, and Transfer Technology ASTD initiative.

The ORNL Liquid Low-Level Waste (LLLW) system is an actively operating collection, treatment, and storage system for management of waste generated by ongoing research and reactor operations. The inactive tank system consists of much older tanks that no longer meet containment requirements and do not collect waste from ongoing operations. Over several decades of use, the active system has collected radiological waste from ongoing nuclear research operations and from inactive tanks that have been, emptied into the active system. The active tank system has limited treatment and storage capacity. The integrated waste management plan called for consolidating all remote-handled transuranic (RH-TRU) tank waste sludge in the Melton Valley Storage Tanks (MVSTs). Waste retrieval activities from inactive tanks generate large volumes of excess water used to mix with sludges and facilitate transfer of these 
slurries. To conserve storage capacity in the active system, the plan called for the evaporator system to be operated to concentrate MVST supematant prior to and during sludge retrieval operations. To reduce radiation exposure and reduce the associated cost of processing and transporting the concentrated liquids, the plan called for the CsR system for removal of radioactive cesium from the waste. The plan also required the extensive use of SLS processing in order to provide solids-free feed to the pretreatment (CsR and OTE) processes and to avoid accumulation of solids in the new MVST Capacity Increase Project (CIP) tanks.

This report provides detailed information regarding the development, demonstration, and operational performance of the three processing modules that constitute the WTP .

\section{INTEGRATED TANK WASTE MANAGEMENT PLAN}

DOE's Environmental Management Program at ORNL developed the Integrated Tank Waste Management Plan,' which combined the accelerated deployment of innovative technologies with an aggressive waste transfer schedule. The plan called for removal of the sludge and supematant wastes from the Bethel Valley Evaporator Service Tanks (BVESTs), the Old Hydrofracture Facility (OHF) tanks, and the Gunite and Associated Tanks (GAAT); consolidation of the waste in the MVSTs; waste treatment and immobilization by the private sector; and disposal of the waste at either the Waste Isolation Pilot Plant (WIPP) or the Nevada Test Site (NTS). This plan was designed to ensure that ORNL meets the State of Tennessee Commissioner's unilateral order that requires treatment of transuranic sludge be initiated by June 2002. The Integrated Waste Management Plan consists of four primary actions: (1) accelerated deployment of innovative technologies; (2) integrated waste retrieval, waste conditioning, transfer, and storage; (3) tank closure, and (4) the privatization of waste processing and packaging for off site-disposal.

The accelerated deployment of innovative technologies included the deployment of eight technologies developed by universities and the private sector and demonstrated through DOE's TFA and/or Office of Science and Technology (OST). Each of the technologies has widespread applications throughout the DOE complex. Although the facilities at SRS and Hanford have larger tanks and more waste to treat, the technologies and techniques utilized at ORNL can be scaled and transferred to these sites for direct use or as specifications for privatization activities. The technologies were integrated into eight modular systems that included a combination of new equipment and improved components for existing systems that had been successfully demonstrated in the past. The integrated modular systems included the following.

Sludge Heel Retrieval System for Large Vertical Tanks: This system coupled the ORNL Tank Cleaning System [developed by TFA, EM-50 Robotics Program, and DOE-Oak Ridge Operations (ORO)] with an improved Waste Dislodging and Conveyance system that employed confined sluicing using the modified light-duty utility arm (MLDUA) and hose management system a high-pressure pump and special MLDUA end effector for wall scarifying, and an improved Houdini remotely operated vehicle. This system was initially deployed for retrieval of waste sludges and tank cleaning for the GAAT system

Sludge Retrieval System for Small Tanks: This system coupled the Borehole Miner extendible nozzle (developed by TFA and DOE-ORO) with an improved Scarab remotely operated vehicle for retrieving sludge from smaller horizontal tanks. This system was initially deployed in the remediation of the OHF tank system 
Bulk Sludge Retrieval System for Large Horizontal Tanks : This system consisted of a modified version of the AEA Technology Fluidic Pulsed-Jet Mixing unit. This system was initially deployed in the BVESTs for mixing and retrieval of sludge from large $(50,000$-gal) horizontal tanks.

Bulk Sludge Retrieval System for Large Vertical Tanks: This system utilized both the Pulsair Mixer and the Flygt Mixer systems to mobilize and mix sludge and supematant in the GAAT waste consolidation tank for transfer by the Sludge Conditioning System to the active tank system

Sludge Conditioning System for Pipeline Transfer: This system was composed of a retrieval pump, solids classifier, solids monitor, and transfer pump that were integrated into a modular unit for retrieval and transfer of GAAT sludge/liquid slurries to the active tank facilities.

Solid/Liquid Separations System: This system, which was part of the WTP, utilized cross-flow filtration technology for removal of suspended solids and efficient liquid management at the MVSTs during consolidation of the GAAT, OHF, and BVEST liquids and sludges.

Cesium Removal System: This system, which was part of the WTP, utilized a newly developed nonelutable crystalline silicotitanate-based ion-exchange sorbent for removal of cesiurn from the tank supematant.

Out-of-Tank Evaporator: This system, which was part of the WTP, utilized a subatmospheric evaporator for volume reduction of the supematant in the MVSTs. This created additional storage capacity, which allowed the effective management of the large quantity of sluice water required for tank waste retrieval activities and the waste being generated from ongoing research and reactor operations at ORNL.

A schematic diagram showing the components in the Integrated Tank Waste Management Plan is presented in Fig. 1. Also shown is the inventory of liquid and sludge in the various tank farms at ORNL in 1997 prior to implementation of the plan, as well as the quantity of waste retrieval liquid estimated to be generated during the remediation activities. Retrieval and transfer of the sludge from the OHF, the GAAT, and the BVEST tanks have now been completed and the sludge from these tanks has been consolidated in the MVSTs. The current inventory in the MVSTs (as of August 2001) is presented in Table 1. This sludge is to be immobilized by Foster Wheeler through a privatization subcontract with DOE. DOE is responsible for the transportation of the immobilized waste to the repository. The process flowsheet to be used by Foster Wheeler has not been finalized.

Table 1. Inventory of sludge and supernatant in the MVSTs as of August 2001

\begin{tabular}{|c|c|c|c|}
\hline Tank number & $\begin{array}{l}\text { Sludge volume } \\
\text { (gal) }\end{array}$ & $\begin{array}{c}\text { Supernatant "volume } \\
\text { (gal) }\end{array}$ & $\begin{array}{c}\text { Waste volume } \\
\text { (gal) }\end{array}$ \\
\hline $\begin{array}{ll}\mathrm{W} & 2\end{array}$ & 29,660 & 980 & 30,640 \\
\hline W25 & 27,639 & 231 & 27,870 \\
\hline W26 & 22,218 & 282 & 22,500 \\
\hline W27 & 28,000 & 700 & 28,700 \\
\hline W28 & 20,183 & 107 & 20,290 \\
\hline w29 & 25,478 & 72 & 25,550 \\
\hline W30 & 21,208 & 582 & 21,790 \\
\hline w31 & 22,380 & 270 & 22,650 \\
\hline Total & 196,766 & 3,224 & 199,990 \\
\hline
\end{tabular}




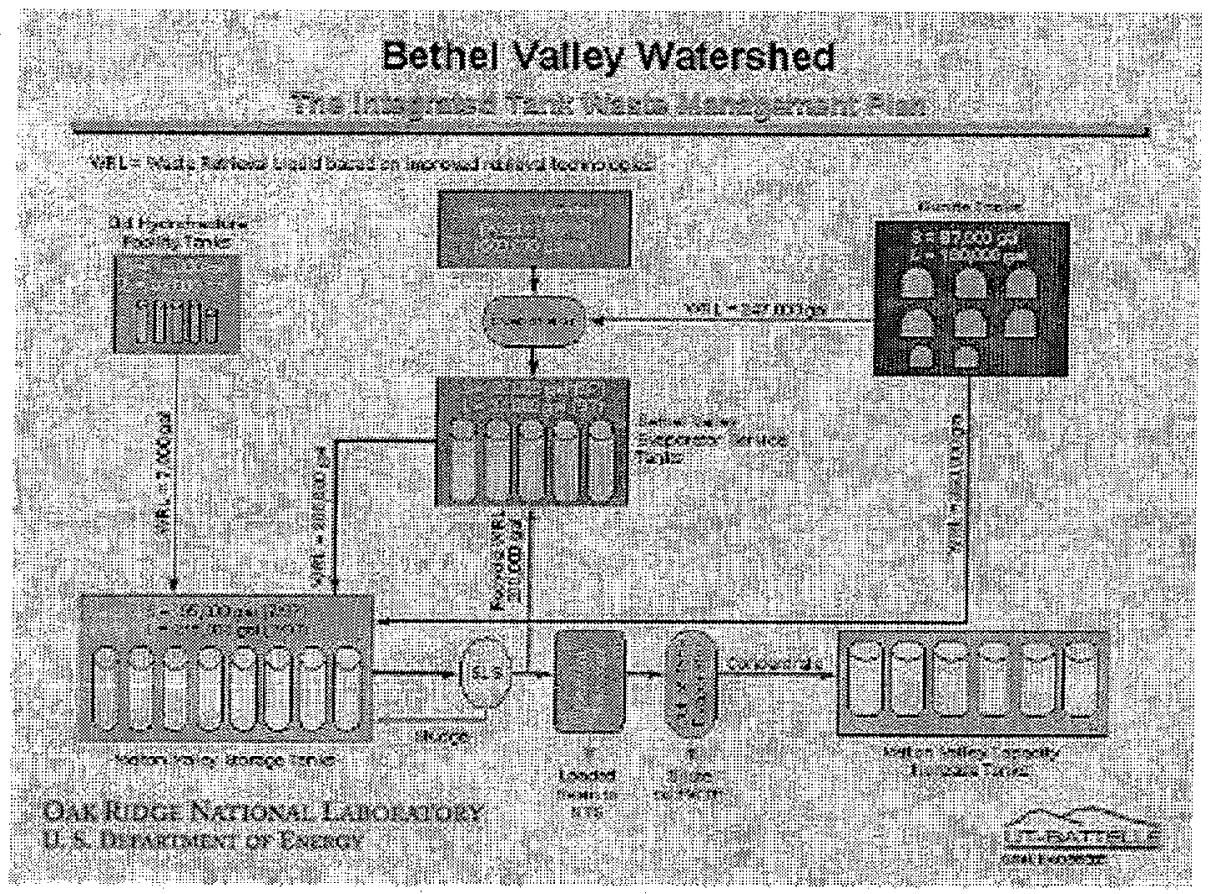

Fig. 1. Inventory of sludge and supernatant in the Bethel Valley watershed prior to the implementation of the integrated tank waste management plan.

\section{WTP SYSTEM FACILITIES AND DESIGN}

Detailed information on the facilities used for the WTP and on the design of the individual treatment systems is presented below.

\subsection{MVST FACILITY DESCRIPTION}

The MVSTs constitute a major fraction of the waste storage capacity for the active LLLW system and are the targeted collection point for waste from ongoing research and reactor operations at ORNL. The MVST facility consists of eight 50,000-gal stainless steel horizontal tanks, each about $60 \mathrm{ft}$ long and $12 \mathrm{ft}$ in diameter. The tanks were built within an underground concrete vault containing a stainless steel liner for spill containment. The walls and ceiling of the vault provide containment and radiation shielding. The vault also includes a pump-and-valve vault (PW), where piping is routed from the MVST feed lines, drain lines, sample lines, and other connections. The waste transfer piping for the tanks is routed within the PW to two large progressive-cavity pumps designed for cross-site and inter-tank transfers. The vault alsoincludes a high-efficiency particulate air (HEPA)-filtered ventilation system for control of airborne contamination. An above-ground control room (Building 7830) housing the tank level instrumentation, ventilation system controls, and pump controls is located adjacent to the south side of the vault. An aerial photograph of the MVST facility is shown in Fig. 2. 


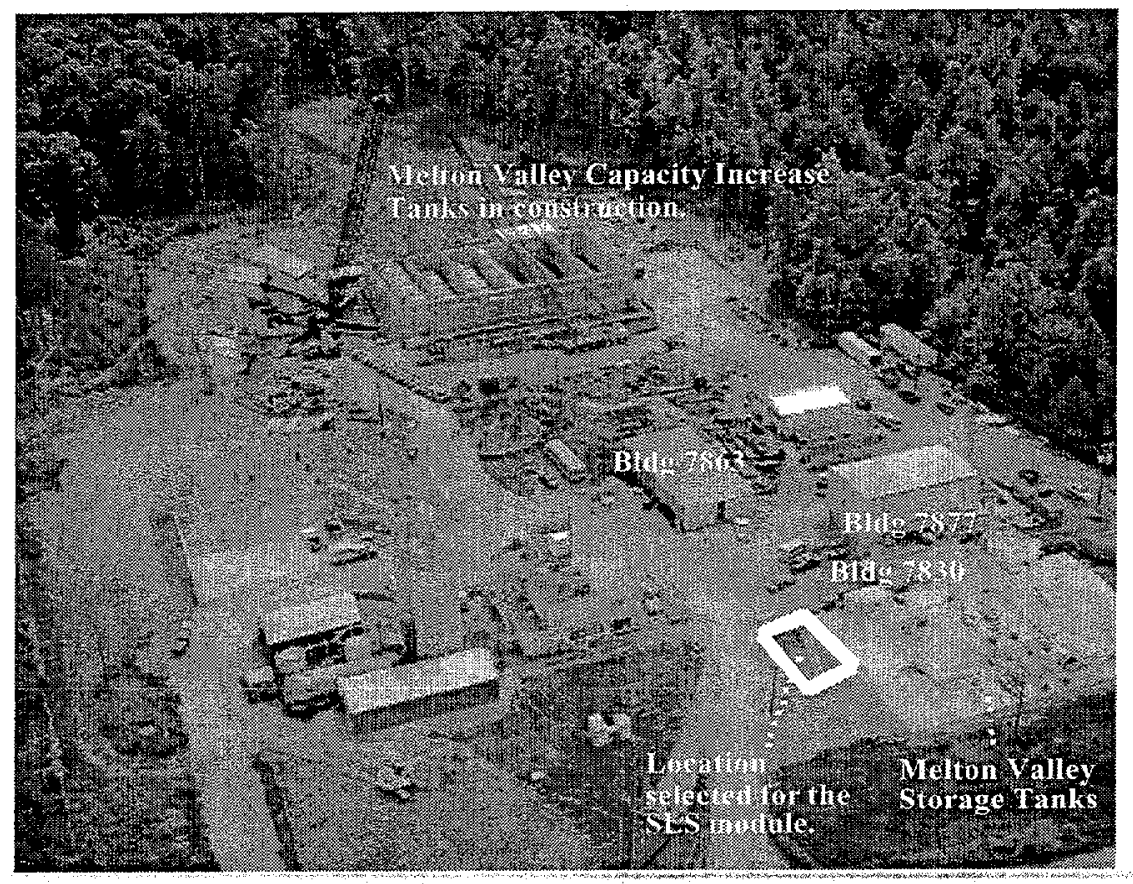

Fig. 2. Aerial photograph of the MVST facilities during construction for the capacity increase tanks.

In the early 1980 s, it became apparent that a supemate treatment system was needed to create additional storage capacity in the MVSTs. A facility (Building 7877) designed to allow grouting of the supemate for disposal was constructed adjacent to the 7830 control room. To provide clarified supemate feed to the grout facility, a supemate decant system was added to the MVSTs. The decant system included the installation of dip-leg piping into tanks W-29 and W-30 to allow decanting of about one-half of the working volume of each tank. The dip legs were piped to a shielded double -diaphragm pump located within a containment structure on top of the vault, The discharge piping of the pump was routed within a shielded pipe chase along the top of the vault into Building 7877. The grouting materials and equipment were provided through a subcontract to a private service company specializing in mobile radwaste grouting services. Building 7877 is a Class III nuclear facility. An additional tank farm, the MVST CIP tank system was placed in service in late 1998 for future storage of LLLW. The MVST and CIP tanks were piped together to allow transfer of liquid waste between the tank farms.

\subsubsection{Waste Composition}

During the spring and summer of 2000, sludge samples from the MVSTs were obtained and analyzed to verify the composition of solids in the tanks after the transfer of sludges from the inactive tanks and the WTP had been completed. These data will be used to (1) address waste processing options being explored by Foster Wheeler, (2) support the performance assessment requirements for WTPP, (3) evaluate the waste characteristics with respect to the Waste Acceptance Criteria (WAC) for WIPP and NTS, (4) address criticality concerns, and (5) meet Department of Transportation (DOT) requirements for transporting the waste. Detailed information on the consolidated MVST sludge composition has been published by Keller and Giaquinto. ${ }^{2}$ The isotopic data support the position that fissile isotopes of uranium $\left({ }^{233} \mathrm{U}\right.$ and $\left.{ }^{235} \mathrm{U}\right)$ and plutonium $\left({ }^{239} \mathrm{Pu}\right.$ and $\left.{ }^{241} \mathrm{Pu}\right)$ were "denatured" as required by the 
administrative controls stated in the ORNL LLLW WAC. In general, the MVST sludge was found to be hazardous by RCRA characteristics based on the total analysis of chromium, mercury, and lead. The alpha activity due to transuranic isotopes was also well above the $100-\mathrm{nCi} / \mathrm{g}$ limit for TRU waste. The characteristics of the MVST sludge relative to the WIPP WAC limits for fissile gram equivalent, plutonium equivalent activity, and thermal power from decay heat were estimated and found to be far below the upper boundary for any of the RH-TRU waste requirements for disposal of the waste at WIPP. ${ }^{2}$

Additional detailed information is available for the composition of the supematant liquids present in the various tank farms prior to consolidation activities. The major components of the supematant include soluble salts such as sodium nitrate, potassium nitrate, sodium carbonate, and smaller amounts of sulfates, chlorides, and other salts. The total salt content of the supematant is typically in the range of 1 to $7 \mathrm{M}$ as nitrate. The major radionuclides in the supematant include ${ }^{137} \mathrm{Cs},{ }^{134} \mathrm{Cs},{ }^{90} \mathrm{Sr},{ }^{60} \mathrm{Co}$, and smaller amounts of other fission and activation products. The activity of cesium, the predominant nuclide, is typically in the range of $0.1 \mathrm{E}+06$ to $1.3 \mathrm{E}+06 \mathrm{~Bq} / \mathrm{mL}$.

\subsection{WTP SYSTEM DESIGN AND DEMONSTRATION OPERATIONS}

The OTE and CsR concepts were conceived in FY 1994 as a way to deal with limited LLLW storage capacity and treatment concerns at ORNL. Completion of a new tank farm, the MVST capacity increase tanks, was planned for 1998; however, the existing MVSTs were approaching their maximum capacity, and it was necessary to reduce the volume in the MVSTs to make room for LLLW generated from ongoing research and reactor operations. On two occasions in the early 1990s, it was necessary for ORNL Waste Operations to conduct very expensive liquid waste solidification campaigns to solidify tank supematant in grout for disposal at NTS. The OTE was designed to deal with this problem by evaporating the excess water from the MVSTs.

There were also concerns regarding increasing leveb of ${ }^{137} \mathrm{Cs}$ in the LLLW in the MVSTs as a result of radiochemical processing, such as the processing of Mark 42 target fuel elements at the Radiochemical Engineering Development Center. The CsR system was designed to deal with this problem by removing the radioactive cesium from the LLLW and concentrating it on a small volume of sorbent. Both the OTE and CsR systems were independently designed, installed, and demonstrated.

Evaluation of the demonstration data indicated that these systems could be placed in baseline operations at ORNL to help alleviate the treatment problems associated with the LLLW. However, the data evaluation also showed that the potential bottleneck in the treatment of the LLLW in the MVSTs was the settle/decant process that had to be performed prior to processing the LLLW in the OTE and CsR systems. The settle/decant process used two of the MVSTs (W29 and W30) from which decant piping was-routed to Building 7877, where the OTE and CsR systems were located. The particular MVST supematant to be treated had to be transferred into W29 or W30 to allow settling. The supematant had to settle for up to 1 month to allow TRU solids to settle before decanting through a dip leg located at the $50 \%$ level of the tank. The SLS system was seen as a way to accelerate the removal of suspended solids and facilitate the waste consolidation activities called for in the Integrated Tank Waste Management Plan.

\subsection{OTE SYSTEM}

The first unit operation deployed for the WTP system was a single -stage subatmospheric evaporator rated to produce $90 \mathrm{gal} / \mathrm{h}$ of distillate. This system was evaluated using bench-scale and small-scale evaporation equipment with simulated liquid waste in FY 1993. ${ }^{3}$ These tests indicated that volume 
reductions from 30 to 55\% could be achieved, and low-pressure (subatmospheric) and low-temperature $\left(120-173^{\circ} \mathrm{F}\right)$ evaporation could be performed with little or no liquid foaming and virtually no fouling of heat transfer surfaces.

After development of design specifications and a competitive bid procurement process, a full-scale evaporator system was selected and procured from Delta Thermal Systems (Pensacola, FL) in FY 1995. This type of evaporator system has been used in several nuclear applications and is routinely used in commercial applications such as concentrating metal plating wastes for recycle and concentrating ethylene glycol solutions. Subatmospheric evaporation is designed for energy efficiency and reduced scaling of heat transfer surfaces because of lower boiling temperatures. The Delta Thermal-design has the additional advantage of having a very efficient vapor separation section for achieving a high-purity distillate.

Fabrication of the unit by Delta Thermal was initiated in the spring of 1995 and completed in September 1995. The system was fabricated in five modular skids including (1) the feed skid, containing the feed holding tank and concentrate recirculation tank; (2) the distillate skid, including a distillate holding tank and transfer pump; (3) the heating skid, including an electric heat exchanger with an ethylene glycol recirculation system; (4) a cooling skid, including two fin-fan heat exchangers and ethylene 'glycol recirculation system; and (5) the main evaporator skid, containing the evaporator heat exchanger, the vapor separation unit, the condenser, and feed circulation pumps. Photographs'of the'evaporator skid and the heating skid are presented in Figs. 3 and 4, and a photograph of the OTE feed skid, evaporator skid, CsR feed skid, and ion-exchange skid after installation in Building 7877 is presented in Fig. 5. A basic flow diagram for the OTE system presented in Fig. 6, shows the four basic loops within the system for heating, cooling, reducing pressure, and concentrating the feed.

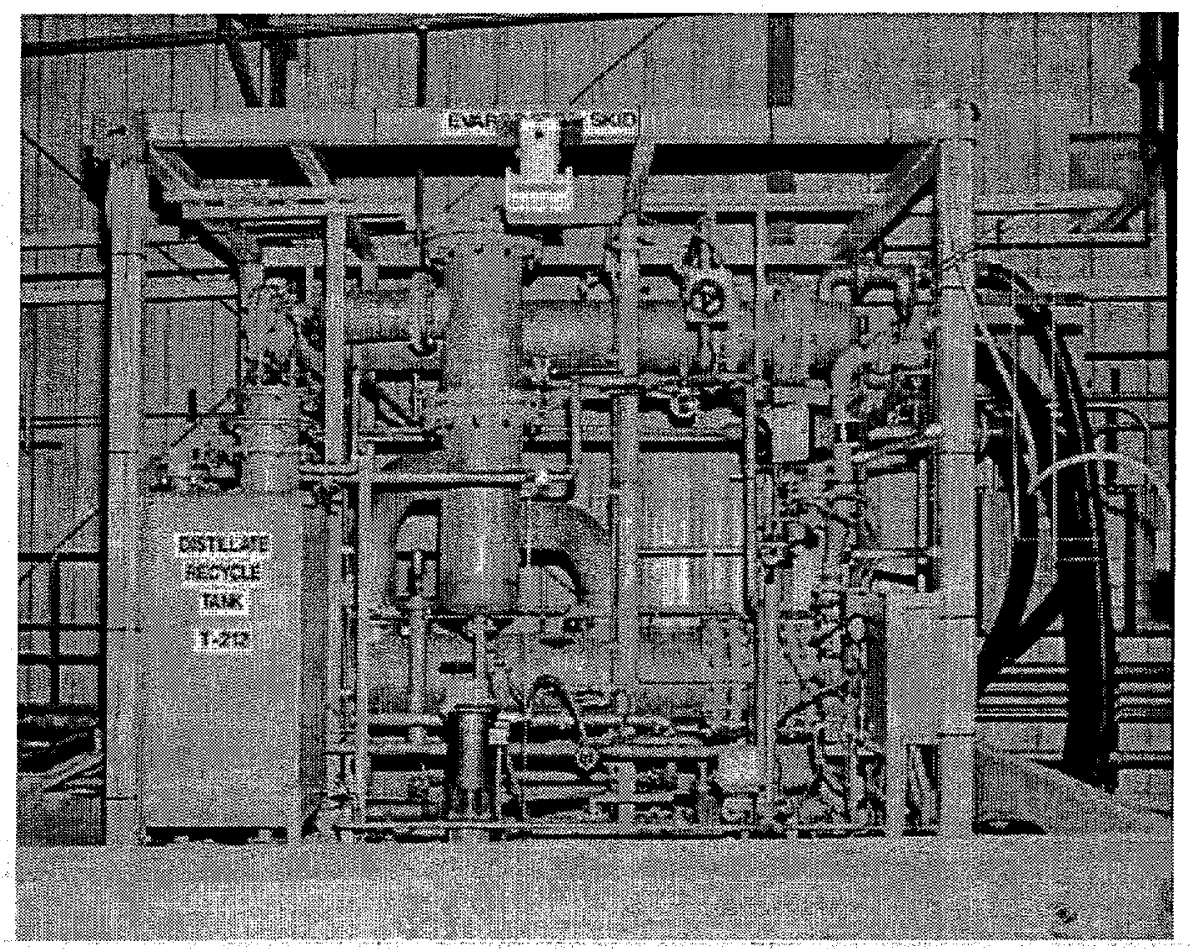

Fig 3. Photograph of the OTE skid prior to the placement of the concrete shields. 


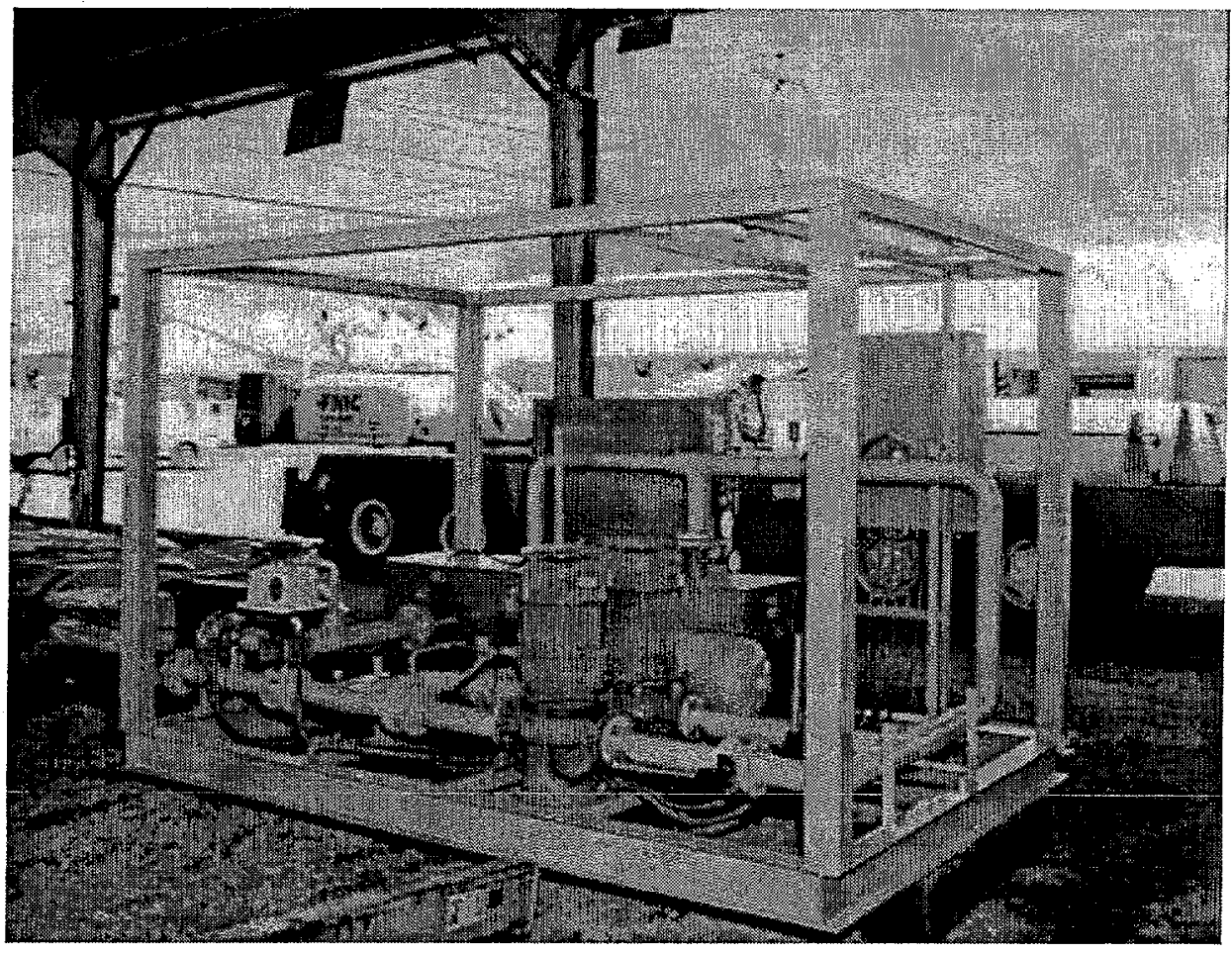

Fig. 4. Photograph of the OTE heater skid prior to installation.

\subsubsection{Heating Loop}

Energy in the form of hot water (at $190^{\circ} \mathrm{F}$ and approximately $190 \mathrm{gal} / \mathrm{min}$ ) was supplied to the evaporator by an electric boiler (a self-contained thermostatically controlled unit, incorporating flow and temperature sensing units) and a pressure relief valve. A conductivity element/transmitter monitored the heating fluid for any indication of a leak and signakd a control valve, which stopped flow to the boiler should the conductivity exceed a predetermined set point. Thermocouples monitored the temperature into and out of the shell and tube heat exchanger. A flow transmitter monitored the heating loop flow.

\subsubsection{Cooling Loop}

Cooling water was circulated through shell and tube condenser at approximately $140 \mathrm{gal} / \mathrm{min}$. The flow of cooling water through an air-cooled heat exchanger and the temperature of the condenser were controlled by a proportional-integral-derivative (PID) loop. As the temperature rose in the condenser, more cooling water was allowed through the air-cooled heat exchangers by a mixing flow control valve. The two blowers were also sequenced "on" with an increase in temperature. Pressure, flow, and temperature were monitored.

\subsubsection{Distillate Loop}

Operation of the distillate loop provided several services to the overall unit process: system vacuum, seal water flow for concentrate recycle, reflux spray, unit rinsing, and distillate discharge to a holding tank. The distillate was pumped from a distillate recycle tank through eductors [serving as vacuum pumps pulling a vacuum on the shell, separator, and condenser assembly) and then back to the distillate tank. 


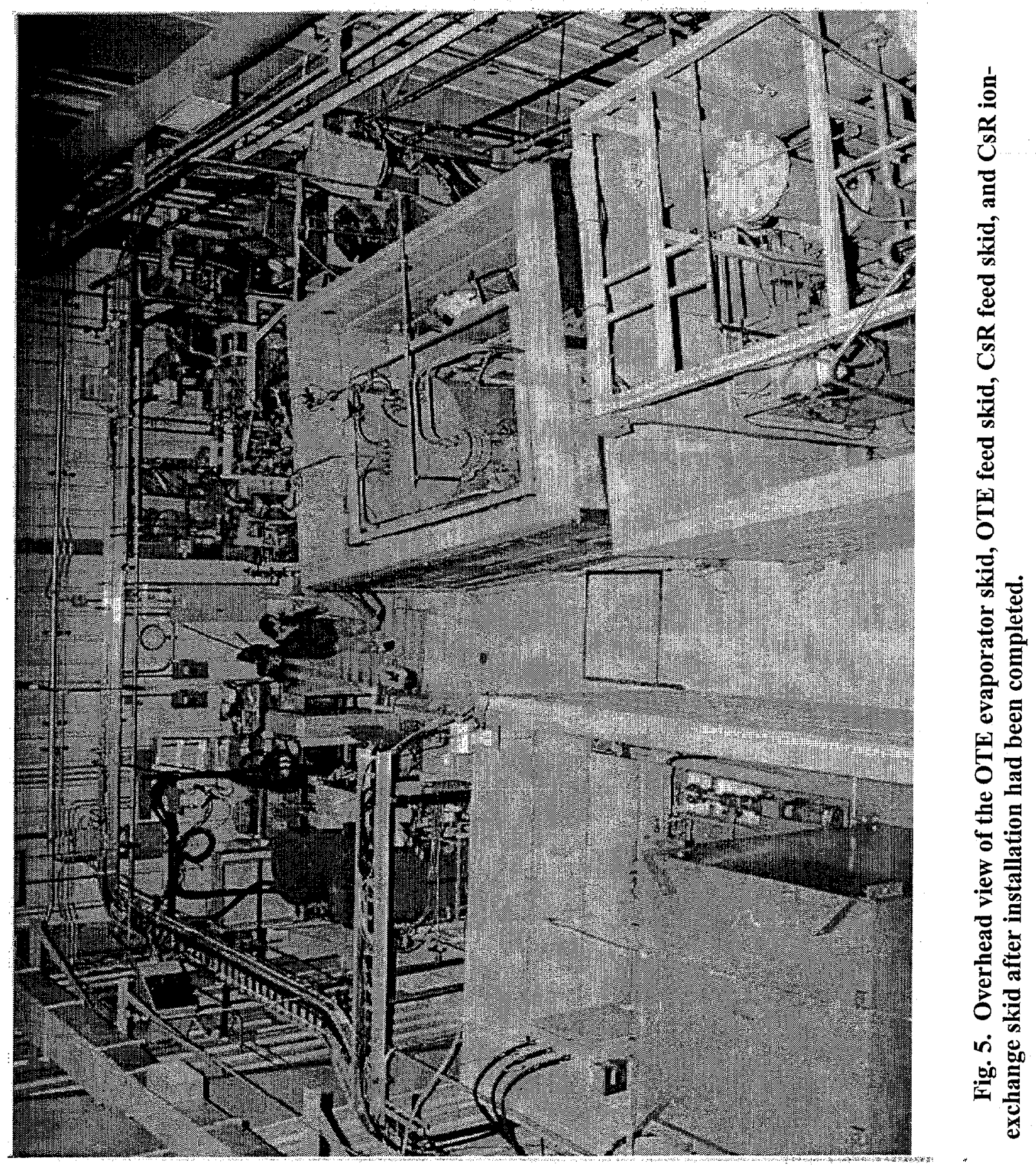




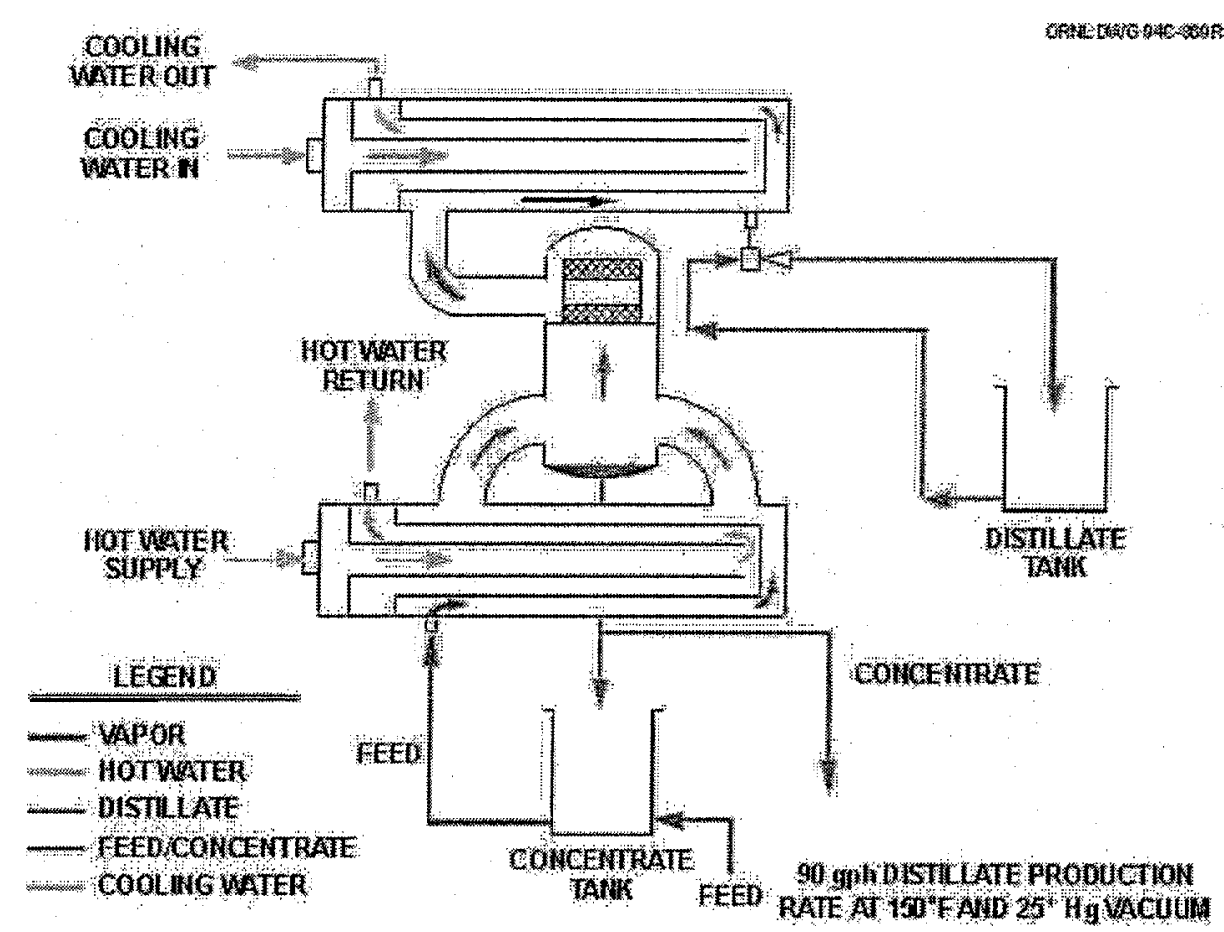

Fig. 6. Schematic diagram showing the four basic loops for the OTE system: the heating loop, the cooling loop, the distillate loop, and the concentrate loop.

Distillate discharge was controlled by four parametersunit temperature, distillate conductivity, distillate tank level, and low-feed-tank recycle mode. Discharge temperature was initially set for $120^{\circ} \mathrm{F}$. Once the distillate loop temperature sensed by a temperature element reached $120^{\circ} \mathrm{F}$, a conductivity control valve opened and allowed distillate to be discharged if the conductivity of the distillate met or exceeded a preprogrammed conductivity set point. Until the distillate loop temperature reached the discharge temperature set point, any distillate produced by the unit was directed back to the concentrate tank via another conductivity control valve. If, at any time during the unit's operation (while distillate was being produced and discharged), the conductivity of the distillate exceeded the preprogrammed setpoint, one conductivity control valve closed and the other opened to recycle distillate back to the concentrate tank. If the unit sensed a low feed tank level (sensed by a level switch), the same sequence of events took place as when a high conductivity level was sensed. The level in the distillate recycle tank was controlled by a PID loop consisting of a level transmitter and flow control valve.

The distillate that met the conductivity requirement was sent to a 5000-gal transport tanker used to transport the distillate to the PWTP feed equalization tanks for treatment and discharge to the environment.

\subsubsection{Concentrate Loop}

Feed was delivered into the 500-gal feed tank using an existing pump module system previously used in solidification operations or from the SLS or CsR systems. Feed was then pumped out of the feed tank to a concentrate recycle tank on an as-needed basis sensed by another level transmitter in that tank. Feed in excess of what was required by the concentrate tank was recycled back to the feed tank. The feed in the 
concentrate tank was vacuum dragged into the evaporator shell and then recycled back to the concentrate tank. The recirculation rate and the level in the shell were controlled by PID loops. The recycle flow rate was'sensed by a flow transmitter, and pump pressure was sensed by a pressure transmitter. Heat exchanged in the shell was sensed by temperature transmitters.

\subsubsection{OTE Demonstration Operations}

In 1996, the evaporator skid, feed skid, and distillate skid were installed in Building 7877, which provided ventilation and spill containment for operation of the systems. The heating and cooling skids were installed outdoors and adjacent to Building 7877 with flexible hoses used to transfer the ethylene glycol heating and cooling solutions to the evaporator heat exchanger and condenser. The existing MVST decant system was used to provide clarified feed to the system inside Building 7877. The evaporator and feed skids were shielded with concrete shielding modules to reduce the general area dose rate and allow limited entry into the building during operations. The modular concrete shielding was provided by Concrete Products, Inc., and consisted of four rectangular stackable concrete sections that surround each of the two skids.

The OTE system was demonstrated during an 8-day campaign in which -22,000 gal of waste was concentrated by $25 \mathrm{vol} \%$. Key information obtained from the demonstration included performance data (production rate, condensate purity, heat transfer efficiency), reliability and operating experience, and determination of the feasibility of decontaminating the system for hands-on maintenance and possible demobilization of the system for use at other locations. The system met or exceeded all performance criteria. ${ }^{4}$ It processed waste containing approximately $8.5 \times 10^{5} \mathrm{~Bq} / \mathrm{mL}^{137} \mathrm{Cs}$ and $4.5 \mathrm{M}$ sodium nitrate to produce a concentrate stream containing approximately $6 \mathrm{M}$ sodium nitrate and most of the contaminants. The distillate stream contained essentially no salts or radionuclides.

Effective performance of the system was defined as the ability to concentrate the MVST supematant by $25 \mathrm{vol} \%$ while producing distillate at a rate of $1 \mathrm{gal} / \mathrm{min}$ with a composition that complied with the WAC at the ORNL Process Waste Treatment Plant (PWTP). At the PWTP, the distillate was combined with large-volume, low-activity wastewater for polishing treatment and discharge to surface waters. The WAC required that the evaporator system achieve an average decontamination factor $[(\mathrm{Cs}$ in feed $) /(\mathrm{Cs}$ in distillate)] of about $5 \times 10^{6}$. No heat exchanger fouling and only minor foaming problems were observed during both surrogate tests and demonstration operations with actual wastes.

\subsection{CsR SYSTEM}

Initial scoping for the CsR demonstration was done during the last quarter of FY 1994 and the first quarter of FY 1995. A Design Alternatives Reportfor the Cesium Removal Demonstration was completed in January $1995 .^{5}$ The report recommended that the design of the CsR demonstration system be based on the performance of a resorcino\&formaldehyde-based resin because it was the most effective material for cesium removal available at the time. However, new sorbents were in later stages of performance testing, and it was recommended that the system be designed with enough flexibility to use alternative materials. It was also recommended that the. demonstration be conducted in the LLLW solidification facility (Building 7877), that the Cs-loaded material undergo a vitrification demonstration at the SRS, and that permanent disposal of the loaded and/or vitrified sorbent at the NTS be pursued

From FY 1995 through FY 1997 several key decisions were made that modified the scope of the CsR demonstration. These'scope changes included (1) the decision in October 1995 to utilize the loaded sorbent from the CsR demonstration in a vitrification demonstration at SRS, (2) the decision in January 1996 to change the sorbent to be used from resorcinolformaldehyde resin to crystalline silicotitanate 
(CST), and (3) the decision in October 1996 to vitrify only a portion of the loaded sorbent at SRS and have the remainder processed to meet the WAC for direct disposal at NTS without further immobilization.

Design specifications for the CsRD system were prepared, and the contract for design and fabrication of the system was competitively bid in May 1995. Details on the design specifications and the procurement have been previously reported. ${ }^{6}$ On July 24,1995 , the contract was awarded to TTI Engineering (Walpole, MA). The system was designed in accordance with specifications, fabricated, and delivered to ORNL on July 12, 1996. All three of these skids were installed in Building 7877 adjacent to the OTE evaporator modules. Installation and testing with water and simulants was completed by August 31 , 1996.

The CsRD system was designed as a modular, mobile system and was supplied on three separate skids: (1) a feed tank skid, (2) an ion-exchange skid, and (3) a sorbent sluicing/drying skid. The as-built piping and instrument diagrams (P\&IDs) for these three skids have been provided in a previous report. ${ }^{6}$

\subsubsection{CsR Feed Skid}

Photographs of the CsR feed skid are presented in Figs. 7 and 8. The feed tank skid consisted of a nominal 1890-L (500-gallon) feed tank, and two (redundant) progressive-cavity transfer pumps. Each of the two progressive-cavity pumps was used to control the flow to the ion-exchange columns at flows up to $-19 \mathrm{~L} / \mathrm{min}$ (5 gal/min). The feed tank (TK- 1) was shielded on four sides by $21 / 2 \mathrm{in}$. of lead shot encased between $1 / 4$-in.-thick steel plates. Penetrations, ranging from $11 / 2$ to 8 in. in diameter, were provided in the side panels for process piping. The sides were designed to be removed individually to provide access to the tank if necessary. The four sides supported a 4-in.-thick steel plate that shielded the top of the tank. To provide additional protection from radiation exppsure, a $-20-\mathrm{cm}$ (8-in.)-thick concrete shield was placed around the feed tank skid. This shield consisted of four stackable sections with a total height of $-213 \mathrm{~cm}(7 \mathrm{ft})$. The concrete shield was not part of the original design and was designed and manufactured by CPI Concrete Products (Memphis, TN). A photograph of the CsR feed skid with all shielding in place is presented in Fig. 8 .

\subsubsection{CsR Ion-Exchange Skid}

A photograph of the ion-exchange skid is presented in Fig. 9. The ion-exchange skid contained a 25- $\mu \mathrm{m}$ stainless steel, back-washable filter (F-1), two ion-exchange vessels, (X-1 and X-2)) and all associated piping and controls. Piping and controls were provided so that the CsR columns could be operated independently, in series with either column in the lead position, or in parallel. The piping also allowed for bypass of the filter unit if desired. Top connections were used for both the filter housing and the columns for access when shield modules were in place. The ion-exchange vessels, with $30-\mathrm{cm}$ inside diameter and $97-\mathrm{cm}$ height $(12 \times 38 \mathrm{in}$.), were fabricated from 316L stainless steel and rated for $150 \mathrm{psig}$. The columns were supplied with 100-mesh Johnson screen outlet collectors. The filter and ion-exchange columns were surrounded by cylindrical shield units providing $53 / 8$ - and $51 / 2$-in. thickness of lead shot encased in 1/4-in. rolled plate. The tops of the filter and ion-exchange columns were shielded with 4-in. thick steel plate. The CsRD system was designed so that the filter or columns could be remotely removed with or without the shielding in place. (Prior to the remote operation, process personnel would have to enter the process building to release the quick disconnects located external to the vessel shielding.) An automated sampling system was used to remotely collect liquid samples from the filter inlet and from the inlet and effluent of both columns. 


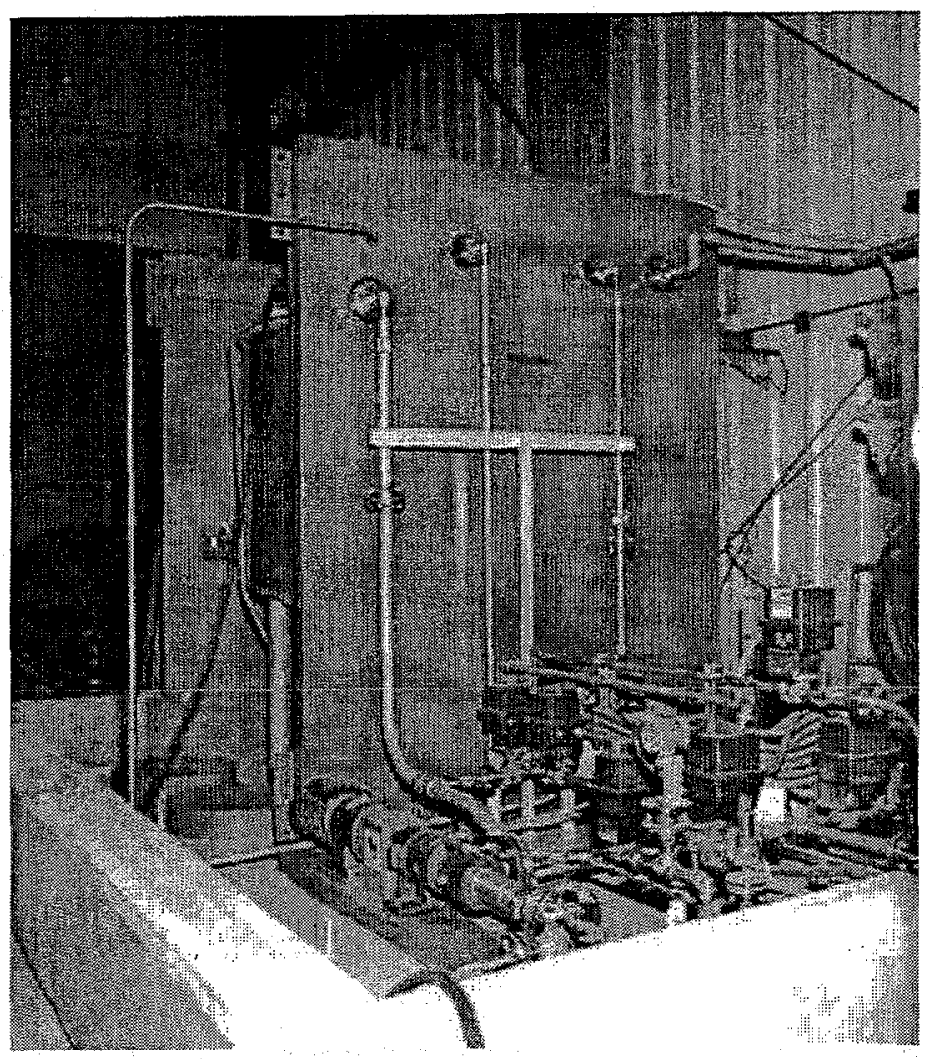

Fig. 7. Photograph of the CsR feed skid during installation of the feed tank shielding.

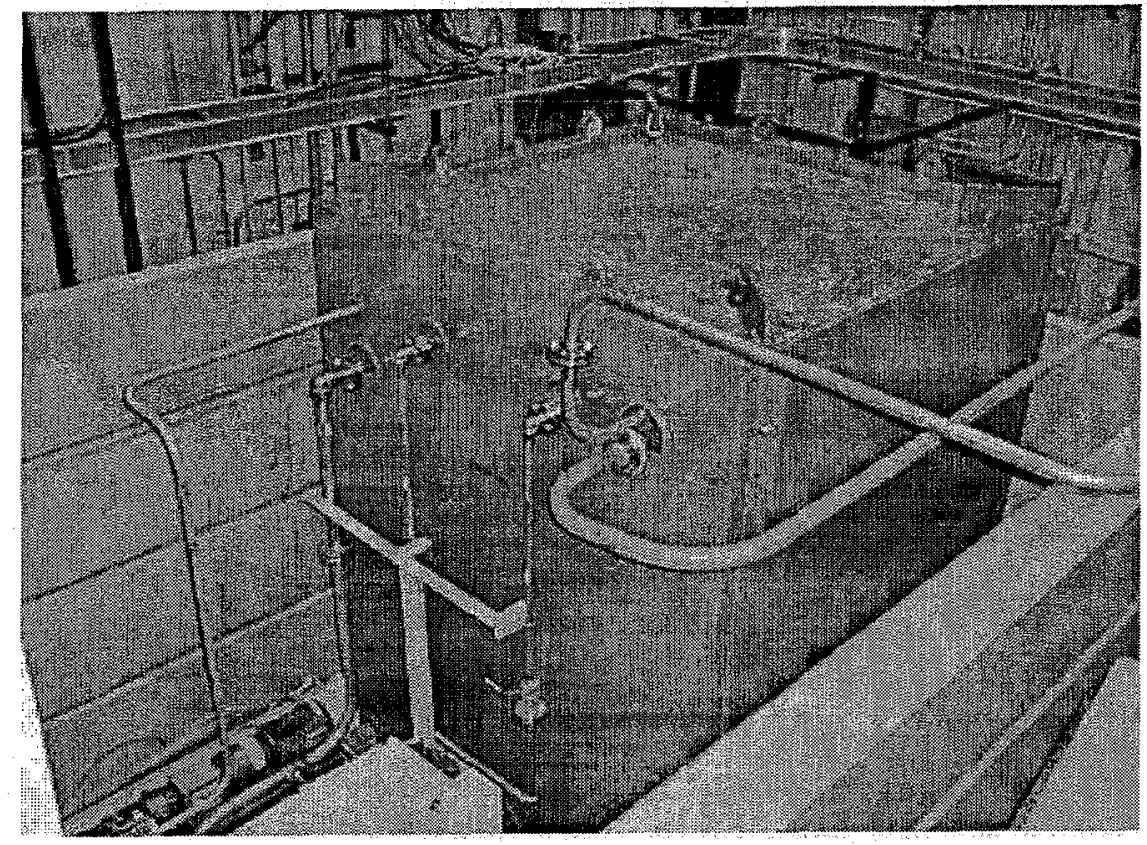

Fig. 8. Photograph of the feed tank skid with all shielding installed. 


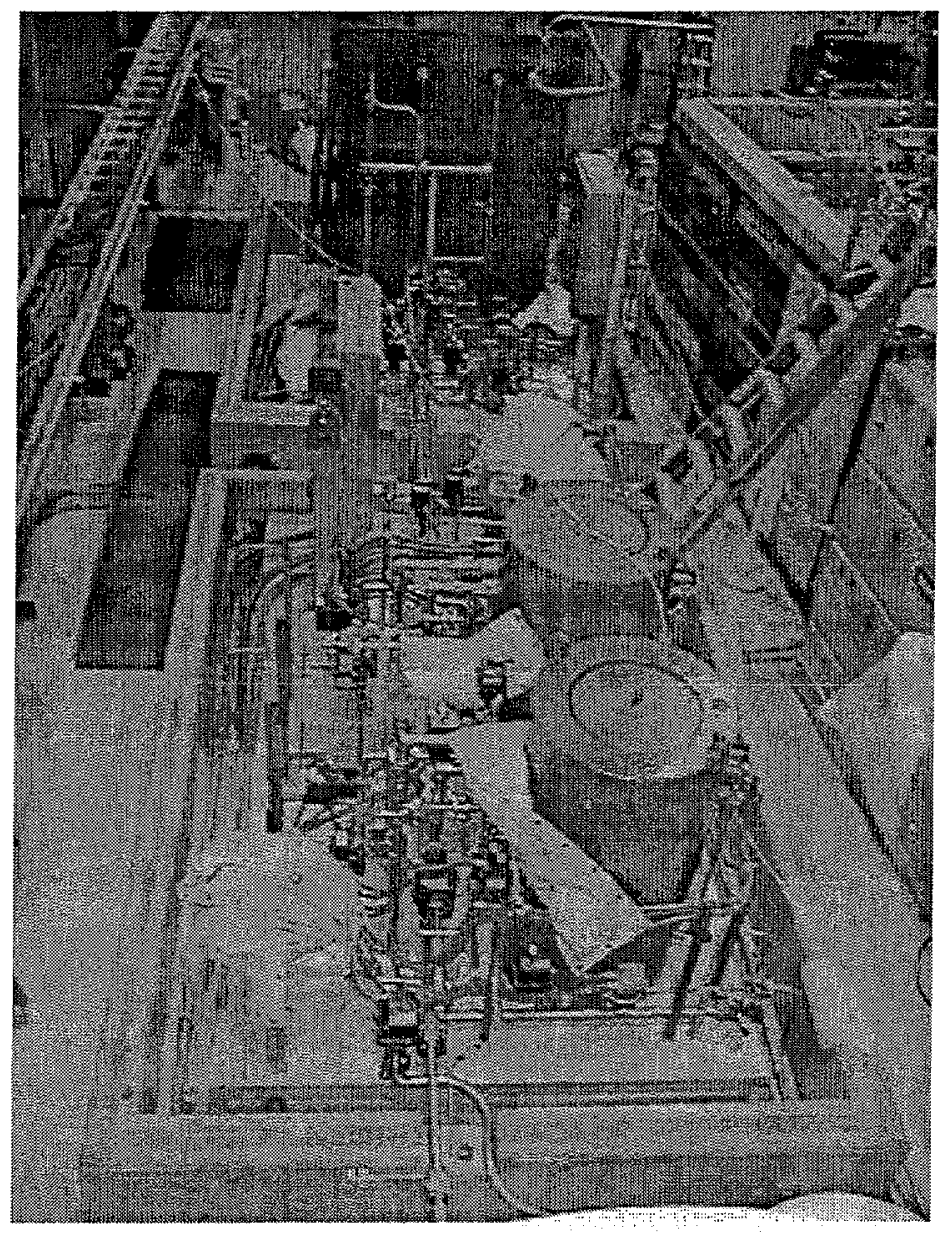

Fig. 9. Photograph of the ion-exchange skid showing the shielded ion-exchange columns during installation.

\subsubsection{CsR Sluicing/Drying Skid}

A photograph of the sorbent sluicing/drying skid is presented in Fig. 10. Using this skid, the fresh sorbent (IE-911) was sluiced into the ion-exchange columns and the exhausted, cesium-loaded sorbent was containerized and dewatered for disposal. The sorbent sluicing/drying skid contained a stainless steel sorbent loading tank (TK-2), which was $\sim 50-\mathrm{cm}$ outside diameter and $-60 \mathrm{~cm}$ in height. The TK-2 vessel was designed and rated for pressures up to 150 psig to allow for pressurized transfer of slurries of water and IE-911. In the initial design and demonstration, the spent sorbent was sluiced and dewatered, using this system, in modified 30-gal stainless steel drums. The initial plans required the use of these drums for transporting all of the spent sorbent to SRS for vitrification studies. Prior to the WTP operations, the CsR system was modified to use stainless steel, high-integrity containers (HICs) with a capacity of $65 \mathrm{ft}^{3}$ for the receiving, drying, and storage of the spent sorbent., These HICs were designed and constructed by TTI Engineering and were designed to meet the Waste Package Criteria, as specified in the NTS WAC, Revision 1, excluding Sects. 3.2.5, 3.2.7, 3.2.9, and 3.2.10. In addition, they were excluded from the stacking requirements in Sect. 3.2.3. 


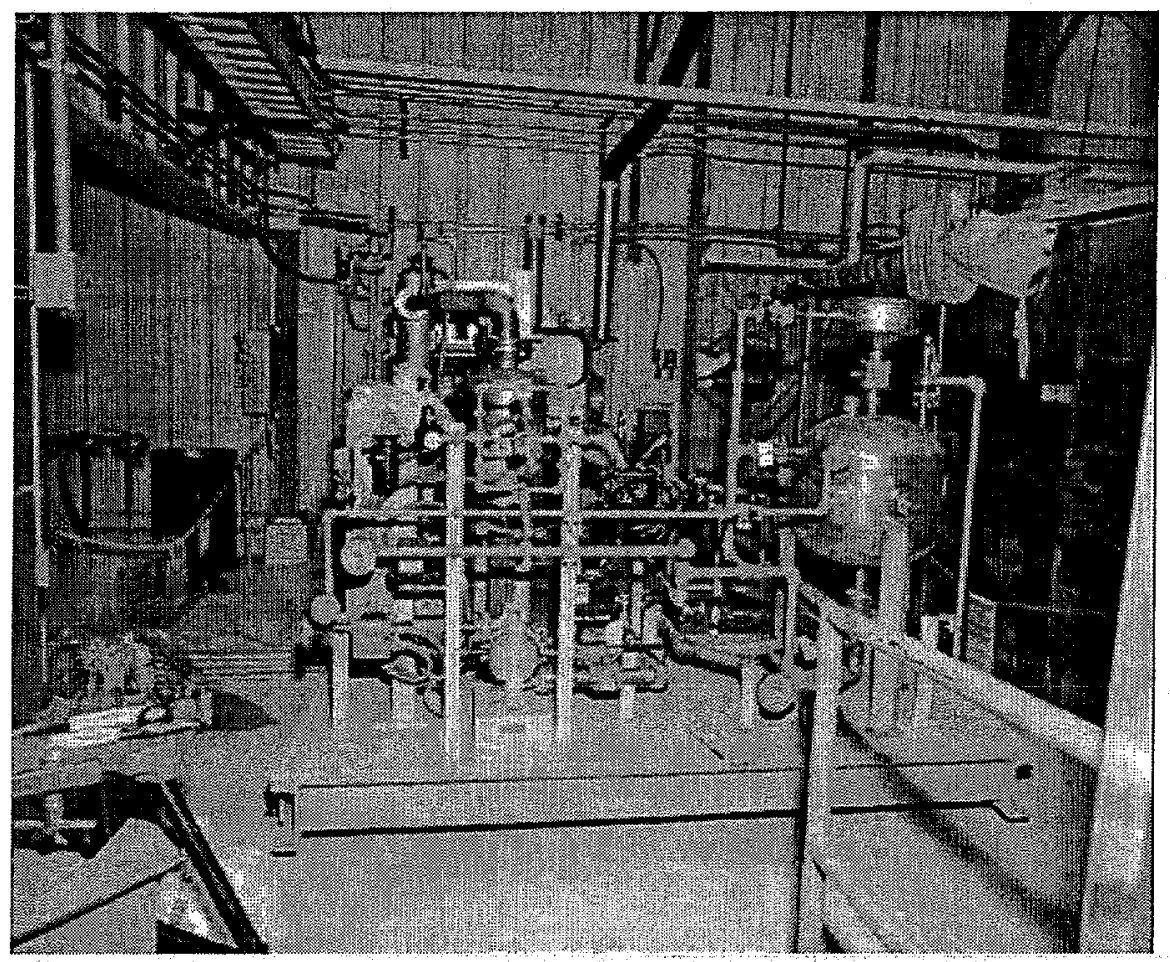

Fig. 10. Photograph of the sorbent-sluicing/drying skid.

The HIC was designed to accept loaded sorbent from the ion-exchange columns and to access the sluicing/drying skid through a fill head. These connections were made using 2-in. flexible, high-pressure hose. A photograph of the fill head installed on the shielded HIC is presented in Fig. 11. It contained level instrumentation for determining the level of material in the HIC, and a camera and a light for viewing the contents of the container. It was placed on the HIC prior to sluicing radioactive materials into the container. The HIC contained spiral-wound filters that allowed water to be pumped from the sorbent and air to be pulled through the sorbent for drying. After the sorbent had been sluiced into the HIC, a diaphragm pump (P-3) was actuated to remove the water from the HIC. A blower (B-1) was then energized to pull ambient air through the sorbent and through two separators. When the in-line relative humidity probe (MI-01) indicated that the sorbent was dry, P-3 and B-1 were de-energized. The fill head was also designed to be remotely removed from the HIC via an overhead crane controlled from an adjacent building once the loading capacity of the container had been reached. Details on the remote crane have been previously reported ${ }^{6}$ Cameras placed in Building 7877 were used to guide the remote crane during removal of the fill head. Following removal of the fill head, the remote crane was also utilized to place a cover on the HIC. A photograph taken during the remote operations with the overhead crane is presented in Fig. 12.

The HIC was placed inside a concrete cask for shielding purposes prior to the introduction of radioactive materials. A photograph of the cask is presented in Fig. 13. It was constructed from reinforced concrete, except for the $30-\mathrm{in}$. access cover, which was steel/concrete. The walls, top, and bottom were $21 \mathrm{in}$.

thick. The cask had an internal volume of $95 \mathrm{ft}^{3}$ and was designed to accept an HIC with a maximum diameter of $58 \mathrm{in}$., a maximum height of $59 \mathrm{in}$., and a maximum weight of $5000 \mathrm{lb}$. The access cover to the cask could be attached by use of the overhead remote crane located in Building 7877. 


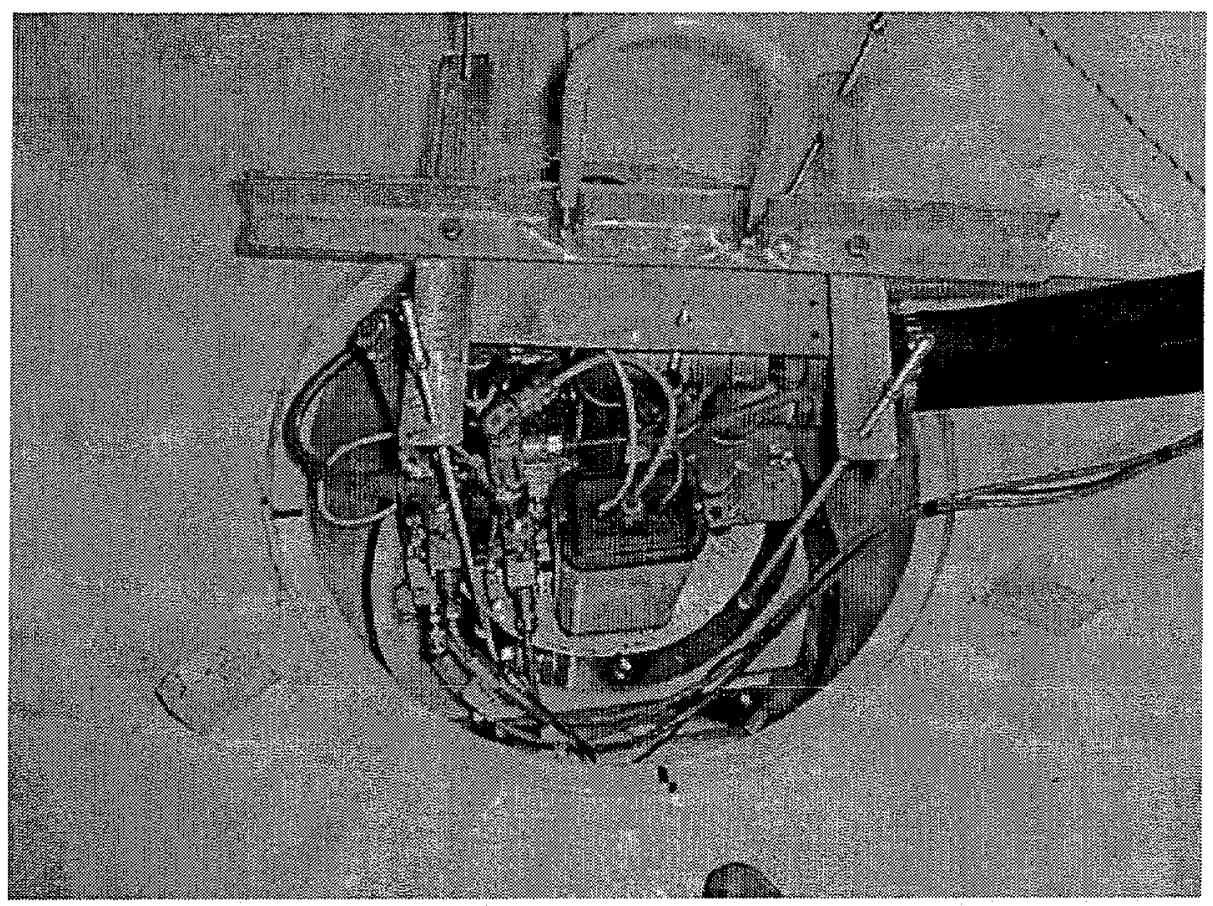

Fig. il. Photograph of the fill head installed on the shielded high-integrity container.

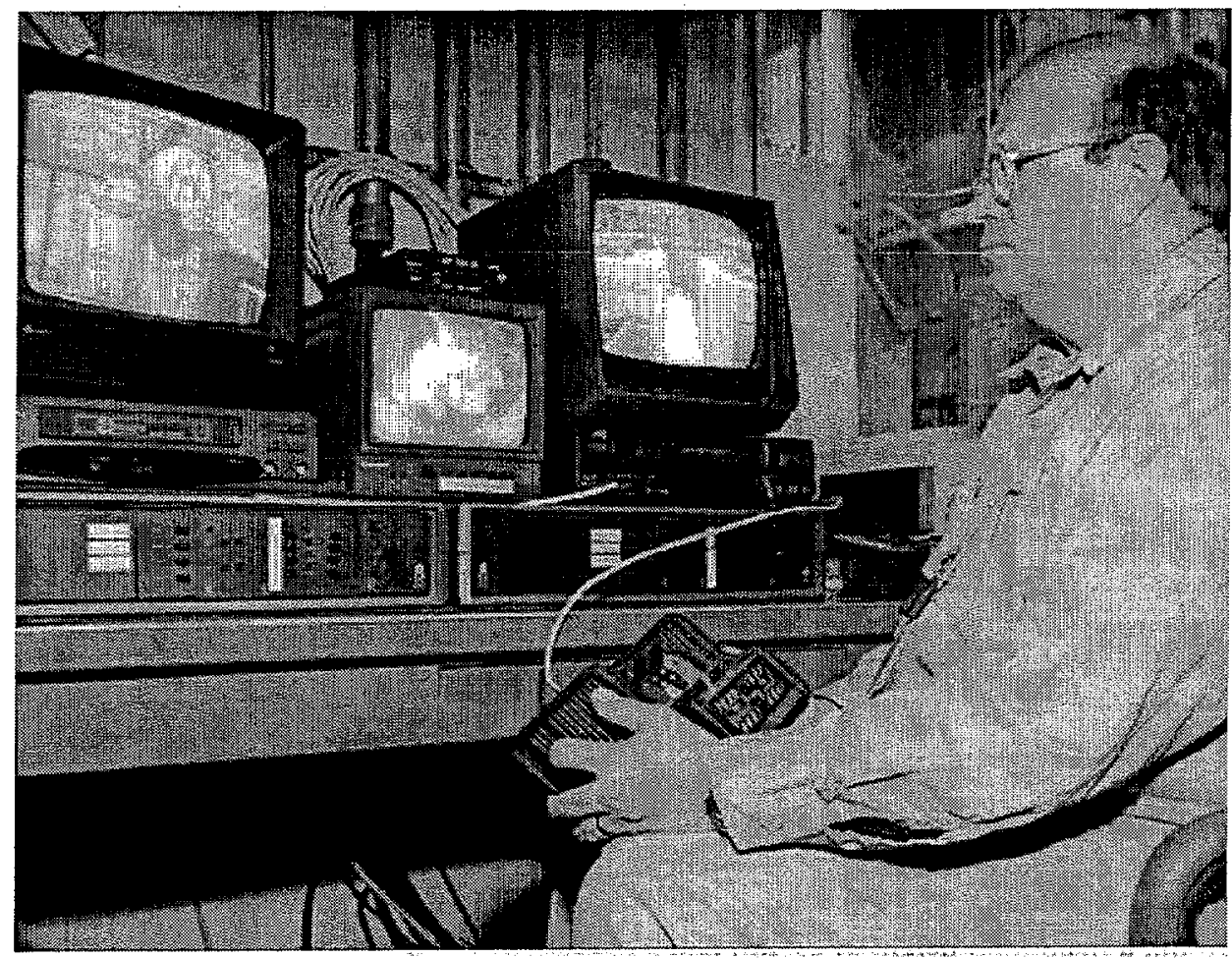

Fig. 12. Photograph taken during remote operations with the overhead crane. 

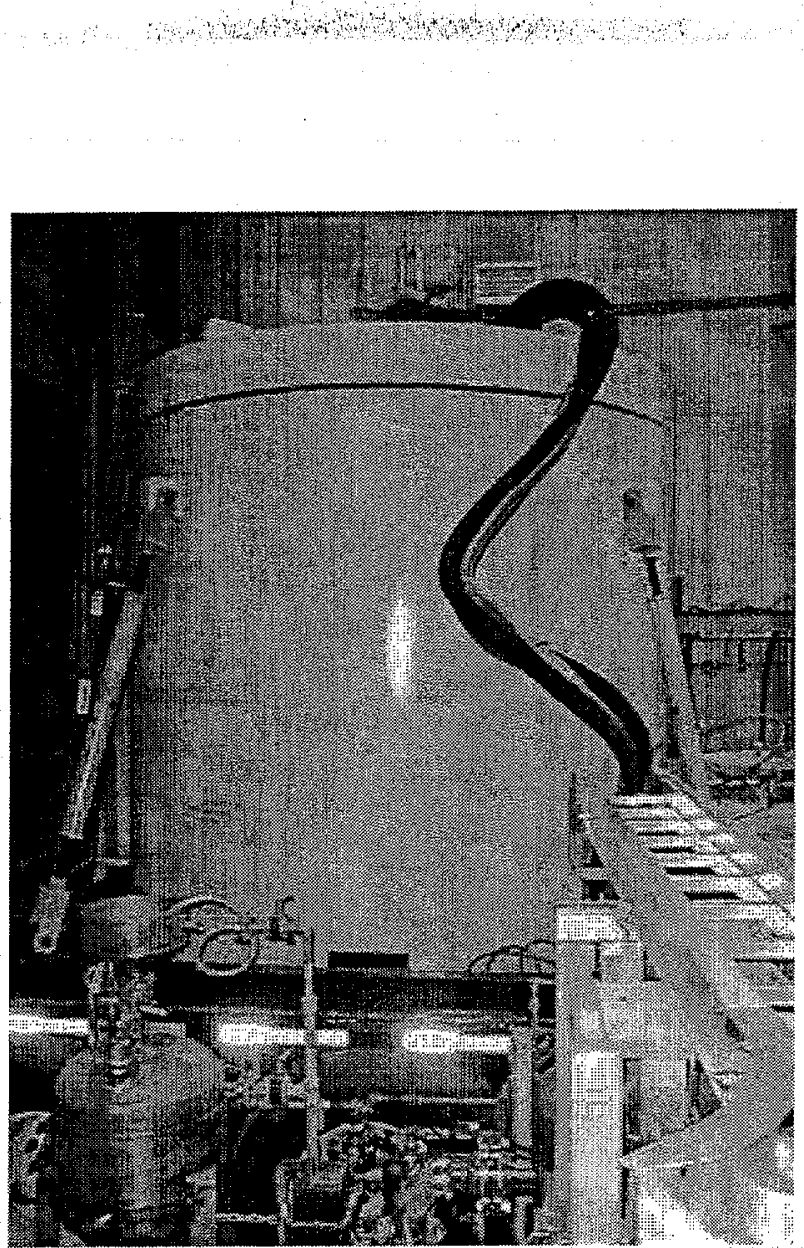

Fig. 13. Photograph of the concrete cask used to shield the higkintegrity container containing the spent sorbent.

\subsubsection{CsR Demonstration Operations}

The CsR system was designed to remove radioactive cesium from tank supernatant using a CST-based sorbent. The CST was developed by Texas A\&MUniversity and Sandia National Laboratories through the EM-50 Efficient Separations and Crosscutting Program (ESP). UOP Molecular Sieves, LLC, developed the engineered form of CST for use in flow-through columns and commercialized the material under the trade name Ionsiv IE-911. The CST was selected for the ORNL application based on the results of experimental data from tests with wastes from ORNL and several other DOE sites. ${ }^{6}$ The use of CST was approved by the ESP, TFA, and the ORNL site technical representatives.

Demonstration operations began in September 1996 and were completed by June 1997. The primary objectives for the demonstration were to process 25,000 gal of radioactive supematant; remove at least $520 \mathrm{Ci}$ of ${ }^{137} \mathrm{Cs}$; demonstrate the use of modular, mobile equipment in existing facilities; evaluate decontamination for hands-on maintenance and possible transfer to other sites; compare bench-scale and full-scale data; provide Cs-loaded IE-911 for vitrification studies; and package Cs-loaded IE-9 11 to meet the WAC for final disposal at the NTS. All these performance objectives were met or exceeded, with $-31,000$ gal of supematant being processed and $1100 \mathrm{Ci}$ of ${ }^{137} \mathrm{Cs}$ being removed. ${ }^{6}$ The radioactive cesium was concentrated on 70 gal of Ionsiv IE-911. Breakthrough curves for the full-scale system agreed well with laboratory hot-cell tests, suggesting that the bench-scale column tests can be used to predict scale -up and actual operating conditions. 
Laboratory analysis demonstrated that the loaded sorbent was not characteristically hazardous under the RCRA and that no further stabilization was necessary to meet the NTS disposal criteria. Therefore, the majority of the sorbent is being stored at ORNL until it can be shipped off-site for permanent disposal at NTS. Ten gallons of Ionsiv IE-91 1 loaded with $23 \mathrm{Ci}$ of ${ }^{137} \mathrm{Cs}$ was shipped to SRS and unloaded into the shielded hot cell facility for use in vitrification demonstrations. The Savannah River Technology Center (SRTC) developed a glass formulation for the Ionsiv IF-91 1 that could incorporate up to $65 \mathrm{wt} \%$ of the sorbent into the glass matrix without crystal formation. ${ }^{7}$ Thirty kilograms of radioactive glass was successfully produced during an 80-h continuously operating run. When the sorbent was added to simulated Defense Waste Processing Facility (DWPF) feed, glass meeting the Waste Acceptance Product Specifications was produced containing up to $28 \mathrm{wt} \%$ SRS tank sludge oxides and $10 \mathrm{wt} \%$ IE-911. Oak Ridge procured equipment and transportation subcontracts for both the ORNL and SRS demonstrations. Personnel from SRS were trained in cask loading and unloading procedures during the CsR operations at ORNL.

\subsection{SOLID/LIQUID SEPARATION SYSTEM}

The SLS system was designed and constructed by NUMET Engineering Ltd in FY 1997 and FY 1998 through an open competitive bid by private industry. Details on the equipment specification, procurement process, design, construction, and installation have been previously reported. ${ }^{4}$ The results of development testing at ORNL and the SRTC were used as a basis for the design. ${ }^{8,9}$ The system includes two sintered metal filter modules manufactured by MOTT Filter Corporation with a total surface area of $50 \mathrm{ft}^{2}$. These filters were expected to perform in a filtrate flux range of 0.02 to $0.1 \mathrm{gal} \mathrm{min}^{-1} \mathrm{ft}^{-2}$ with a filtrate flow of 1 to $5 \mathrm{gal} / \mathrm{min}$. To minimize filter cake buildup on the filter surface, the system was designed for an axial velocity through the filter tubes of up to $10 \mathrm{ft} / \mathrm{s}$. At $10 \mathrm{ft} / \mathrm{s}$, the total axial flow rate would be $-410 \mathrm{gal} / \mathrm{min}$. The pump chosen for this service was a Discflo ${ }^{\mathrm{TM}}$ pump, which is designed for pumping fluids with high solids content and large particle sizes with low shear requirements. A progressive-cavity Moyno pump had been successfully used in small-scale testing; however, the physical size and cost for a Moyno with this flow capacity was prohibitive.

\subsubsection{SLS Module}

The process flowsheet and instrumentation drawing, isometric drawing of the SLS piping system, and system enclosure drawing prepared by NUMET have been published in a previous report.' Photographs of the system are presented in Figs. 14-17. The system was constructed on a single skid about $20.5 \mathrm{ft}$ long, $10.5 \mathrm{ft}$ wide, and $12.5 \mathrm{ft}$ high. The cross-flow filter consisted of two Mott HyPulse LSX filter modules connected in series, each consisting of a 5-ft-long bundle of 31 elements with a $0.75-\mathrm{m}$ outside diameter and a 0.5 - $\mu \mathrm{m}$ pore size. The tube side of the filter modules was connected to the circulation loop and Discflo pump. The shell, or filtrate, side of the modules was connected to the filtrate holding tank with a working volume of 120 gal. A 30-gal/min filtrate transfer pump was connected to the filtrate holding tank with a recirculation loop for obtaining optimum pump performance and maintaining a uniform filtrate composition. The Mott filter modules were enclosed on four sides by carbon steel shield walls. The filtrate tank, Discflo pump liquid end, and larger-diameter piping (4-m diam) were also located within a heavily shielded enclosure. The filtrate pump, feed piping (1.5 in. diam), concentrate return piping (1 .5-in. diam), filtrate piping $(0.5-\mathrm{m}$ diam), sample tubing $(0.375-\mathrm{m}$. diam), and various valve actuators, control valves, flow transmitters, and other instrument components were located in a shielded maintenance area. Since many of the components in this area could require maintenance, a shielded door (about 1.5-in-thick steel) was included for access. The filtrate tank and filter modules were not expected to require frequent maintenance and did not include access doors. These areas could be accessed only by making a confined space entry over the shield wall or by removing one of the shield walls with an overhead crane. 


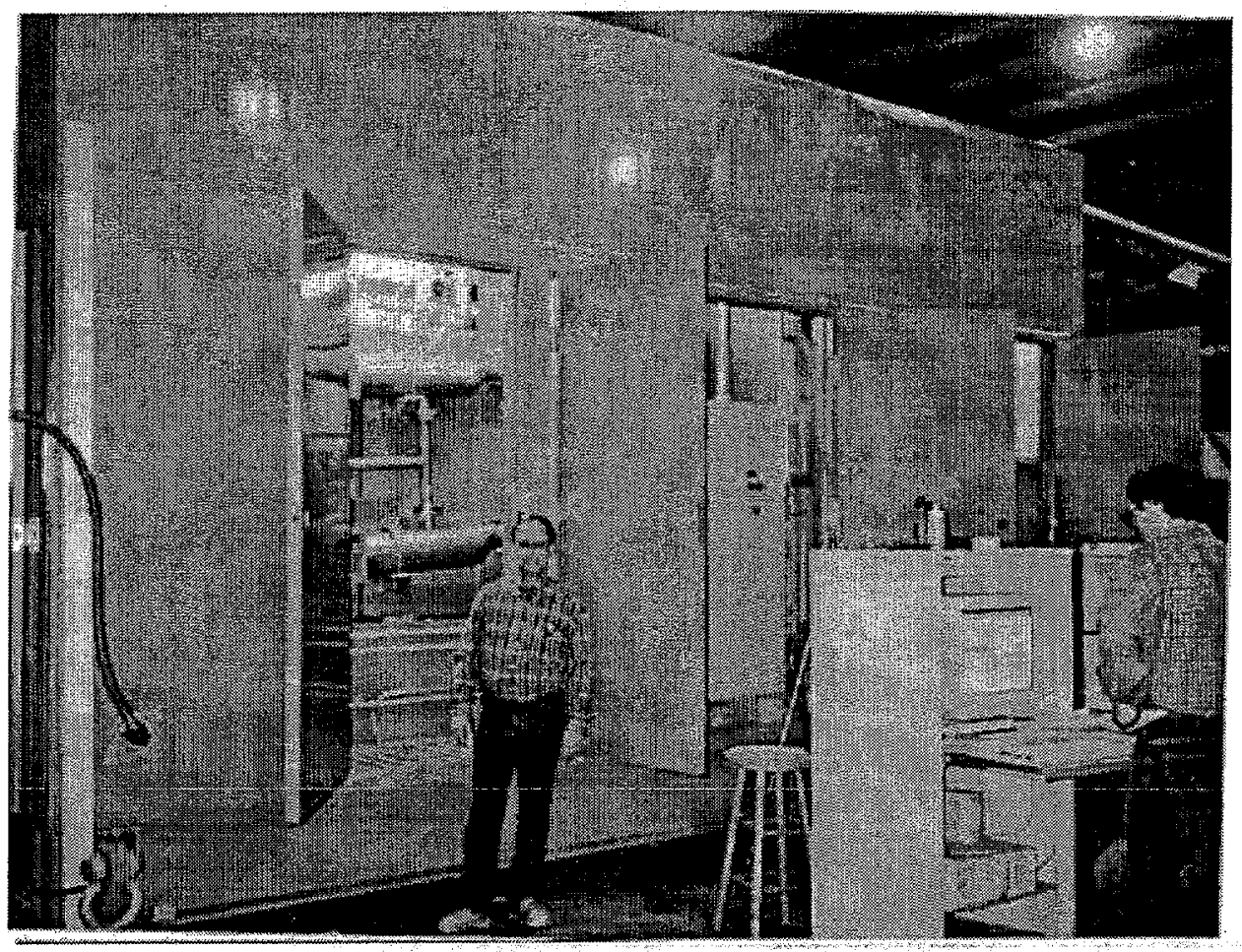

Fig. 14. SLS system during acceptance testing at the NUMET facility.

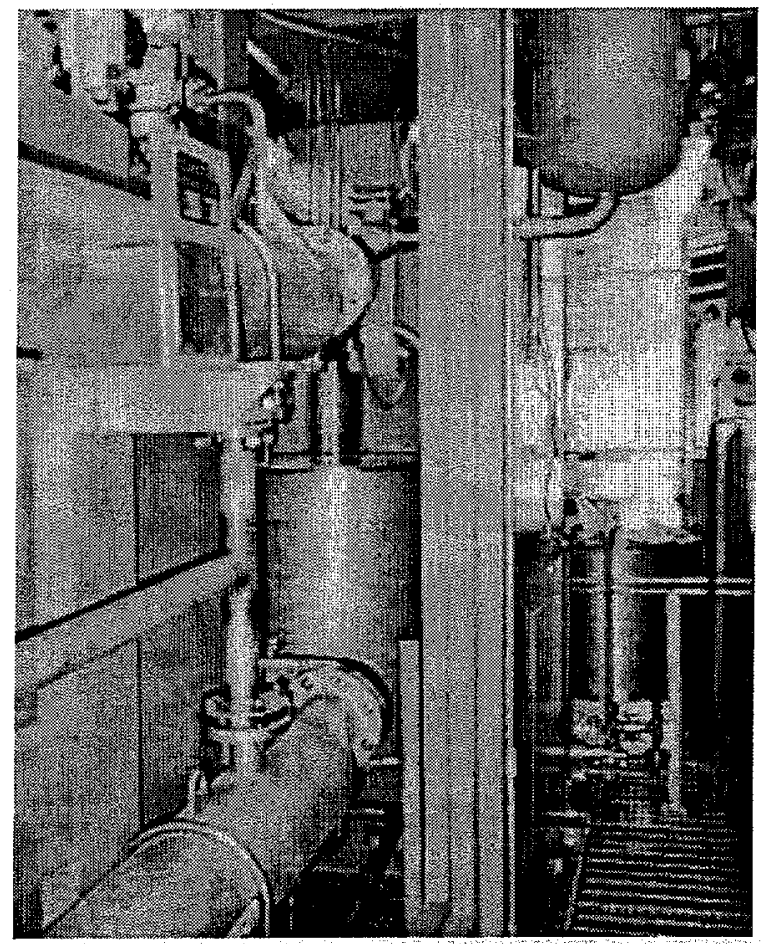

Fig. 15. SLS components prior to installation of shielding. 


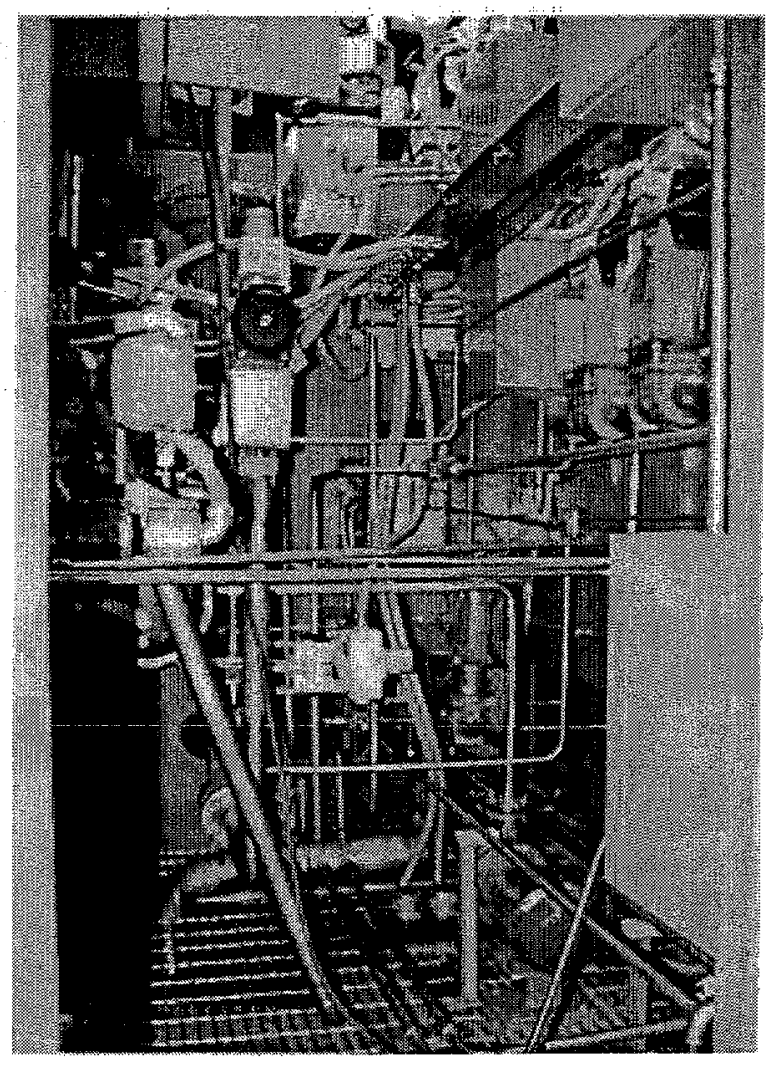

Fig. 16. Shielded maintenance area of the SLS system.

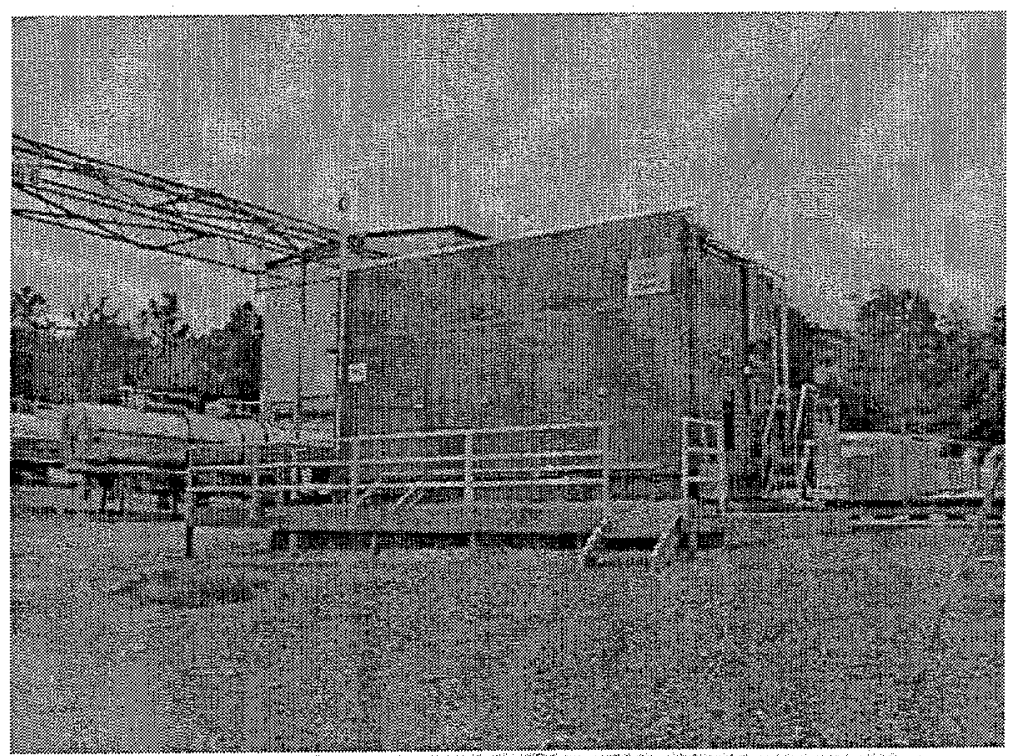

Fig. 17. Placement of the shielded SLS system after construction. 


\subsubsection{Backpulse System}

Despite the high velocity flow through the filter elements, a layer of solids tends to build up on the surface of the filter elements. In addition, some of the smaller sludge particles can penetrate and become lodged in the pores of the filter elements, reducing filtrate production. Therefore, a backpulse mechanism was included with the Mott filter units to periodically remove accumulated sludge. Backpulsing, which takes only seconds to perform, involved the application of a pulse of fluid in the reverse direction of the filtrate flow to push the solids away from the tube wall and into the flow stream, which flushes them out of the tube. The solids removed from the filter were returned to the storage tank, where they settle $\mathrm{d}$ out. A filtrate reservoir collected liquid for the backpulse, and air pressure was used to force the filtrate from the reservoir into the shell side of the Mott units in the reverse direction. The reservoir provided a volume of filtrate for the backpulse equal to at least two times the volume held by the filter bundle. Additional filtrate reservoir capacity was provided to prevent introducing air into the filter tubes during the backpulse operation. Backpulsing frequency was determined during startup optimization testing but was typically performed at a frequency of once per hour or less. Frequent backpulsing exposes filter pores to smaller penetrating particles that would otherwise be removed by the layer of solids on the filter surface,

\subsection{Chemical Addition System}

In addition to the backpulse system, a chemical cleaning system was required to chemically dissolve sludge particles that penetrate the pores of the filter and could not be removed by backpulsing. The cleaning system was designed for the use of dilute nitric acid and sodium hydroxide in separate flushes. The use of deionized water was required for flushing the system after cleaning to avoid the precipitation of tap-water carbonate compounds within the pores of the filter. The chemical feed system consisted of two 50-gal tanks for the acid and caustic solutions with positive-displacement transfer pumps piped from the tanks to feed points on the filtrate and concentrate piping systems. External to the SLS system, a small deionizer/filter system was provided for treatment of tap water used for preparation of chemicals and-for rinsing.

\subsubsection{Sampling System}

Three Isolok (Bristol Equipment Company) sample devices were provided in a central location near the shielded area doorway. Tubing for sampling the filtrate, feed, and concentrate liquids was connected to the samplers from high- and low-pressure taps on the system to establish flow through the sample cell and collect real-time samples. The samples were deposited into bottles within a shielded cabinet. The system was automated by the control system and provided interlocks to prevent sampling while the shielded cabinet door was open. The system also provided an audible alarm if liquid was detected in a containment pan located under the sample bottle rack.

\subsubsection{Instrumentation}

Magnetic flowmeters were used for monitoring the process water supply flow, feed flow, concentrate flow, filtrate flow, and axial flow of the system. A Coriolis mass flowmeter by Endress+Hauser was installed on the feed piping outside the SLS enclosure to monitor the mass flow and suspended solids content of the feed. Pressure sensors were provided for the Discflo pump discharge pressure, the transmembrane pressure, the backpulse air reservoir pressure, and the axial-flow pressure drop across the filter modules. A level controller was included for the filtrate tank, and level monitoring was provided for the chemical feed tanks. Ultrasonic sensors were used for level detection. A temperature indicator was supplied for the filtration loop to monitor the temperature increase from Discflo pump operation. To automate the filling and draining processes for the system, flow sensors and switches were provided on 
the principal vents and drams of the system. A backpressure control valve was included on the concentrate return piping, and a filtrate control valve was provided on the filtrate discharge piping. For visual monitoring of the system, a pan-and-tilt camera was supplied for the shielded maintenance area and a fixed camera was provided for the chemical feed area. After the system was received at ORNL, modifications were made to include a pan-and-tilt camera for the heavily shielded filtrate tank area and to add pan-and-tilt capability for the camera in the chemical feed area.

\subsubsection{Waste Feed System}

A separate pumping system was installed within the MVST PW to deliver the feed to the filtration loop from the underground storage tanks. With the filtration system installed aboveground, the elevation difference between the system and the MVST liquid level was in the range of 8-to18 ft, depending on the volume of waste in the tank. Two air-operated double -diaphragm (D/D) pumps (nominal rating,

$100 \mathrm{gal} / \mathrm{mm}$ each) were specified for the feed system. Through minor piping modifications, these pumps were connected to the existing suction and discharge piping headers used by the existing Moynos. Using the existing piping allowed for interface of the SLS system with any of the eight 50,000-gal waste storage tanks. The only limitation of this approach was that the suction legs for this system were located near the bottom of the tanks, well below the level of the accumulated sludge in the tanks. To avoid transfer of concentrated sludge to the SLS system, the Moyno pumps were be operated initially to recirculate the sludge in the tank and clear the sludge surrounding the suction leg. After the sludge was cleared from the dip leg, the Moynos were deenergked and operation of the D/D pumps was initiated

Figure 18 shows the flowsheet for the filtration loop and feed system. The feed rate from the waste tank to the cross-flow filtration loop (using the D/D pumps) was specified for a flow of 30 to $50 \mathrm{gal} / \mathrm{min}$. Since the maximum filtrate production rate was expected to be about $5 \mathrm{gal} / \mathrm{min}$, the concentrate production rate (feed rate minus filtrate rate) was only slightly less than the feed slurry rate.

Consequently, the solids concentration of the concentrate was only slightly higher than the solids concentration of the feed slurry. The concentrate stream was returned to the tank from which the feed was taken; therefore, a gradual increase in the solids content of feed occurred The rate at which the solids content increased depended on the extent to which the suction leg remained clear of sludge, the amount of liquid in the tank, and the extent to which solids settled from the liquid before it was pumped through the filter again.

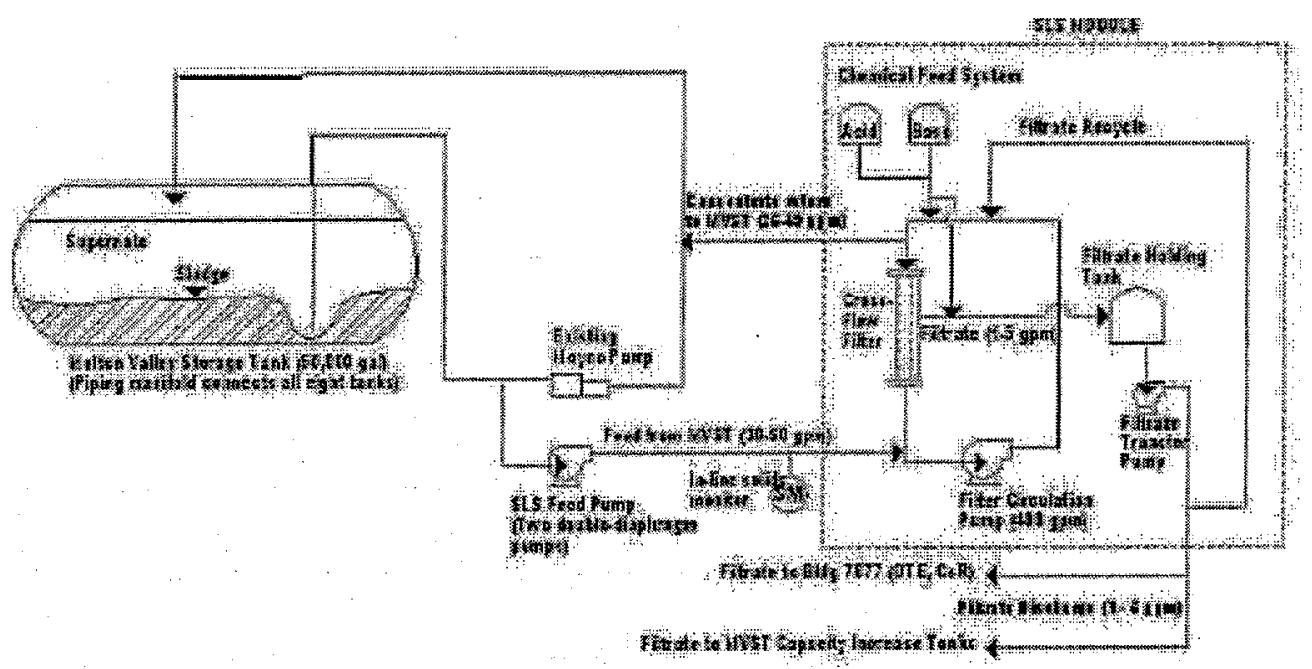

Fig. 18. Flowsheet of the SLS filtration loop and feed system. 


\subsubsection{SLS Demonstration Operations}

The completed SLS module was delivered to ORNL by NUMET in December 1998 and installed adjacent to the MVSTs with piping ties to the existing waste collection and transfer system. . In June 1999, the SLS system operation was demonstrated successfully in two waste treatment campaigns in which the filtrate was further processed by the CsR and OTE systems. Filtrate production and solids removal performance met expectations based on laboratory testing performed in FY $1996^{8}$

\subsection{WTP INTEGRATED FLOWSHEET}

Following the successful demonstration of the OTE and CsR systems, the ASTD program co-funded the procurement and installation of the SLS system and upgraded the OTE and CsR equipment for deployment in baseline operations. The project upgraded the piping, instrumentation, and control systems to allow the systems to be operated individually, in parallel, or in series to optimize waste treatment flexibility and efficiency. Design of the piping, electrical, and structural interfaces between the WTP system and the MVST facility was provided by ORNL Engineering. These designs, as well as the changes and upgrades to the facilities that were necessary to accommodate the WTP equipment have been detailed in previous reports. ${ }^{4,6,8}$

A schematic diagram of the WTP system can be seen in Fig. 19. Detailed piping and instrument diagrams for the systems have been detailed in previous reports. ${ }^{4,6,8,9}$ With the exception of a limited number of manual valves, the WTP systems were automated-for remote operation from a control room situated in Building 7863, approximately $75 \mathrm{ft}$ away from Building 7877. The control system for the WTP included computer-based operator interfaces using FIX-32 software by Intellution for the SLS and CsR system and Paragon software from Intec Controls for the OTE system. The software was installed on separate personal computers for each system with input/output (I/O) modules (MTL, Inc.) for interfacing the control system with the process equipment. The user interface for each system consisted of a color monitor, mouse, and graphical user interface (GUI) flowsheet display, including updated instrument readouts, valve status, alarms, and data archiving. A supervisory mode was provided to set critical operating parameters, and manual operation was also provided to allow the operator to manipulate individual components of the systems (e.g., valves, pumps, samplers). Remote overhead video cameras were utilized to view the processing equipment from the control room at many different angles.

\subsection{PERFORMANCE REQUIREMENTS AND OPERATING PLANS}

The performance requirements for the evaporator system in baseline operations included the ability to concentrate tank supematant with nitrate content of 0 to $5 \mathrm{M}$ to the limit of salt saturation. Laboratory tests indicated that saturation would be reached at 6 to $8 M$, depending on the composition variations of the waste. The salt and radionuclide content of the distillate stream was required to meet the acceptance criteria for the ORNL PWTP, which treats dilute wastewaters for discharge to the environment. This required that the evaporator system achieve an average decontamination factor of $5 \times 10^{6}$. For highactivity waste feed, cesium removal was required prior to evaporation to meet the PWTP acceptance requirements.

The CsR system was required to remove at least $90 \%$ of the cesium from the waste to allow the evaporator to reach the required decontamination factor (DF) for discharge to the PWTP. In addition, it was'required that the Cs-loaded IE-911 meet the acceptance criteria for disposal at the NTS. Each IE-911 package must contain less than the Class $\mathrm{C}$ limit of $4600 \mathrm{Ci}^{137} \mathrm{Cs}^{13} / \mathrm{m}^{3}$, as specified in the existing NTS acceptance criteria, and the waste must be transported in a Type B cask. In addition, because the 


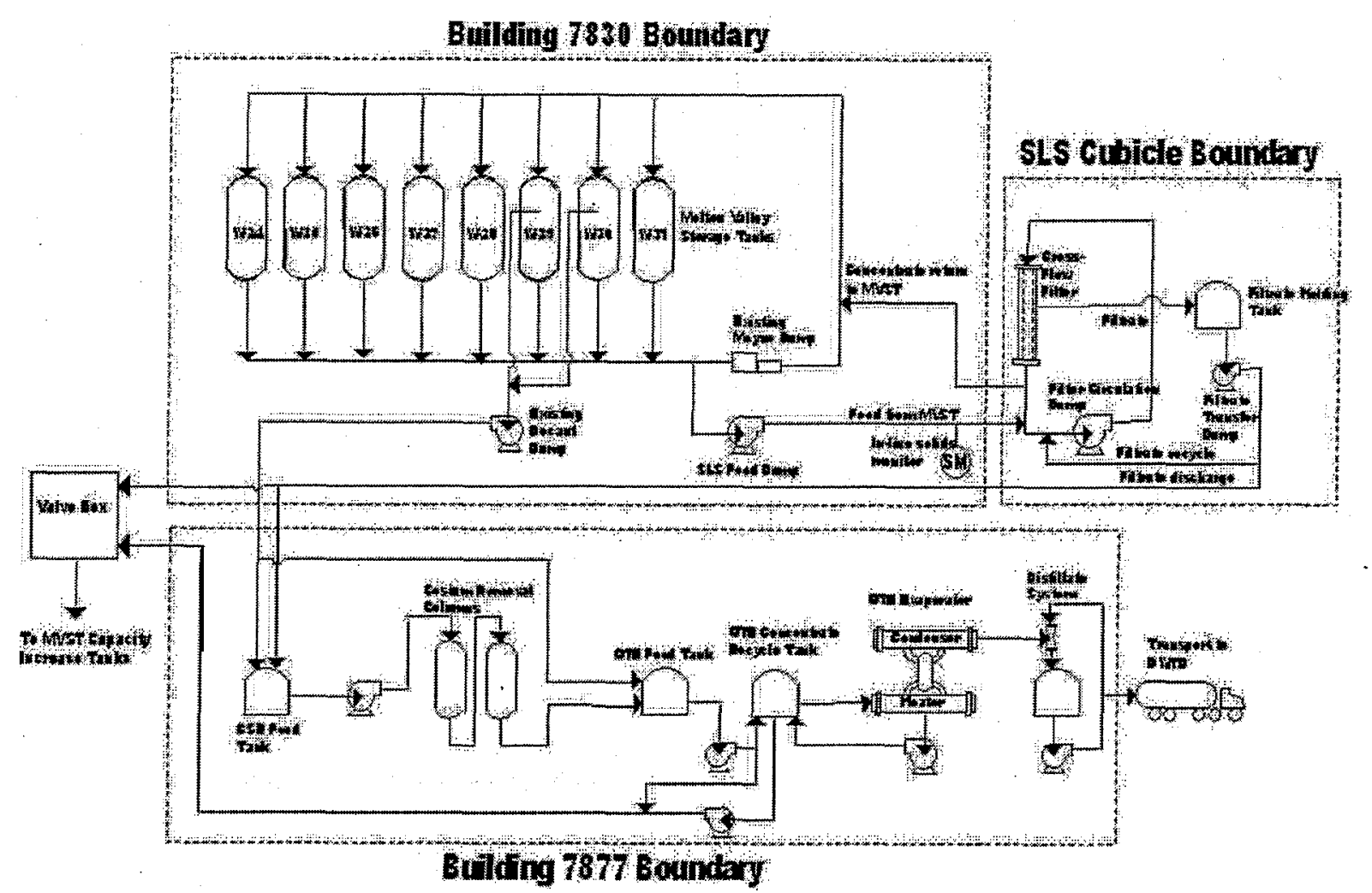

Fig. 19. Schematic drawing of the WTP system.

supematant contained measurable concentrations of heavy metals (lead, mercury, chromium) regulated under RCRA, the loaded\&91 1 had to be certified as nonhazardous. This certification was obtained by pumping a volume of actual tank waste at a liquid-to-solid ratio equivalent to what would be achieved in the actual field treatment process through a small column containing $-10 \mathrm{~cm}^{3}$ of IE-911. The small sample of loaded IE-911 was then subjected to the Toxicty Characteristic Leaching Procedure (TCLP) to verify that any RCRA metals that may have loaded onto the IE-911 would not leach from the loaded sorbent. This testing also served the dual purpose of providing useful information regarding the IE-911 cesium bading characteristics for the particular waste tank to be processed

The SLS system was designed to remove suspended solids from the supematant to prevent plugging and fouling of the CsR and OTE systems and also to minimize carryover of TRU solids to the new CIP tanks, which do not have equipment for mixing and suspension of accumulated sludges. The SLS system was also designed to provide clarified supematant at a much faster rate than the existing gravity settling system and to allow the flexibility of processing waste from any of the eight MVSTs. It was planned that the two tanks occupied by the gravity settling system would eventually be used to collect and store TRU sludge, thus becoming ineffective as settling tanks. The SLS system would provide continued solids removal capability once the gravity settling system was no longer in service.

In the treatment process, LLLW from any one of the eight MVSTs (W-24 through W-3 1) was typically pumped first through the SLS system for filtration. The filtrate was transferred batch-wise to the CsR system feed tank (500-gal capacity), from which it was pumped through two IE-911 ion-exchange columns in series to remove ${ }^{137} \mathrm{Cs}$. The ion-exchange effluent was then routed to the OTE system feed 
tank, which holds about 350 gal. The OTE system heated and evaporated water from the liquid and transferred the concentrated LLLW to the MVST CI tanks for storage. The evaporated water was condensed, cooled, collected in a transport tanker, and transported to the PWTP for treatment and discharge to the environment. The cesium-loaded IE-911 was sluiced from the ion-exchange column into a disposal container, dewatered, and packaged to meet the NTS WAC. The packaged IE-91 1 is being stored on site temporarily until plans and permits are finalized for shipment to NTS.

The WTP system was piped to maximize process flexibility. Optional processing scheines included (1) independent operation of the CsR or the OTE using either the 7830 decant system or the SLS system to provide LLLW feed, (2) independent operation of the SLS system to filter LLLW for storage in the MVST CI tanks, (3) operation of the OTE feed tank as a booster station for transferring LLLW from the MVSTs to the MVST CI tanks, and (4) receipt of LLLW from the MVST CI tanks to perform CsR and/or OTE processing. All of these operational schemes were used during the deployment of the WTP system.

\section{WTP SCHEDULE}

In FY 1997 the CsR system was demonstrated, and in FY 1998, the OTE system was deployed in routine operations. Later in FY 1998, the CsR system was reinstalled in Building 7877 and integrated with the OTE piping system In FY 1999, fabrication of the SLS system, upgrades to the MVST facilities necessary to accommodate the SLS system as part of the WTP, and all documentation requirements necessary to operate the three triad processes were completed An operational readiness assessment to verify the startup readiness was completed, and approval was given to begin operation of the WTP in May 1999. Ten operational WTP operational campaigns were completed between May 1999 and April 2000. Following the shutdown in April 2000, the system was decontaminated and turned over to Bechtel Jacobs Company LLC (BJC). System performance evaluation and processing documentation were completed in FY 2001.

\section{PROCEDURES}

Detailed operating procedures were prepared for each 'operational mode that was expected to be used during the WTP deployment. This included operation of each system individually or operations in series with either two or all three of the systems. The procedures included a review of the job hazards, a review of the facility safety requirements, preoperational checks, valve alignment and verification, stepby-step operating instructions, data collection instructions and log sheets, and emergency procedures. The procedures were prepared using a format consistent with that used by the BJC Liquid and Gaseous Waste Operations Project (LGWOP) because the WTP system was to eventually become the responsibility of BJC. This format reduced the cost of future procedure revisions.

\section{VALIDATION AND TRAINING}

A preoperational test was conducted on the individual process units and the combined Triad system for an extended period to validate the procedures as well as to check the operation of all equipment, instruments, and control logic. The procedures were revised as necessary to complete the validation and approval The approved procedures were issued and used as a basis for operator training. The LGWOP Training Department assumed responsibility for preparing the training plan and coordinating the training of both 
Chemical Technology Division (CTD) and LGWOP operators. After classroom training, operators completed a Procedure User Examination (PUE), which involved reading the procedure and completing a written test. A Performance Document Checklist (PDC) was prepared by the LGWOP Training Department and used to document on-the-job training. The PDCs included a detailed list of operational tasks that had to be performed correctly and witnessed by a subject matter expert (SME) from CTD. The CTD SMEs were responsible for operations during the initial runs with LLLW, and the BJC operators completed the PDCs during actual processing of radioactive waste.

\section{DOCUMENTATION REQUIREMENTS AND READINESS SELF-ASSESSMENT}

The Readiness Self-Assessment, which is required by DOE orders, involves preparation of documentation ensuring that equipment and personnel are ready and that all document and management controls are in place prior to the start of operations with radioactive wastes. There are different levels of rigor for these assessments, depending on the potential safety, environment, facility, and cost impacts of the operation. Based on the characteristics of this project, a Readiness Self-Assessment was recommended and accepted by DOE-ORO. The equivalent of this task for BJC LGWOP was an Internal Field Evaluation (IFE). Since BJC had very recently become responsible for operation of all waste systems at ORNL, DOE-ORO worked closely with BJC to ensure that the IFE was sufficiently rigorous and satisfied the intent of a complete self-assessment. DOE-ORO provided a Readiness Criteria list to BJC to use as a guide for the self-assessment.

The criteria list was broken down into three categories-Personnel Availability and Training, Procedures and Management Controls, and Facilities and Equipment. Using the DOE criteria list, indexes were prepared showing the criteria and the appropriate documentation and evidence that must be collected to satisfy the criteria. Since two readiness assessments were held, one for the CsR/OTE systems and one for the SLS system, two indexes were prepared. These indexes can be found in Appendix A. CTD collected the necessary documentation and evidence for the criteria. The IFE process involved organizing a Line Management Team to collect the evidence, an Independent Review Team to review the evidence collected for the criteria, a BJC Evaluation Review Board to approve the evidence, and a DOE Evaluation Review Board to review and approve the entire IFE process and evidence. In addit ion to the documentation requirements, personnel interviews and several surveillances were conducted to assess training, procedures, management controls, facilities, and equipment. This was an intensive and costly effort that required about 12 weeks to complete. With DOE approval of the assessment, BJC

management gave approval for hot operations to begin. Approval for the CsR/OTE system was granted in May 1999 while approval for the SLS system was granted separately in June 1999. 


\section{OPERATIONS}

The results of earlier demonstrations and deployment projects are covered in other reports. ${ }^{4,6}$ The WTP operations began in May 1999 after personnel received approval to start from DOE-ORO. A processing summary for all of the demonstrations and deployments is presented in Table 2. The deployment work spanned the period from December 1997 through April 2000. During this period, a total of -267,000 gal of radioactive supernatant was processed, $>117,000$ gal of additional tank volume was made available for storage due to the use of the OTE system, and $-7700 \mathrm{Ci}$ of ${ }^{137} \mathrm{Cs}$ was removed from the supematant and concentrated on 540 gal of an inorganic sorbent. A graph of the DF for the CsR system during operations is presented in Fig. 20. The DF for the ion-exchange system typically varied from 50 to 500. In most instances, samples of the LLLW effluent from the ionexchange system were taken only after the column had reach its designated loading limit, and few attempts were made to determine the change in concentration versus gallons processed. Details on the operations during FY 1998 OTE deployment have been published. ${ }^{9}$ Details on the operations for the ten WTP runs are presented below.

\subsection{WTP CAMPAIGN 1}

In the first WTP campaign, the CsRD system was used to treat the supematant located in MVST W30 and to transfer the treated supematant to MVST-CI tank W33. This particular supematant was highly concentrated and had been settling for months; therefore, the OTE and SLS systems were not needed for the processing. The following flow scheme was utilized for this campaign: (1) a transfer pump for the settle/decant system J-01 was used to pump the supematant from settling tank W30 to the CsR feed tank (TK-1), (2) two progressive-cavity pumps (P-1 and P-2) operating in parallel were used to pump the supematant from the CsR feed tank, through a $25 \mu \mathrm{m}$ backwashable filter (F-1), through two ionexchange columns in series (X-1 and X-2) and into the OTE feed tank (T-314). One of the two OTE centrifugal pumps (P-355 or P-356) was used to transfer the treated supematant to MVST-CI tank W33. When a predetermined concentration of ${ }^{137} \mathrm{Cs}$ had been loaded on the ion-exchange columns, the system was shut down long enough to sluice the cesium-loaded sorbent from the ion-exchange columns into a shielded HIC. The ${ }^{137} \mathrm{Cs}$ and nitrate concentrations in the storage tank to be processed were $1,000,000 \mathrm{~Bq} / \mathrm{ml}$ and $286,000 \mathrm{mg} / \mathrm{L}$, respectively. Prior to initiating the first campaign, the two ionexchange columns (X-1 and X-2) were loaded with 10 gal each of CST sorbent, a preoperational checklist wascompleted, an initial valve lineup check sheet was completed, and a calculation of ${ }^{90} \mathrm{Sr}$ equivalent activity was completed as a requirement of the facility safety documentation.

The campaign lasted $168 \mathrm{~h}$ during which about 19,000 gal of liquid was processed and $1900 \mathrm{Ci}$ of cesium was removed using $120 \mathrm{gal}$ of CST. Several operating difficulties were encountered, but the operating team was able to address the problems quickly. Total unplanned downtime was only $11 \mathrm{~h}$, equivalent to 93\% availability. Downtime for normal operations such as unloading and loading the CST columns, backwashing, and LLLW transfers required about $34 \mathrm{~h}$. Pertinent details of the operation in chronological form are given in the following paragraphs.

Campaign 1 was initiated on May 18, 1999, at 0800 h. Prior to startup, the ion-exchange columns were backwashed with supematant at $1.5 \mathrm{gal} / \mathrm{min}$ with the backwash solution being returned to the CsR feed tank (TK-1). When the OTE control system was activated, the level in the CsR feed tank was not being detected by the programmable logic controller (PLC) of the OTE control. A loose connection was 
Table 2. Summary of demonstration and deployment campaigns

\begin{tabular}{|c|c|c|c|c|c|c|c|}
\hline Run identification & $\begin{array}{c}\text { Processes } \\
\text { used }\end{array}$ & Start-end date & $\begin{array}{l}\text { Volume } \\
\text { processed, } \\
(\text { gal) }\end{array}$ & $\begin{array}{l}\text { cs-137 } \\
\text { removed } \\
\text { (Ci) }\end{array}$ & $\begin{array}{c}\text { Volume } \\
\text { evaporated }\end{array}$ & $\begin{array}{c}\text { Inlet Cs-137 } \\
\text { concentration } \\
(\mathrm{Bq} / \mathrm{mL})\end{array}$ & $\begin{array}{c}\text { Inlet nitrate } \\
\text { concentration } \\
(\mathrm{mg} / \mathrm{L})\end{array}$ \\
\hline OTE Demo & OTE & $4 / 4 / 95-4 / 12 / 95$ & 22,000 & NA & 5,500 & 900,000 & 230,000 \\
\hline CsR Demo Run 1 & CsR & $9 / 15 / 96-9 / 17 / 96$ & 500 & 22 & NA & 418,000 & 270,000 \\
\hline CsR Demo Run 2 & CsR & $2 / 16 / 97-2 / 23 / 97$ & 4,763 & 154 & NA & 418,000 & 270,000 \\
\hline CsR Demo Run 3 & CsR & $3 / 3 / 97-3 / 23 / 97$ & 10,320 & 334 & NA & 398,000 & 270,000 \\
\hline CsR Demo Run 4 & CsR & $5 / 5 / 97-5 / 16 / 97$ & 15,000 & 632 & NA & 490,000 & 270,000 \\
\hline OTE Campaign 1 & OTE & $12 / 5 / 97-12 / 17 / 97$ & 23,800 & NA & 9,660 & 560,000 & 217,000 \\
\hline OTE Campaign 2 & OTE & $1 / 12 / 98-1 / 30 / 98$ & 16,150 & NA & 7,909 & 320,000 & 217,000 \\
\hline OTE Campaign 3 & OTE & $3 / 9 / 98-3 / 28 / 98$ & 22,400 & NA & 13,317 & 940,000 & 128,000 \\
\hline OTE Campaign 4 & OTE & $5 / 29 / 98-6 / 19 / 98$ & 20,272 & NA & 10,880 & 580,000 & 182,000 \\
\hline WTP Campaign 1 & CsR & $5 / 18 / 99-5 / 25 / 99$ & 19,340 & 1,930 & NA & $1,000,000$ & 286,000 \\
\hline WTP Campaign 2 & CsR, OTE & $5 / 26 / 99-6 / 4 / 99$ & 19,244 & 1,017 & 5,400 & 520,000 & 271,000 \\
\hline WTP Campaign 3 & SLS, CsR, OTE & $6 / 7 / 99-6 / 24 / 99$ & 28,450 & 1,896 & 11,000 & 800,000 & 201,000 \\
\hline WTP Campaign 4 & OTE & $6 / 25 / 99-7 / 15 / 99$ & 20,565 & NA & 9,800 & 460,000 & 150,000 \\
\hline WTP Campaign 5 & SLS, CsR, OTE & $7 / 24 / 99-8 / 21 / 99$ & 13,590 & 438 & 7,968 & 750,000 & 2,750 \\
\hline WTP Campaign 6 & CsR, OTE & $9 / 14 / 99-10 / 31 / 99$ & 20,427 & 1,796 & 9,012 & 860,000 & 192,000 \\
\hline WTP Campaign 7 & CsR, OTE: OTE & $10 / 31 / 99-1 / 26 / 00$ & 21,202 & 89 & 8,991 & 190,000 & 37,000 \\
\hline WTP Campaign 8 & CsR, OTE & $2 / 3 / 00-2 / 19 / 00$ & 17,277 & 495 & 10,034 & 280,000 & 54,900 \\
\hline WTP Campaign 9 & SLS, OTE & $3 / 10 / 00-3 / 28 / 00$ & 11,911 & NA & 5,685 & 198,000 & 3,390 \\
\hline WTP Campaign 10 & SLS, OTE & $3 / 29 / 00-4 / 15 / 00$ & 13,357 & NA & 6,937 & 132,000 & 6,010 \\
\hline Total & & & 320,568 & 8,803 & 122,093 & & \\
\hline
\end{tabular}




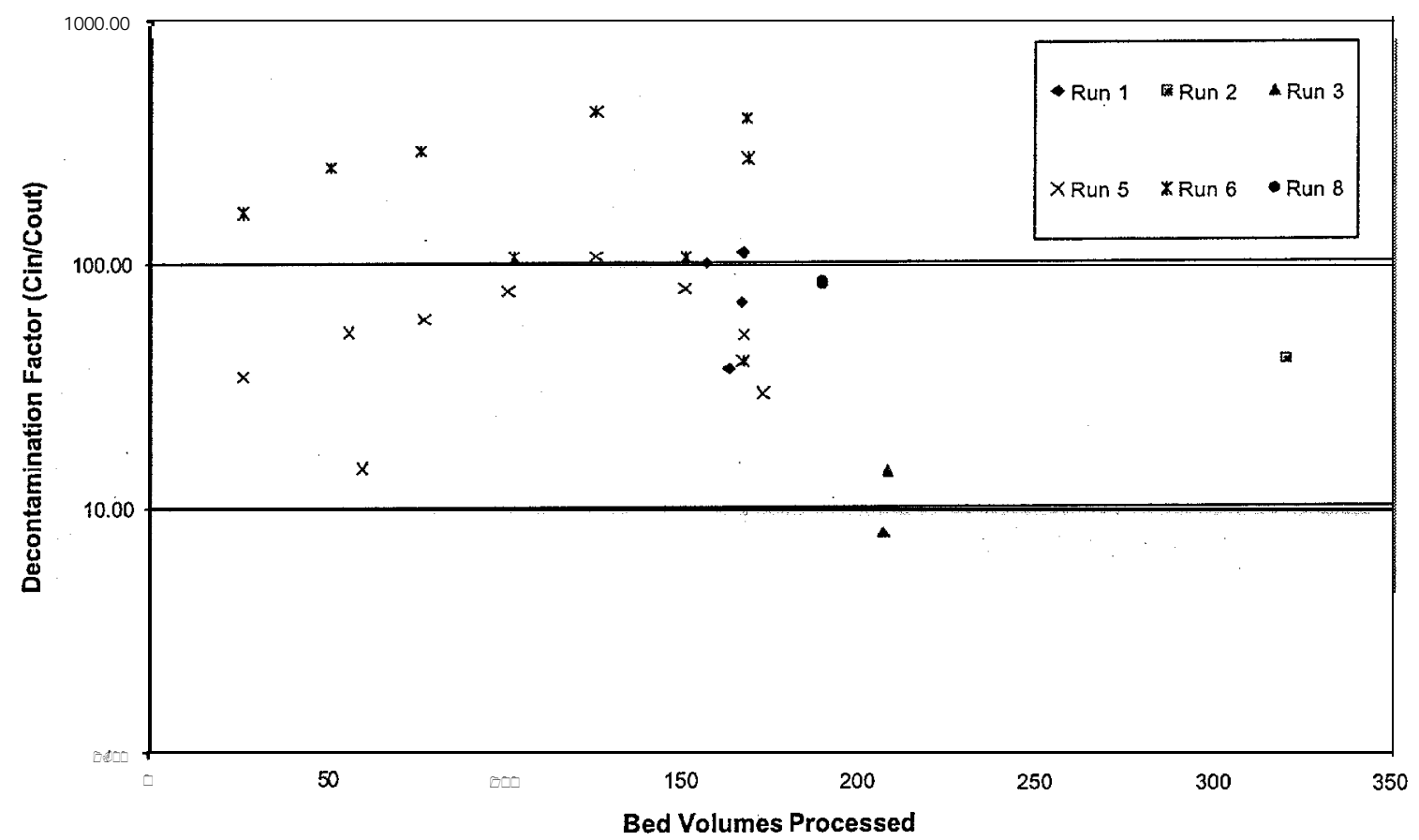

\section{Fig. 20. Graph of the decokamination factors for the CsR system for the WTP operational campaigns.}

discovered on the input module of the OTE local maintenance panel. This connection was repaired, and radioactive supematant was introduced to the CsR system at $2300 \mathrm{~h}$ on May 18. The flow-rate with time for the first campaign is presented in Fig. 21, and the pressure drop though the filter and two ionexchange columns is presented in Fig. 22. The flow-rate through the ion-exchange columns was maintained at $2 \mathrm{gal} / \mathrm{min}$ for the first $18 \mathrm{~h}$ of operation and raised to $2.5 \mathrm{gal} / \mathrm{min}$ for the remainder of the run.' Immediately after startup, the pressure drop across the first column, X-1, started to increase and, after $9 \mathrm{~h}$ of operation, had reached $32 \mathrm{psig}$. Over the next $6 \mathrm{~h}$, the pressure drop had increased to $>36 \mathrm{psig}$ and the control system was issuing periodic high-pressure warnings because the maximum pressure drop across the colunms was approaching the maximum allowable limit of 50 psig. As a result, X-1 was backwashed in an attempt to reduce the pressure drop across the column. Immediately after backwashing, the pressure drop across the column fell to less than 5 psig. It is speculated that the pressure drop increase was the result of solids precipitating from solution as the $\mathrm{pH}$ of the sorbent reached equilibrium with the supematant being processed. After the $\mathrm{pH}$ of the sorbent and supematant reached equilibrium, no additional precipitation occurred and no increase in the pressure drop across the columns was noted.

Operation of the system continued until $0500 \mathrm{~h}$ on May 20, when the system was shut down to sluice the contents of the ion-exchange columns into the shielded HIC. At this point, $3300 \mathrm{gal}$ of supematant had been processed, and it was estimated that the 20 gal of sorbent in the two ion-exchange columns had accumulated $-340 \mathrm{Ci}$ of ${ }^{137} \mathrm{Cs}$, the maximum allowed for NTS disposal During the sluicing operation, a radiation meter remotely placed next to the sluice line exceeded the instrument limit of $5 \mathrm{R} / \mathrm{h}$, and the level on the outside of the building at the south door reached $270 \mathrm{mR} / \mathrm{h}$. The high radiation levels lasted 


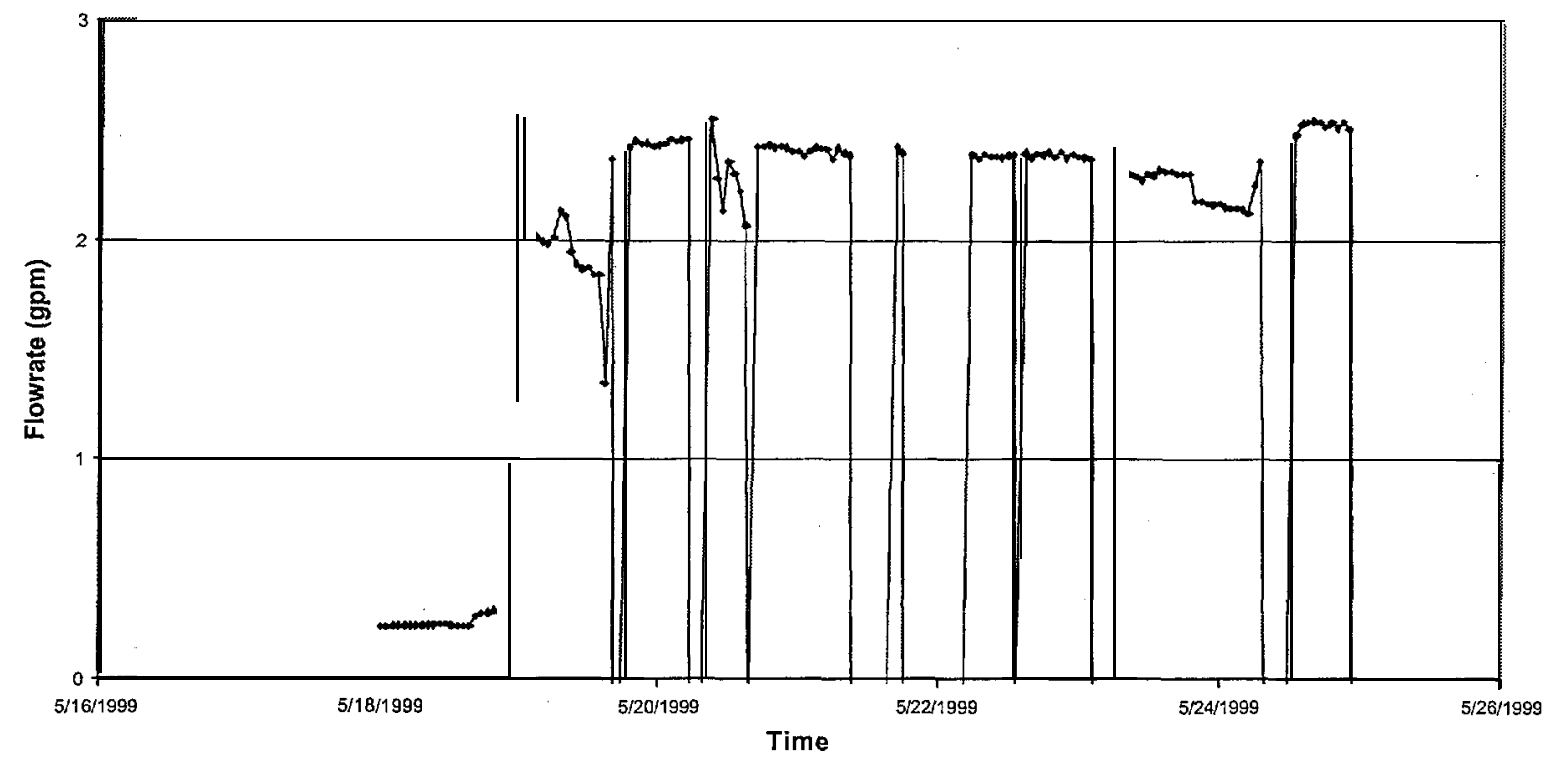

Fig. 21. Flow rate for the WTP system as a function of time for the first WTP operational campaign.

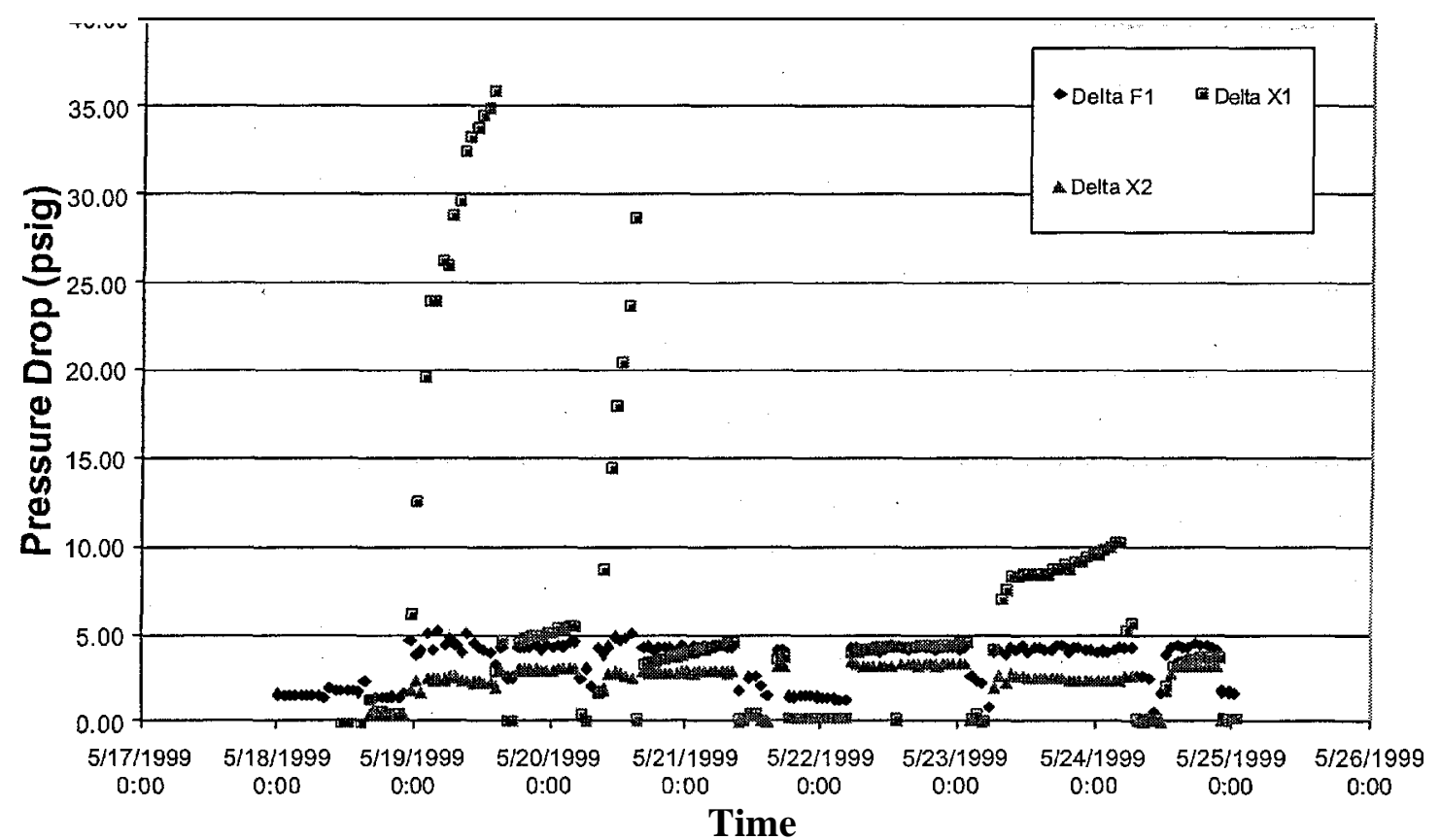

Fig. 22. Pressure drop through the CsR prefilter and ion-exchange columns during the first WTP operational campaign. 
only a few minutes, and access to the area was controlled during the sluicing operations to prevent inadvertent exposure. After the transfer and rinsing operations had been completed, the radiation level in the sluice hose was reduced to $-0.5 \mathrm{mR} / \mathrm{h}$, indicating that it was safe to enter the processing area.

The ion-exchange columns were refilled with 10 galeach of sorbent and backwashed, the HIC was dewatered, all valves were realigned, and operations with radioactive supematant resumed at $-0800 \mathrm{~h}$. The sluicing, dewatering, valve alignment, and startup operations required $-3 \mathrm{~h}$ to complete. The system operated for $-7 \mathrm{~h}$ and then the pressure drop across the first column climbed rapidly to $-30 \mathrm{psig}$. The column was backwashed, reducing the pressure drop to $<5$ psig. Again, it is speculated that the increase in the pressure drop across the columns resulted from solids precipitating from solution and collecting on the ion-exchange bed as the $\mathrm{pH}$ of the solution and the sorbent reached equilibrium. After backwashing, the system was restarted and operated for $-21 \mathrm{~h}$, with no increased pressure drop, until cesium loading reached the targeted value. The system was shut down for $-2 \mathrm{~h}$ for sluicing of the sorbent and for an additional $-3 \mathrm{~h}$ for a LLLW transfer from the GAAT.

The system was restarted and operated for $3 \mathrm{~h}$. During this 3-h period, control/instrument problems with the OTE/CsR systems resulted in erratic and inaccurate level readings for the OTE feed tank (T-3 14). The system was shut down and personnel from the Instrumentation and Controls Division, (I\&C) were called in to troubleshoot and solve the problem. It was determined that an input module to the OTE system had malfunctioned, and the module was replaced. Since this problem' occurred at night, the I\&C and Plant and Equipment (P\&E) personnel who support the WTP were off-shift; therefore, it required 11 $\mathrm{h}$ to get personnel on-site, troubleshoot the problem, and repair the system.

The system was restarted on May 22 at $-0500 \mathrm{~h}$ and operated with only minor problems for the remainder of the first WTP campaign, which ended on May 25 at $-2300 \mathrm{~h}$. During this period, there were two short shutdowns to sluice sorbent from the ion-exchange columns into the HIC. The campaign was terminated when pump J-01, whose suction leg terminated in the middle of MVST W30, could no longer pull supematant from the tank.

\subsection{WTP CAMPAIGN 2}

In the second WTP campaign, both the CsR and OTE systems were operated in series over a period of $228 \mathrm{~h}$ (9.5 days). During this period the systems were shut down for $-17 \mathrm{~h}$ for scheduled normal operations (sluicing, waste transfers) and $-21.5 \mathrm{~h}$ (91\% availability) for unscheduled operational problems and maintenance activities. The flow of supematant through the system typically varied from 1.5 to $2.0 \mathrm{gal} / \mathrm{min}$, the pressure drop though the ion-exchange prefilter typically ranged from 8 to $16 \mathrm{psig}$, and the pressure drop through the ion-exchange columns was less than $10 \mathrm{psig}$. The flow and pressure drops, as a function of time, are presented in Figs. 23 and 24, respectively. The WTP system processed a total of 19,000 gal of LLLW, and $1000 \mathrm{Ci}$ of ${ }^{137} \mathrm{Cs}$ was removed from the LLLW using $100 \mathrm{gal}$ of CST. The evaporator reduced the volume of the supematant by 5400 gal.

The second campaign was initiated immediately following the completion of the first. About $3 \mathrm{~h}$ was required to complete all the paperwork and valve realignment necessary to restart the processing. Supematant in MVST W29, the second of the two tanks used in the settle/decant system had a nitrate concentration of $-271,000 \mathrm{mg} / \mathrm{L}(4.3 \mathrm{M})$ and a ${ }^{137} \mathrm{Cs}$ concentration of $-520,000 \mathrm{~Bq} / \mathrm{mL}$. Based on the concentration of nitrate in the supematant, it was calculated that a concentrate reduction ratio (distillate flow/feed flow) of 0.33 would be required to obtain a $6.5 M$ nitrate concentration from the evaporator. During the second campaign, the CsR and OTE systems were operated in series with the W29 feed 


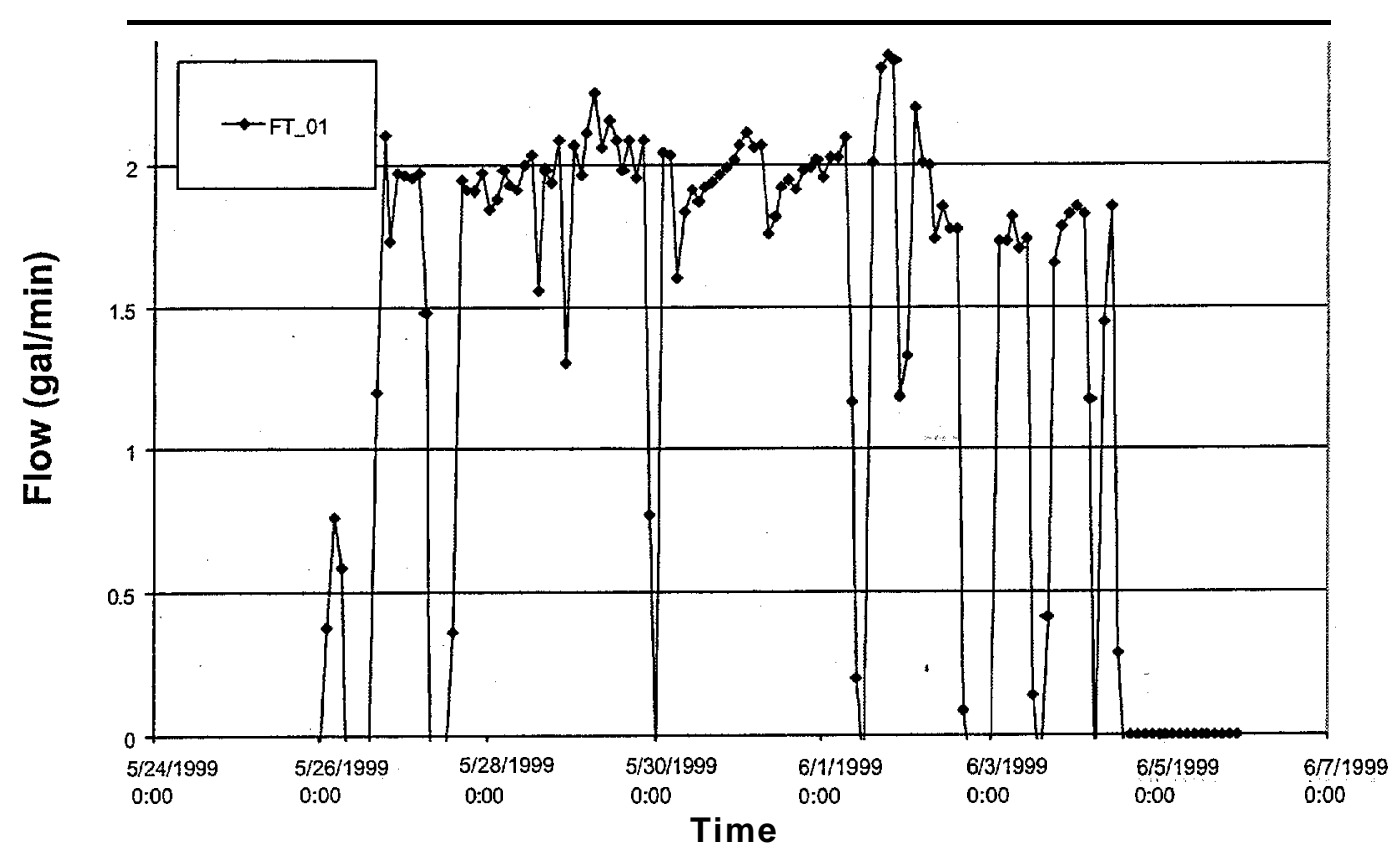

Fig. 23. Flow rate through the WTP system as a function of time for the second WTP campaign.

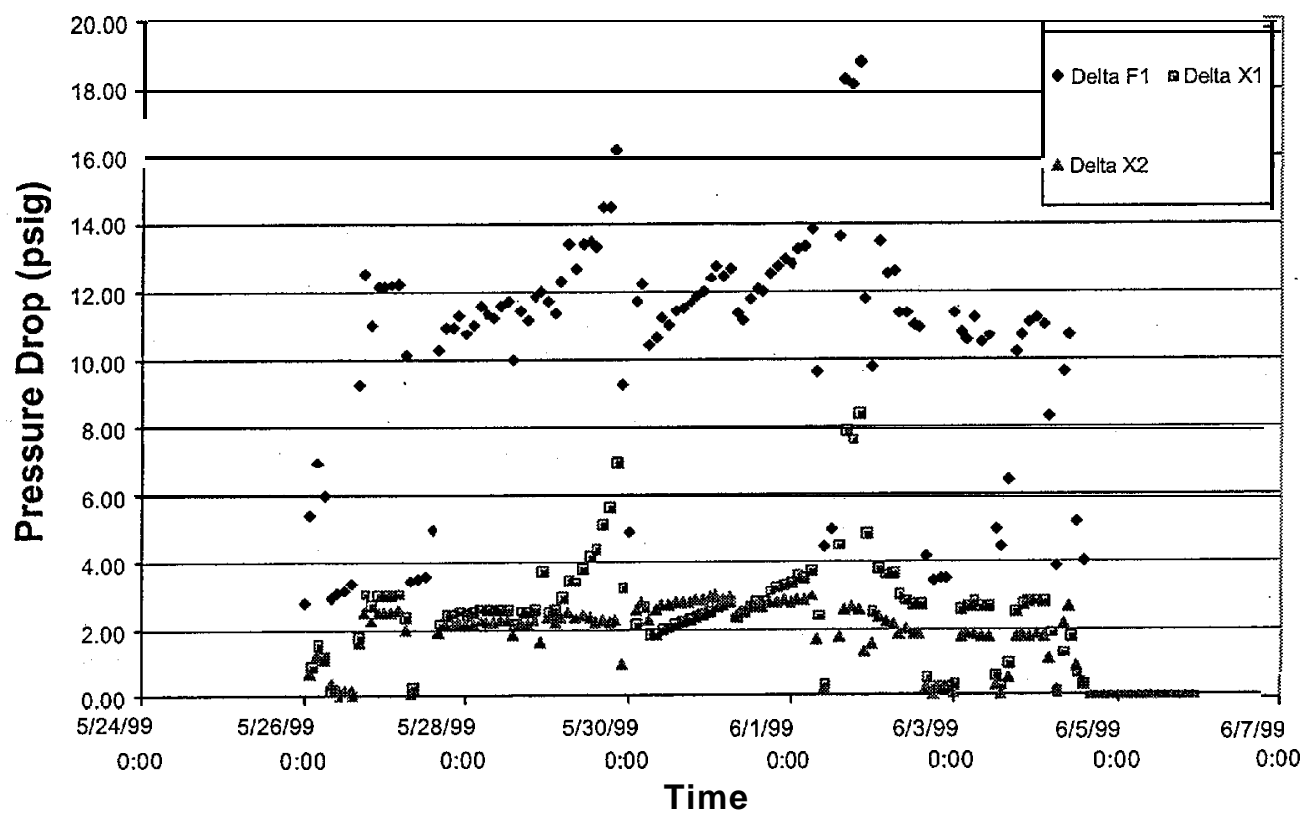

Fig. 24. Pressure drop through the CsR prefilter and ionexchange columns during the second WTP operational campaign. 
decanted to the CsR system, followed by evaporation and transfer to tank W34. For a detailed description of the operation of the OTE system, see Sect. 4.5 of this report. It should be noted that the evaporation rate of the OTE system controlled the flow to the WTP system through a cascading control system. A level transmitter located in the OTE feed tank controlled the speed of the progressive-cavity pumps (P-1 and P-2), which controlled the flow rate of supematant through the CsR system.

The second campaign was initiated at $0200 \mathrm{~h}$ on May 26, 1999. It was noted, after $13.5 \mathrm{~h}$ of operation, that pump J-01, which transfers liquid from the MVST to the CsR feed tank, was not functioning properly. The system was shut down, and it was discovered that the pump had a bad diaphragm. The pump was replaced, and the system was restarted at $1630 \mathrm{~h}$. The system was restarted and operated stably for $16.5 \mathrm{~h}$, when it was shut down for $4.5 \mathrm{~h}$ to sluice sorbent into the HIC and to replace a flow totahzer that had stopped functioning. During sluicing operations, it was noted that the radiation level in the sluice line typically peaked at $40 \mathrm{R} / \mathrm{h}$ for $\mathrm{X} 1$ and $5 \mathrm{R} / \mathrm{h}$ for X2. After the sluicing and flushing operations had been completed, the radiation level in the sluice line typically read $<30 \mathrm{mR} / \mathrm{h}$. The system was restarted and ran stably for $150 \mathrm{~h}$ (6.3 days) with only short shutdowns for sluicing and valving operations. Following these 6.3 days, the system operated for an additional $38 \mathrm{~h}$, with the second campaign being completed on June 4 at $1430 \mathrm{~h}$. During this final $38 \mathrm{~h}$ of operation, the system was shutdown for a total of $16.5 \mathrm{~h}$ (14.5 h for maintenance activities and $2.5 \mathrm{~h}$ for sluicing operations). Both maintenance activities were associated with leak detectors. The first occurred as a result of the high humidity in Building 7877. Water had condensed on the cool process piping, collected in one of the catch pans under the process skids, and was detected by the leak detector. The leak alarm sounded in the control room, shutting down the CsR system. Samples had to be taken to make sure the liquid was condensate, not processed LLLW. The second maintenance activity was associated with the replacement of a leak detector that malfunctioned.

\subsection{WTP CAMPAIGN 3}

The third WTP campaign was the first in which all of the treatment, systems- the SLS, CsR, and OTEwere operated together in series. The W3 1 supematant had nitrate and. ${ }^{137}$ Cs concentrations of $176,000 \mathrm{mg} / \mathrm{L}(2.8 \mathrm{M})$ and $800,000 \mathrm{~Bq} / \mathrm{mL}$, respectively. The concentration reduction ratio (distillate flow/feed flow) of the evaporator was set to 0.55 to provide a concentrate stream containing $6.2 \mathrm{M}$ nitrate. The operation was initiated on June 7, 1999, at $2000 \mathrm{~h}$ and terminated on July 24, 1999, at $0400 \mathrm{~h}$.

Approximately 28,000 gal of supematant from tank W-31 was processed, $1900 \mathrm{Ci}$ of ${ }^{137} \mathrm{Cs}$ was removed from the supematant and concentrated on 120 gal of sorbent, and 11,000 gal of distillate was evaporated from the supematant. The. total run time was $392 \mathrm{~h}$ (16.3 days), with about $80 \mathrm{~h}$ of downtime during the third campaign: $61 \mathrm{~h}$ to allow for a routine transfer of LLLW between MVSTs, $17 \mathrm{~h}$ for CST sluicing operations, and $2 \mathrm{~h}$ for unscheduled maintenance. The unscheduled maintenance activity involved the replacement of pump J-01 on the MVST settle/decant system. The remote automatic sampler used for process sampling of the CsR/OTE systems also malfunctioned due to a hard drive failure. The drive had to be replaced, and all software was reloaded. Since the sampler was on a separate computer system, the WTP system continued to operate while the hard drive was replaced and the software for the sampler was reloaded. In general, all three WTP systems ran smoothly with very few operational problems. The flow rate through the WTP system is presented in Fig. 25 and typically operated at $1-2 \mathrm{gal} / \mathrm{min}$. The flow rate through the system was limited by the evaporation rate of the OTE. The pressure drop through the CsR prefilter and ion-exchange columns during this campaign was $<4$ psig. 


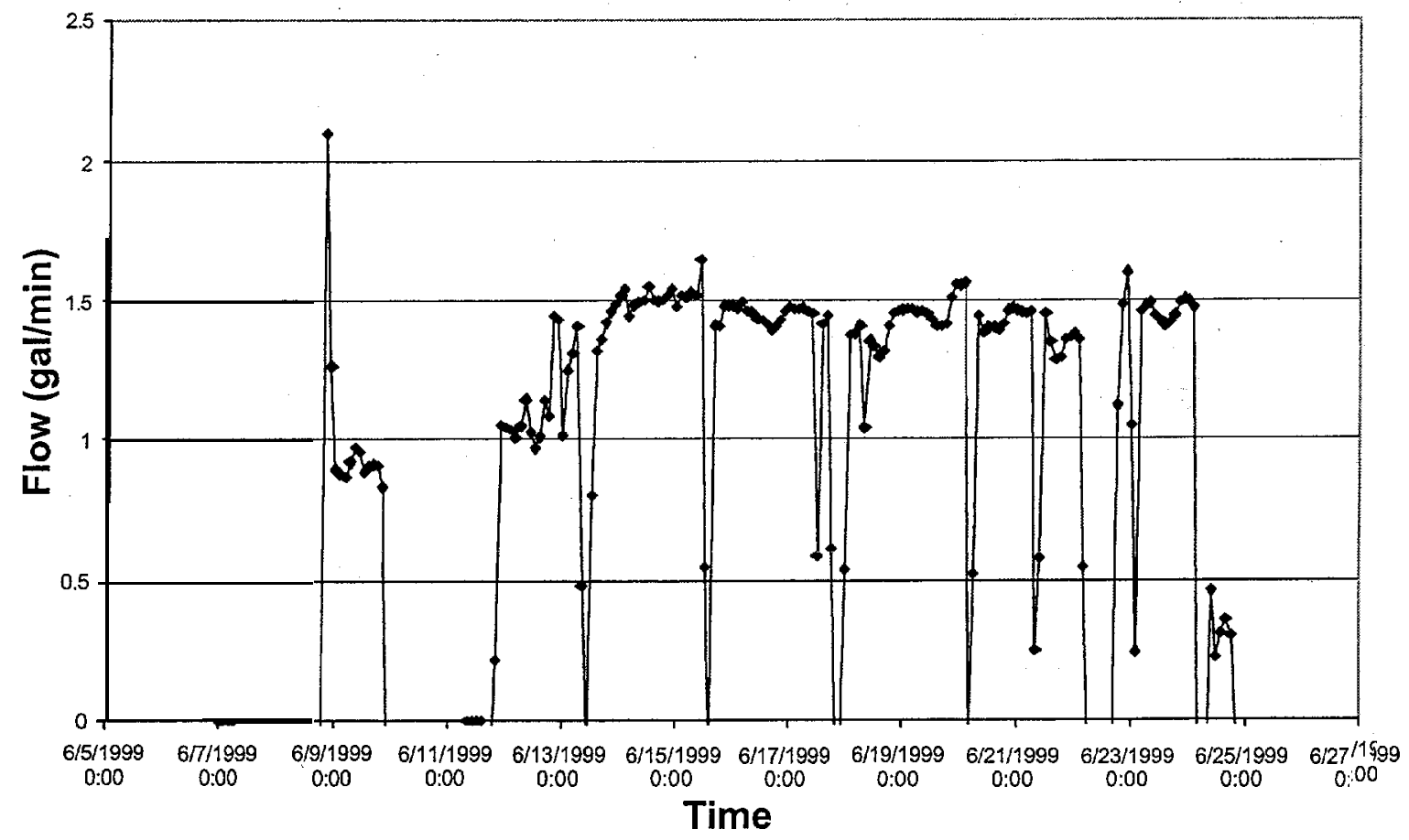

Fig. 25. Flow rate through the WTP system as a function of time for the third WTP operational campaign.

The system was initially operated with the processed filtrate being recycled back into the feed rather than being transferred to the CsR/OTE systems. This was necessary in order to sample and analyze the filtrate for TRU constituents, mainly plutonium and americium. The concentration of these components in the filtrate had to be less than $1815 \mathrm{~Bq} / \mathrm{mL}$ in order to avoid the potential for contaminating the IE-911 and having it classified as a TRU waste. The designated disposal site (NTS) for the spent IE-911 would not accept TRU waste for disposal. Analyses of the filtrate verified that the concentration of alpha components was $<100 \mathrm{~Bq} / \mathrm{mL}$. Processing of the SLS filtrate with the CsR/OTE systems was started on June 8 at $2000 \mathrm{~h}$. The filtrate was processed with the CsR system prior to evaporation through the OTE. The concentrate from the evaporator was pumped to tank W34 and the distillate was collected in a tanker for transport to the PWTP.

\subsubsection{WTP Campaign 3-SLS Performance}

A series of tests were performed during the processing of W3 1 to evaluate the performance of the SLS. Detailed information on these tests has been previously reported. ${ }^{8}$ Typical data from one of these test series are presented in Figs. 26 and 27, which shows the flow rate, transmembrane pressure, and filtrate flow rate versus time during the Series 1 tests for tank W-31. While axial flow is very stable, the transmembrane pressure varies significantly around the set point. This is principally due to the operating characteristics of the D/D feed pumps. Despite the use of pulsation dampeners on the D/D discharge piping, the discharge pressure was erratic, causing an equally erratic transmembrane pressure. The filtrate production dropped to zero periodically because the filtrate is produced in 80 -gal batches with a variable 


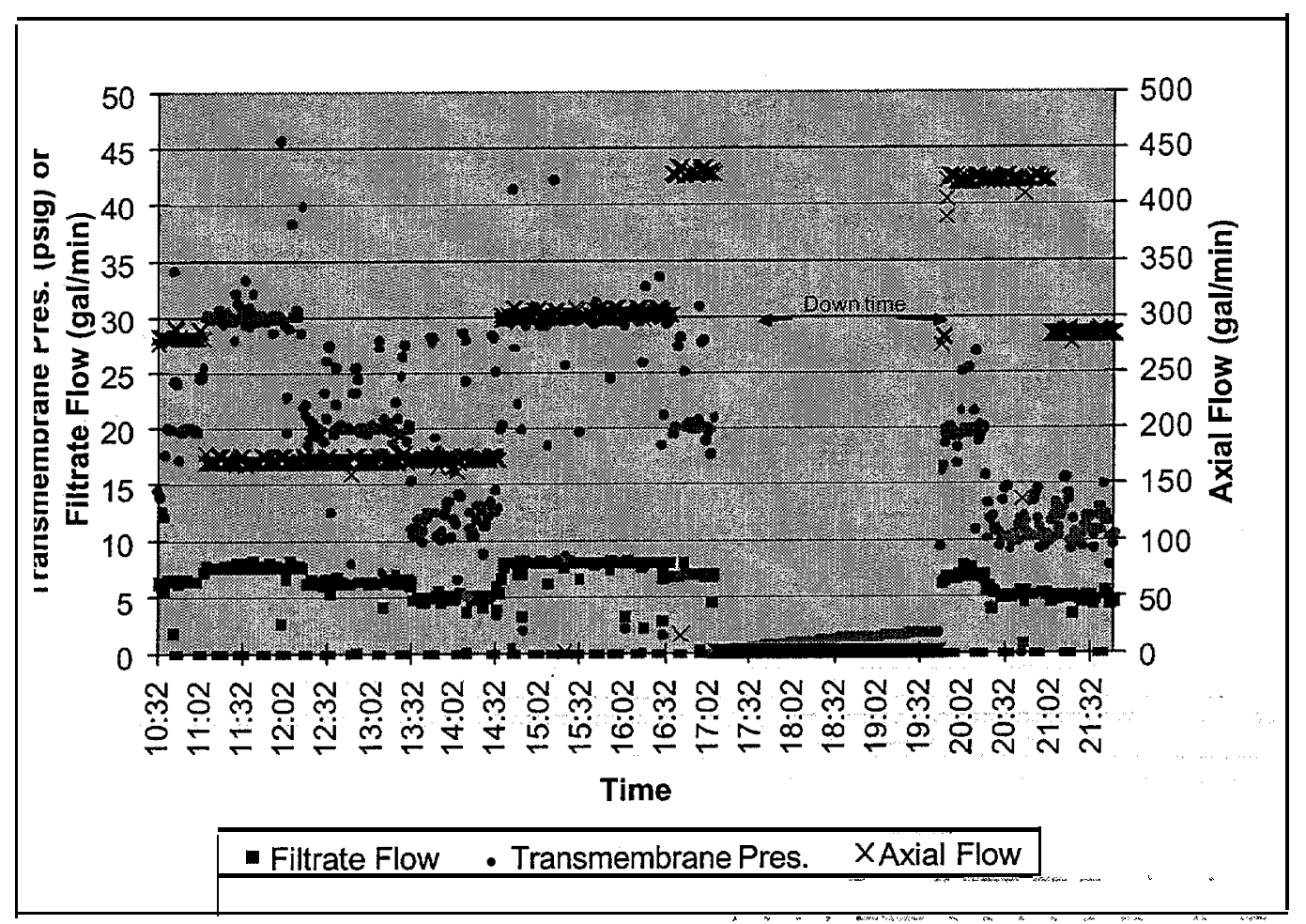

Fig. 26. Filtrate flow, transmembrane pressure, and axial flow as a function of time during the third WTP Campaign (Series 1, tests 1-7, tank W31).

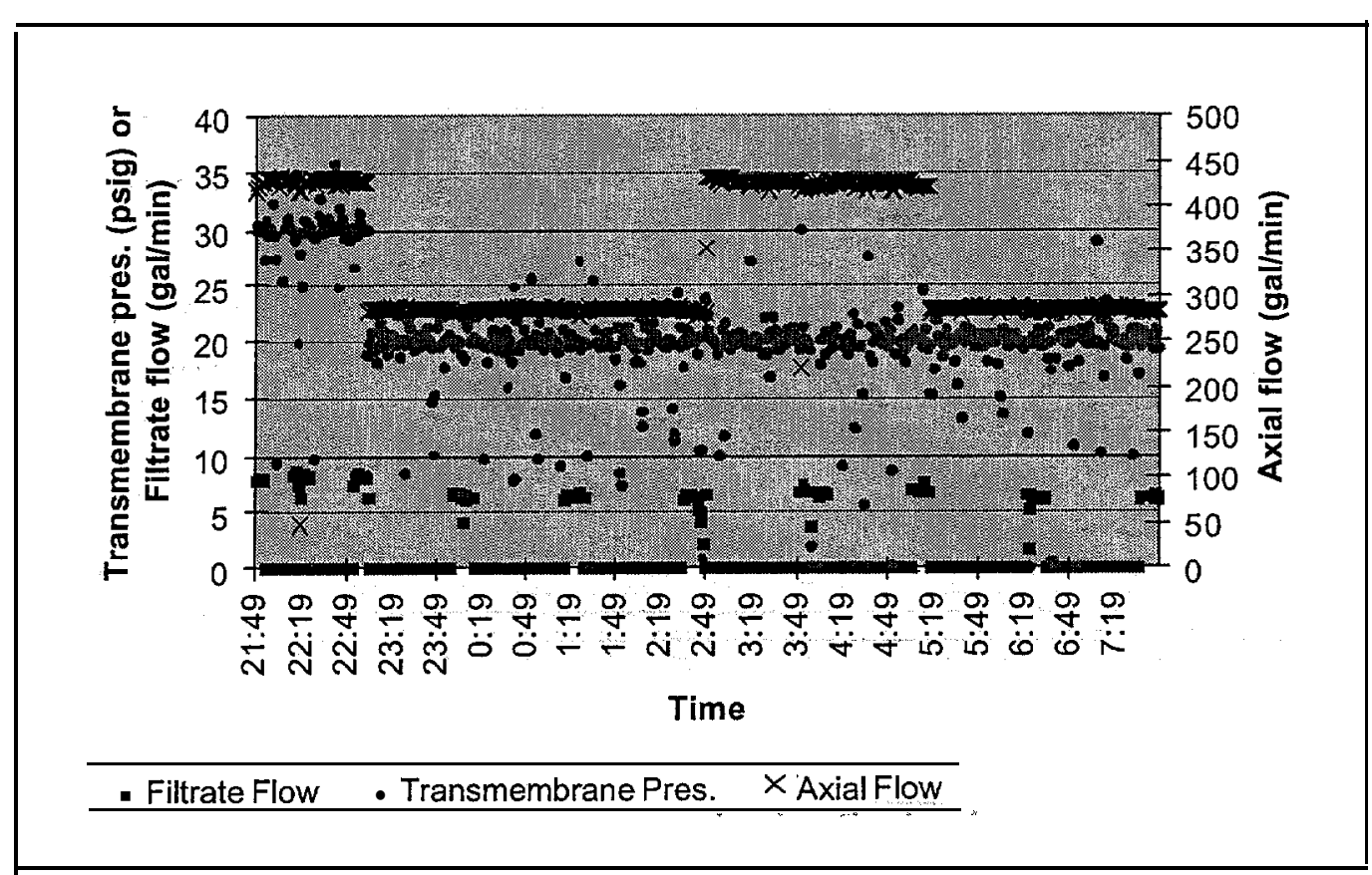

Fig. 27. Filtrate flow, transmembrane pressure, and axial flow as a function of time during the third WTP Campaign (Series 1, tests S-12, tank W31). 
hold time between batches. Filtrate production is automatically halted between batches to allow time for CsR /OTE processing. The filtrate flow was usually between 5 and $8 \mathrm{gal} / \mathrm{min}$ and exceeded the requirement of the other two systems, which were processing the filtrate at about $2 \mathrm{gal} / \mathrm{min}$. Figures 28 and 29 show trends of SLS filtrate flow, feed mass flow, and feed solids content'versus time. The feed mass flow varies significantly during the processing due to the $\mathrm{D} / \mathrm{D}$ pump operating characteristics. The suspended solids content of the feed shows a gradually declining trend, beginning at $2 \mathrm{wt} \%$ and slowly dropping to zero. The SLS performance data for W3 1 indicate the expected behavior for cross-flow filtration when the undissolved solids (UDS) content is low $(<0.5 \mathrm{wt} \%)$. The filtrate production is only slightly improved when the axial velocity is increased; however, an increase in transmembrane pressure increases filtrate production significantly. Data from Series 1 tests showed that an increase in axial velocity from 4 to $10 \mathrm{ft} / \mathrm{s}$ increased the filtrate production rate by no more than $10 \%$, or $0.01 \mathrm{gal} \mathrm{min}^{-1} \mathrm{ft}^{-2}$, while increasing the transmembrane pressure from 10 to 30 psig, increased the filtrate flux by $\sim 60 \%$, or $0.06 \mathrm{gal} \mathrm{min}^{-1} \mathrm{ft}^{-2}$. The high filtrate flux and minor influence of axial velocity were indications that filter cake was not accumulating on the surface of the filter elements. In general, this operational behavior was consistent throughout the W3 1 campaign.

On June 23, the UDS content of the feed began a steady increase, rising from 1.5 to $16.7 \%$ over a $14-\mathrm{h}$ period. Operational data for the SLS system during this period is presented graphically in Fig. 30 and 31. The increasing UDS concentration and corresponding increase in feed density resulted in a filtrate flow reduction from 6 to $1 \mathrm{gal} / \mathrm{min}\left(0.12\right.$ to $\left.0.02 \mathrm{gal} \mathrm{min}^{-1} \mathrm{ft}^{-2}\right)$. This increase in solids content was caused by the gradual collapse of the depression in the sludge surrounding the SLS suction pipe in W3 1 . When UDS concentrations in the feed increased to $22 \%$, the third campaignwas terminated and draining/flushing of the SLS system was initiated. Problems were encountered during the draining and flushing operations due to the flow characteristics of the heavy sludge. These problems have been detailed in a previous report. ${ }^{8}$

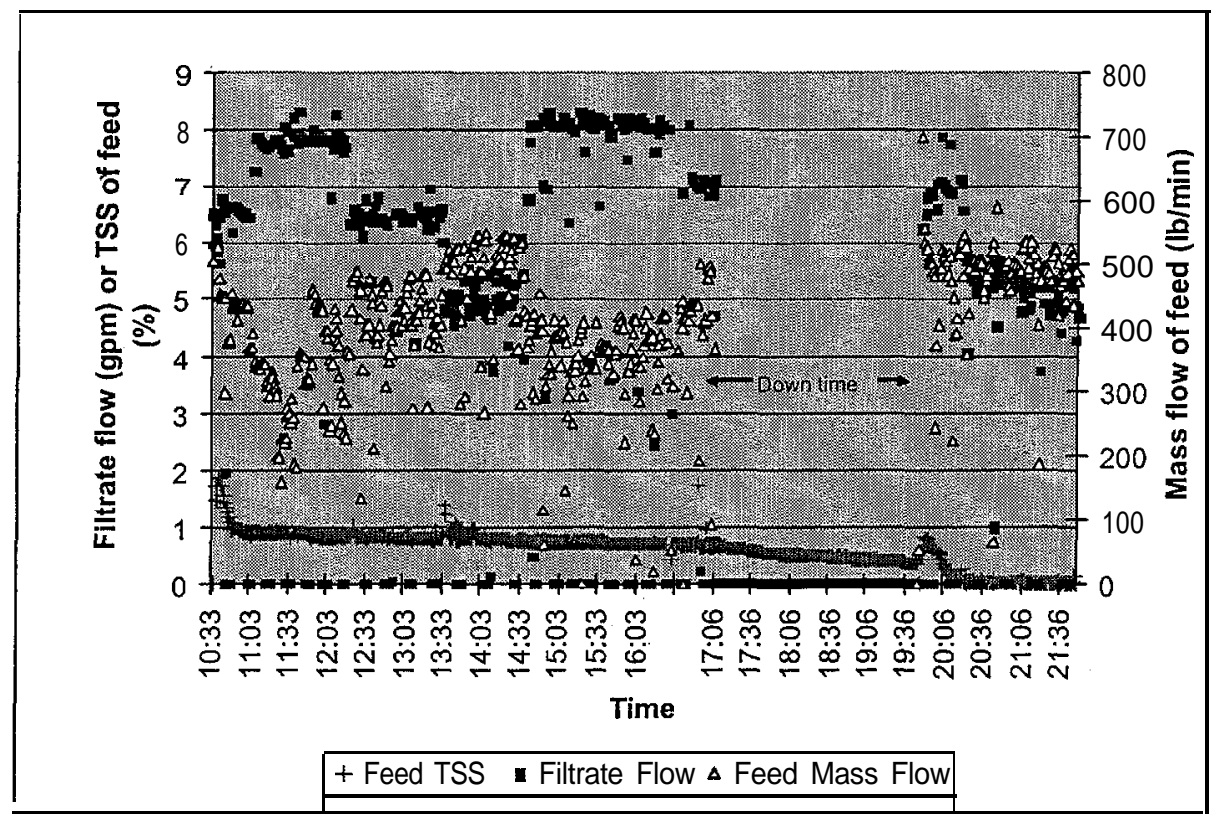

Fig. 28. Filtrate flow, feed TSS, and feed mass flow as a function of time during the third WTP Campaign (Series 1, tests 1-7, tank W31). 

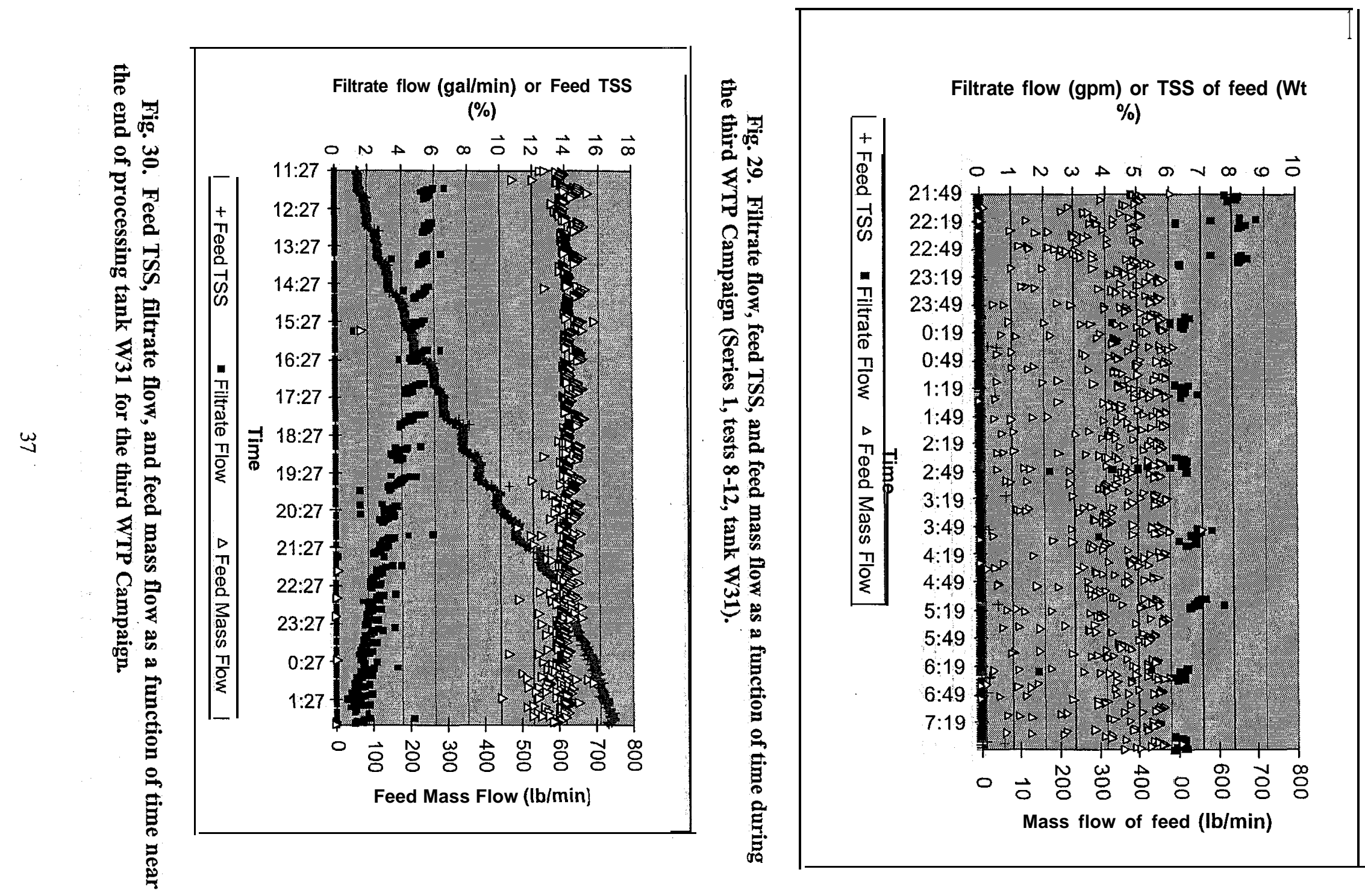


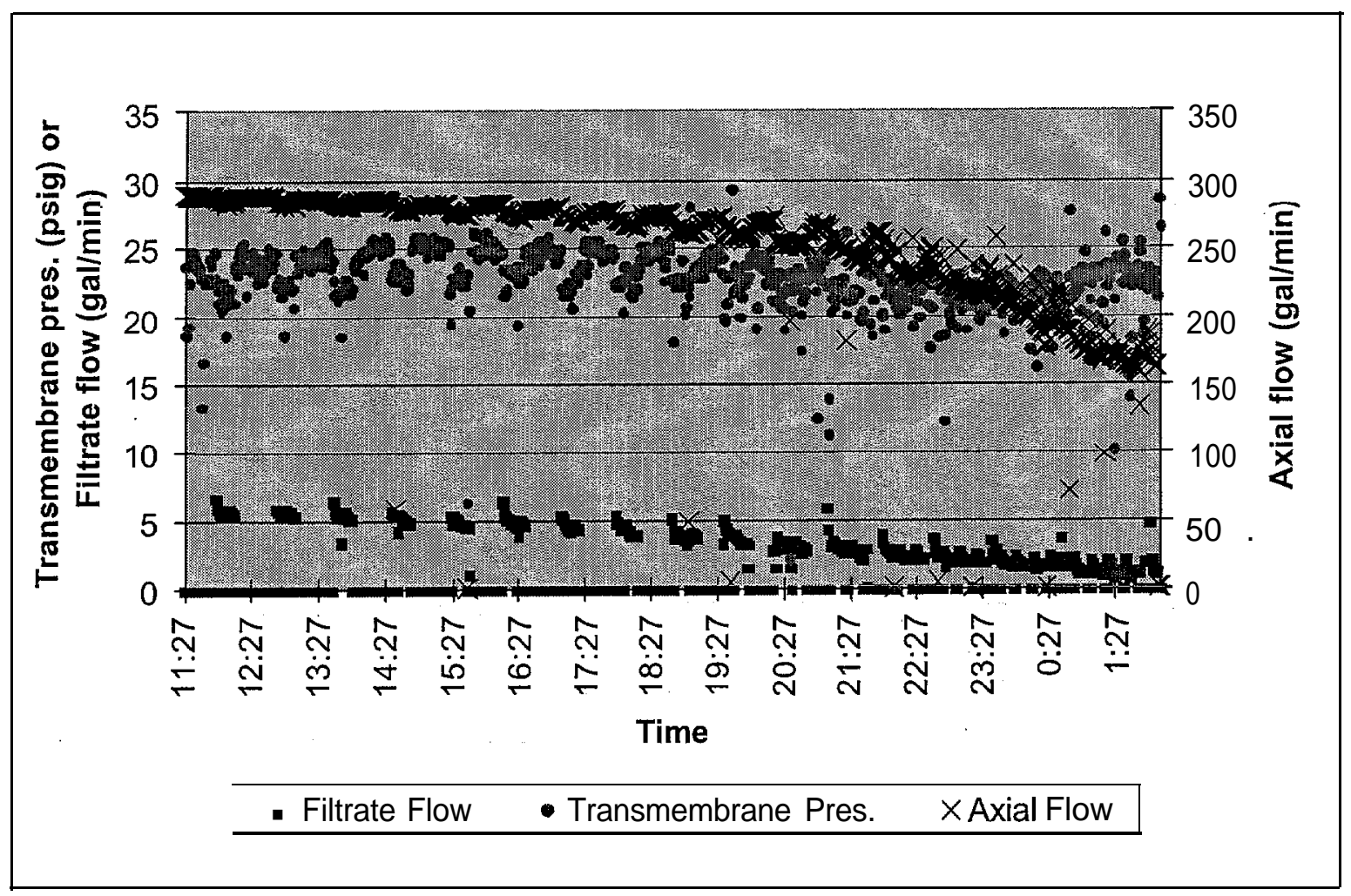

Fig. 31. Filtrate flow, axial flow, and transmembrane pressure as a function of time near the end of processing for tank W31 during the third WTP Campaign.

\subsection{WTP CAMPAIGN 4}

The fourth WTP campaign utilized only the OTE system. MVST W29 had a nitrate concentration of $150,000 \mathrm{mg} / \mathrm{L}(2.4 \mathrm{M})$. The volume reduction for the OTE was set at $63 \%$ when the run was initiated to obtain a nitrate concentration of $6.5 \mathrm{M}$ in the evaporator bottoms. In summarizing this campaign, the operational period lasted $467 \mathrm{~h}$ (19.5 days), with $-63 \mathrm{~h}$ (2.6 days) of downtime. All of the downtime for this campaign was associated with operational or equipment problems. Foaming of supematant during processing was the principal cause of operational difficulties. The adverse consequences of foaming included level control difficulties for process vessels, poor distillate quality, scaling of heat exchange surfaces, and subsequent overall system control problems. These problems reduced the throughput of the evaporator to 0.6-0.8 gal/min, as shown in Fig. 32. During this campaign, 21,000 gal of LLLW was processed, 9800 gal of distillate was produced, and an overall volume reduction of $48 \%$ was achieved. 


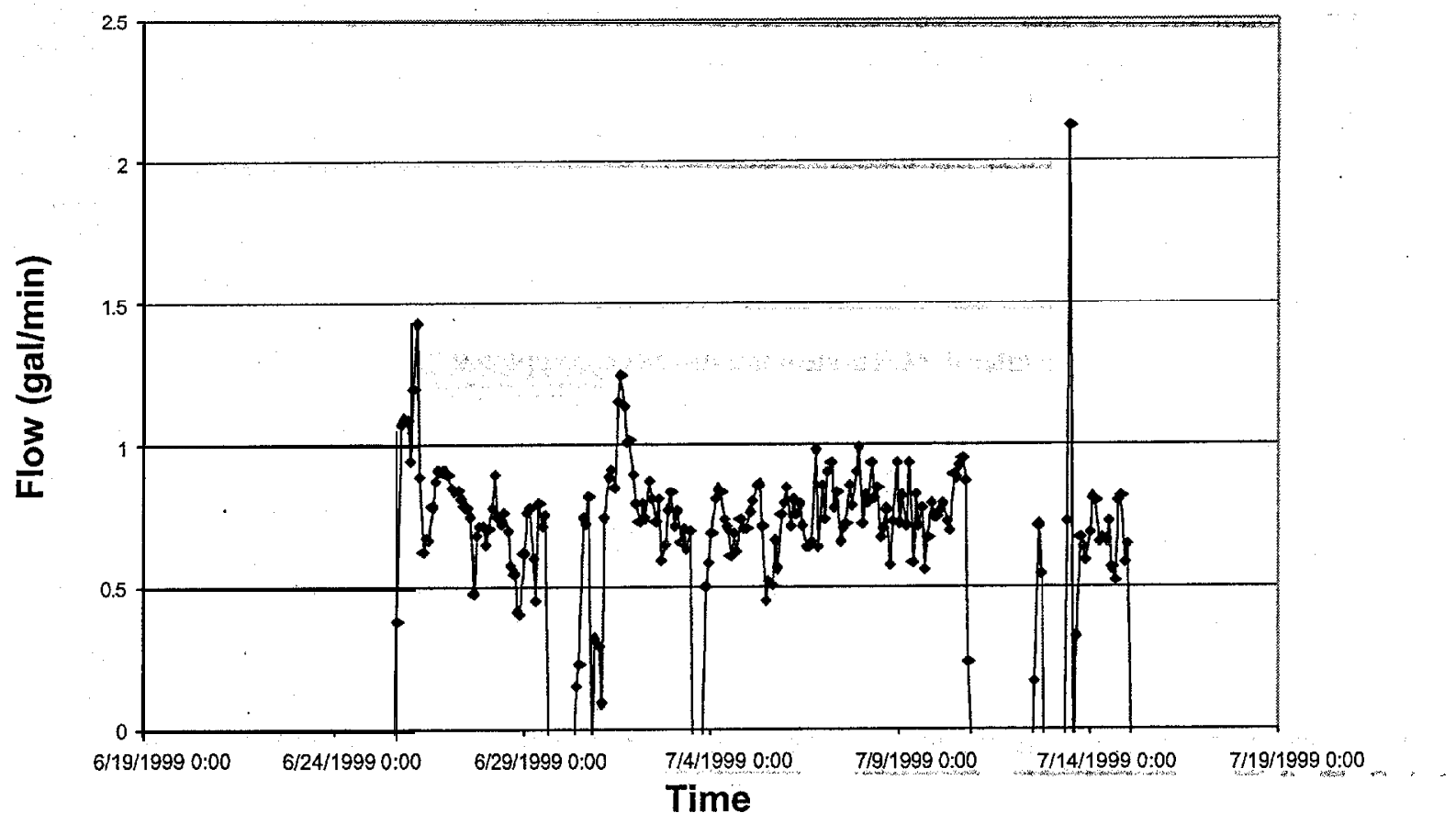

\section{Fig. 32. Flow rate through the WTP system as a function of time for the fourth WTP operational campaign.}

The campaign was initiated on 6/25/99 at $1500 \mathrm{~h}$. Heavy foaming was noted in the evaporator shell immediately following startup, and the shell level and the heater temperature were reduced to prevent carryover into the distillate. The system operated with only minor problems until June 29 at $1400 \mathrm{~h}$ when the system unexpectedly shut down Several attempts were made to restart the evaporator but were unsuccessful. An I\&C engineer was called in to troubleshoot the system and found that the control system was not picking up the position' of a remotely operated control valve on the OTE discharge line. The-problem was corrected and the system restarted after being down for $12 \mathrm{~h}$. Operation of the evaporator continued to be difficult for the next $13 \mathrm{~h}$ due to the level control problems in the evaporator heater shell, and the system shut down due to a blown fuse in flow control valve (FCV)-305. FCV-305 controlled the flow of concentrate from the OTE shell based on the level of the shell. The position of FCV-305 was constantly changing due to the problems with the liquid level instrument located in the evaporator shell. The fuse apparently blew due to an inrush of current as a result of the rapidly changing rotation of the control valve and/or from overheating of the control valve. Eight hours was required to diagnose the problem, make the repair, and get the system restarted. The system ran for the next 7 days without shutdown; however, foaming of the supernatant continued to cause problems with control of the level in the evaporator shell and the concentrate recycle tank, and the distillate production rate fluctuated badly. The system again automatically shut down on July 10 at $2045 \mathrm{~h}$ due to a small amount of liquid that had collected in the containment pan under the evaporator and set off the global leak alarm. The leak was very small, and it required $-42 \mathrm{~h}$ to determine that its source was the line supplying seal water to the OTE pumps, not a leak of radioactive supematant. A small catch pan was placed under the leak to contain the water until after the campaign had been completed. After placing the catch pan, the system was restarted and operated for $11.5 \mathrm{~h}$ before the feed supply was expended, ending the campaign. 
Since control of the liquid levels in the OTE system had been difficult to maintain due to the solids accumulation in the OTE shell and concentrate recycle tank, a thorough cleaning of the OTE system was conducted after the completion of the fourth triad campaign. The OTE system was filled and circulated with a 5\% nitric acid solution for $2 \mathrm{~h}$ at $100^{\circ} \mathrm{F}$ and then allowed to soak overnight with the acid solution in the system. The system was then drained, circulated with water for $6 \mathrm{~h}$, operated in recycle mode with a $5 \%$ nitric acid solution for $2 \mathrm{~h}$ at $100^{\circ} \mathrm{F}$ for a second time, and allowed to again soak overnight. The following morning, the system was placed back in recycle mode and operated for $6 \mathrm{~h}$ with the 5\% acid solution. During this period the OTE temperature was increased in $10^{\circ} \mathrm{F}$ increments from 100 to 130 " $\mathrm{F}$. The system was then drained and circulated with clean water to flush the acid from the system.

A radiation survey was done after the OTE cleaning had been completed. It was discovered that the drain line that had been used to drain the OTE system following cleaning had a radiation reading of $-400 \mathrm{mR} / \mathrm{h}$. Other than this hot spot, the general area dose was acceptable. The radiation dose came from solids that had collected in the drain tank during the cleaning and recycling operations. Flushing the drain line with water successfully removed the radioactive solids and reduced the radiation level in the drain line.

During this outage, maintenance personnel repaired the leak in the seal water line that had caused the system to shut down during the fourth campaign. Also, the CST that had been left in the columns at the completion of the third WTP campaign was sluiced into the shielded HIC. Column X-1 was sluiced without incident; however, column X-2 could not be sluiced using the standard procedure. The standard procedure was to pressurize the column to $30 \mathrm{psig}$ with air and then to open the discharge valve to send the CST slurry to the HIC. However, it became evident that the effluent collector screen through which air is added to the column had become restricted and prevented the column from pressurizing. Since the column could not be pressurized through the effluent collector, air was added to the column through an alternative port and the sorbent was successfully sluiced into the HIC. It should be noted that while air or water could not be forced backward through the collector screen to pressurize the column, the normal flow path from the column through the collector screen did not appear to be restricted. A possible cause of the plugging may have been the inadvertent transfer of CST fines that had been backwashed to and accumulated in the feed tank. When the CST columns were bypassed to send feed directly to the OTE system, the fines that were suspended in the feed were allowed to settle in the column effluent piping. When bypass valving was closed to add air to the columns via the effluent piping flow path, the settled fines were resuspended and transferred through the collector screen, which acted as a strainer until the fines accumulated and compacted to the point that the flow through the screen was severely restricted. Attempts to flush the fines from the system using supematant, water, and air proved unsuccessful. The flow required to suspend and remove the fines from the piping could not be obtained due to the pressure drop across the column. Therefore, procedures were changed to utilize the alternate port for future sluicing operations from X-21

\subsection{WTP CAMPAIGN 5}

The fifth WTP utilized all three systems to process the supematant stored in MVST W26, which had a nitrate concentration of $2750 \mathrm{mg} / \mathrm{L}(0.04 \mathrm{M})$ and a ${ }^{137} \mathrm{Cs}$ concentration of $750,000 \mathrm{~Bq} / \mathrm{mL}$. The campaign was initiated on July 24 at $1930 \mathrm{~h}$ and terminated on August 21 at $0530 \mathrm{~h}$. The campaign lasted $658 \mathrm{~h}$ (27.4 days), and the system was shut down for a total of $242 \mathrm{~h}$ (10.1 days): $47 \mathrm{~h}$ for scheduled operations (sluicing and LLLW transfers) and $195 \mathrm{~h}$ for unscheduled maintenance activities, translating to a $70 \%$ availability. Of the $195 \mathrm{~h}$ of unscheduled maintenance activities, 17.5 was associated with the CsR system and the remainder with the OTE system. During the campaign 14,000 gal of supematant was processed, $438 \mathrm{Ci}$ of ${ }^{137} \mathrm{Cs}$ was removed from the supematant, and 8000 gal of distillate was produced. The-flow through the WTP system as a function of time is presented in Fig. 33. As can be seen, the flow 
rate through the system was very erratic and was typically $<0.6 \mathrm{gal} / \mathrm{min}$. The erratic flow can be attributed to the fouling of the evaporator, leading to reduced evaporator efficiency and causing the level sensor in the evaporator shell to malfunction

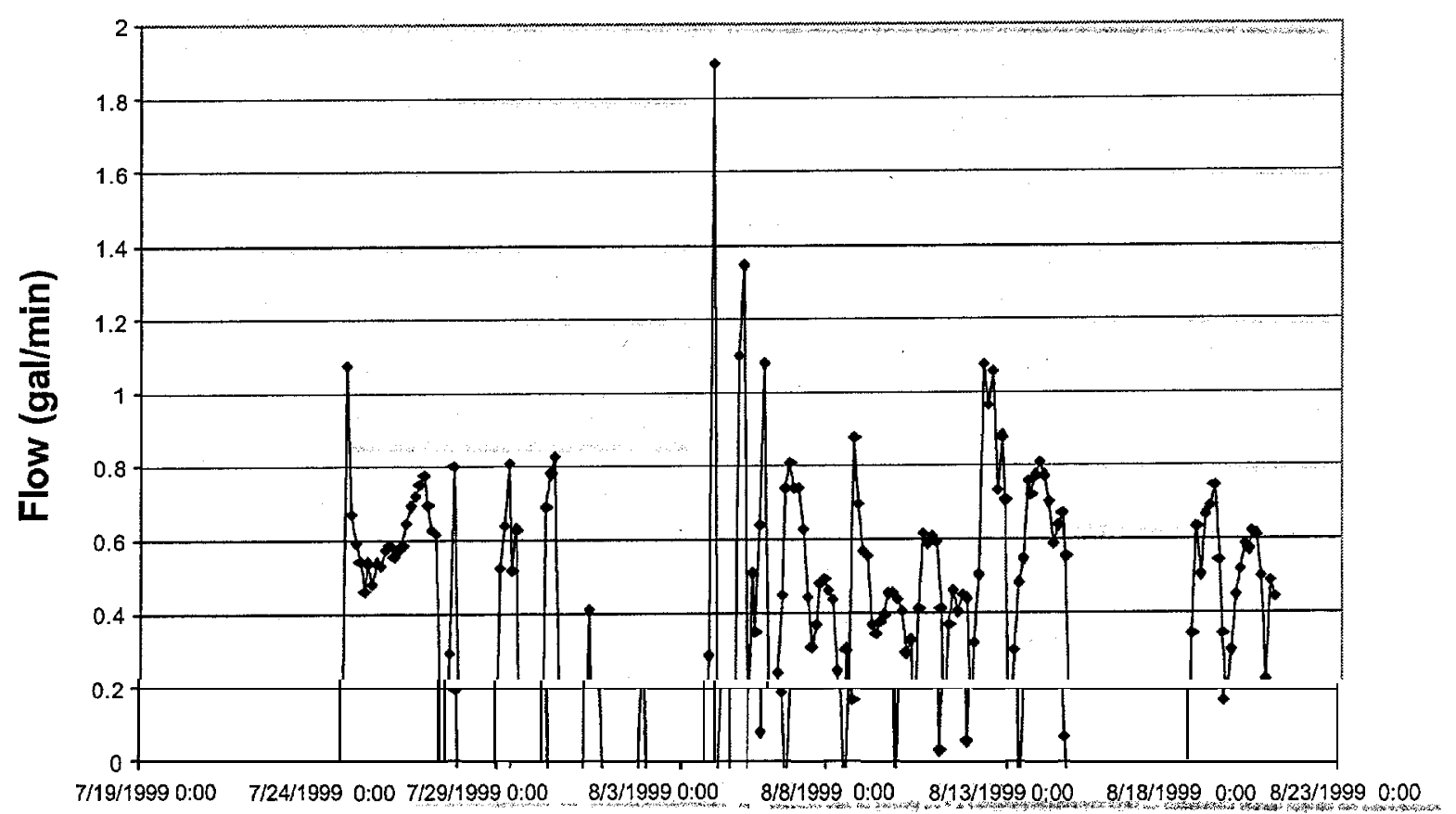

Time

Fig. 33. Flow through the WTP system as a function of time for the fifth WTP campaign.

The W26 tank had recently received sludge from the retrieval and transfer of tank W9 of the GAAT South Tank Farm. It was estimated that W26 held 20,000 gal of sludge, roughly double the amount in tank W3 1 (Campaign 3). With the larger volume of sludge and the limited settling time, the feed to the SLS system was expected to contain a much higher amount of suspended solids. As in Campaign 3, the SLS filtrate was pumped to CsR for removal of radioactive cesium and. then to the OTE, for volume reduction. The W26 supematant was more dilute than in previous campaigns due to the use of process water to mobilize and transfer sludges from the GAAT to the MVSTs.

After analysis of the filtrate verified that it met the WAC for TRU content, the CsR and OTE systems were started on July 25 at $2245 \mathrm{~h}$. After startup, foaming problems were immediately noted in the evaporator. The addition of an antifoam agent (Surfynol 104E) was initiated, and operations were reasonably stable until July 27 at $1900 \mathrm{~h}$ when the system shut down due to the unexpected presence of liquid in the Building 7877 sump. Water had leaked into the building during a thunderstorm and tripped the leak detector in the sump, which automatically deenergized the WTP system. Approximately $6.5 \mathrm{~h}$ was required to empty the sump and restart the systems. After restart, the system operated for $5.5 \mathrm{~h}$ before being shut down for $30 \mathrm{~h}$ to allow ORNL Waste Operations to complete a routine LLLW transfer. During this shutdown, maintenance was performed on a solenoid valve located on the air line to the D/D pumps supplying supematant feed to the SLS 'system The system was restarted on July 29 at $1300 \mathrm{~h}$ and 
operated for $14 \mathrm{~h}$ before having to be shut down again. Both the camera and the level probe installed in the fill head for the HIC containing the cesium-loaded CST had stopped functioning. Maintenance support personnel from I\&C could not repair or replace the components due to the high radiation field and contamination levels. Since a detailed inventory of sluice water and CST in the columns and HIC was maintained at all times and only known batch quantities of water and CST were added to the HIC, the procedures were modified to allow use of the material balance for sluicing additionalamounts to the HIC. The modifications ensured that sluice water added to the HIC was pumped out before additional water/sorbent was introduced. Approximately $17.5 \mathrm{~h}$ was required for approval of the new procedures and to complete the required reading on the changes by the operators. The system was restarted on July 30 at $2130 \mathrm{~h}$ and operated for $11 \mathrm{~h}$ before having to be shut down due to operational problems with the OTE. A conductivity sensor in the distillate system and a pressure transmitter malfunctioned and had to be replaced. Approximately $96 \mathrm{~h}$ was required to investigate these problems and complete the repairs. Over the final 10 days of operation, frequent problems were encountered with the OTE, which resulted in numerous unscheduled shutdowns. This work included control valve repairs, replacement of cooling fan belts on the cooling skid, replacement of the concentrate recycle pump (P-350), and replacement of the flow totalizer for the distillate. Foaming was a problem during this campaign until a new antifoam (Surfynol 104E) was identified and added to the evaporator feed. Control of the level in the evaporator and concentrate/recycle tank also continued to be a problem due to buildup of scale in the evaporator, which interfered with the level instrumentation for the evaporator shell. The campaign was terminated on August 21, when the UDS concentration in the feed to the SLS became too high for the SLS system to process.

\subsubsection{WTP Campaign 5-SLS Performance}

During this campaign, the SLS experienced only minimal operational problems and no unplanned shutdowns. A series of tests were conducted to evaluate the performance of the SLS. The test series were designed to evaluate filtration performance as the percent solids in the SLS feed increased and the results have been detailed in a previous report.* During the first series of tests, the UDS concentration in the SLS was low, typically running at $-0.3 \mathrm{wt} \%$. Performance was very similar to that achieved while processing W3 1, which also had a low TJDS concentration. Increases in the transmembrane pressure resulted in an increased filtrate flux, while increases in the axial velocity of the fluid across the membrane had no effect on the filtrate flux. Again, the axial velocity did not affect the flux because the solids content of the feed was low and it was unlikely that filter cake had formed on the surface of the filters.

On August 9-1 1, a second series of tests were performed Downtime was minimal during this test series and the test parameters were reasonably well controlled. The range of filtrate flow achieved during the tests was 0.5 to $7.9 \mathrm{gal} / \mathrm{min}$ ( 0.01 to $\left.0.16 \mathrm{gal} \mathrm{min}^{-1} \mathrm{ft}^{-2}\right)$, with the higher flow values immediately following a backpulse cycle. As shown in Fig. 34, a sharp increase in filtrate production followed the hourly backpulse cycle, but production quickly dropped to lower values within 10 to 20 min. following the backpulse. Figure 35 shows a very steady and gradual increase in the feed solids from -0.6 to 0.83 wt \% during the test series. Figure 36 shows the influence of transmembrane pressure on filtrate flux for the second test series. In general, this influence is small except at very high axial velocity. Figure 37 shows that increasing axial velocity has a significant impact on filtrate flux, as would be expected when UDS content is higher and filter-cake material is building up.

A third series of tests were conducted on August 13, during a period when the solids content of the feed was increasing significantly. The tests were conducted over a 25 -h period, during which the feed solids content increased from 2.1 to $3.9 \mathrm{wt} \%$. The filtrate flow range during this period was 0.63 to $4.0 \mathrm{gal} / \mathrm{mm}$ ( 0.013 to $0.08 \mathrm{gal} \mathrm{min}^{-1} \mathrm{ft}^{-2}$ ). Figure 38 shows the increasing trend of feed solids content as well as the trend of high, then rapidly declining, filtrate flow following the backpulse. Figure 39 shows that the axial flow and transmembrane pressure were well controlled during the tests. Figure 40 indicates a slightly 
greater influence of transmembrane pressure on filtrate flux than was shown in the Series 2 tests.

Figure 41 shows that increasing the axial velocity also increased filtrate flux by an amount similar to that caused by increasing the transmembrane pressure.

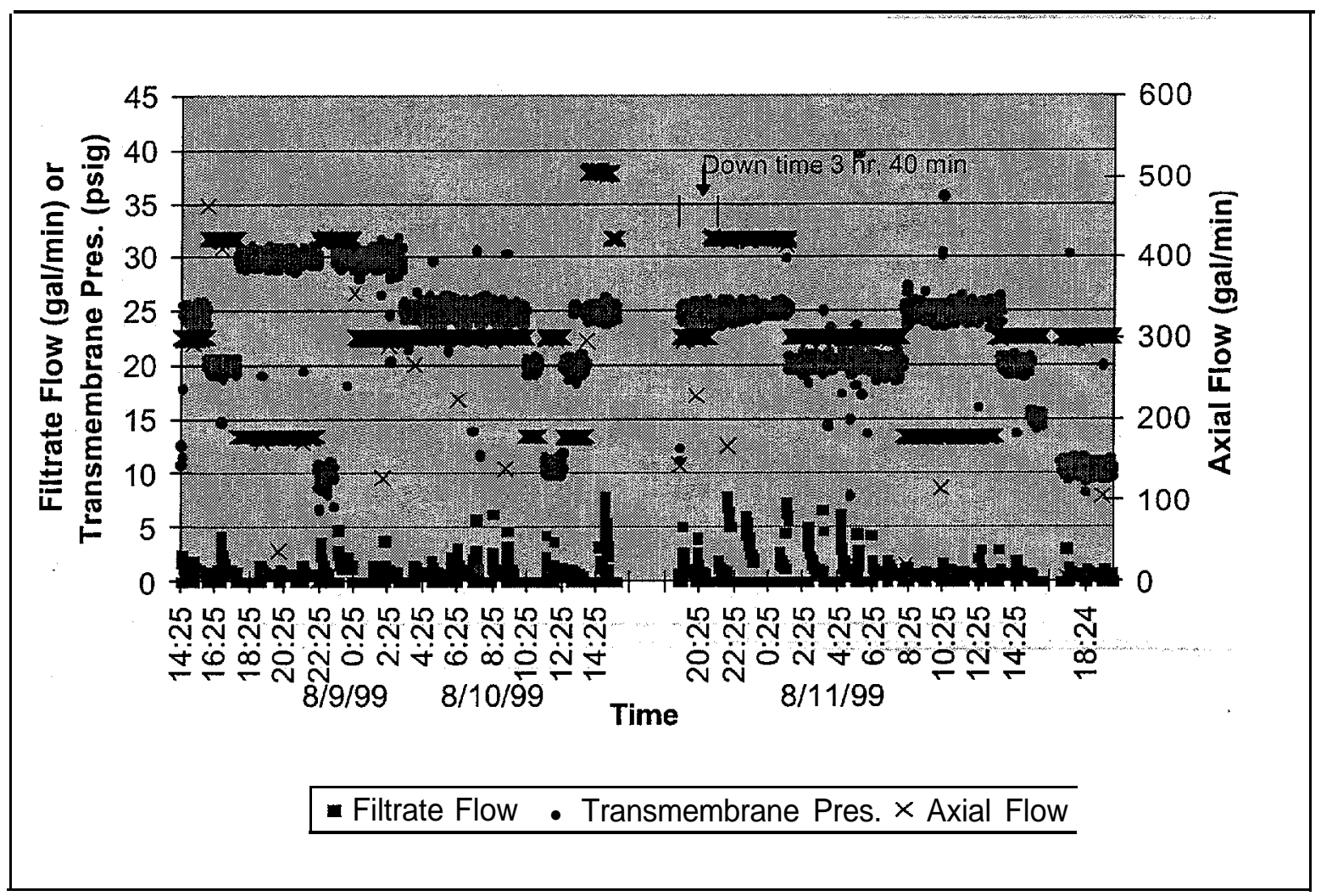

Fig. 34. Filtrate flow, transmembrane pressure, and axial flow as a function of time during the fifth WTP Campaign (Test Series 2, tank W26).

A fourth series of tests were initiated on August 20 but operations were terminated before the series could be completed. In Figure 42, the results of all of the Series 1-4 tests are plotted as a function of the chronological order of the tests. These data collectively indicate that the filtrate flux declined and appeared to stabilize in the range between 0.8 and $1.25 \mathrm{gal} / \mathrm{min}\left(0.016\right.$ and $\left.0.025 \mathrm{gal} \mathrm{min}^{-1} \mathrm{ft}^{-2}\right)$. In a production-oriented mode, higher levels of transmembrane pressure and axial velocity could be used along with regular chemical cleanings to maintain higher filtrate production than is shown here.

The WTP system was down for 22 days following completion of the fifth campaign. During this shutdown, the following items were completed (1) the OTE system was cleaned twice with $5 \%$ nitric acid, (2) the CST in the HIC was dried to meet the NTS WAC, (3) the shielded HIC was transported to the Solid Waste Storage Area (SWSA), (5) a new level sensor and camera were installed on the HIC fill head, and (7) another shielded HIC was installed in the process building. 


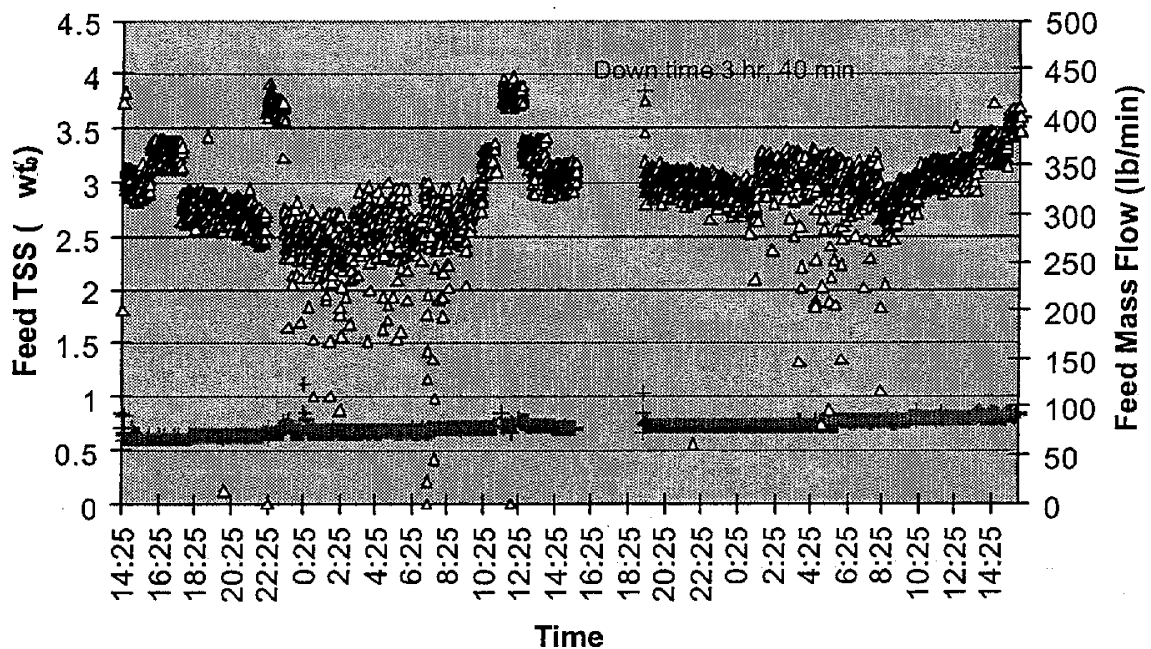

+ Feed TSS $\% \quad \Delta$ Feed Mass Flow

Fig. 35. Feed mass flow and TSS as a function of time during the fifth WTP Campaign (Series 2, tank W26).

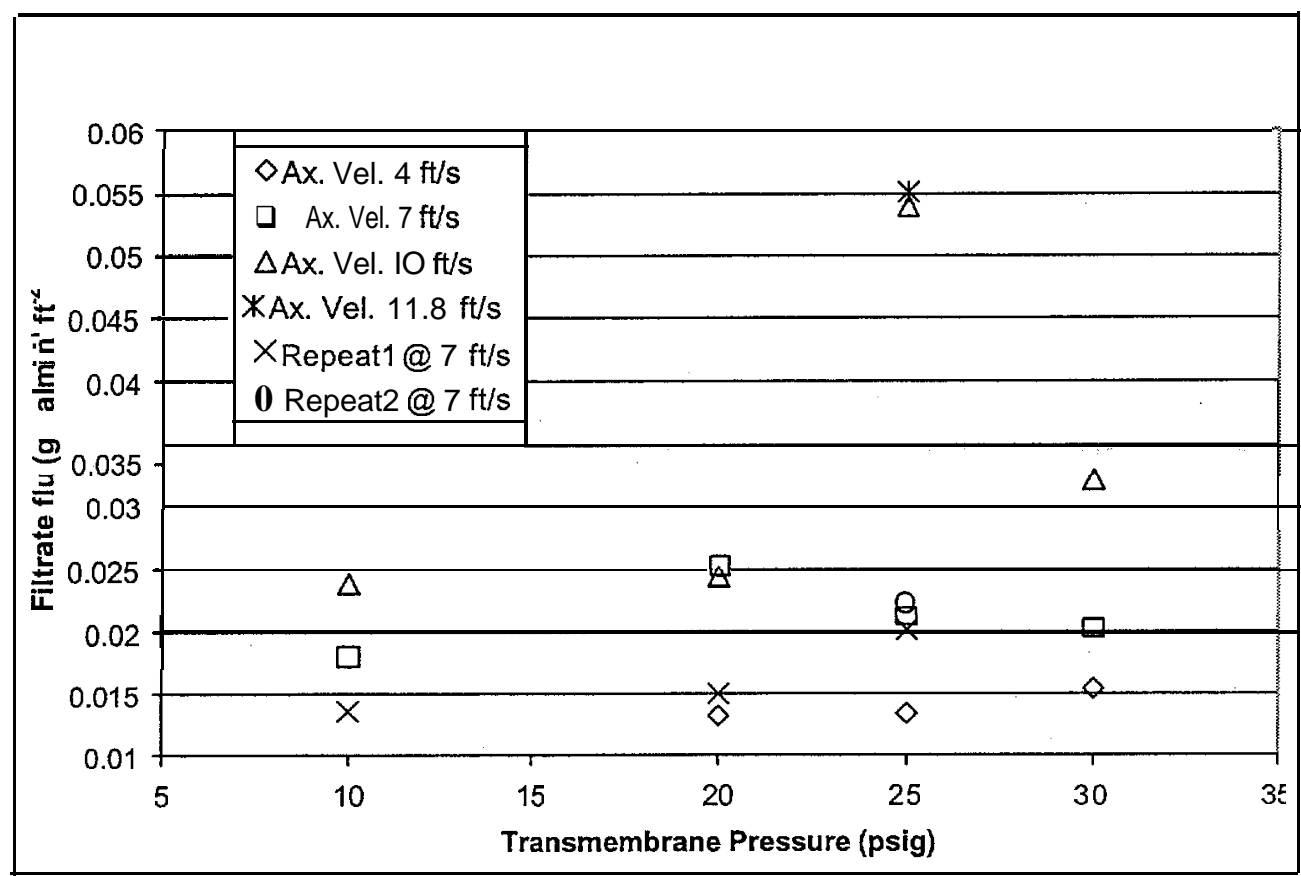

Fig. 36. Average filtrate flux as a function of transmembrane pressure during the fifth WTP Campaign (Test Series 2, tank W26). 


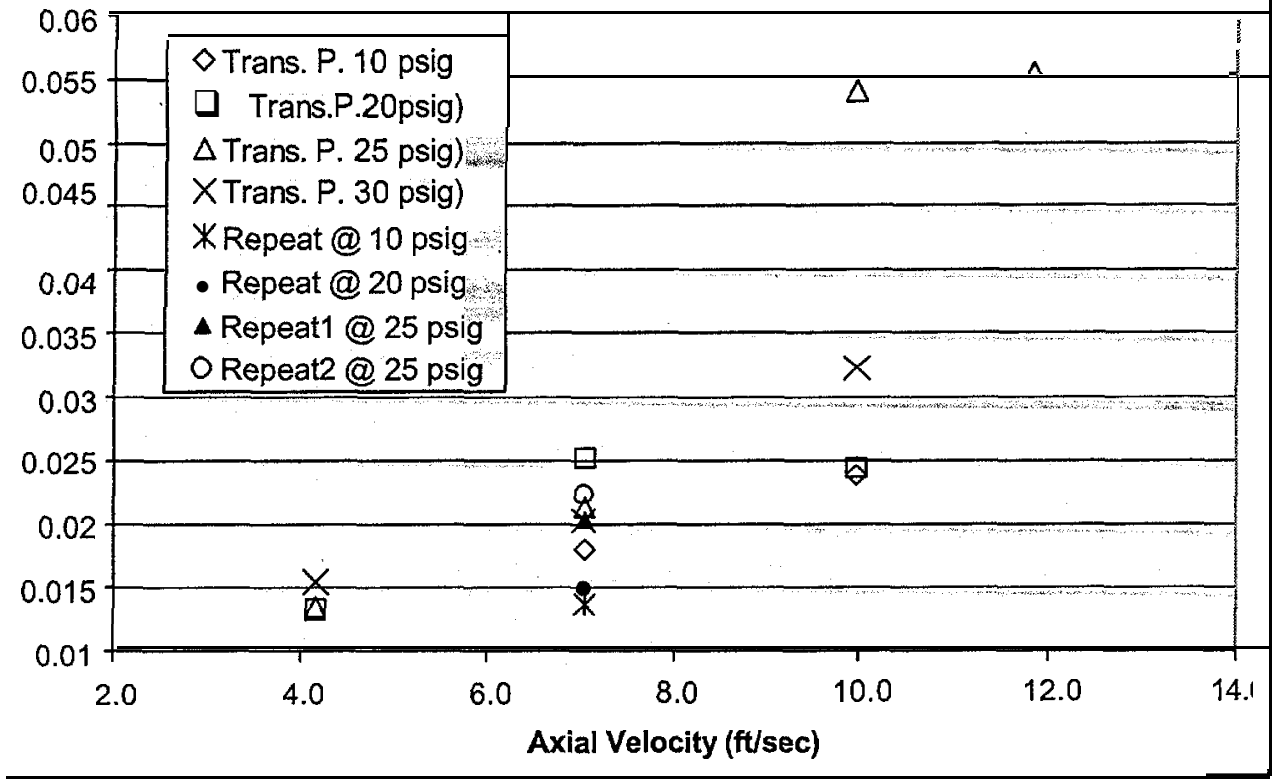

Fig. 37. Average filtrate flux as a, function of axial velocity during the fifthWTP Campaign (Test Series 2, tank W26).

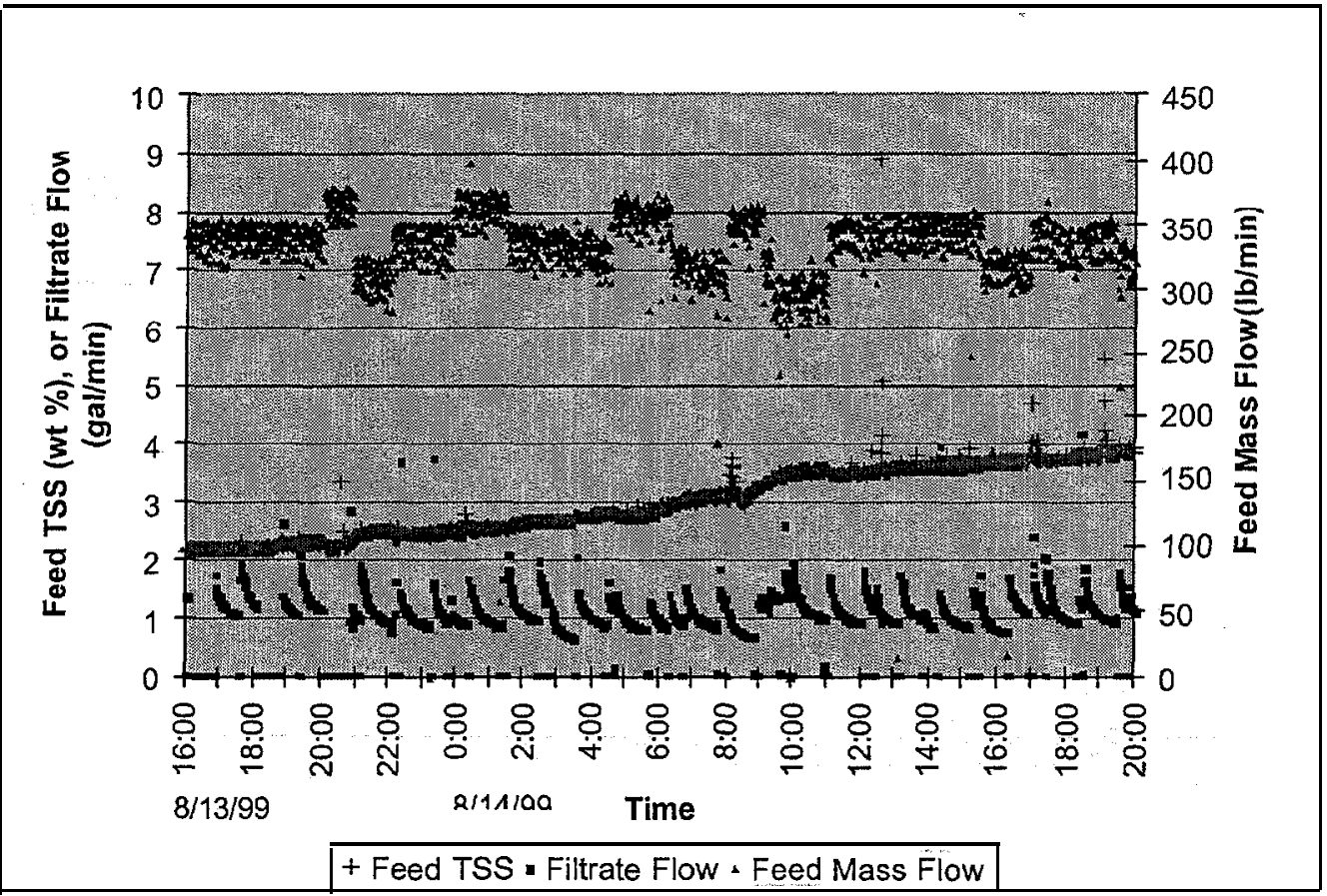

Fig. 38. Feed mass flow, feed TSS, and filtrate flow as a function of time during the fifth WTP Campaign (Test Series 3, tank W26). 


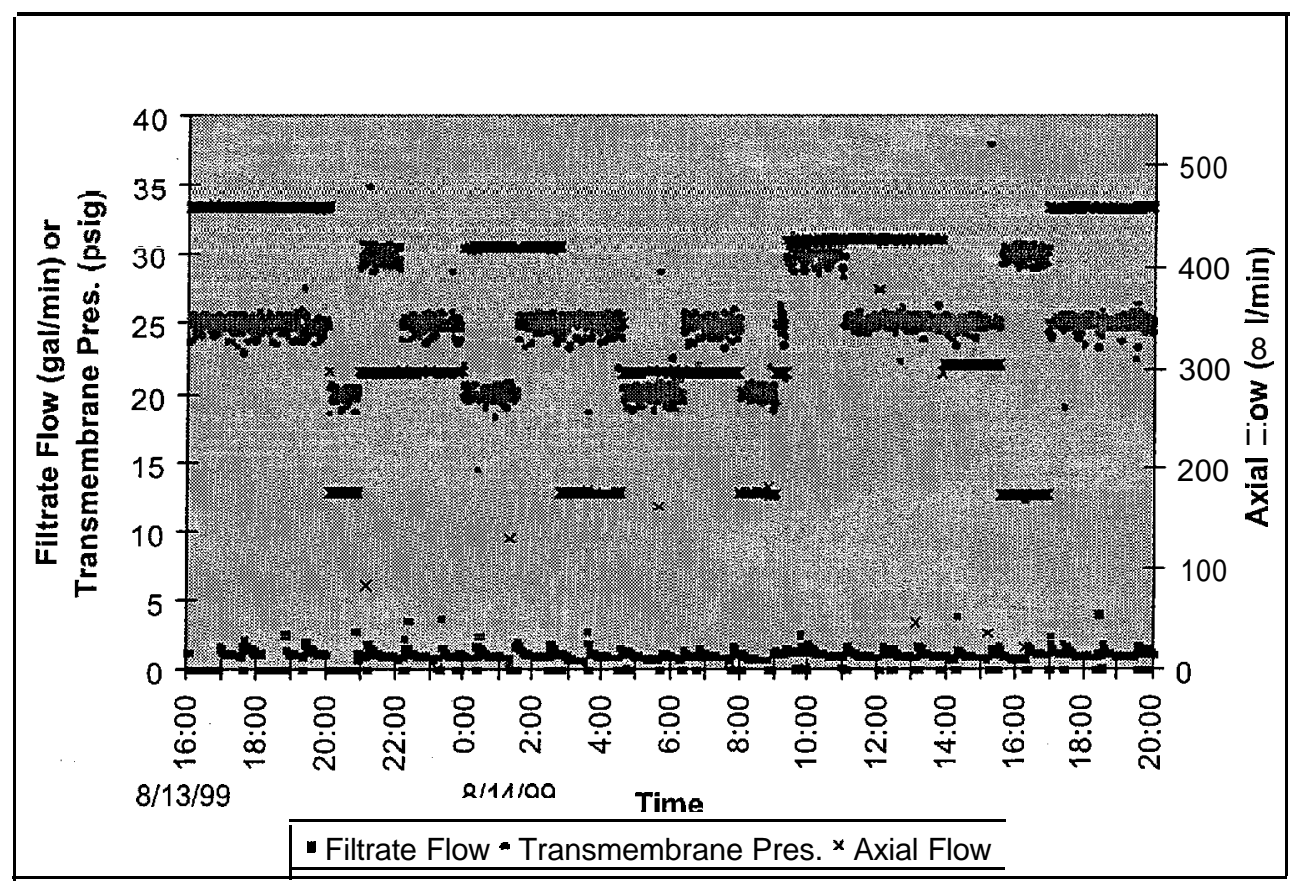

Fig. 39. Filtrate flow, axial flow, and transmembrane pressure as a function of time during the fifth WTP Campaign (Test Series 3, tank W26).

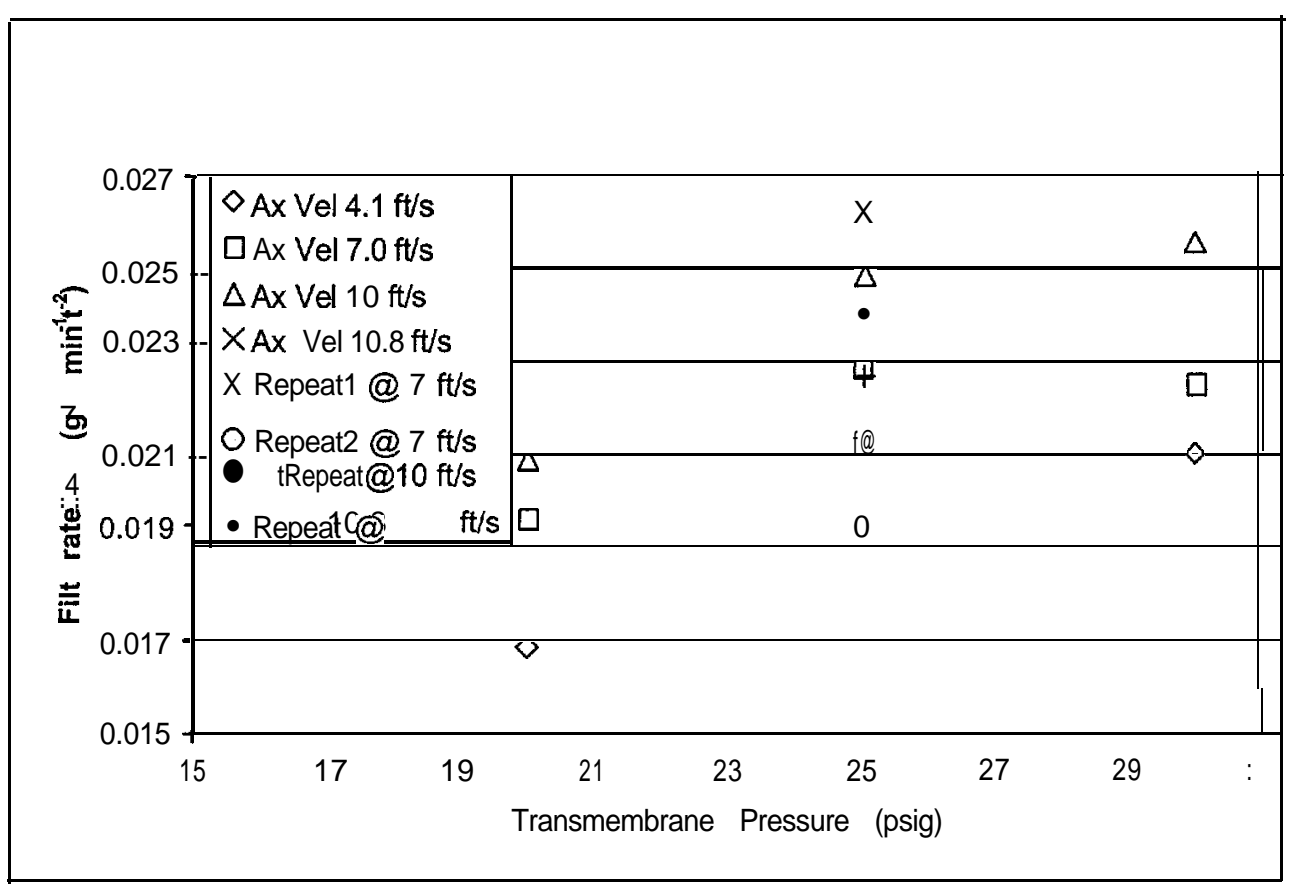

Fig. 40. Average filtrate flux as a function of transmembrane pressure during the fifth WTP Campaign (Test Series 3, tank W26). 


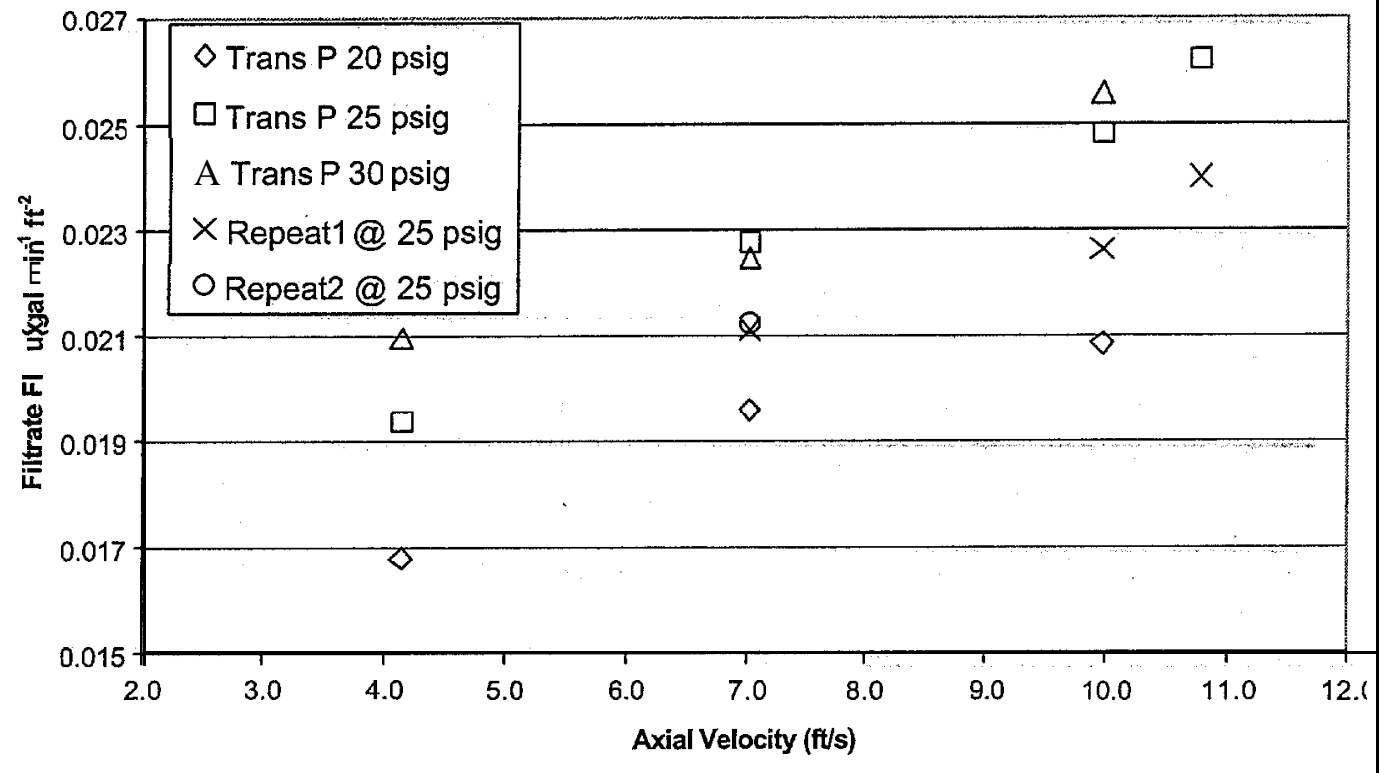

Fig. 41. Average filtrate flux as a function of axial velocity during the fifth WTP Campaign (Test Series 3, tank W26).

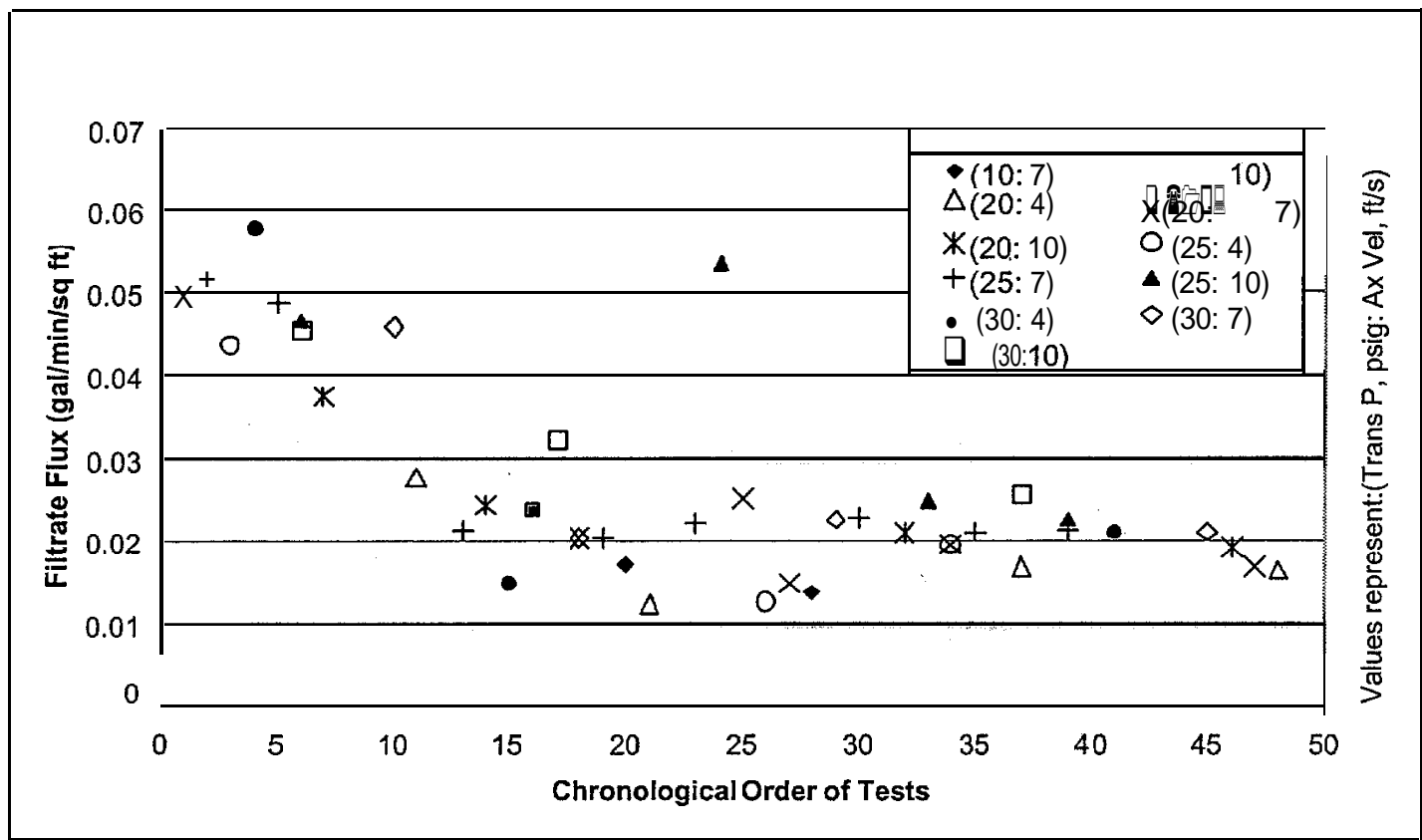

Fig. 42. Average filtrate flux as a function of test chronological order for tank W26 during the fifth WTP Campaign. 


\subsection{WTP CAMPAIGN 6}

The CsR and OTE systems were used in this campaign to remove the radioactive cesium and reduce the volume of the supernatant. The SLS was not necessary because the supernatant/sludge mixture in W30 had been allowed time to settle sufficiently for processing. The supematant had a nitrate concentration of $192,000 \mathrm{mg} / \mathrm{L}$ and a ${ }^{137} \mathrm{Cs}$ concentration of $860,000 \mathrm{~Bq} / \mathrm{mL}$. 'The operational period lasted for $1128 \mathrm{~h}$ (47 days). The system was shut down for a total of $752 \mathrm{~h}$ ( 31 days) during the operational period: $702 \mathrm{~h}$ for unscheduled maintenance and $52 \mathrm{~h}$ for scheduled maintenance (38\% availability). The majority of the unscheduled downtime was associated with the plugged lines between the CsR feed tank and the CsR feed pumps. During the campaign, 20,000 gal of LLLW was processed, $1800 \mathrm{Ci}$ of ${ }^{137} \mathrm{Cs}$ was removed from the waste, and $9000 \mathrm{gal}$ of water was evaporated from the LLLW. The overall volume reduction was $44 \%$. The flow rate through the system typically ranged from 0.6 to $1.0 \mathrm{gal} / \mathrm{min}$. The pressure drop through the prefilter and the ion-exchange columns for this run is presented in Fig. 43. The pressure drop thorough the CST columns was minimal for the first portion of the operation; however, it later increased to levels approaching 50 psig. Backwashing of the columns proved ineffective in reducing the pressure drop across the columns. Since the CsR system was set to shut down at a pump discharge pressure of $100 \mathrm{psig}$, the columns had to be changed from series to parallel operation to allow continued operation. The loaded sorbent was replaced with new sorbent on October 26; however, after restart, the pressure drop across each column again increased to $-50 \mathrm{psig}$. (The columns were being operated in parallel) The cause for the high-pressure drop across the columns during the latter portion of this campaign was not determined. Pertinent details of the operation in chronological order are given in the following paragraphs.

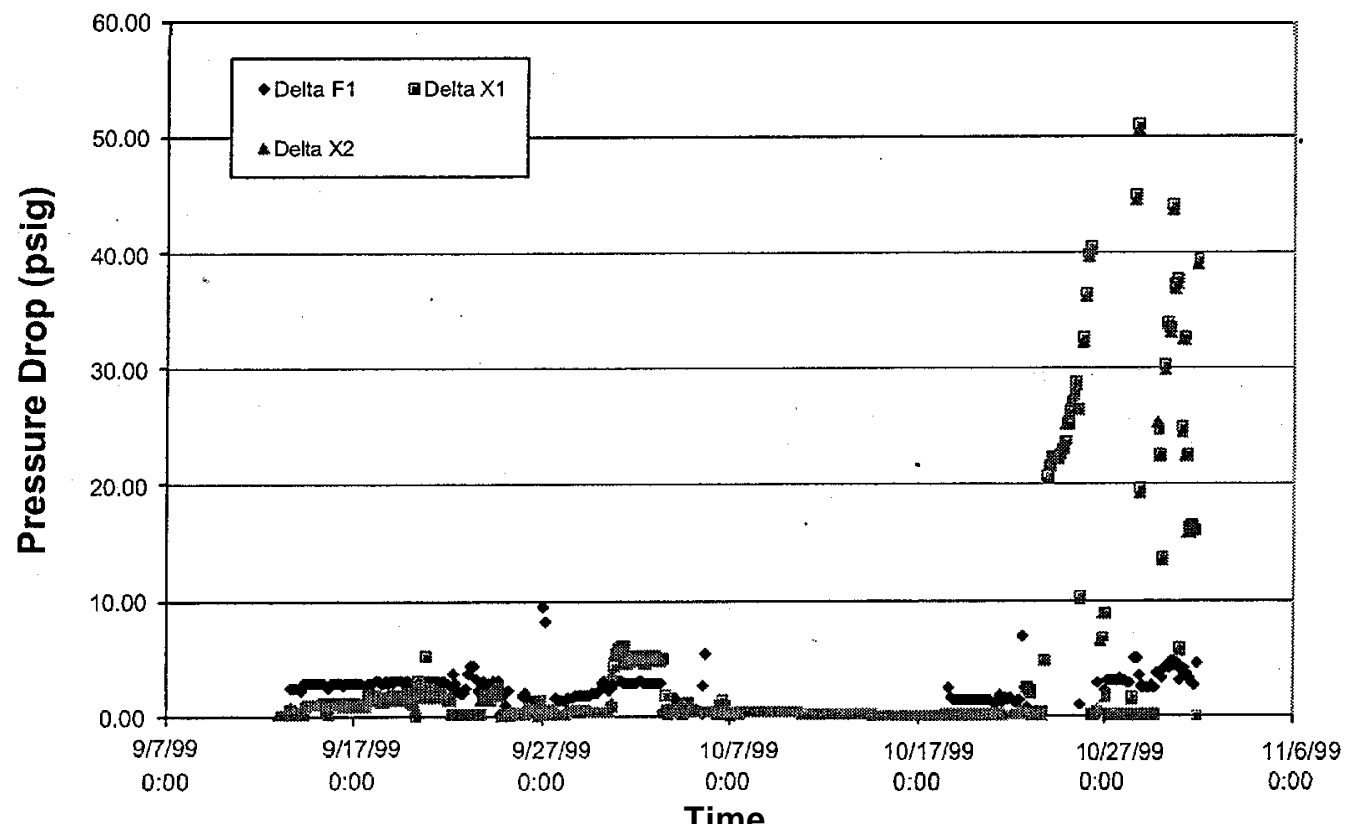

Fig. 43. Pressure drop across the prefilter and ion-exchange columns during the sixth WTP campaign. 
The campaign was initiated on September 14 at $0900 \mathrm{~h}$ and operated for $28 \mathrm{~h}$ before shutting down with OTE alarms due to a low level in the concentrate/recycle tank and low seal water flow. A faulty flow switch was discovered on the seal water line (FSH-204). The switch was replaced and the system restarted after being down for $4 \mathrm{~h}$. Operations'were stable for the next $218 \mathrm{~h}$, with three scheduled shutdowns for-sluicing the loaded CST to the HIC and one unscheduled shutdown $(38 \mathrm{~h})$ for troubleshooting and replacing the level transmitter (LT-306) in the OTE concentrate recycle tank.

On September 24 at $-2300 \mathrm{~h}$, the triad system was shut down due to problems maintaining flow from the CsR system to the OTE system. A flow restriction was traced to the line between the CsR feed tank (TK-1) and the CsR feed pumps (P1 and P2). Additional flow restrictions were discovered between column X-2 and the OTE feed tank. Water was used to flush the clogged lines to remove the restrictions. This proved successful, and the WTP system was restarted on September 30 at $1800 \mathrm{~h}$, after being down for $139 \mathrm{~h}$. However, the CsR pumps were no longer able to develop enough pressure to push the supematant through the two columns in series. As a result, the WTP system valves were realigned so that the ion-exchange columns would operate in parallel. The system had operated in this mode for 3 days when it was shut down for $3 \mathrm{~h}$ to sluice the loaded sorbent into the, HIC. Upon restart, however, it was found that the flow was again restricted between the feed tank and feed pumps. Radiation levels were as high as $8 \mathrm{R} / \mathrm{h}$ around the pumps, in the line back to the feed tank, and around the pump pressure relief valves. Numerous attempts were made to clear the line by remote flushing and none were successful. It was thought that CST fines from backwashing operations had accumulated in the CsR feed tank and moved into Moyno pump suction piping. An attempt was made to flush each pump by attaching a flush line to the drain plug opening on the fluid end of the pump. The flush line was routed to the sump for discharge of the flush water. Lead sheets and blankets were placed over radiation hot spots to reduce radiation exposure, and health physics technicians were present at all times while completing this work.

The lines and pump cavities were successfully flushed, which reduced the radiation levels around the pumps. The pressure transmitters in the lines around the pumps were flushed to remove packed sorbent. When the flushing was complete, the feed tank, pumps, and columns were circulated with a $0.5 \mathrm{M}$ nitric acid solution for several hours to remove any residual scale deposits. The system was checked for leaks and pressure tested following this activity.

Processing of supematant was resumed on October 23. From October 23 through October 31, when the campaign was complete the WTP system was shut down three additional times: twice for maintenance activities associated with the level instruments in the OTE system and once for a routine LLLW transfer.

\subsection{WTP CAMPAIGN 7}

In this campaign, the CsR and OTE systems were used to remove cesium and reduce the volume of the supematant. The use of the SLS system was not necessary because the W29 supematant had remained undisturbed in the tank for a length of time sufficient to settle the solids. The supematant had a nitrate concentration of $37,000 \mathrm{mg} / \mathrm{L}(0.6 \mathrm{M})$ and a ${ }^{137} \mathrm{Cs}$ concentration of $190,000 \mathrm{~Bq} / \mathrm{mL}$. These concentrations were lower than previous campaigns because large quantities of process water were used to mobilize and transfer tank sludge from the GAAT system to the MVSTs.

The campaign lasted a total of $2094 \mathrm{~h}$ (87.3 days) with $1029 \mathrm{~h}$ (42.9 days) downtime (51\% availability). Essentially all of the downtime was associated with the level control problems in the OTE evaporator shell. To address this problem, a new evaporator shell extension with a modified level sensor configuration was designed, fabricated, and installed. After installing this unit, the system operated for the final $220 \mathrm{~h}$ with minimal problems and no unscheduled downtime. 
Approximately 21,000 gal of LLLW was processed during this campaign, $89 \mathrm{Ci}$ of ${ }^{137} \mathrm{Cs}$ was removed from the supematant, and $9000 \mathrm{gal}$ of distillate was produced. The overall volume reduction, was $42 \%$. The Surfynol 104E antifoam proved effective for reducing the foam in the evaporator during this campaign. It should also be noted that there was very little pressure drop across the ion-exchange columns for the majority of this campaign. However, during the final day of operation, when the ionexchange columns were being bypassed, there was a sudden spike of -15 psig in the pressure at the effluent of the CsR feed pumps (P-1 and P-2), which w\&e being used to feed the OTE feed tank. It was discovered that an inadvertent transfer of sludge solids from the MVST had occurred. The solids were detected through the site glass in the OTE shell. These solids were very light and could not be totally dissolved with 5\% nitric acid. Samples of the solids could not be obtained due to the high radiation level in the system. It was suspected that the solids contained some bentonite that had been used in years past to suspend and transfer GAAT sludge to hydrofracture system tanks. The campaign was terminated at this point, and the waste/sludge mixture was pumped back to W29. The OTE system was cleaned with $5 \%$ nitric acid and rinsed several times prior to the start of the eighth campaign.

The evaporator shell level control had been a recurring problem with the evaporator and was caused primarily by the design of the level instrument ports located on the evaporator shell extension. The evaporator shell level control had a cascading effect on the control of the rest of the system, so operational stability of the evaporator system as a whole was dependent on accurate level control in this vessel. Views of the evaporator she\&-with the level instrument configuration highlighted-are shown in Figs. 44 and 45. The level float was placed in a 3-in.-diam standpipe piped to the top and bottom of the evaporator shell with $3 / 4$ in.-diam lines. Solids that had accumulated in the lines connecting the standpipe to the evaporator shell could not be removed by flushing and acid cleaning. Attempts to remove the solids using a plumber's auger were also unsuccessful The 16-in.-diam flange and sight glass for the OTE evaporator shell were removed and replaced with a modified extension and new sight glass. A drawing of the extension is shown in Fig. 46. The extension added 11 in. to the evaporator length and included a standpipe located within the evaporator shell. The standpipe was open ended to prevent accumulation of solids. The liquid level float was moved to the new standpipe. This work was carefully planned to minimize radiation exposure to those performing the installation.

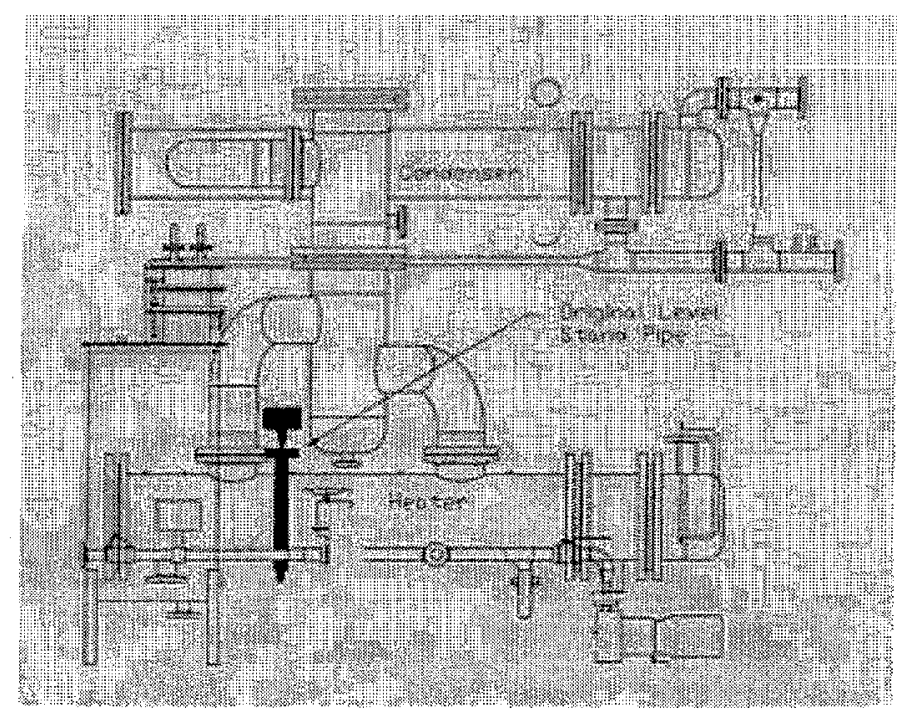

Fig. 44. Front view of the OTE evaporator skid showing the location of the standpipe containing the instrument for monitoring the OTE shell level. 


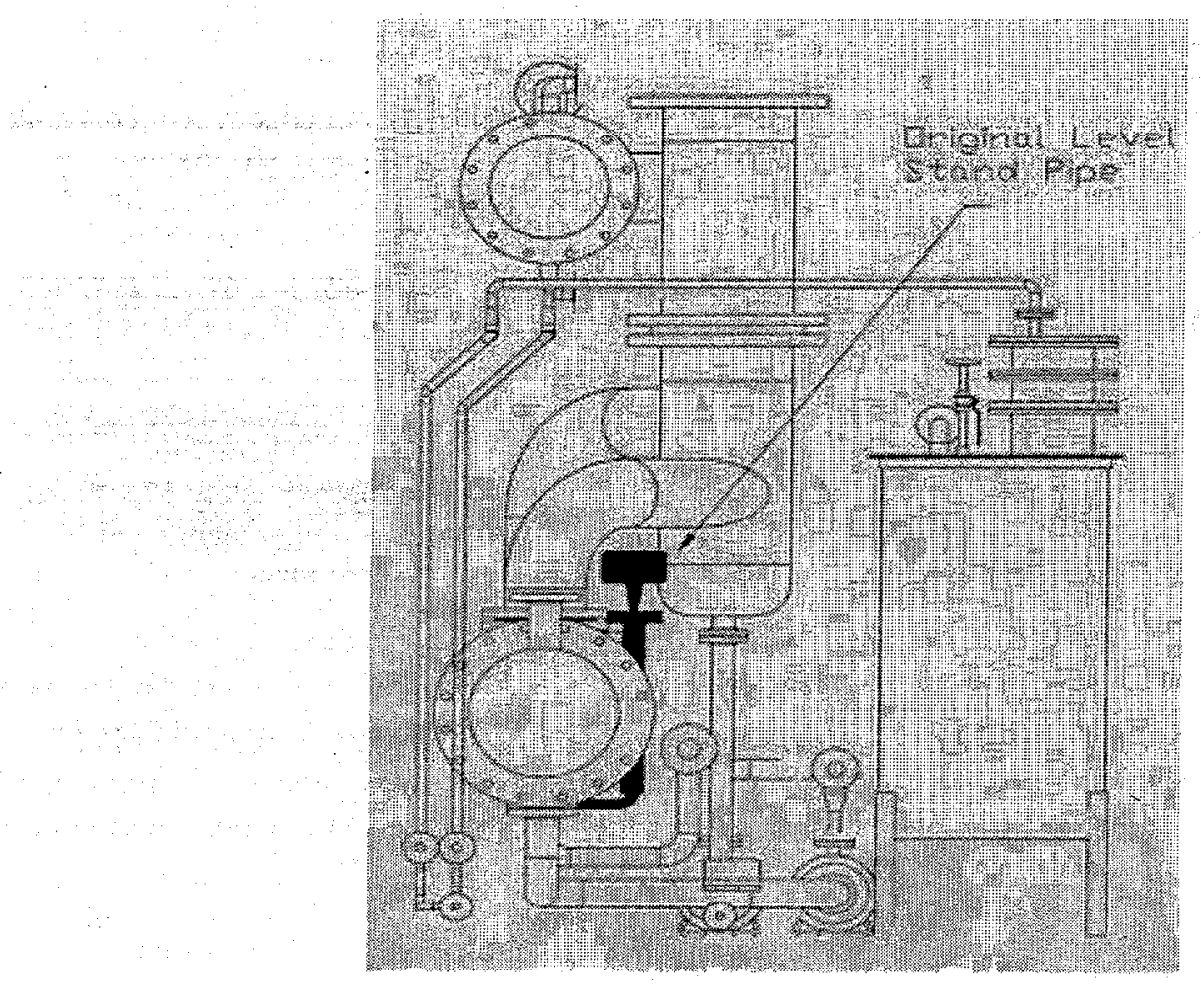

Fig. 45. End view of the OTE evaporator skid showing the location of the standpipe containing the instrument for monitoring the OTE shell level.

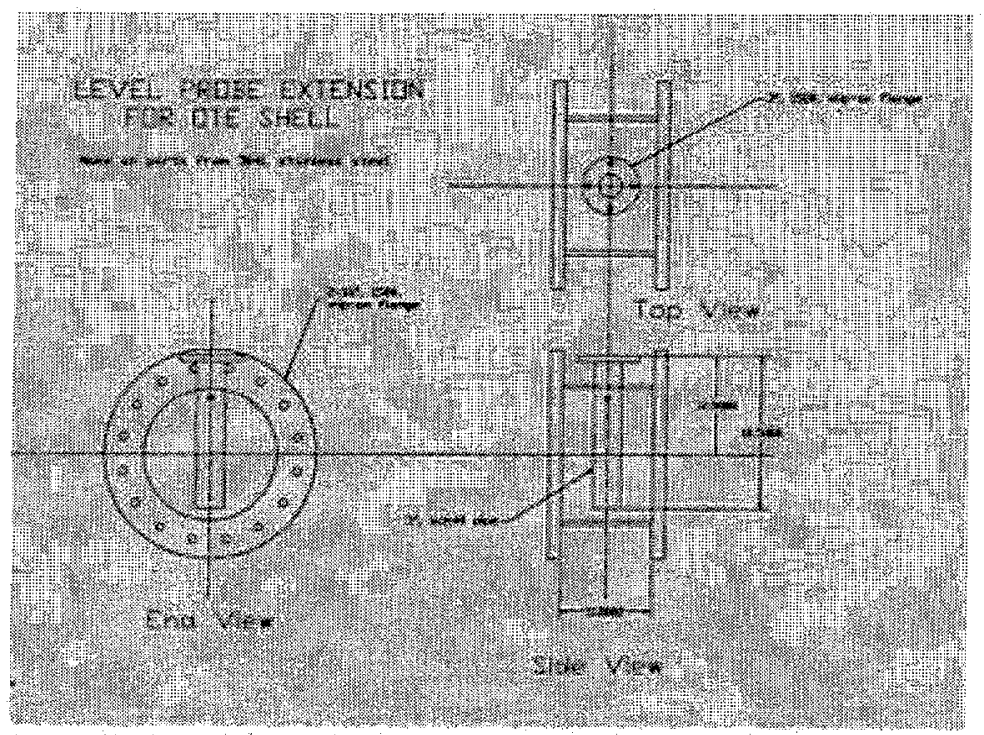

Fig. 46. Drawing showing the design of the new spool piece to change the location of the OTE shell level instrument from a standpipe to a location within the shell. 


\subsection{WTP CAMPAIGN 8}

The CsR and OTE systems were used in this campaign to process supematant from tank W30. This tank had been allowed to settle for several months; therefore, the SLS system was not utilized. As in Campaign 7, this supematant was somewhat dilute with a nitrate concentration of $54,900 \mathrm{mg} / \mathrm{L}(0.9 \mathrm{M})$ and a ${ }^{137} \mathrm{Cs}$ concentration of $280,000 \mathrm{~Bq} / \mathrm{mL}$. Operations began on February 3, 2000, at 11:00 and were completed on February 19 at 23:00, for a total operational period of $396 \mathrm{~h}$ (16.5 days). The WTP system had two unscheduled shutdowns during the run: one to replace an actuator on FCV-305 that had failed $(64 \mathrm{~h})$ and another to investigate a small leak that was detected in the catch pan under the CsR feed skid (6 hours). Operational availability was $82 \%$ for this campaign. There were three scheduled shutdowns for routine transfer of LLLW, which totaled $38 \mathrm{~h}$. The level control modifications made on the evaporator shell continued to perform well for the duration of this campaign. Approximately 17,000 gal of LLLW was treated during the campaign, $495 \mathrm{Ci}$ of ${ }^{137} \mathrm{Cs}$ was removed from the supematant, and 10,000 gal of distillate was removed from the LLLW, giving a volume reduction of $58 \%$.

\subsection{WTP CAMPAIGN 9}

The ninth campaign was initiated at on March 10 at 14:00, utilizing the SLS system to filter the MVST W24 supematant and the OTE evaporator to reduce the volume. Tank W24 had a nitrate concentration of $3390 \mathrm{mg} / \mathrm{L}(0.05 \mathrm{M})$ and a ${ }^{137} \mathrm{Cs}$ concentration of $189,000 \mathrm{~Bq} / \mathrm{mL}$. The CsR system was not used because the pressure transmitters around the columns were no longer functioning. The benefits of cesium removal for this tank were outweighed by the radiation exposure that would have been received in conducting instrument repairs on the system. The campaign was terminated on March 28 at 04:00, for a total operational period of $422 \mathrm{~h}$ (17.6 days). During this period, there was one unscheduled shutdown of $52 \mathrm{~h}$ to troubleshoot the SLS system and adjust the limit switch on SLS BV2-5, which had caused the system to shut down. Two scheduled shutdowns for transfer of LLLW totaled $20 \mathrm{~h}$. Approximately 12,000 gal. of LLLW was processed and $5600 \mathrm{gal}$ of distillate was removed, for a volume reduction of $48 \%$.

During preparation for Run 9, there were two separate incidences of leaking of the ethylene glycol, which was used to heat the evaporator, from the high-pressure hose that was used to circulate it between the heater skid and the evaporator skid. The first leak was repaired, but after the second leak, it was decided to replace all of the high-pressure hose carrying ethylene glycol in the OTE system. Also, during this period it was noted that the actuator on LCV-308 had failed and had to be replaced. Approximately 15 days was required to plan the maintenance, to procure and receive the necessary material, and to complete work.

\subsubsection{WTP Campaign 9-SLS Performance}

Operations on the SLS for the ninth WTP campaign have been detailed in a previous report. ${ }^{8}$ The following is an excerpt from that report. The figures have been renumbered to fit sequentially in the current report.

A graph showing the weight percent of undissolved solids in the SLS feed during the ninth campaign as a function of time is presented in Fig. 47. The concentration of solids initially started at $-2 \mathrm{wt} \%$ and then rapidly decreased to $<1 \mathrm{wt} \%$. It is typical for the solids level in the SLS feed to be higher initially due to the design of the MVST facility. The "suction legs for the SLS system are located near the bottom of the MVSTs, well below the level of the accumulated sludge in the tanks. To avoid transferring concentrated sludge to the SLS system, Moyno pumps, which are part of the MVST facility, are initially operated to recirculate the sludge in the tank and clear the sludge surrounding the suction leg. After the sludge has been cleared from the dip leg, the Moynos are de-energized and the double- 
diaphragm pumps that feed the SLS system are energized. Several hours may be required for the latter pumps to pick up the loose solids in the cone formed by the Moyno pumps and for the cone to stabilize. After the cone had been stabilized in WTP Campaign 9, the solids content remained below $1 \mathrm{wt} \%$ for -16 days of operation. On March 27, however, the solids content in the feed started to rise, increasing from $-0.6 \mathrm{wt} \%$ to $-3 \mathrm{wt} \%$ over a period of approximately $28 \mathrm{~h}$. The solids content then jumped from $-3 \mathrm{wt} \%$ to $-22 \mathrm{wt} \%$, indicating that the cone had collapsed around the suction leg in the MVST being processed. The SLS system was subsequently flushed with water to remove any solids that were present. During the flushing operation, meetings were held with personnel responsible for waste operations at ORNL to assess the possibility of re-forming the cone in MVST W-24. Material balances indicated that the liquid level in MVST W-24 had dropped below the surface of the sludge layer in the tank and the cone could not be re-formed.

Figure 48 presents the filtrate flow rate as a function of time for Run 9. As shown in the figure, this flow rate often dropped to zero. This decrease occurred because the filtrate was produced in 80-gal batches and the filtrate discharge valve would close when the high-level set point indicated that the filtrate tank was full. The SLS control system was programmed to send the filtrate to the CsR feed tank only when the CsR feed tank had enough capacity to accept the 80 -gal batch. As can be seen from Fig. 48, the filtrate production rate increased to $4-5 \mathrm{gal} / \mathrm{min}$ and operated at this level for 8 days before declining to $-1 \mathrm{gal} / \mathrm{min}$ over the next 2 days. The $4-5 \mathrm{gal} / \mathrm{min}$ rate was typical of that observed during the latter stage of the SLS demonstration which occurred in WTP Campaign 5. The filtrate production rate for a cross-flow filter typically declines for a period after startup and then reaches steady state. The $\sim 1$-gal/min rate achieved at the close of Run 9 was adequate for the WTP because the OTE system generally operated at $<1 \mathrm{gal} / \mathrm{min}$; therefore, the SLS did not become a bottleneck for the downstream process.

The feed flow rate to the SLS system as a function of time is presented in Fig. 49. The target flow rate to the SLS system was typically 30 to $50 \mathrm{gal} / \mathrm{min}$; however, the inlet flow was very erratic and was often above or below the target value. Some of this variability can be attributed to the pulsed flow from the double -diaphragm pumps that fed the SLS system. Operational problems occurred with these pumps, possibly because of solids buildup in the piping to the pump suction.

The axial flow rate across the filter elements, which is delivered by the filter circulation pump, is presented as a function of time in Fig. 50. As can be seen, the axial flow rate across the filters was fairly constant. The step changes shown in Fig. 50 typically occurred when the pump output was changed at the control screen so that the corresponding effect on the filtrate output through the filter elements could be examined. Also, even though the feed to the SLS was very erratic (Fig. 49), the filter elements that were performing the separation were experiencing a very steady axial flow rate; therefore, the erratic feed flow did not affect the separation.

The transmembrane pressure, shown as a function of tune in Fig. 51 , was typically maintained at -8 psig. On March 16, the transmembrane pressure was increased to -25 psig for $-24 \mathrm{~h}$ and on March 22 it was decreased to -3 psig to determine its effect on the filtrate production rate. As can be seen from comparing Figs. 48 and 51 , the filtrate production rate increased from -1 to $-3.5 \mathrm{gal} / \mathrm{min}$ when the transmembrane pressure was increased from 8 to $25 \mathrm{psig}$. However, the filtrate rate did not decrease when the transmembrane pressure was returned to 8 psig. Therefore, the increase in filtrate production could not be directly attributed to the increase in transmembrane pressure. 


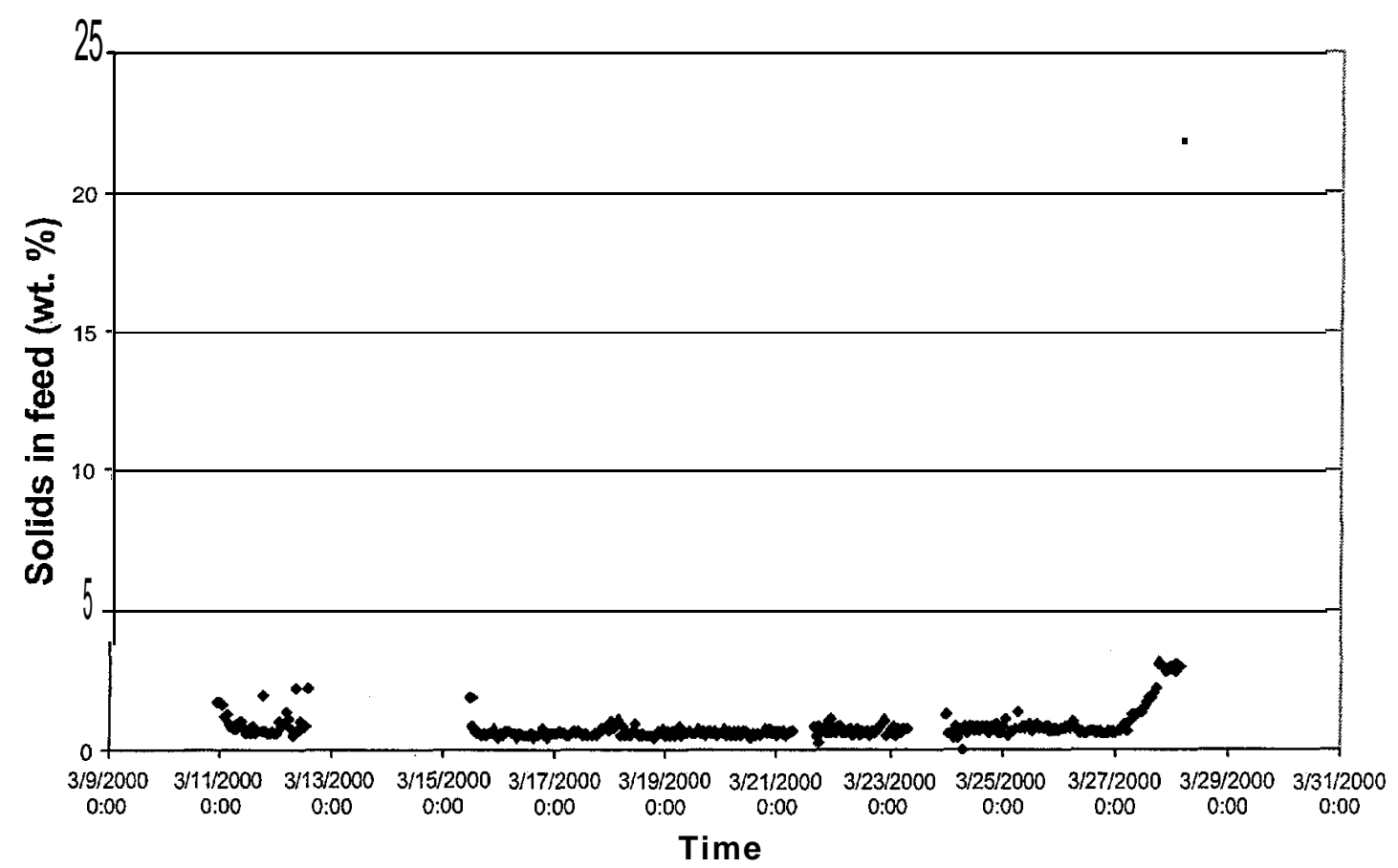

Fig. 47. Solids content of the SLS feed as a function of time for the ninth WTP campaign.

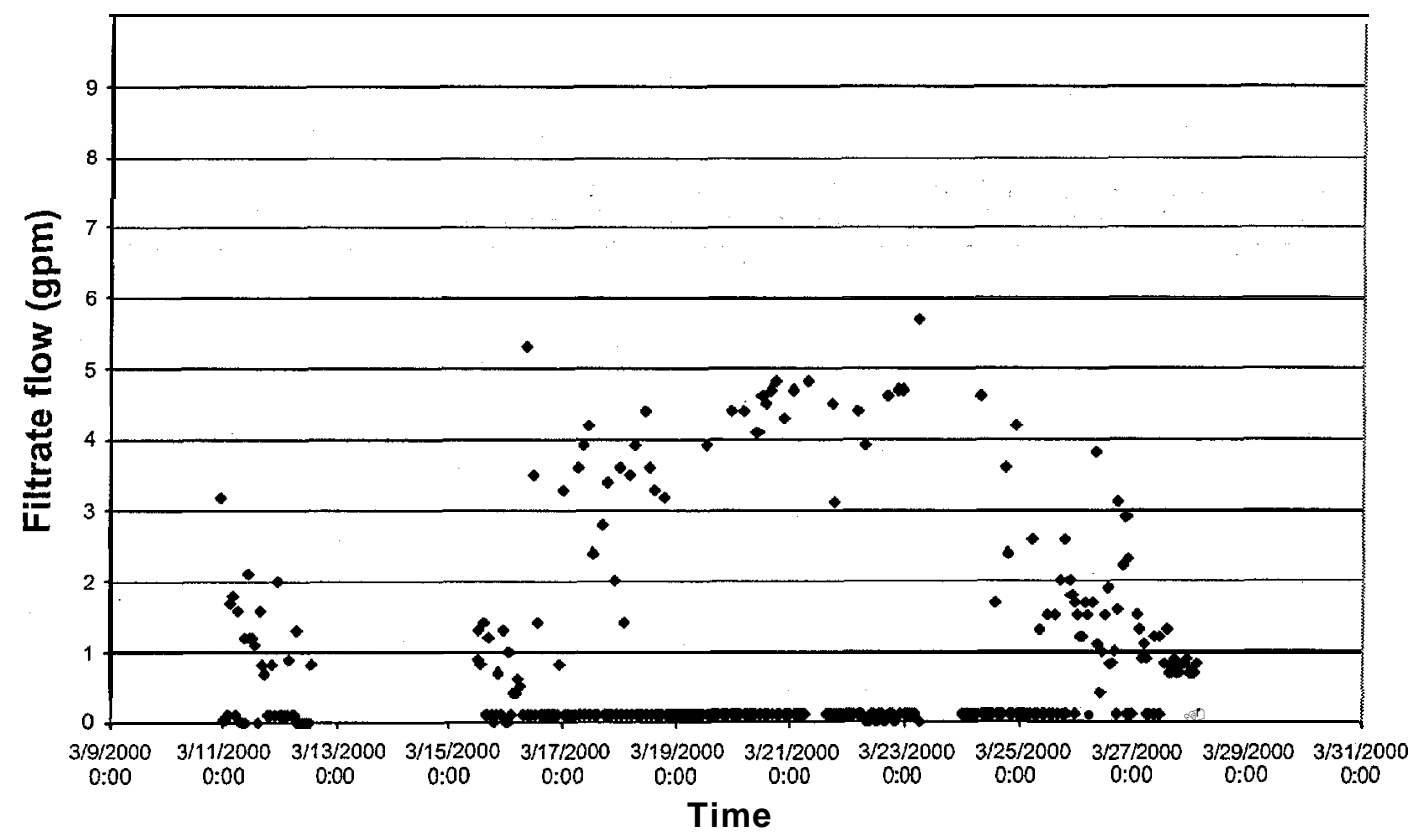

Fig. 48. Filtrate flow rate as a function of time for the ninth WTP operational campaign. 


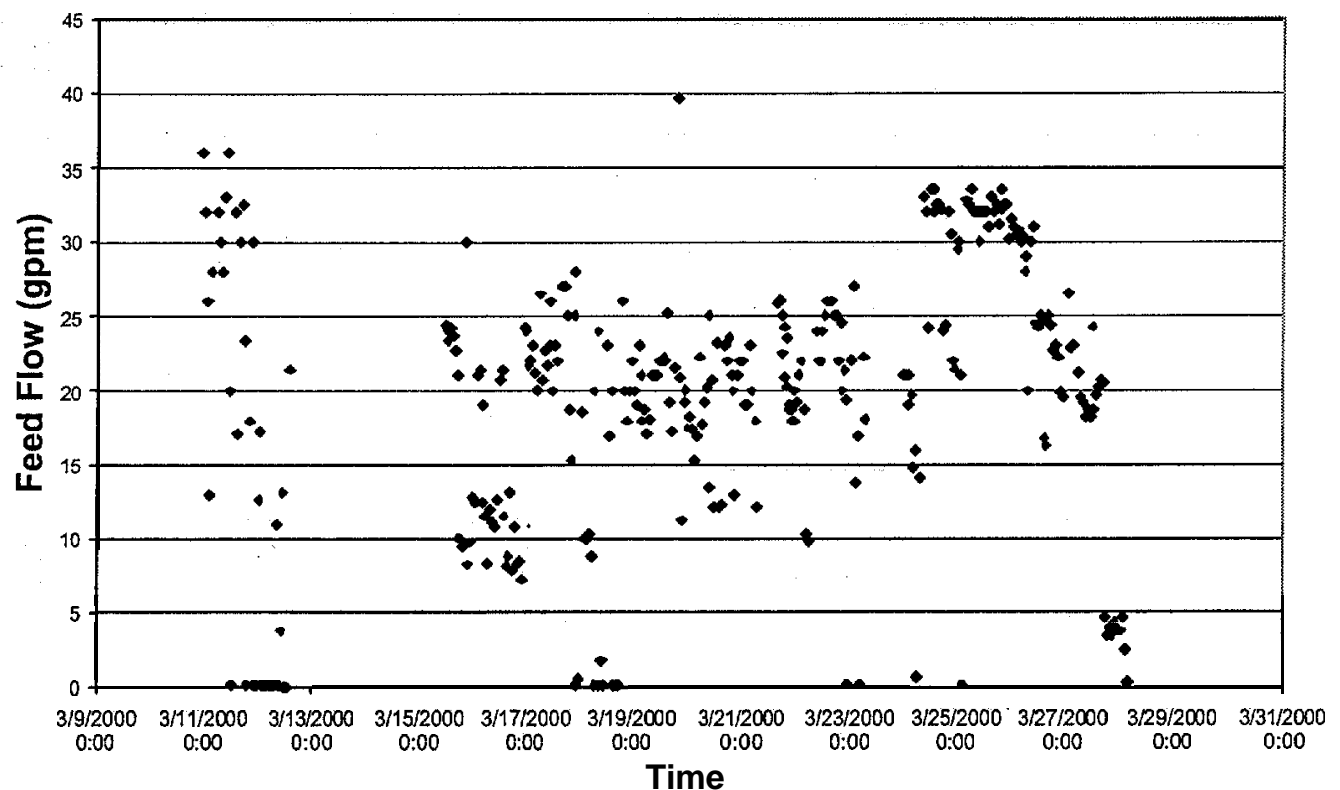

Fig. 49. Feed flow rate to the SLS system as a function of time for the ninth WTP operational campaign.

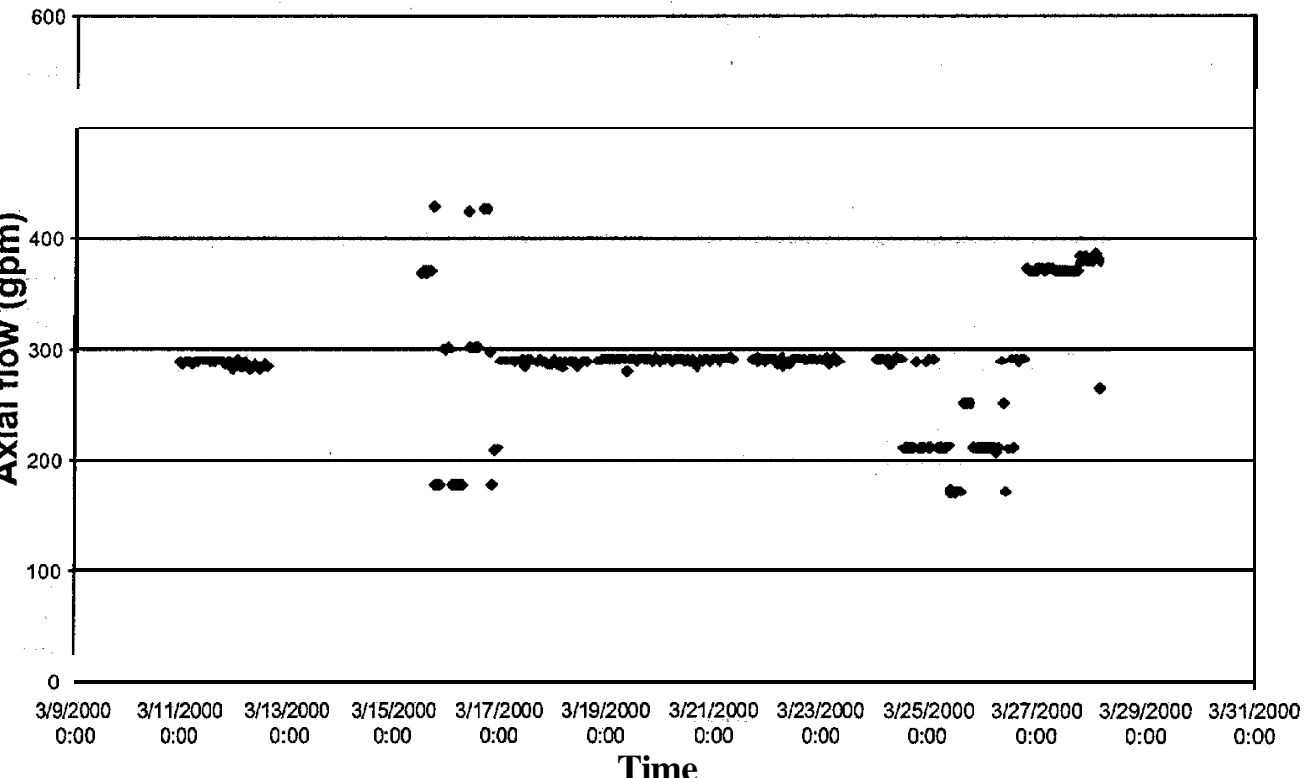

Fig. 50. Axial flow rate across the filter elements as a function of time for Run 9. 


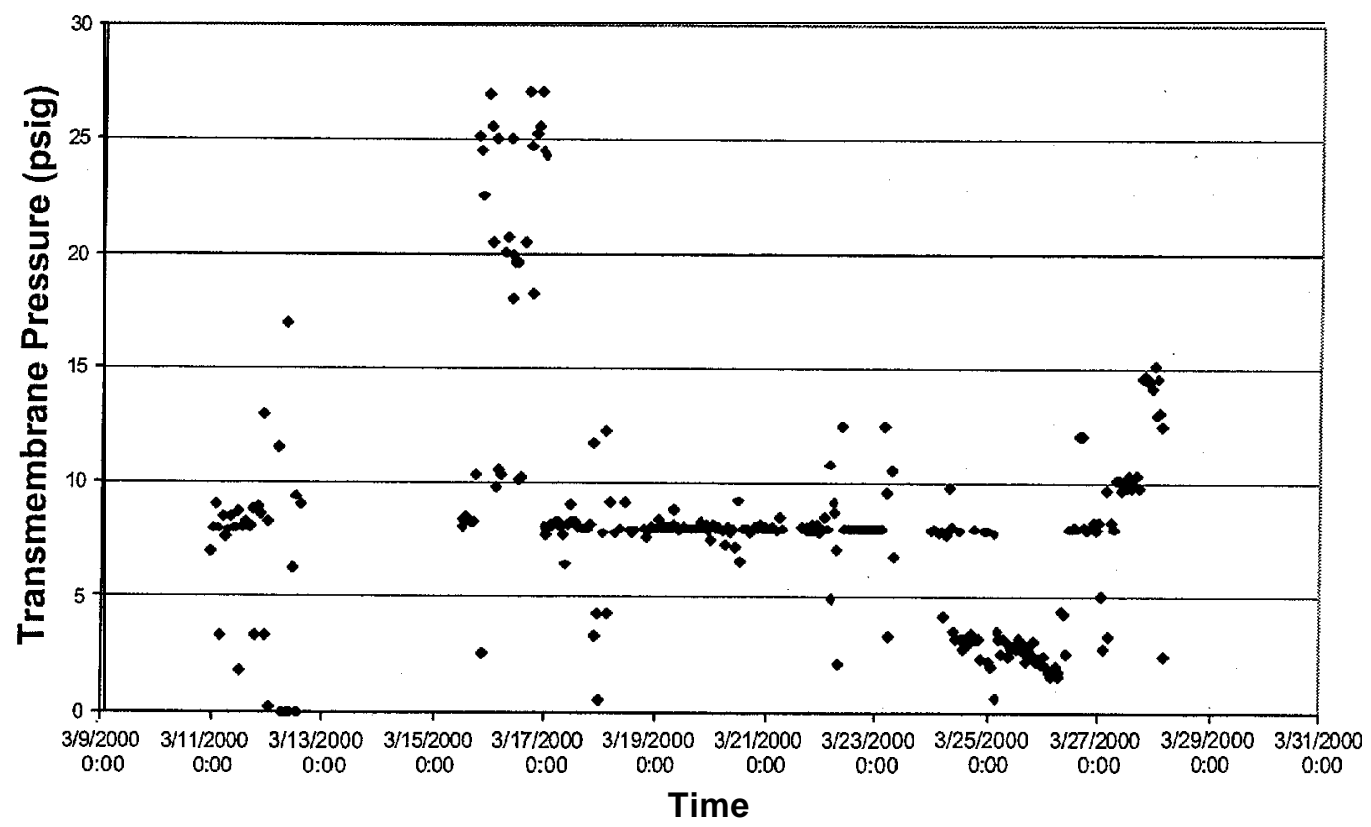

Fig. 51. Transmembrane pressure as a function of time for the ninth WTP operational campaign.

\subsection{WTP CAMPAIGN 10}

The tenth and final WTP campaign was initiated at on March 28 and completed on April 15, for a total operational period of $429 \mathrm{~h}$ (17.9 days). During this campaign, there was one scheduled shutdown for transfer of LLLW $(10 \mathrm{~h})$ and no unscheduled shutdowns lasting more than $1 \mathrm{~h}$. The SLS was used to remove the solids from the MVST W26 supematant, which had a nitrate concentration of $6010 \mathrm{mg} / \mathrm{L}$ $(0.1 \mathrm{M})$ and a ${ }^{137} \mathrm{Cs}$ concentration of $132,000 \mathrm{~Bq} / \mathrm{mL}$, while the OTE was used to reduce the volume. The CsR system was not used because the pressure transmitters around the ion-exchange columns were no longer functioning. Approximately 13,400 gal of LLLW was processed and 7000 gal evaporated during the final campaign, for a volume reduction of $52 \%$.

\subsubsection{WTP Campaign 10—SLS Performance}

The solids content of the feed to the SLS as a function of time is presented in Fig. 52. As can be seen, it was much more difficult to maintain the cone or depression in the sludge within MVST W-26 during the early part of Run 10 than in the previous run, which utilized the SLS. Following the formation of the cone or depression in the sludge with the Moyno pumps, the percent solids fed to the SLS was erratic until the cone stabilized. A total of $-72 \mathrm{~h}$ of operation was required to stabilize the cone after it had been initially formed. During this 72-h period, the solids content of the feed decreased from -10 to $-0.6 \mathrm{wt} \%$. The solids content then remained below -1 wt $\%$ for -4 days, and the cone began to break up, introducing more solids into the SLS feed. On April 10, the cone again seemed to stabilize and the solids content of the feed increased from -1 wt $\%$ to -9 wt \% over a period of -5 days. The feed to the SLS was shut off and the solids were rinsed from the system when the solids content reached $>9 \mathrm{wt} \%$, "completing the campaign. 


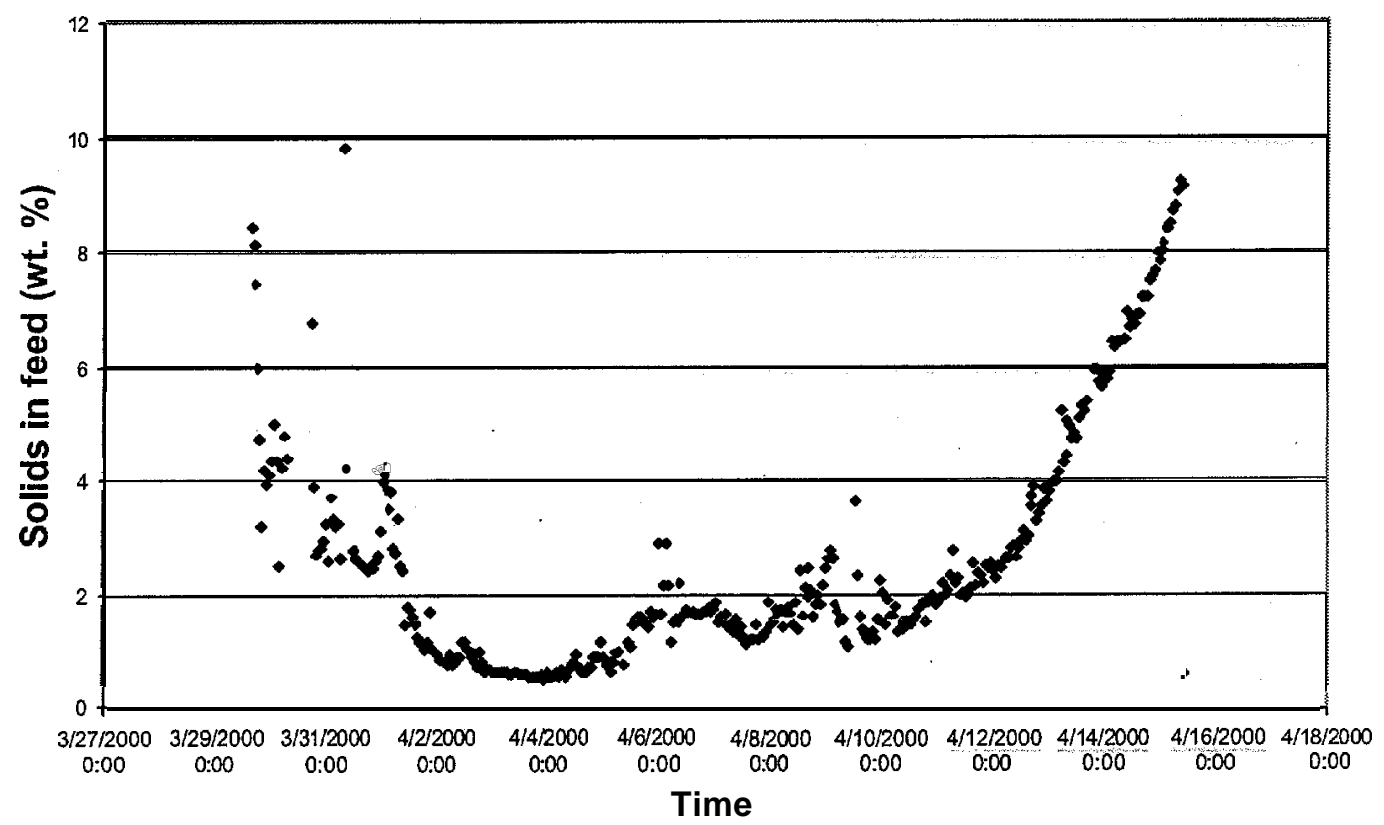

Fig. 52. Solids content of the SLS feed as a function of time for the tenth WTP campaign.

The feed flow rate to the SLS system and the axial flow rate across the filters as a function of time are presented in Figs. 53 and 54, respectively, for Run 10. The results are very similar to those from Run 9; the feed flow rate was erratic, while the axial flow rate was steady except for step changes made by the operator to examine the effects on the filtrate production rate. Again, the erratic feed flow rate can be attributed to operational problems with the D/D pumps.

The filtrate flow rate is presented as a function of time in Fig. 55. As shown, the filtrate production rate typically ran at $1-2 \mathrm{gal} / \mathrm{min}$. This filtrate production rate was similar to the rate observed at the end of Run 9, indicating that filtrate production may have reached a steady-state level for this system. Also, a comparison of Figs. 54 and 55 shows that changes in the axial flow had no obvious effect on the filtrate production rate.

The transmembrane pressure and the pressure drop across the filters with time are presented in Figs. 56 and 57, respectively. The transmembrane pressure held steady until April 4 and then became very erratic. A comparison of Figs. 53 and 56 shows that the transmembrane pressure was affected by the variability of the inlet flow rate. However, the variability in the transmembrane pressure (Fig. 56) appeared to have no negative impact on the filtrate flow rate (Fig. 55).

Figure 57 shows that the pressure drop across the filters typically varied from -4 to -10 psig. This range did not appear to increase as the percentage of solids in the feed increased, indicating that the axial flow across'the surface of the filter was sufficient to keep the solids from building up on the surface of the filter and impeding flow through it. 


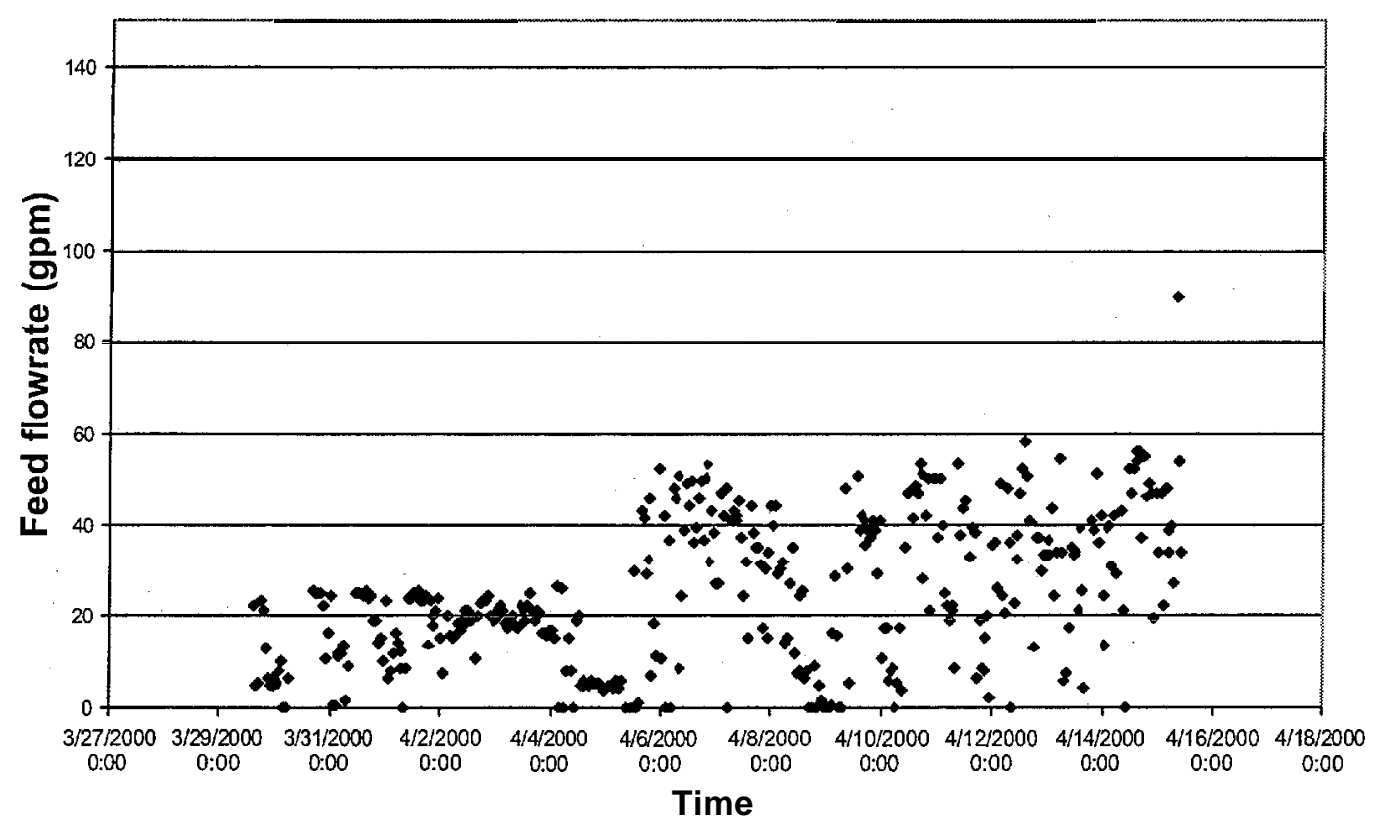

Fig. 53. Flow rate of the feed to the SLS system as a function of time during the tenth WTP operational campaign.

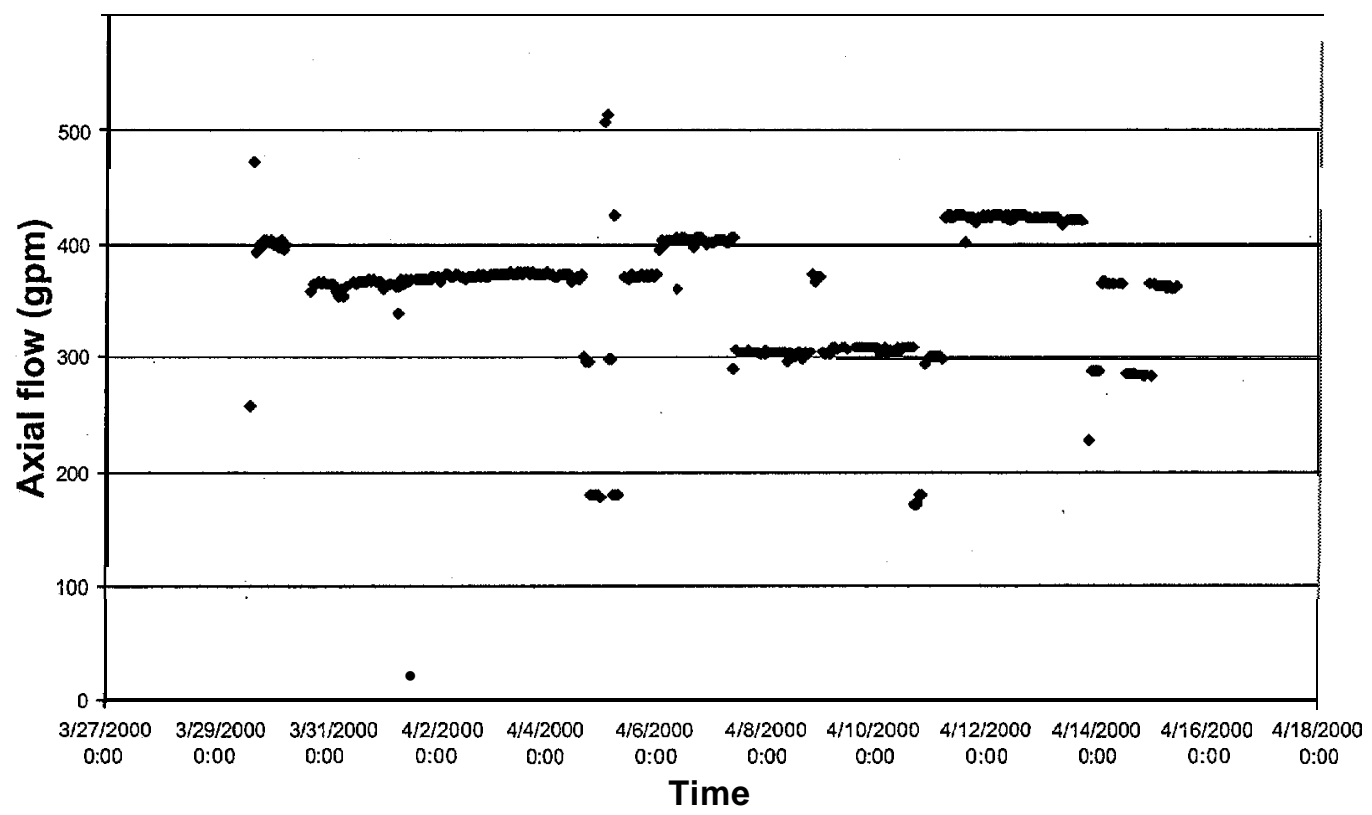

Fig. 54. Axial flow rate across the filter elements as a function of time for the tenth WTP operational campaign. 


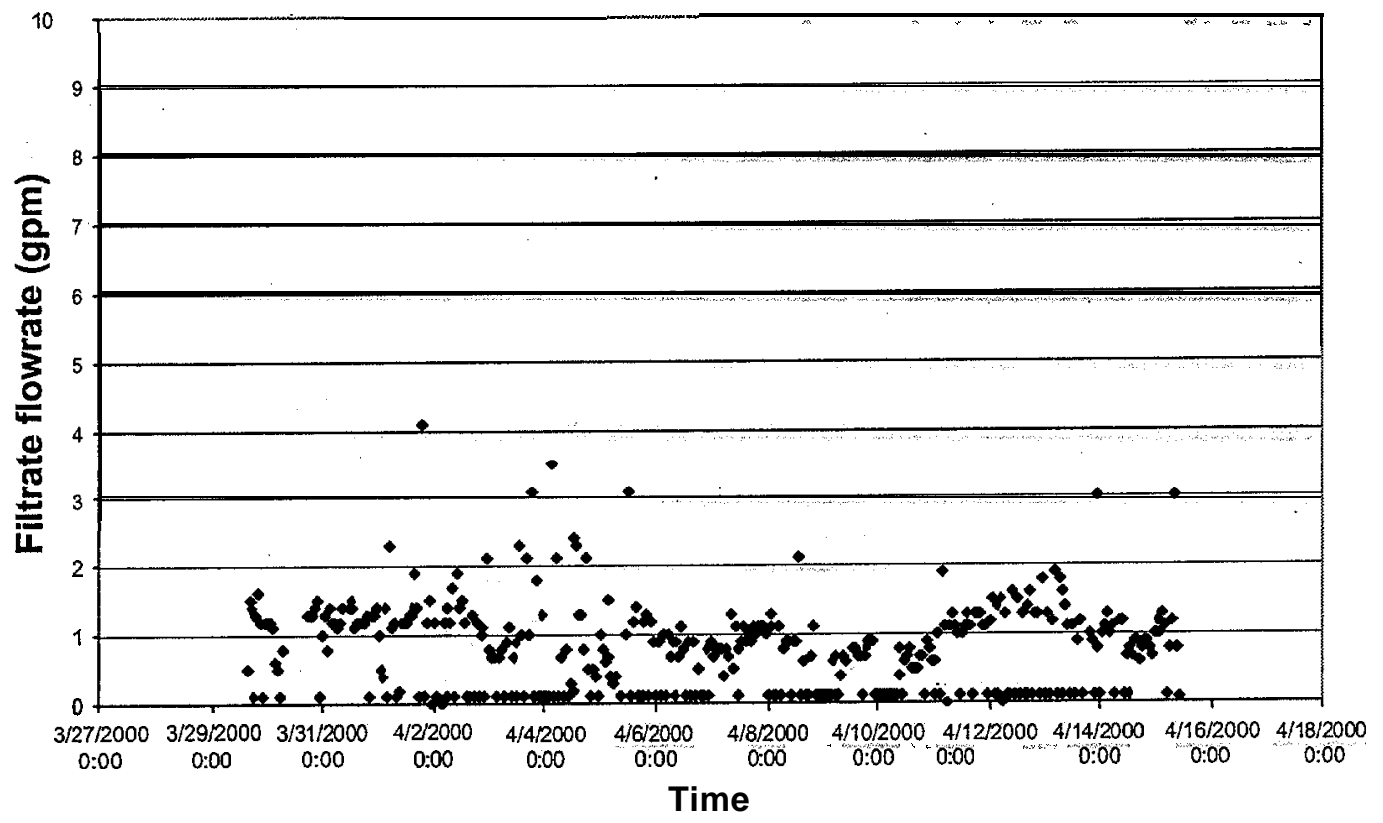

Fig. 55. Filtrate flow rate as a function of time for the tenth operational campaign.

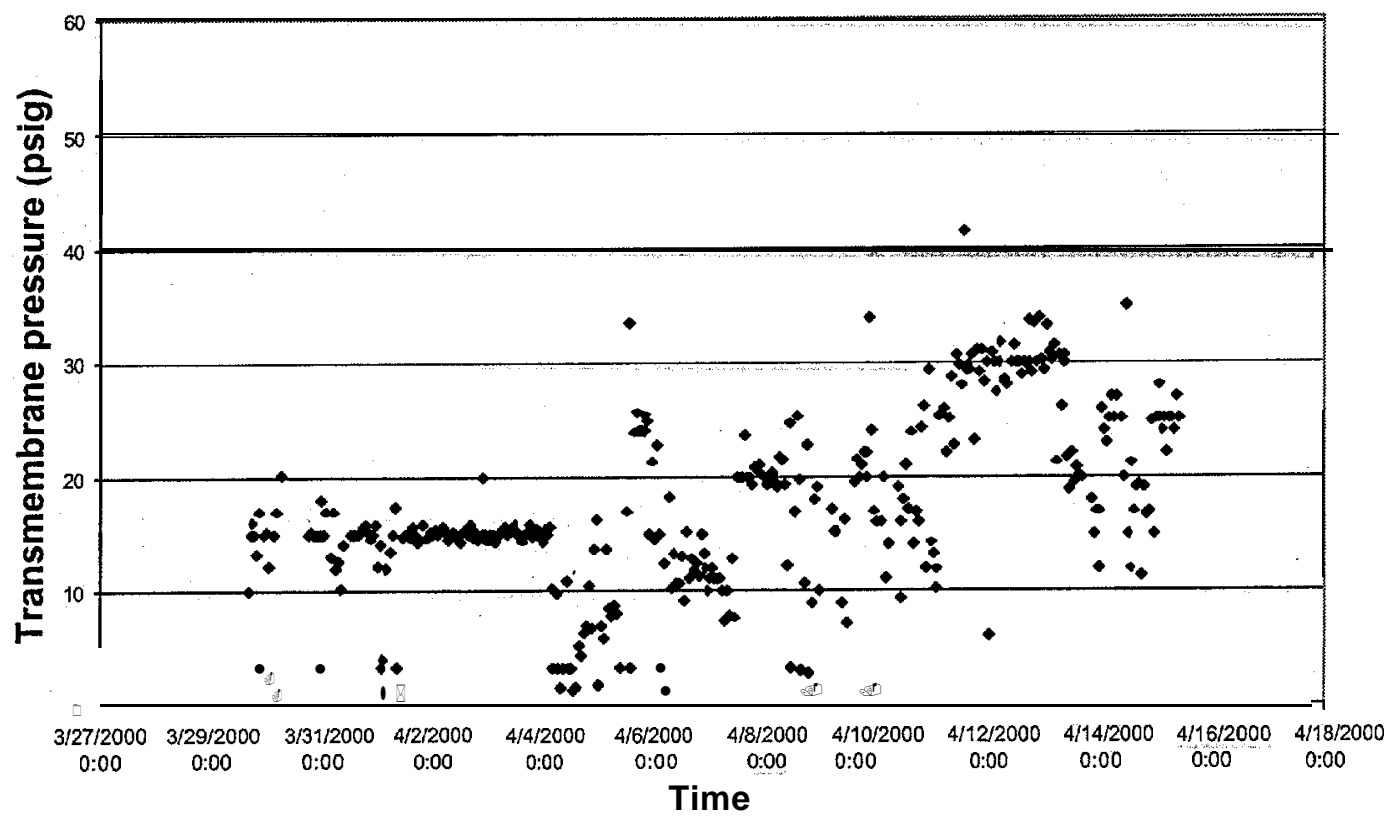

Fig. 56. Transmembrane pressure as a function of time for the tenth WTP operational campaign. 


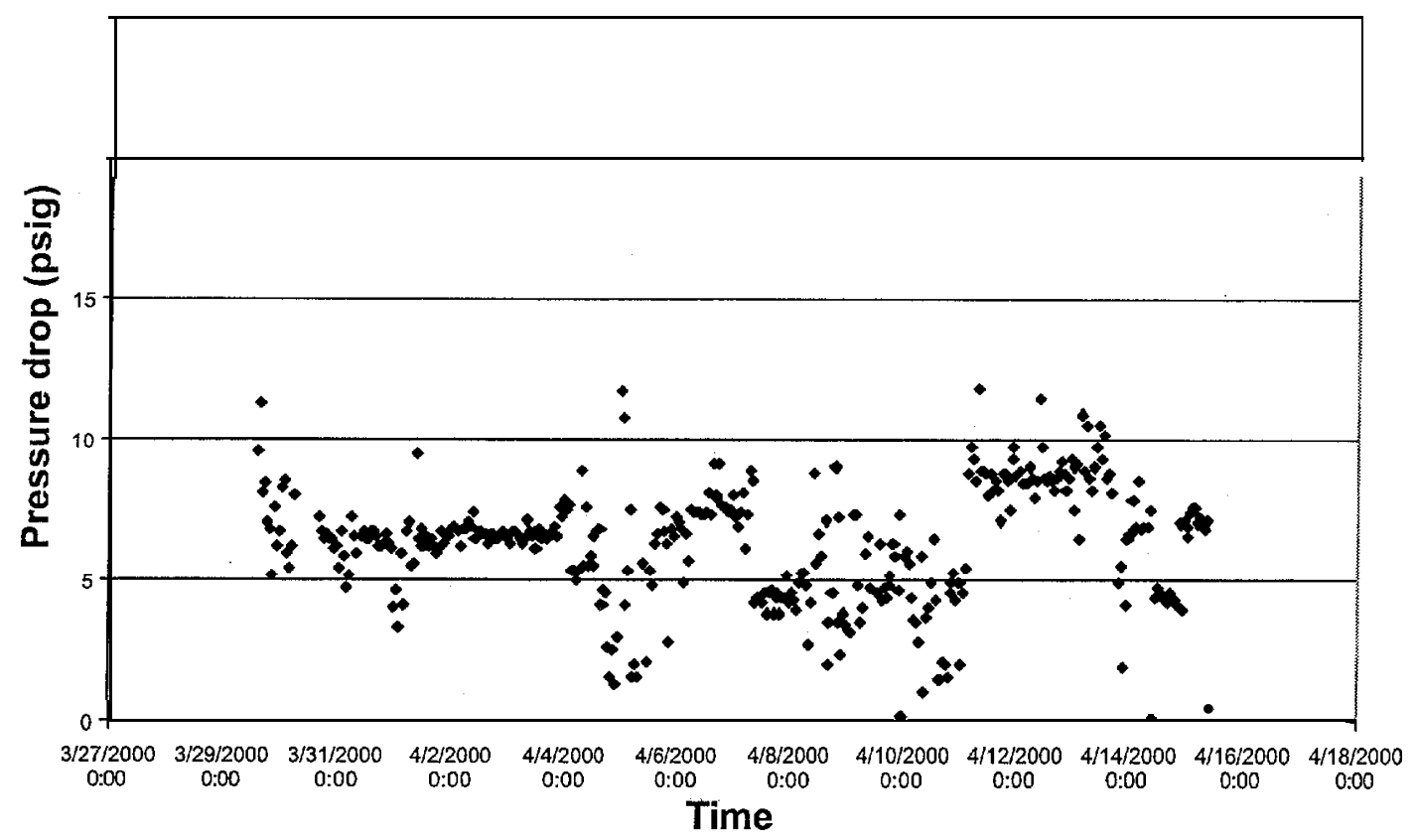

Fig. 57. Pressure drop across the filters as a function of time for the tenth WTP operational campaign.

\subsection{OPERATIONAL DOWNTIME AND EQUIPMENT PROBLEMS}

A summary of the operational problems, along with time required for scheduled and unscheduled maintenance, is presented in Table 3. Scheduled maintenance was typically for either transfer of LLLW to the MVSTs, during which period the WTP had to be shut down because of the use of common lines, or for sluicing the spent sorbent from the CsR system to the HIC. A graph of the percent downtime for each run is presented in Fig. 58. The percent downtime is defined as follows: Percent downtime $=$ [Unscheduled downtime/(Operational Period - Scheduled Downtime)] $\times 100$. During the first four runs, there were few shutdowns for unscheduled maintenance.

During Runs 5, 6, and 7, the downtime for unscheduled maintenance increased substantially. The majority of downtime for Campaign 6 was associated with solids clogging the lines between the CsR feed tank and the CsR feed pumps. Backwashing operations had resulted in sorbent fines getting into and settling to the bottom of the CsR feed tank. These fines then settled out in the suction lines and the cavities of the CsR feed pumps. The solids also damaged the rotor and stator in each pump. The pumps had to be pulled, the lines had to be flushed, and the pumps had to be rebuilt and reinstalled before operations could continue.

The major maintenance problem in the seventh campaign was associated with the level control system in the OTE evaporator shell. The system was poorly designed to accommodate the quantity and types of solids experienced during the WTP operations. These solids collected in a standpipe containing the OTE shell level sensor and could not be removed or dissolved. During the fifth and sixth campaigns, the shell 
Table 3. Summary of operational problems and time requirements for each operational run

\begin{tabular}{|c|c|c|c|c|}
\hline $\begin{array}{l}\text { WTP } \\
\text { campaign } \\
\text { number }\end{array}$ & $\begin{array}{l}\text { Total } \\
\text { operational } \\
\text { period }(\mathrm{h})\end{array}$ & $\begin{array}{l}\text { Scheduled } \\
\text { maintenance } \\
(\mathrm{h})\end{array}$ & $\begin{array}{l}\text { Unscheduled } \\
\text { maintenance } \\
\quad(\mathrm{h})\end{array}$ & $\begin{array}{l}\text { Operation problems during campaign associated with } \\
\text { unscheduled maintenance }\end{array}$ \\
\hline 1 & 168 & 33.5 & 11 & OTE input module \\
\hline 2 & 228 & 17 & 21.5 & $\begin{array}{l}\text { Replace J01 pump, replace totalizer (FQI601), humid air condensation } \\
\text { sets off leak detectors, leak detector malfunction }\end{array}$ \\
\hline 3 & 392 & 78 & 2 & Replace J01 pump \\
\hline 4 & 467 & 0 & 63 & $\begin{array}{l}\text { Roof leak, problem with ROV1300, level sensor in OTE shell, fuse blown } \\
\text { in FCV305, small leak in catch pan }\end{array}$ \\
\hline 5 & 658 & 47 & 195 & $\begin{array}{l}\text { Heavy rain leak into building sump, failed solenoid, HIC camera and level } \\
\text { sensor failure, procedure modification and approval, OTE conductivity probe } \\
\text { failure, failed pressure transmitter PT209, leak on OTE distillate line }\end{array}$ \\
\hline 6 & 1128 & 52 & 702 & $\begin{array}{l}\text { OTE shell level sensor, failed flow switch FSH204, failed level transmitter } \\
\text { LT306, blockages in CsR feed line and line between CsR and OTE, clean } \\
\text { solids from process lines }\end{array}$ \\
\hline 7 & 2094 & 0 & 1029 & $\begin{array}{l}\text { OTE shell level sensor, replace pump J01, acid clean OTE shell, clean } \\
\text { standpipe containing OTE shell level sensor; designed, fabricated, and } \\
\text { installed OTE shell level sensor system }\end{array}$ \\
\hline 8 & 396 & 38 & 70 & $\begin{array}{l}\text { Replace faulty leak detector, replace actuator for FCV305, small water } \\
\text { leak in catch pan }\end{array}$ \\
\hline 9 & 422 & 20 & 52 & $\begin{array}{l}\text { Reform cone in MVST feed to SLS system, drain and rinse SLS system, } \\
\text { leak in SLS sampler }\end{array}$ \\
\hline 10 & 429 & 10 & 0 & None \\
\hline
\end{tabular}




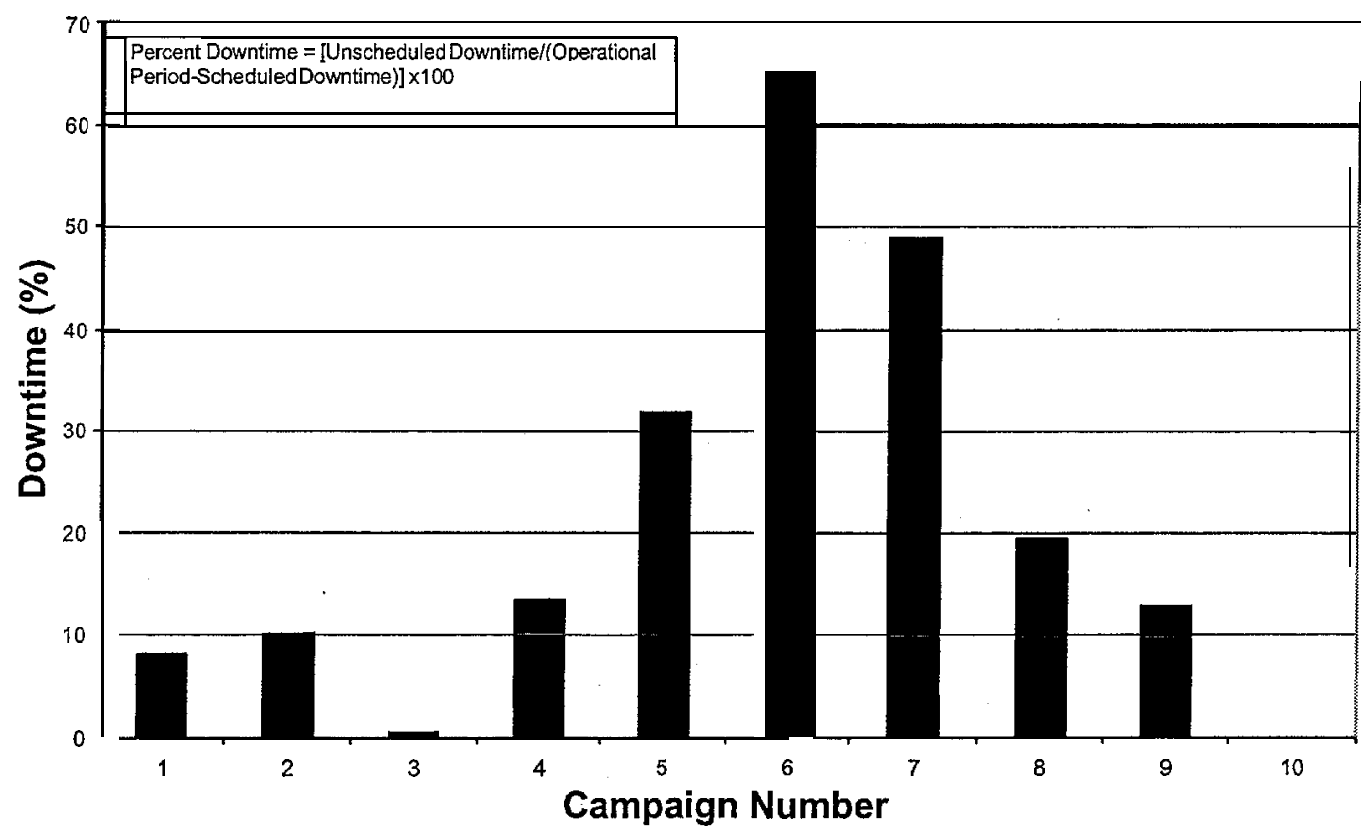

Fig. 58. Percent operational downtime for each WTP campaign.

level sensor responded very slowly, causing much operational difficulty and many shutdowns of short duration. During the seventh campaign, the level sensor became completely unusable and all attempts to remove the solids from the standpipe were unsuccessful. A new level sensing system was designed, fabricated, and installed in the OTE. This design proved to be very effective in subsequent runs. Details of this design are discussed in 'Sect. 8.7 of this report. After the pump replacement in Campaign 6 and the redesign of the shell level sensor system in Campaign 7, the system operated much more reliably for the final three campaigns.

\subsection{DECONTAMINATION AND DECOMMISSIONING}

The WTP team was instructed by BJC, which controlled the facilities in which the WTP campaigns were conducted, to do minimal D\&D at the end of operations. BJC at that time planned on contracting the D\&D activities to a private contractor.

After the tenth campaign was finished the following activities were completed. (1) The SLS system was drained, cleaned with acid and caustic, and rinsed with water. (2) The OTE system was drained, cleaned with 5\% nitric acid, and rinsed with water. (3) The CsR system was drained and rinsed with water.

(4) Following the rinsing operations, the low-point drains on all systems were opened and compressed air " was use to remove most of the residual water left in the piping to the three systems. (5) The fill head was removed from the shielled HIC, the top was bolted on the HIC, and the plug was installed on the shielded cask. (6) All contaminated material was removed from Building 7877 and placed in disposal containers. (7) The ethylene glycol solution was pumped from the OTE system into disposal drums. (8) All systems were electrically de-energized. 
Extensive radiation surveys were conducted on all three treatment systems and Building 7877 prior to turning the equipment and facilities over. to BJC. Copies of the detailed surveys can be found in Appendix B. The survey taken outside of Building 7877 indicated that the highest levels of exposure were found on the northwest portion of the building, with contact dose rates on this area ranging from 40 to $170 \mathrm{mrem} / \mathrm{h}$. This area contained a 55 gal drum located in the building sump. The drum was fitted with a D/D pump and was used to drain the CsR and OTE systems during and after operations. The high radiation levels in this area were due to radioactive sorbent and solids that accumulated in the drain lines and the sump drum.

Radiation surveys of the individual process skids showed "hot spots" reading of $15 \mathrm{R} / \mathrm{h}$ under the OTE feed tank, $8 \mathrm{R} / \mathrm{h}$ on the OTE shell piping, and $20 \mathrm{R} / \mathrm{h}$ around the CsR feed pumps and the CsR feed tank drain line. In general, smears of Building 7877 and the catch pans to the individual skids showed lessthan-detectable quantities of transferable alpha contamination and transferable beta ranging from 50 to $200,000 \mathrm{dpm} / 100 \mathrm{~cm} "$. Most of the beta contamination was in the lower range.

Contact dose rates on the shielded HIC located in Building 7877, which contained the spent sorbent from the CsR operations, ranged from 10 to $20 \mathrm{mrem} / \mathrm{h}$. Therefore, the HIC meets the DOT regulation

(49 CFR 173.443) requirements of $<200 \mathrm{mrem} / \mathrm{h}$, which is necessary to transport the shielded HIC in commerce. Smears taken on the HIC and trailer supporting the HIC indicated less-than-detectable limits of alpha contamination and beta contamination ranging from 300 to $176,000 \mathrm{dpm} / 100 \mathrm{~cm}^{2}$.

Surveys taken outside the building housing the SLS system indicated that the highest levels of exposure were on the southwest side of the building, with contact readings as high as $260 \mathrm{mrem} / \mathrm{h}$. This reading was taken on the shielded transfer lines from the MVSTs to the SLS system. Inside the SLS enclosure, the radiation levels ranged from -0.2 to $50 \mathrm{mrem} / \mathrm{h}$. Smears taken inside the SLS enclosure indicated less-thandetectable limits of alpha contamination and beta contamination ranging from $<200$ to $19,000 \mathrm{dpm} / 100 \mathrm{~cm}^{2}$.

\section{LOADED SORBENT FROM CSR OPERATIONS}

The spent sorbent from the CsR operations was processed and packaged to meet the WAC for the NTS. Prior to implementation of the of the WTP, a sampling and analysis plan (SAP) for the loaded radioactive sorbent was prepared and approved. ${ }^{10}$ The object of the plan was to present an acceptable SAP to sufficiently characterize MVST loaded sorbent that results from the CsR operations. The SAP was submitted as part of the BJC and Lockheed Martin Energy Research, Inc. (LMER) Oak Ridge Reservation (ORR), "Nevada Test Site Waste Profile for Dried Cesium Contaminated, Sorbent." The SAP details the requirements for (1) ensuring that the loaded cesium-contaminated sorbent meets the requirements of the NTS WAC and (2) providing legally defensible data regarding the waste form. The SAP itself can be referenced for details." Highlights of the SAP are summarized below.

\subsection{TOTAL RADIOLOGICAL CONTENT}

Unless specific arrangements are made, the NTS WAC requires that the total radiological content not exceed the NRC Class C levels. The principal radioisotope of concern for the CsR operations was ${ }^{137} \mathrm{Cs}$. The Class $\mathrm{C}$ limit for ${ }^{137} \mathrm{Cs}$ is $4600 \mathrm{Ci} / \mathrm{m}^{3}$. To ensure that this limit was not exceeded the loading of ${ }^{137} \mathrm{Cs}$ was limited to $3900 \mathrm{Ci} / \mathrm{m}^{3}$ of sorbent in the HIC. Strontium 90 was also present in the waste and was removed by the sorbent; however, the isotope was at much lower concentrations and was of little concern 
with respect to the Class $\mathrm{C}$ limit. To ensure that the ${ }^{90} \mathrm{Sr}$ limit was not exceeded, feed samples were analyzed for strontium, and it was assumed that all of the ${ }^{90} \mathrm{Sr}$ in the feed was loaded on the sorbent. The sum-of-fractions rule also applies to this waste. Since ${ }^{137} \mathrm{Cs}$ and ${ }^{90} \mathrm{Sr}$ were the major radioisotopes, documentation was provided that these isotopes did not exceed the sum-of-fractions rule. Calculations on the basis of sorbent volume were conducted to demonstrate that the loaded sorbent did not exceed the NRC Class C limit.

\subsection{TRANSURANICS AND HAZARDOUS WASTE COMPONENTS}

The NTS WAC requires that the TRU nuclide concentration of waste not be $>100 \mathrm{nCi} / \mathrm{g}$ of alpha-emitting TRU radionuclides with a half-life greater than 20 years. Low-level waste to be disposed of at NTS cannot exhibit characteristics of or be listed as a hazardous waste as identified in 40 CFR 261 . Therefore, analytical data must be provided to show that the waste is not TRU or hazardous.

During early WTP campaigns, LLLW samples were taken from the MVSTs to be processed and passed through a small ion-exchange column containing a portion of the sorbent to be used during processing. The bed volumes passed thought the small column were equal to or exceeded those to be processed through the full-scale columns to be used in the CsR operations. The sorbent sample was then analyzed for TRU and hazardous components. The use of a small column to simulate the full-scale column was acceptable because previous testing had demonstrated that the loadings per unit volume were equivalent for these columns. Calculations on the basis of sorbent volume were conducted to demonstrate that the TRU nuclide concentration in the sorbent was $<100 \mathrm{nCi} / \mathrm{g}$. The sorbent from the small column tests were also subjected to a TCLP analysis for RCRA metals to ensure that it was not hazardous. Analyses for polychlorinated biphenyls (PCBs), volatiles, semi-volatiles, low-molecular alcohols, and organic halides were not necessary due to process knowledge.

In later WTP campaigns, the SAP was revised (Revision 1) to eliminate the requirement for a smallcolumn test unless the concentrations of RCRA metals and TRU components were at levels $>25 \%$ of those supemates that had been previously processed and documented. This value was determined to be reasonable because previous analyses had shown that essentially no RCRA metals leached from the sorbent and the loading of TRU components never exceeded $30 \mathrm{nCi} / \mathrm{g}$.

\subsection{HIGH-INTEGRITY CONTAINER CONTENTS}

Two HICs were used during the ten WTP campaigns. Each HIC was designed to hold and dry up to $60 \mathrm{ft}^{3}$ (448.9 gal) of sorbent. The SAP limited the ${ }^{137} \mathrm{Cs}$ content to $3900 \mathrm{Ci} / \mathrm{m}^{3}$, or a maximum of $6627 \mathrm{Ci}$ for a full $60-\mathrm{ft}^{3} \mathrm{HIC}$. The NTS limited the ${ }^{90} \mathrm{Sr}$ content to $7000 \mathrm{Ci} / \mathrm{m}^{3}$.

Details for each run that contributed sorbent to HIC no. 1-including the average feed concentrations for cesium and Stontium 90, the ion-exchange columns, the volume of supernatant processed through the columns, and the total ${ }^{137} \mathrm{C}$ and ${ }^{90} \mathrm{Sr}$ loaded per run-are presented in Table 4. A summary of the contents in the first HIC, along with the HIC limits, is presented in Table 5. The HIC has a total of 405 gal of sorbent containing $5142 \mathrm{Ci}$ of ${ }^{137} \mathrm{Cs}$ and $35 \mathrm{Ci}$ of ${ }^{90} \mathrm{Sr}$.

Details for each run that contributed sorbent to HIC no. 2-including the average feed concentrations for cesium and Stontium 90, the ion-exchange columns, the volume of supematant processed through the columns, and the total ${ }^{137} \mathrm{C}$ and ${ }^{90} \mathrm{Sr}$ loaded per run-are presented in Table 6. A summary of the contents in the first HIC, abng with the HIC limits, is presented in Table 7. The HIC has a total of $220 \mathrm{gal}$ of sorbent containing $2144 \mathrm{Ci}$ of ${ }^{137} \mathrm{Cs}$ and $56 \mathrm{Ci}$ of ${ }^{90} \mathrm{Sr}$. 
- Table 4. Details on the WTP campaigns for the sorbent loaded into HIC \# 1

\begin{tabular}{|c|c|c|c|c|c|c|c|c|c|}
\hline $\begin{array}{l}\text { Summary information } \\
\text { for each run }\end{array}$ & $\begin{array}{c}\text { Run \# } 1 \\
\text { Col \# }\end{array}$ & $\begin{array}{c}\text { Supemate } \\
\text { processed } \\
\text { (gal) }\end{array}$ & $\begin{array}{c}\text { Run \#2 } \\
\text { Col \# }\end{array}$ & $\begin{array}{c}\text { Supernate } \\
\text { processed } \\
(\mathrm{gal})\end{array}$ & $\begin{array}{c}\text { Run \# } 3 \\
\operatorname{col} \# \\
\end{array}$ & $\begin{array}{c}\text { Supernate } \\
\text { processed } \\
\text { (gal) }\end{array}$ & $\begin{array}{l}\text { Run \# } 5 \\
\text { col \# }\end{array}$ & $\begin{array}{c}\text { Supernate } \\
\text { processed } \\
(\mathrm{gal})\end{array}$ & $\begin{array}{c}\text { Totals } \\
\text { for Run } \\
1-5 \\
\end{array}$ \\
\hline & $\mathrm{Cl}$ & 3285 & $\mathrm{c} 5$ & 1955 & $\mathrm{C9}$ & 4036 & $\mathrm{C} 15$ & 3409 & \\
\hline & $\mathrm{C} 2$ & 3257 & C6 & 6391 & $\mathrm{ClO}$ & 4158 & $\mathrm{Cl} 6$ & 3362 & \\
\hline & c3 & 3338 & c 7 & 6397 & $\mathrm{C} 11$ & 4246 & $\mathrm{C} 17$ & 3457 & \\
\hline & c 4 & 3339 & C8 & 4154 & $\mathrm{C} 12$ & 4200 & $\mathrm{Cl} 8$ & 3362 & \\
\hline & $\mathrm{c} 5$ & 2308 & $\mathrm{C} 9$ & 347 & $\mathrm{C} 13$ & 4270 & & & \\
\hline & $\mathrm{C} 8$ & 1243 & & & $\mathrm{C} 14$ & 2356 & & & \\
\hline Volume per run (gal) & & 16,770 & & 19,244 & & 23,266 & & 13,590 & 72,870 \\
\hline Avg ${ }^{137} \mathrm{Cs}$ feed $(\mathrm{Bq} / \mathrm{mL})$ & $1,100,000$ & & 520,000 & & 740,000 & & 320,000 & & \\
\hline Avg ${ }^{90} \mathrm{Sr}$ feed $(\mathrm{Bq} / \mathrm{mL})$ & 9,200 & & 4,200 & & 2,400 & & 3,500 & & \\
\hline $\begin{array}{l}\text { Total }{ }^{137} \mathrm{Cs} \text { loaded } \\
\text { per run }(\mathrm{Ci})\end{array}$ & 1,930 & & 1,017 & & 1,754 & & 438 & & 5,139 \\
\hline $\begin{array}{l}\text { Total }{ }^{90} \mathrm{Sr} \text { loaded } \\
\text { per run }(\mathrm{Ci})\end{array}$ & 15.8 & & 8.3 & & 5.7 & & 4.9 & & 34.7 \\
\hline
\end{tabular}

Table 5. Summary of HIC \# 1 contents and HIC limits

\begin{tabular}{|c|c|c|}
\hline & In high-integrity container & High-integrity container limit \\
\hline Volume sorbent used: $\mathrm{Cl}-\mathrm{Cl} 8$ (gal) & 405 & 448 \\
\hline Total ${ }^{137} \mathrm{Cs}$ in $\mathrm{HIC}(\mathrm{Ci})$ & 5,142 & 6,983 \\
\hline${ }^{137} \mathrm{Cs}$ loaidhing $\mathrm{HIC} \quad\left(\mathrm{Ci} / \mathrm{m}^{3}\right)$ & 3,355 & 3,900 \\
\hline Total ${ }^{90} \mathrm{Sr}$ in $\mathrm{HIC}(\mathrm{Ci})$ : & 34.7 & 11,895 \\
\hline${ }^{90} \mathrm{Sr}$ loaiahing HIC $\quad\left(\mathrm{Ci} / \mathrm{m}^{3}\right)$ & 22.6 & 7,000 \\
\hline Fraction rule $(<1)$ & 0.66 & $(<1)$ \\
\hline
\end{tabular}


Table 6. Details on the WTP campaigns for the sorbent loaded into HIC \# 2

\begin{tabular}{|c|c|c|c|c|c|c|c|}
\hline $\begin{array}{l}\text { Summary information } \\
\text { for each run }\end{array}$ & $\begin{array}{c}\text { Run \# } 6 \\
\text { co1 \# } \\
\text { C19 } \\
\end{array}$ & $\begin{array}{c}\text { Supernate } \\
\text { processed } \\
\text { (gal) } \\
3337 \\
\end{array}$ & $\begin{array}{c}\text { Run \#7 } \\
\text { co1 \# } \\
\text { C26 } \\
\end{array}$ & $\begin{array}{c}\text { Supernate } \\
\text { processed } \\
\text { (gal) } \\
4567\end{array}$ & $\begin{array}{c}\text { Run \#8 } \\
\text { Col \# } \\
\text { C27 } \\
\end{array}$ & $\begin{array}{c}\text { Supernate } \\
\text { processed } \\
\text { (gal) } \\
11097 \\
\end{array}$ & Totals for Run $1-5$ \\
\hline & $\mathrm{C} 20$ & 3384 & & & $\mathrm{C} 28$ & 6195 & \\
\hline & $\mathrm{c} 21$ & 3353 & & & c29 & 0 & \\
\hline & $\mathrm{c} 22$ & 3333 & & & & & \\
\hline & $\mathrm{C} 23$ & 0 & & & & & \\
\hline & $\mathrm{C} 24$ & 3165 & & & & & \\
\hline & $\mathrm{C} 25$ & 3855 & & & & & \\
\hline Volume per run (gal) & & 20,427 & & 4,567 & & 17,292 & 42,286 \\
\hline Avg ${ }^{137} \mathrm{Cs}$ feed $(\mathrm{Bq} / \mathrm{mL})$ & 747,000 & & 190,000 & & 280,000 & & \\
\hline Avg ${ }^{90} \mathrm{Sr}$ feed $(\mathrm{Bq} / \mathrm{mL})$ & 25,000 & & 2,300 & & 1,400 & & \\
\hline Total ${ }^{137} \mathrm{Cs}$ loadederun $(\mathrm{Ci})$ & 1,560 & & 89 & & 495 & & 2,144 \\
\hline Total ${ }^{90} \mathrm{Sr}$ loadederirun $(\mathrm{Ci})$ & 52.2 & & 1.1 & & 2.5 & & 55.8 \\
\hline
\end{tabular}

\section{Table 7. Summary of HIC \# 2 contents and HIC limits}

\begin{tabular}{lcc}
\hline & In high-integrity container & High-integrity container limit \\
\hline Volume sorbent used: $\mathrm{C1}-\mathrm{C} 18(\mathrm{gal})$ & 220 & 448 \\
$\mathrm{Total}^{137} \mathrm{Cs}$ in HIC $(\mathrm{Ci})$ & 2,144 & 6,983 \\
${ }^{137} \mathrm{Cs}$ loaiding HIC $\quad\left(\mathrm{Ci} / \mathrm{m}^{3}\right)$ & 2,575 & 3,900 \\
$\mathrm{Total}^{90} \mathrm{Sr}$ in HIC $(\mathrm{Ci})$ & 55.8 & 11,895 \\
${ }^{90} \mathrm{Sr} \mathrm{LoandingHIC} \quad\left(\mathrm{Ci} / \mathrm{m}^{3}\right)$ & 67 & 7,000 \\
Fraction Rule $(<1)$ & 0.28 & $(<1)$ \\
\hline
\end{tabular}




\section{RADIATION EXPOSURE}

Information on the total radiation exposure for the various tasks and for individuals is presented in Figs. 59 and 60, respectively. The information for these graphs was gathered from Radiation Work Permits (RWP) prepared by the health physics technician assigned to the project. The RWPs were utilized to assess the potential for radiation exposure and/or contamination on each specific task and to maintain a running total of the exposure to all personnel to make sure that these levels were kept as low as reasonably achievable (ALARA). During performance of jobs with greater potential for contamination or higher radiation fields, health physics technician were physically present to monitor activity.

The WTP can be divided into four activities: (1) installation and shakedown, (2) routine operations, (3) removal and transportation of the HIC containing the spent sorbent from the CsR operations, and (4) maintenance and troubleshooting after hot operations had been initiated. These activities occurred over approximately a 2-year period, during which $>70$ different personnel worked on the project and a cumulative total of $\mathbf{2 0 4 6}$ manhours was spent in the radiation facilities. Two, contamination incidences occurred during the project. These occurrences are summarized in the paragraphs that follow.

The installation and shakedown period had a duration of -217 days, during which 70 different personnel worked on the installation and/or shakedown.. During this 217-day period, 1581 man-hours was spent in the radiation facilities and a total of $2525 \mathrm{mR}$ was accumulated Most of the exposure during this period was from the OTE system, which remained in Building 7877, after completion of the fourth OTE operational period on June 19, 1998. No contamination incidences occurred during installation and shakedown.

Routine operations occurred over a period of -356 days and $>52$ personnel were utilized during these operations. A core team of seven CTD personnel were, involved in operations, and at least one of these individuals was present during all operations. Personnel involved in the routine operations received a total cumulative dose of $4013 \mathrm{mR}$. There was one contamination incident during routine operations, which occurred while fresh sorbent was being sluiced into the ion-exchange columns on the CsR system. The personnel involved failed to follow w\&ten procedures to close a ball valve that isolated the, radioactively contaminated ion-exchange columns from the noncontaminated fill hopper prior to adding fresh sorbent to the feed hopper. As a result, the vapor in the line between the ion-exchange columns and the hopper burped back into the hopper when the valve at the top of the hopper was opened to add fresh sorbent. The vapor sprayed the workers, who also received a small uptake of radioactive contamination. Investigation of the incident determined the cause of the occurrence to be worker error and inattention to .... detail. Training was put in place to emphasize 'the findings. However, the training was not implemented because the incident happened on the last column that was sluiced on the final WTP run; therefore, no additional work was to be performed with the system.

The third activity involved removal and transportation of the $\mathrm{HIC}$ containing the spent sorbent from the CsR operations. This required eight workers over a 2-day period. These workers spent 18.8 man-hours in the radiation facilities and acquired a total cumulative dose of $47 \mathrm{mR}$. No contamination incidences occurred during this activity.

A number of maintenance activities occurred during the WTP. As seen in Fig. 59, 13 separate maintenance/troubleshooting activities occurred in which contamination and/or radiation exposure was at levels high enough to require tracking in a separate RWP (i.e., not routine operations). During these activities, a total cumulative dose of $3615 \mathrm{mR}$ was received by -25 workers, who spent a total of 79 man hours in the radiation facilities. One-contamination incident occurred during' the maintenance activities, when an electrician was replacing a malfunctioning level instrument on the fill head connecting the ion- 


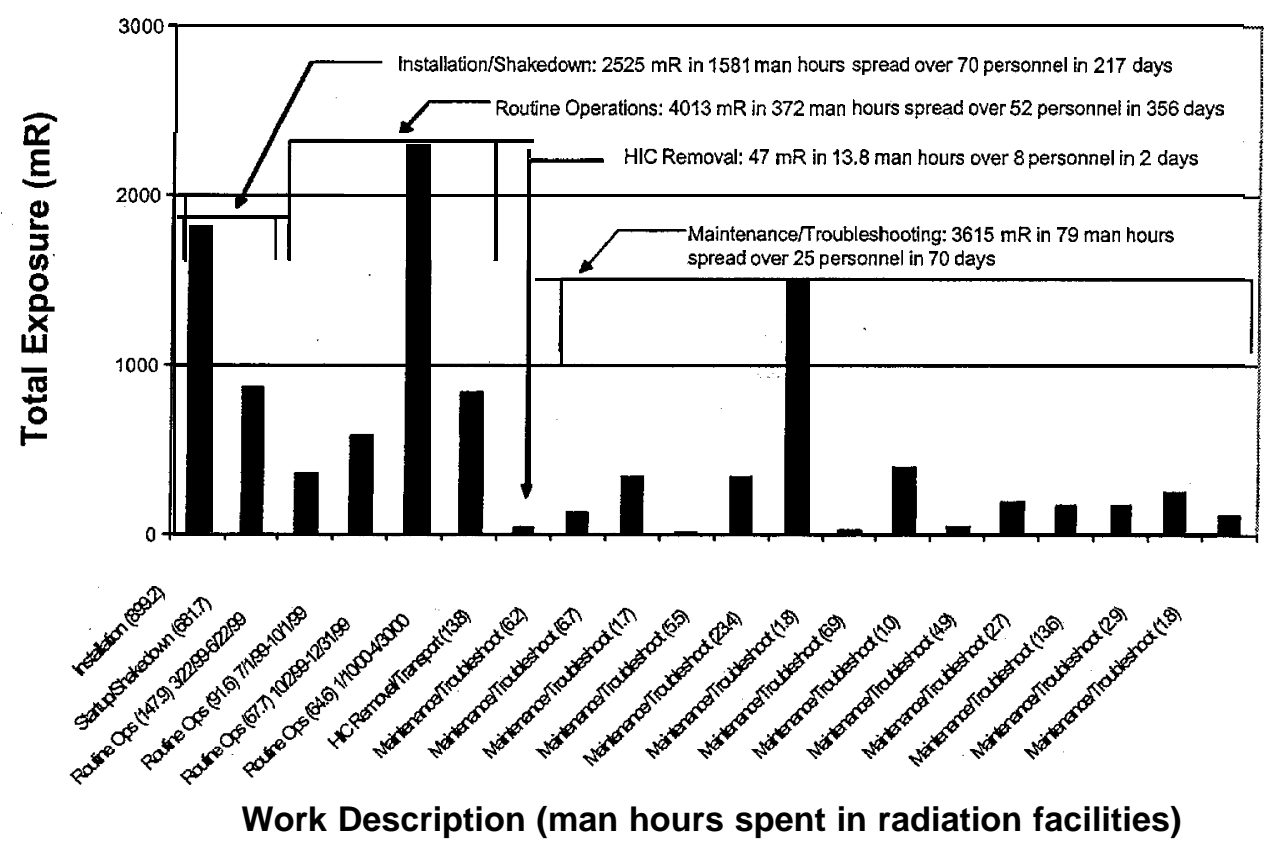

Fig. 59. Total radiation exposure received during the WTP during the various operational periods.

exchange system to the HIC. The fill head had been removed from the HIC, sprayed down, and allowed to air dry. When the worker reached into the fill head to remove the failed instrument, radioactive contamination got on his sleeve, wicked through the Tyvek suit as a result of perspiration, and contaminated his skin. Investigation of the occurrence resulted in additional training regarding the possibility of this type of contamination and outlining the required use of impermeable gloves with longer sleeves for similar jobs in the future.

The total exposure received by all individuals working on the WTP was examined for CY 1999 to determine how these exposures compared with the yearly limit $(5000 \mathrm{mR})$ set by DOE and the yearly goal (600 mR) set by LMER. Eighty-four workers signed the WTP RWPs and logged time in the radiation facilities during CY 1999. Of those 84 workers, 46 received cumulative doses less than $10 \mathrm{mR}$ for the year. The doses received by the remaining 38 employees are presented in Fig. 60 . The individuals in this graph are grouped by organization as follows: (1) HE' - health physics technicians, who were responsible for monitoring radiation/contamination and making sure procedures and operations were consistent with ALARA goals; (2) CTD - Chemical Technology Division personnel, who were responsible for oversight, operations, and project management; (3) I\&C - Instrumentation and Controls personnel, who were responsible for installation, calibration, and maintenance of instruments; (4) lead workers, who were responsible for lead fabrications and placement for shielding purposes; (5) P\&E -piping and electrical personnel, who were responsible for installation and maintenance activities; and (6) WMO - Waste Management Operators, who were responsible for operations of the WTP system. It should be noted that the operational period in Fig. 60 covered the maintenance activities that resulted in the highest radiation doses received during the WTP, which were the removal of the feed pumps to the CsR system and the maintenance and replacement of the level instrument in the OTE shell. As can be seen, no individual approached the DOE yearly limit and no individual exceeded the yearly goal set by LMER. The primary health physicist assigned to the project received the highest individual cumulative dose. 


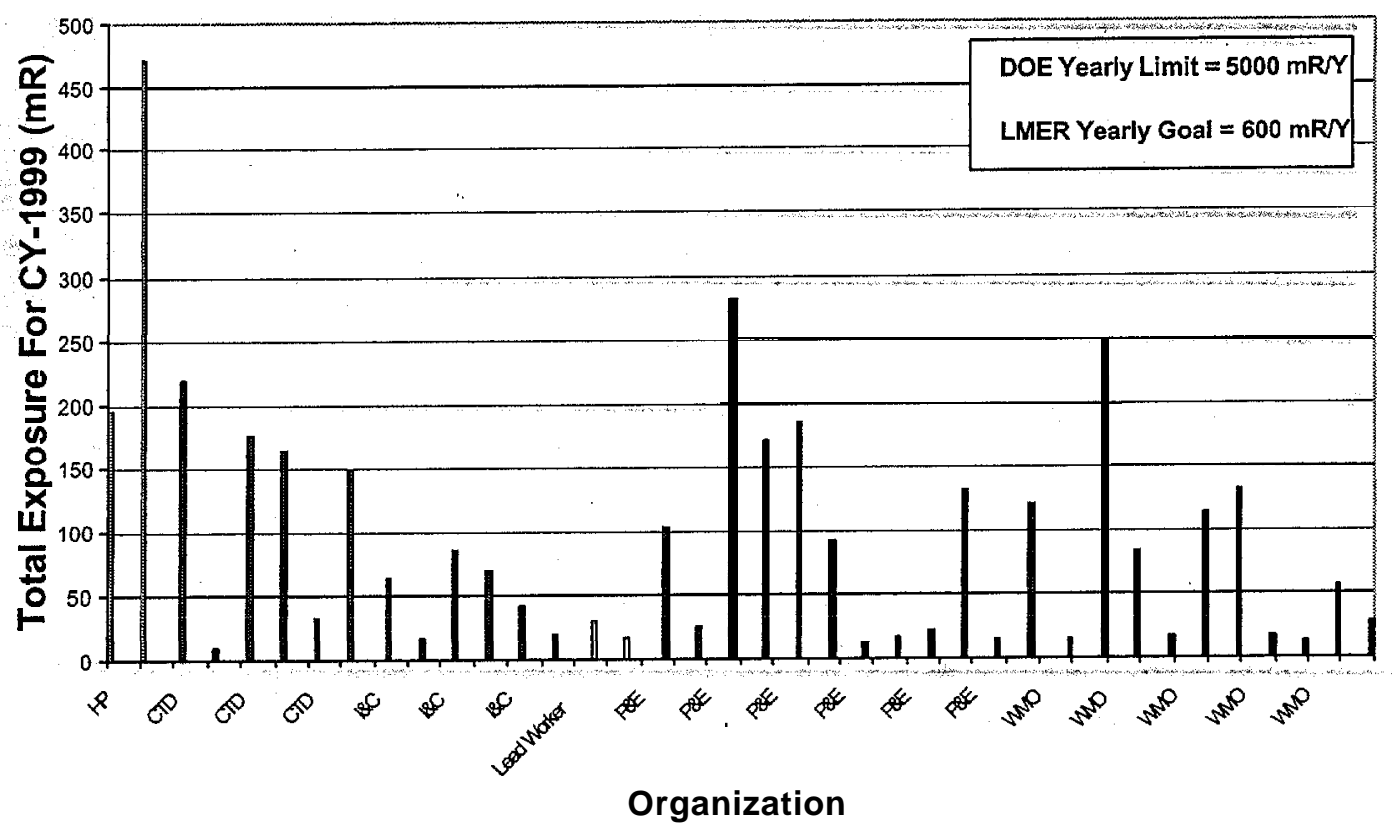

Fig. 60. Radiation levels received by WTP individuals during the 1999 calendar year broken down by organization (includes only personnel whose exposure exceeded $10 \mathrm{mR}$ for the calendar year).

\section{LESSONS LEARNED}

Many of the lessons learned from the WTP were associated with the equipment and operations of the systems. These are summarized below.

Foaming: Foaming of the supematant in the evaporator shell reduced the processing rate; led to fouling of the heat-exchanger surfaces; and caused carryover, which resulted in contamination of the distillate. Silicon-based antifoaming agents decreased-foaming but dispersed poorly in the supematant and caused fouling problems with the level instruments in the evaporator shell and the concentrate recycle tank. An alcoholbased antifoam, Surfynol 104E from Air Products, greatly reduced foaming and did not promote scaling.

Leaks : Leaks developed in the OTE system around flanges and valve bodies as a result of the cooling/heating cycles. These leaks were typically small and could be corrected by tightening the bolts on the flanges or bodies; however, configuration of the system and the radiation field sometime made this difficult.

Level Instruments : Several types of level instruments were used during WTP operations. As a result of fouling, many operational problems occurred with float-type instruments that were located in the OTE system. Fouling was particularly bad when silicone-based antifoams were utilized in the evaporator. An alcohol-based antifoam reduced the fouling of the float-type level instruments somewhat, but fouling continued to be a major problem. Ultrasonic sensors on the CsR system performed well for a period of time but eventually failed, presumably due to the radiation field from the CsR operations. Differential 
pressure cells utilizing "bubblers" worked well in many of the tanks; however, solids sometime built up in the air dip lines located in the tanks. Valves that allowed the differential pressure cells to be periodically isolated and the lines to be flushed with air or water typically worked well.

Electronic Valve Actuators : Fuses in the electronic valve actuators supplied by Valvcon were initially located within the actuators. However, after numerous blown fuses on the actuators resulted in higher levels of radiation exposure than necessary, the actuators were rewired so that the fuses could be accessed from outside of the shielded area. There were also numerous incidences of the actuators themselves failing and having to be replaced. Replacement of the failed actuators with those rated for a continuousduty cycle greatly reduced the frequency of actuator failure.

OTE Control System The OTE control system was complicated and difficult to troubleshoot. The vendor who supplied the system was not located in the area and was sometime difficult to reach. A control system with better in-house expertise would have made troubleshooting, maintenance, and operations much easier.

No Individual Drain Valve on OTE Feed Tank: There was no individual drain valve on the OTE feed tank. The liquid in the feed tank had to be transferred to other tanks to empty the tank. This was timeconsuming.

OTE Heating/Cooling Lines : The heating and cooling lines on the OTE system were pumped through flexible hose. The hoses cracked and leaked and eventually had to be replaced. The heating and cooling lines should have been hard piped at the beginning of the project.

Double -Diaphragm Pump J01 : The Wilden D/D pump that pumped the supematant from the MVSTs into the CsR or OTE systems failed several times and had to be replaced. This pump had a high suction lift, which challenged the pump. A different pump configuration should be considered in future applications.

Drain Valves: The drain valves on the OTE system were $1 / 2$ to $3 / 4$ in. and were not full-bore valves. This made draining slow and eventually led to plugging. Larger full-bore valves should be used in future applications.

Venting to CsR Feed Tank During Backwashing : The CsR ion-exchange columns were vented to the CsR feed tank during backwashing operations. This lead to transfer of sorbent fines to the feed tank and eventually to other process lines. Backwashing operations should be vented to a separate tank or filter to prevent the fines from entering the feed tank.

Bottom Discharge from CsR Feed Tank: The discharge from the CsR tank to the pumps that fed the ion-exchange columns was taken from the bottom of the feed tank. Solids accumulated in the bottom of the tank and eventually caused plugging problems in downsteam piping. Future applications should utilize a side discharge, which would allow the solids to settle in the bottom of the tank and not get pumped throughout the system. Provisions should be made to allow the solids that settle in the bottom of the tank to be removed separately.

HIC Camera Failure: Cameras located on the fill head to the HIC were subjected to continuous radiation exposure. The cameras were not radiation hardened, and both the original camera and a replacement failed. Later operations utilized a camera that was pushed over the plexiglass plate to view the contents of the HIC only during sluicing operations; therefore, the camera was not in the radiation field most of the time. This camera remained operable for the duration of the project. 
HIC Level Detector: The sonar level detector supplied for the HIC failed early in the operation. This detector was replaced by a guided wave radar unit that also failed fairly quickly. These instruments were not radiation hardened and presumably failed because of the high radiation fields in which they were placed. Mass balances were. utilized to maintain inventories and levels in the HICs after the level instruments and cameras failed.

SLS Drain Lines: Process drain lines and drain lines from the SLS containment pans were piped together. This led to contamination of these pans when the system was drained too quickly. A check valve should have been installed to prevent the backup into the containment pans.

SLS Pressure Relief Valve Damage : A pressure relief valve was damaged during hydrostatic testing. The valve should have been isolated prior to testing.

Remote Transmitters : A level transmitter. on the SLS filtrate holding tank failed. The transmitter was. integrated with the sensor, making it necessary to enter a shielded confined space to troubleshoot the-unit. The replacement unit included a separate transmitter that was installed outside the shield wall. Future applications for all systems should utilize remote transmitters where possible.

Pump Amperage Overload: The filtrate discharge pump experienced an amperage overload in early processing of radioactive waste. The impeller on this pump had been replaced during installation, but the amperageoverload switch had not been reset for a higher load.

Discflo Pump: A Discflo pump was very effective for providing high-volume, controlled flow of slurry through the cross-flow filter system. This type of pump should be considered for other applications.

Double -Diaphragm Pumps : Redundant Warren Rupp D/D pumps with pulsation dampeners were used to provide pressurized feed to the cross-flow filter loop. Performance of these pumps was inconsistent during much of the operational period, possible due to high negative suction head. Alternative pumping systems should be considered for this application.

Single Coriolis Mass Flowmeter: The percent solids output from density measurements of a single Coriolis mass flowmeter was very sensitive to error in the value input for specific gravity of the solidsfree fluid and not very accurate below 1 wt \% solids. Continuous monitoring of the solids-free fluid was needed. ${ }^{11}$

Dual Coriolis Mass Flow System A second Coriolis meter was used to measure the density of the solids-free filtrate, which greatly improved the accuracy and precision of the solids-monitoring system Small differences were still noted between the monitor values and those from laboratory samples. It is expected that improved calibration with actual process fluids and improved density information for the undissolved solid particles would improve the accuracy of the monitor." It should be noted since the second Coriolis meter measures the density of the solids-free filtrate, dual Coriolis mass flow systems are limited to processes that have-solids-free streams.

OTE Shell Design: The design of the level control for the OTE shell made the OTE unsuitable for applications where solids are involved. Solids precipitated from the supernatant during concentration and accumulated in the standpipe containing the level float for the OTE shell, The solids could not be removed from the standpipe, which made control of the level in the shell and control of the OTE system in general very difficult. A level monitor-that measured the actual level within the OTE shell was designed, fabricated, and installed during the seventh WTP campaign. No operational problems were encountered with this new design for the remainder of the WTP operations (Campaigns 7-10); however, additional operational time would be required to fully evaluate the new design. 
OTE Design: The OTE system was complicated and difficult to control. The number of local instruments and remote valves also increased the time required for maintenance. Of the three WTP system, many more operational, control, and maintenance problems were associated with the OTE system than with the other two systems. A simpler evaporator system should be considered for future work with radioactive materials.

\section{ECONOMICS}

The schedule acceleration was better than anticipated in the ASTD proposals. The ASTD proposals covered a number of activities identified in the integrated waste management plan as necessary to retrieve and consolidate the RH-TRU sludges in the MVSTs. A schedule reduction of 8 years was estimated in the ASTD proposals for inactive tank remediation by using innovative technologies for retrieval, conditioning, and pretreatment. The actual GAAT retrieval project was completed 12 years ahead of schedule. ${ }^{12}$

The costs for implementing the Triad were very close to the original estimates. The ASTD proposals estimated that $\$ 10 \mathrm{M}$ would be required to implement the WTP, with $\$ 7.8 \mathrm{M}$ being provided by EM-50 and $\$ 2.2$ being provided by EM-30. To date, the actual costs are $\$ 8.4 \mathrm{M}$ for EM-50 and $\$ 1.9 \mathrm{M}$ for EM-30, for a total of $\$ 10.3 \mathrm{M}$. The EM-30 costs will increase when decontamination and disposal of WTP equipment is completed

The actual GAAT retrieval project was completed 12 years ahead of schedule at a cost savings of $\$ 135 M^{12} .^{12}$ By operating the Triad evaporator system in FY 1998, ORNL avoided the cost of a supematant grouting campaign, which could have cost $\$ 3 \mathrm{M}$ to $\$ 6 \mathrm{M}$. However, during the ASTD project, the baseline plans for treatment and disposal of the LLLW supematant changed from grouting to a stabilization process that is under development by Foster Wheeler. Until the Foster Wheeler process is finalized, the additional cost benefits of reduced volume and cesium content from the Triad operations cannot be quantified.

\section{SUMMARY}

The WTP is part of the integrated tank waste management plan at ORNL and involved the development, demonstration, and deployment of three treatment process for reducing the volume and radioactivity of the ORNL LLLW stored in the MVSTs. These processes were the OTE, the CsR system, and the SLS. The deployment of these three treatment units together as the WTP made it possible to (1) handle the large volumes of LLLW being generated from tank remediation, (2) handle the LLLW being generated from typical R\&D and reactor operations, and (3) assist in meeting the State of Tennessee's requirements that processing of TRU sludge be initiated by June 2002. Each process was demonstrated and deployed using co-funding from EM-30/50 and placed in existing facilities at ORNL. A total of 19 operational campaigns were completed during the period from April 1996 though April 2000. A total of $-321,000$ gal of LLLW was processed, $-122,000$ gal of tank storage volume was created by evaporation of the LLLW and treatment of the distillate at the PWTP, and $-8900 \mathrm{Ci}$ of ${ }^{137} \mathrm{Cs}$ was removed from the supematant and concentrated on 625 gal of inorganic sorbent. The sorbent, Ionsiv IE-911, manufactured by UOP LLC, was processed and packaged to meet the WAC for the NTS. A portion of the cesiumloaded sorbent was also shipped to the SRTC and unloaded into the hot cell facility for use in vitrification demonstrations. The SRTC developed a glass formulation for the Ionsiv IE-911 that could incorporate up 
to $65 \mathrm{wt} \%$ of the sorbent into the glass matrix without crystal formation. Ionsiv IE-911 is one of the alternatives being evaluated at both Savannah River and Hanford to treat their tank wastes.

All systems worked reliably during the demonstrations and deployments; however, toward the end of the WTP operations, substantial downtime resulted from maintenance. activities required to keep the systems operable. The OTE was often difficult to operate due to the buildup of solids in the evaporator shell, which fouled the level instrument located in a standpipe connected to the shell. A modification to the OTE system that allowed the level in the evaporator shell to be monitored within the shell worked well and greatly decreased operational problems in the latter runs.

The primary problems with operation in the CsR system were associated with getting sorbent in to the process lines. The CsR ion-exchange columns were vented to the CsR feed tank during backwashing operations. This allowed Ionsiv IE-91 1 fines to settle in the tank and be pumped along with the LLLW through the CsR and OTE systems. The sorbent collected in valves, bends, fittings, and tanks, greatly increasing the radiation field within the processing facility. The sorbent also collected in the Moyno pump cavities and caused failure of both CsR feed pumps due to its abrasiveness. In future applications with Ionsiv IE-9 11, the system design should limit the possibility of getting sorbent into the process lines.

The SLS was the last of the WTP systems to come on-line. From an equipment and controls standpoint, the modular system (pumps, valves, sensors, monitors, controls, shielding, and containment) functioned well during the operational campaigns. In general, much less maintenance was required on the SLS than on the other two systems. Part of this can probably be attributed to the fact that the SLS was involved in only 4 of the 19 operational campaigns; therefore, most of the components on the system were relatively new. The quality of filtrate consistently met the requirements for feed to the downstream ion-exchange and evaporator systems. The $50-\mathrm{ft}^{2}$ cross-flow filter was designed to provide filtrate at a rate of 1 to $5 \mathrm{gal} / \mathrm{min}$ (flux range of 0.012 to $0.1 \mathrm{gal} \mathrm{min}^{-1} \mathrm{ft}^{-2}$ ). During the first two campaigns in which the SLS was used, the actual filtrate production ranged between 0.6 and $8.0 \mathrm{gal} / \mathrm{min}$ (flux range of 0.02 to $0.16 \mathrm{gal} \mathrm{min}^{-1} \mathrm{ft}^{-2}$ ). During the third run, the SLS typically produced filtrate at the rate of 1 to $5 \mathrm{gal} / \mathrm{min}$ (flux range of 0.012 to $0.1 \mathrm{gal} \mathrm{min}^{-1} \mathrm{ft}^{-2}$ ), with most of the run at the higher production rate. In the final campaign with the SLS system, the filtrate production rate typically $\mathrm{ran} 1-2 \mathrm{gal} / \mathrm{min}$.

\section{REFERENCES}

1. K. M. Billingsley, C. Mims, and S. M. Robinson, "Integrated Tank Waste Management Plan at Oak Ridge National Laboratory," Proceedings of Spectrum '98, vol. 2, p. 1376, American Nuclear Society, LaGrange Park, Illinois, 1998.

2. J. M. Keller and J. M. Giaquinto, Characterization of the ORNL MVST Waste Tanb After Transfer of Sludge from BVEST, GAAT, and OHF Tanks, ORNL/TM-2000/323, Oak Ridge National Laboratory, Oak Ridge, Tennessee, January 2001.

3. V. L. Fowler and J. J. Perona, Evaporation Studies on Oak Ridge National Laboratory Liquid Low Level Waste, ORNL/TM-12243, Oak Ridge National Laboratory, Oak Ridge, Tennessee, March 1993.

4 - A. J. Lucero et al., Out-of-TankEvaporator Demonstration: Final Report, ORNL/TM-13501, Oak Ridge National Laboratory, Oak Ridge, Tennessee, February 1998. 
5. J. F. Walker and E. L. Youngblood, Design Alternatives Reportfor the Cesium Removal Demonstration, ORNL/TM-12939, Oak Ridge National Laboratory, Oak Ridge, Tennessee, September 1995.

6. J. F. Walker et al., Cesium Removal Demonstration Utilizing Crystalline Silicotitanate Sorbent for Processing Melton Valley Storage Tank Supernate: Final Report, Oak Ridge National Laboratory, Oak Ridge, Tennessee, March 1998.

7. J. R. Harbour and M. K. Andrews, Compliance with the Nevada Test Site's Waste Acceptance Criteria for Vitrified Cesium-Loaded Crystalline Silicotitanate (CST), WSRC-MS-97-00050, Westinghouse Savannah River Company, Savannah River Technology Center, Aiken, South Carolina, June 1997.

8. T. E. Kent, J. H. Wilson, and J. R. Farmer, Development and Deployment of a Full-Scale CrossFlow Filtration System for Treatment of Liquid Low-Level Waste at Oak Ridge National Laboratory, ORNL/TM-2000/27, Oak Ridge National Laboratory, Oak Ridge, Tennessee, 2000.

9. J. F. Walker, Jr., and T. E. Kent, Wastewater Triad Project: Solid-Liquid Separator FY 2000 Deployment, ORNL/TM-2000/186, Oak Ridge National Laboratory, Oak Ridge, Tennessee, November 2000.

10. Sampling and Analysis Plan for Loaded Radioactive Sorbent Generated from Melton Valley Storage Tank Liquid Low-Level Waste, Revision 1, March 25, 1999.

11. T. D. Hylton, An Evaluation of a Dual Coriolis Meter System for In-Line Monitoring of Suspended Solids Concentrations in Radioactive Slurries, ORNL/TM-2000/184, Oak Ridge National Laboratory, Oak Ridge, Tennessee, September 2000.

12. B. E. Lewis et al., Tank Waste Retrieval Performance and Lessons Learnedfor the Gunite and Associated Tanks Remediation at the Oak Ridge National Laboratory, ORNL/TM-2001/142, Oak Ridge National Laboratory, Oak Ridge, Tennessee, September 2001. 
APPENDIX A

INDEXES USED IN SELF-ASSESSMENT AND EVALUATION 
WT PROJECT EVIDENCE FILE INDEX

\section{A. Personnel Availability and Training}

\begin{tabular}{|c|c|c|c|c|c|}
\hline$\#$ & Criteria & Evidence (Document Title) & Docume nt No. & \multirow{2}{*}{$\begin{array}{l}\text { MT* } \\
\text { AvG }\end{array}$} & $\underset{* *}{\text { ERB }}$ \\
\hline$A .1$ & $\begin{array}{l}\text { A well defined and documented } \\
\text { operations plan exists that defines } \\
\text { the types of jobs needed for } \\
\text { project completion, how many of } \\
\text { each function are required, and } \\
\text { who will be serving in each } \\
\text { function. }\end{array}$ & $\begin{array}{l}\text { Training Matrices and Job Task Analysis } \\
\text { for operating procedures. }\end{array}$ & $\begin{array}{l}\text { ORNL Triad Project Training } \\
\text { Program Manual, Liquid and } \\
\text { Gaseous Waste Operations Project, } \\
\text { March } 1999 \\
\text { (separate } 3 \text { ring binder) }\end{array}$ & & JK \\
\hline A.2 & $\begin{array}{l}\text { The minimum staff that must be } \\
\text { present and/or on call for safe } \\
\text { operations has been well defined; } \\
\text { staffing requirements must } \\
\text { consider both project staff and } \\
\text { matrix support staff. }\end{array}$ & $\begin{array}{l}\text { a. Wastewater Triad MOU. } \\
\text { b. Problem Safety Summary (PSS) } \\
\text { provides a listing of CTD support } \\
\text { staff (phone number, address). } \\
\text { c. LGWOP web page provides a listing } \\
\text { of LGWOP contacts (name, phone, } \\
\text { pager). }\end{array}$ & $\begin{array}{l}\text { a. MOU, January 22, } 1999 . \\
\text { b. } \\
\text { PSS WT Operations, E.D.S. 99- } \\
\text { 02-23, 4/19/99, Rev 2. } \\
\text { c. LGWOP web site address: } \\
\text { http://gwo.ct.ornl.gov/overvie } \\
\text { w/Liqdt.htm }\end{array}$ & TK & $\mathrm{cs}$ \\
\hline A.3 & $\begin{array}{l}\text { Training requirements have been } \\
\text { defined for each operation and } \\
\text { safety related job function. These } \\
\text { training requirements must be } \\
\text { inclusive of all ES\&H related } \\
\text { training (Hazwoper, HazCom, } \\
\text { RadWorker II, RCRA generator, } \\
\text { etc.) and any job specific training } \\
\text { required to conduct the assigned } \\
\text { functions (Operating procedures, } \\
\text { Safety Plans, QA Plans, NCSA, } \\
\text { etc.). }\end{array}$ & $\begin{array}{l}\text { Required Training Matrix for CTD staff } \\
\text { personnel \& operators. } \\
\text { Required Training Matrix for C.B. Scott, } \\
\text { J.J. Maddox, D. J. Peterson \& LGWOP } \\
\text { operators. } \\
\text { (GET, LOTO, Shift Emergency Squad } \\
\text { Training, LLLW System \& LGWO } \\
\text { Operations, and EDS Procedural } \\
\text { Training) }\end{array}$ & $\begin{array}{l}\text { ORNL Triad Project Training } \\
\text { Program Manual (separate } 3 \text { ring } \\
\text { binder) }\end{array}$ & $\mathrm{AvG}$ & $\mathrm{JK}$ \\
\hline A. 4 & $\begin{array}{l}\text { Review of training program } \\
\text { indicated it is geared toward } \\
\text { ensuring and verifying that } \\
\text { personnel actually learn } \\
\text { something and is not a paperwork } \\
\text { exercise just for creating a file. }\end{array}$ & $\begin{array}{l}\text { See previous RAs of WMOD's Training } \\
\text { Program (PUEs/PDC) - Management } \\
\text { Plan for the WMOD - Section 7, The } \\
\text { Training Program. (BJC has blue sheeted } \\
\text { this document.) }\end{array}$ & $\begin{array}{l}\text { MVST-CIP RA (MVST.CR02) } \\
\text { WMOD-AD-119/R3, Section } 7\end{array}$ & $\mathrm{AvG}$ & JK \\
\hline
\end{tabular}

* MT - Management Team Presenter

** ERB - Independent/Internal ERB Reviewer 

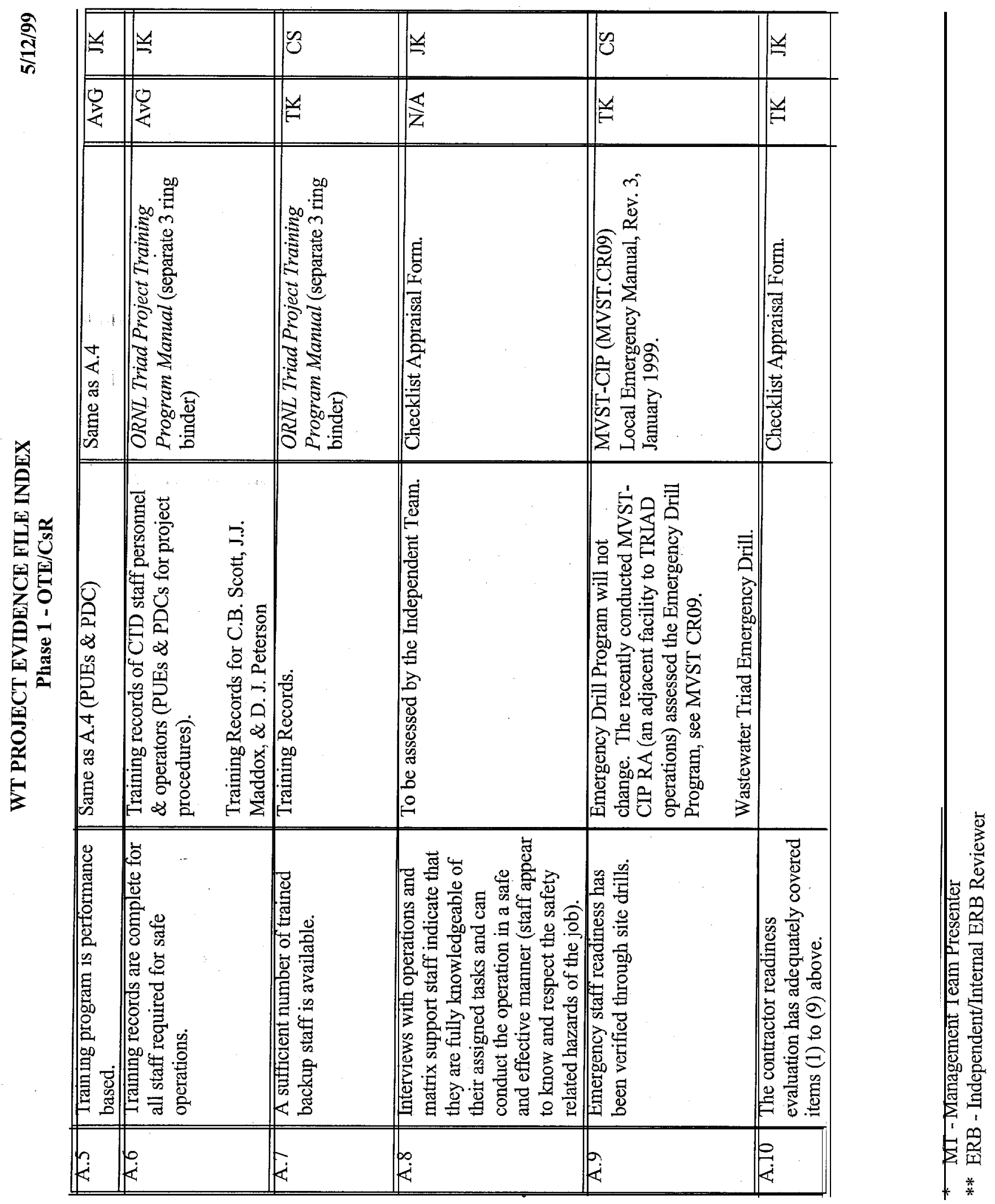
WTT PROJECT EVIDENCE FILE INDEX

Phase 1 - OTE/CsR

B. Procedures and Management Controls

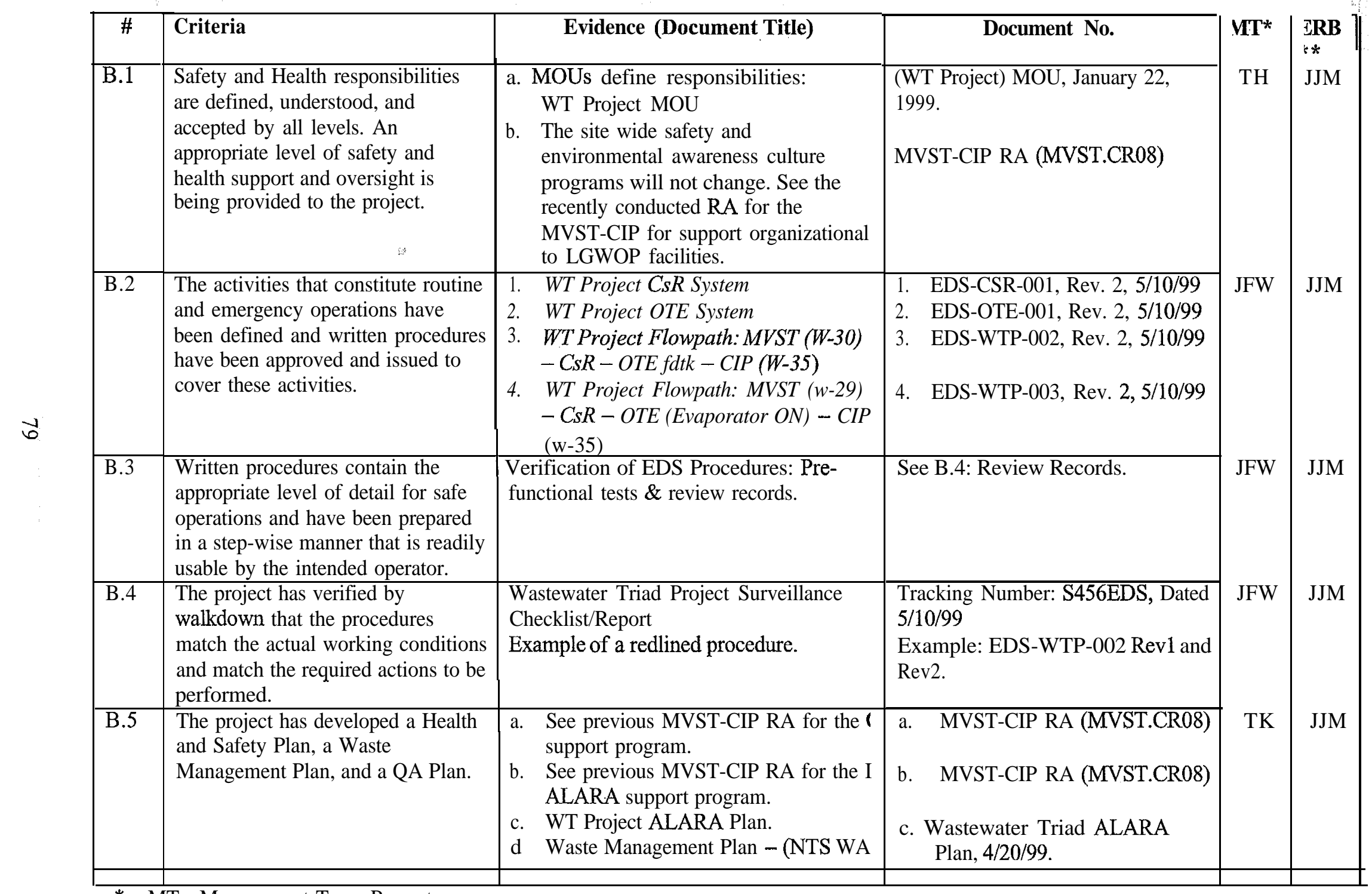

* MT - Management Team Presenter

** ERB - Independent/Internal ERB Reviewer 


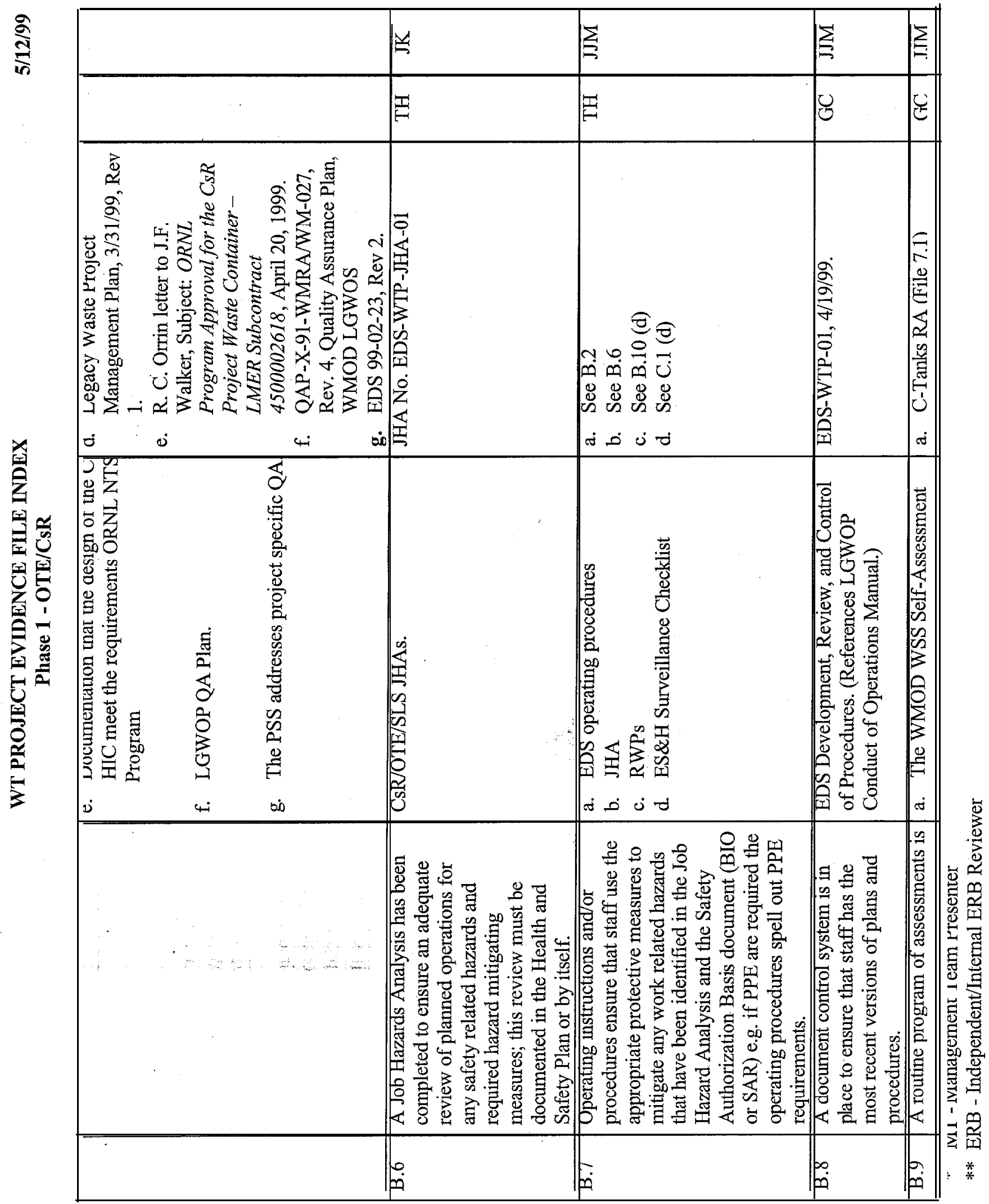


WT PROJECT EVIDENCE FILE INDEX

Phase 1 - OTE/CsR

(1/2/99

\begin{tabular}{|c|c|c|c|c|c|c|}
\hline & $\begin{array}{l}\text { planned including surveillance and } \\
\text { inspections of routine operations; } \\
\text { these assessments are geared } \\
\text { towards verifying that the job is } \\
\text { being conducted per procedures and } \\
\text { that all required safety controls are } \\
\text { being met. }\end{array}$ & b. & $\begin{array}{l}\text { Program has been reviewed } \\
\text { previously during the C-Tanks RA. } \\
\text { Schedule of ES\&H surveillance for } \\
\text { EDS. }\end{array}$ & $\begin{array}{l}\text { b. WT Project - } 1999 \text { Assessment } \\
\text { Schedule - Rev } 0 .\end{array}$ & $\mathrm{AvC}$ & \\
\hline B. 10 & $\begin{array}{l}\text { All required operating permits and } \\
\text { approvals have been issued. } \\
\text { Examples include: Radiation Work } \\
\text { Permits (RWPs), Nuclear Criticality } \\
\text { Safety Approvals (NCSAs), Safety } \\
\text { Work Permits, Drilling Permits, } \\
\text { Regulatory Approvals, Lift tlans, } \\
\text { Labor Standards Determinations, } \\
\text { Environmental Permits (Clean Air } \\
\text { Act, NESHAPS, NPDES, etc.), } \\
\text { NEPA and NEPA related statutes, } \\
\text { Hot 'Work Permits. }\end{array}$ & a. & $\begin{array}{l}\text { OTE RSA Notebook, November } \\
\text { 1997: NCSA review, Environmental } \\
\text { Permits, and NEPA CX. } \\
\text { NCSA coverage - operating } \\
\text { procedures review and Minor } \\
\text { Modification B } \\
\text { RWP(s) - to be provided by LMER } \\
\text { BJC Hoisting and Rigging Program, } \\
\text { critical lift plan for CsR HICs. }\end{array}$ & $\begin{array}{ll}\text { a. } & \text { CsR (RSA section): NCSA } \\
& \text { review (2.6); Environmental } \\
& \text { Permits (2.11, 2.12, 2.13). } \\
\text { b. } & \text { Letter to D.G. Cope \& J.F. } \\
& \text { Walker, from D.C. Parzyck, } \\
& \text { 1/19/99; PRS \& NEPA Status: } \\
& \text { FY 1998 WMO Expense } \\
& \text { Project, CsR Operations } \\
& \text { (2713X). } \\
\text { c. } & \text { OTE (RSA section): NCSA } \\
& \text { review (2.6); Environmental } \\
& \text { Permits (2.12, 2.13, 2.14); } \\
& \text { NEPA CX (2.15). } \\
\text { d } & \text { E-Mails from Don Mueller to } \\
& \text { Chris Scott, dated 5/3/99 } \\
\text { e. } & \text { ORNL RWP Number HAZWL- } \\
& 4170,3 / 22 / 19999, \text { Building } \\
& 7877 \text { \& 7830 } \\
\text { f. } & \text { SH-A-2008, Hoisting and } \\
& \text { Rigging, form completed } \\
& \text { 4/5/99. } \\
\end{array}$ & $\begin{array}{l}\mathrm{TH} \\
\mathrm{TK}\end{array}$ & CS \\
\hline
\end{tabular}

\footnotetext{
* MT - Management Team Presenter

** ERB - Independent/Internal ERB Reviewer
} 
WT PROJECT EVIDENCE FILE INDEX

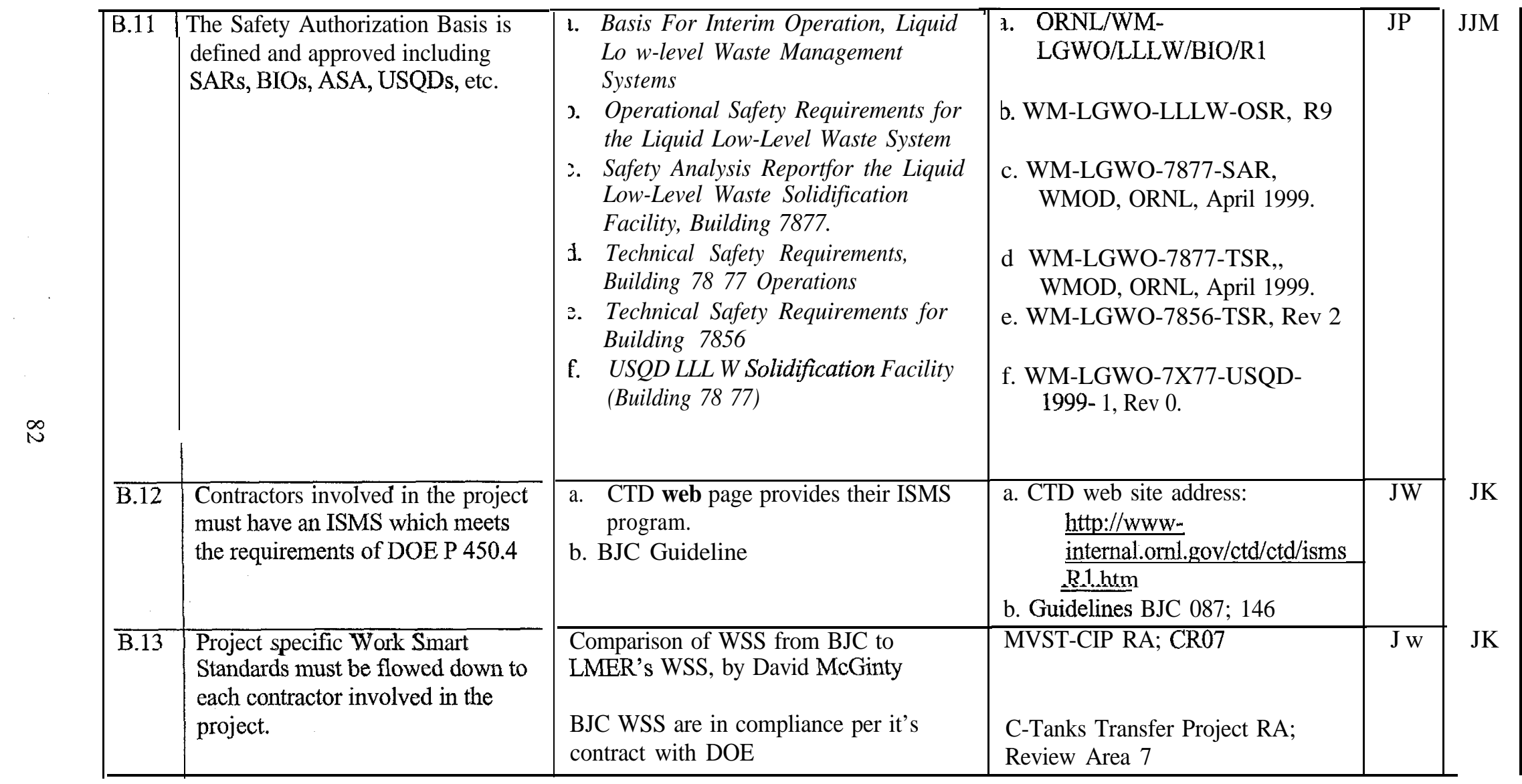

\footnotetext{
* $\quad$ MT - Management Team Presenter

** ERB - Independent/Internal ERB Reviewer
} 
ลิ
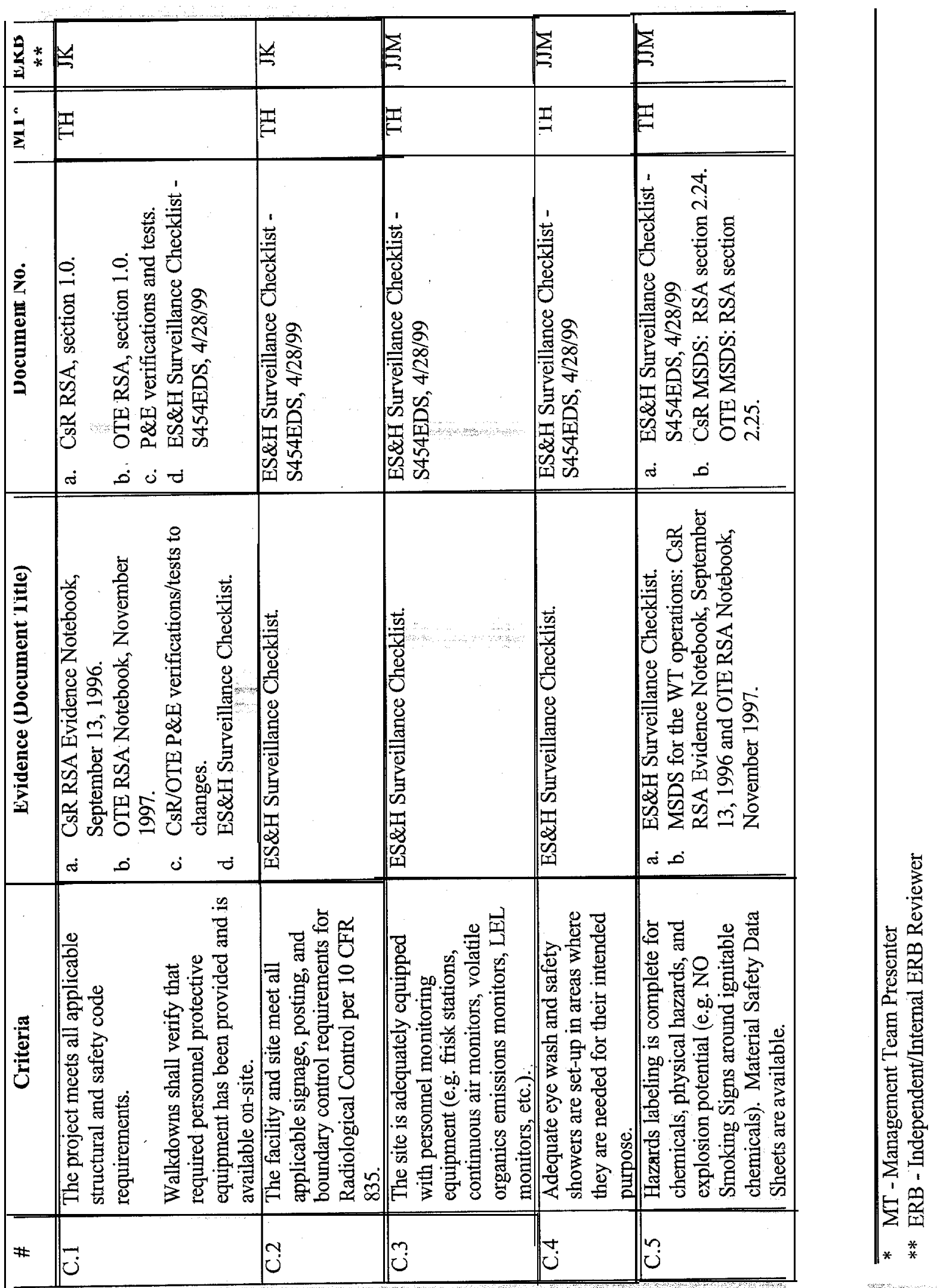
WT PROJECT EVIDENCE FILE INDEX

\section{Phase 1 - OTE/CsR}

\begin{tabular}{|c|c|c|c|c|c|}
\hline 2.6 & $\begin{array}{l}\text { Key process piping, equipment } \\
\text { components, and valves are labeled } \\
\text { to provide easy location and } \\
\text { adequate implementation of } \\
\text { operating procedures. }\end{array}$ & $\begin{array}{l}\text { Verified during procedure validation. } \\
\text { Facility walk down and documented on } \\
\text { the ES\&H Surveillance Checklist. }\end{array}$ & $\begin{array}{l}\text { See B.4 evidence. } \\
\text { ES\&H Surveillance Checklist - } \\
\text { S454EDS, } 4 / 28 / 99\end{array}$ & $\mathrm{TH}$ & JJM \\
\hline 3.7 & $\begin{array}{l}\text { All process and safety related } \\
\text { instrumentation, monitoring } \\
\text { equipment, and gages are calibrated } \\
\text { with a certified and traceable source } \\
\text { (e.g. NIST), and building/site } \\
\text { emergency contacts have been } \\
\text { contacted and coordinated with } \\
\text { concerning the project and } \\
\text { Site/building Lock Out/Tag Out } \\
\text { Procedures. }\end{array}$ & $\begin{array}{ll}\text { a. } & \text { See C.8 below for CsR and OTE } \\
& \text { Systems. } \\
\text { b. } & \text { List Emergency Preparedness } \\
\text { equipment unique for the operating } \\
\text { systems. }\end{array}$ & $\begin{array}{l}\text { a. Recall Program (C.8 below). } \\
\text { b. Correspondence with site } \\
\text { contacts: } \\
\text { E-Mail from Bill Eldridge, } \\
\text { LSS, } 3 / 31 / 99 \text {. } \\
\text { E-Mail from David Baity, Fire } \\
\text { Department Manager, 4/15/99. }\end{array}$ & JFW & JJM \\
\hline 3.8 & $\begin{array}{l}\text { A routine calibration recall and } \\
\text { preventative maintenance program } \\
\text { is established for equipment and } \\
\text { instrumentation, and a formal } \\
\text { mechanism is in place to ensure that } \\
\text { required frequencies for calibration } \\
\text { and preventative maintenance are } \\
\text { not exceeded (includes HEPA } \\
\text { filters, radiological monitors, } \\
\text { valves, gages, flow meters, etc.). }\end{array}$ & $\begin{array}{l}\text { a. } \text { CsR RSA Evidence Notebook, } \\
\text { September 13, } 1996 . \\
\text { b. OTE RSA Notebook, November } \\
\text { 1997. } \\
\\
\text { c. CsR/OTE: P\&E, I\&C, and QE\&I - } \\
\text { equipment entered into Recall } \\
\text { Programs. } \\
\text { d Critical Spare Parts List provided. }\end{array}$ & $\begin{array}{ll}\text { a. } & \text { CsR RSA initial Recall } \\
& \text { Programs (sections 1.1.5, 1.1.6, } \\
& \text { 1.2.3, 1.2.4, 3.6); vendor } \\
& \text { material (section 2.21). } \\
\text { b. } & \text { OTE RSA initial Recall } \\
& \text { Programs (sections 1.1.5, 1.1.6, } \\
& \text { 1.2.3, 1.2.4, 2.8); vendor } \\
& \text { material (section 2.21). } \\
\text { c. I\&C and P\&E Recall Program } & \text { Iheets for CsR \& OTE } \\
\text { equipment. } \\
\text { d CsR spare parts ordered Excel } \\
\text { spreadsheet, 11/4/98. } \\
\text { OTE Spare Parts List print out } \\
\text { sheet. }\end{array}$ & JFW & JJM \\
\hline
\end{tabular}

\footnotetext{
* MT - Management Team Presenter

** ERB - Independent/Internal ERB Reviewer
} 
WT PROJECT EVIDENCE FILE INDEX

\section{Phase 1 - OTE/CsR}

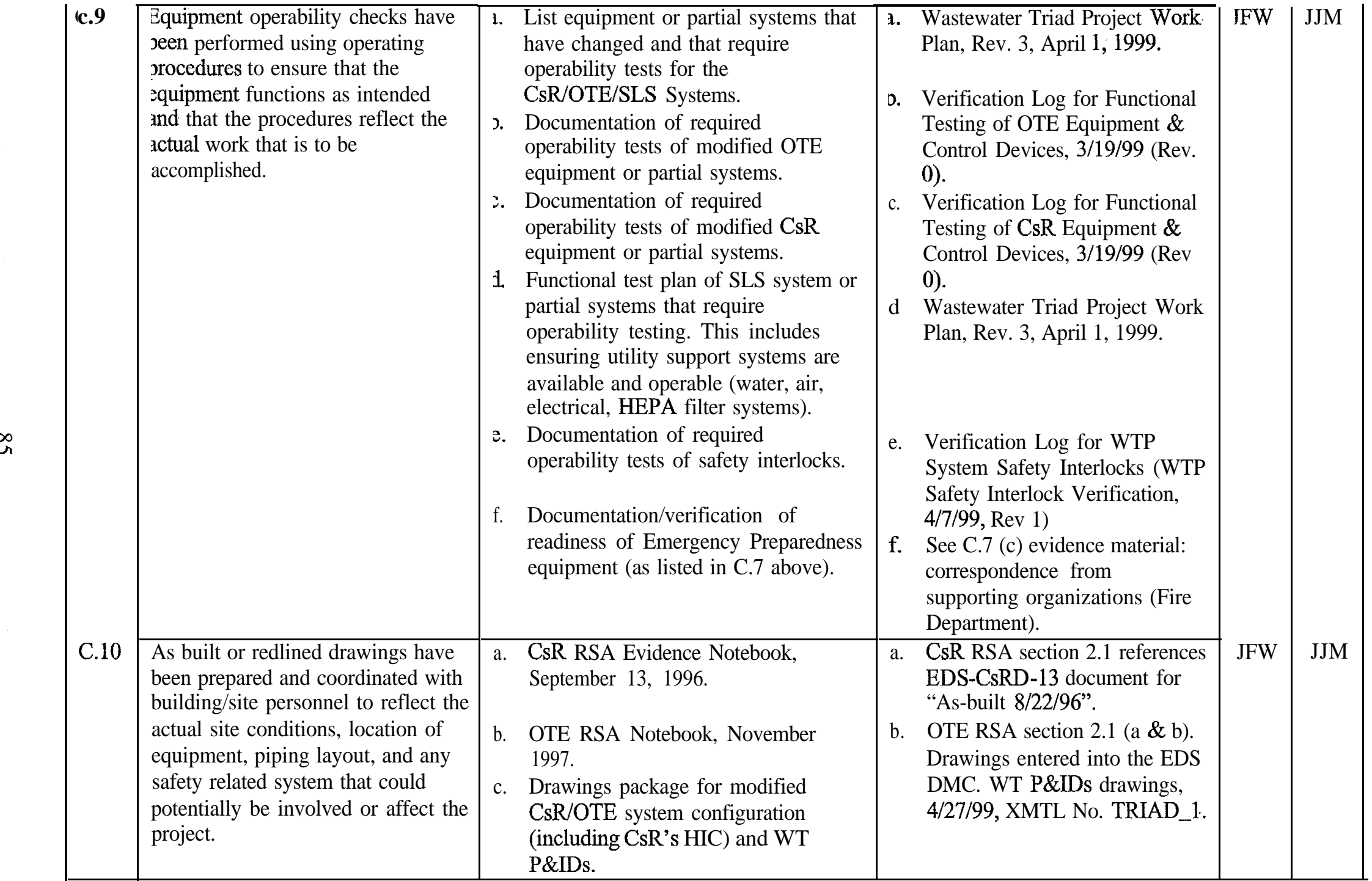

*. $\quad$ MT - Management Team Presenter
** ERB - Independent/Internal ERB Reviewer 
WT PROJECT EVIDENCE FILE INDEX

A. Personnel Availability and Training

\begin{tabular}{|c|c|c|c|c|c|}
\hline \# & Criteria & Evidence (Document Title) & Document No. & MT* & $\begin{array}{l}\text { ERB } \\
* *\end{array}$ \\
\hline A. 1 & $\begin{array}{l}\text { A well defined and documented } \\
\text { operations plan exists that defines } \\
\text { the types of jobs needed for project } \\
\text { completion, how many of each } \\
\text { function are required, and who will } \\
\text { be serving in each function. }\end{array}$ & 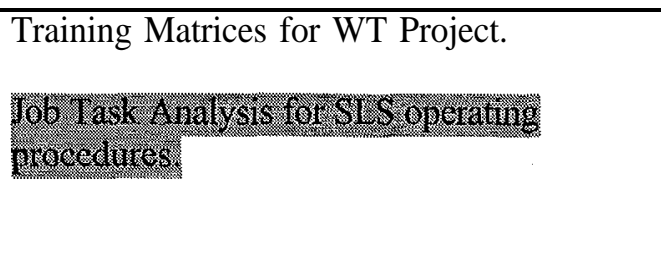 & $\begin{array}{l}\text { ORNL Triad Project Training } \\
\text { Program Manual, Liquid and } \\
\text { Gaseous Waste Operations Project, } \\
\text { March } 1999 \\
\text { (separate } 3 \text { ring binder) }\end{array}$ & AvG & JK \\
\hline A.2 & $\begin{array}{l}\text { The minimum staff that must be } \\
\text { present and/or on call for safe } \\
\text { operations has been well defined; } \\
\text { staffing requirements must consider } \\
\text { both project staff and matrix } \\
\text { support staff. }\end{array}$ & $\begin{array}{l}\text { d Wastewater Triad MOU. } \\
\text { e. Problem Safety Summary (PSS) } \\
\text { provides a listing of CTD support staff } \\
\text { (phone number, address). } \\
\text { f. LGWOP web page provides a listing of } \\
\text { LGWOP contacts (name, phone, pager). }\end{array}$ & $\begin{array}{ll}\text { d. } & \text { MOU, January 22, } 1999 . \\
\text { e. } & \text { PSS WT Operations, E.D.S. 99- } \\
& \text { 02-23, 4/19/99, Rev2. } \\
& \\
\text { f. } & \text { LGWOP web site address: } \\
& \text { http://gwo.ct.ornl.gov/overvie } \\
& \text { w/Liqdt.htm } \\
\end{array}$ & TK & $\mathrm{CS}$ \\
\hline A.3 & $\begin{array}{l}\text { Training requirements have been } \\
\text { defined for each operation and } \\
\text { safety related job function. These } \\
\text { training requirements must be } \\
\text { inclusive of all ES\&H related } \\
\text { training (Hazwoper, HazCom, } \\
\text { RadWorker II, RCRA generator, } \\
\text { etc.) and any job specific training } \\
\text { required to conduct the assigned } \\
\text { functions (Operating procedures, } \\
\text { Safety Plans, QA Plans, NCSA, } \\
\text { etc.). }\end{array}$ & $\begin{array}{l}\text { Required Training Matrix for CTD staff } \\
\text { personnel \& operators. } \\
\text { Required Training Matrix for C.B. Scott, } \\
\text { J.J. Maddox, D. J. Peterson \& LGWOP } \\
\text { operators. } \\
\text { (GET, LOTO, Shift Emergency Squad } \\
\text { Training, LLLW System \& LGWO } \\
\text { Operations, and EDS Procedural Training) }\end{array}$ & $\begin{array}{l}\text { ORNL Triad Project Training } \\
\text { Program Manual (separate } 3 \text { ring } \\
\text { binder) }\end{array}$ & $\mathrm{AvG}$ & JK \\
\hline
\end{tabular}

* MT - Management Team Presenter

** ERB - Independent/Internal ERB Reviewer 
WT PROJECT EVIDENCE FILE INDEX

$5 / 17 / 99$

Phase 2 - SLS

\begin{tabular}{|c|c|c|c|c|c|}
\hline A.4 & $\begin{array}{l}\text { Review of training program } \\
\text { indicated it is geared toward } \\
\text { ensuring and verifying that } \\
\text { personnel actually learn something } \\
\text { and is not a paperwork exercise just } \\
\text { for creating a tile. }\end{array}$ & $\begin{array}{l}\text { See previous RAs of WMOD's Training } \\
\text { Program (PUEs/PDC) - Management Plan } \\
\text { for the WMOD - Section 7, The Training } \\
\text { Program. (BJC has blue sheeted this } \\
\text { document.) }\end{array}$ & $\begin{array}{l}\text { MVST-CIP RA (MVST.CR02) } \\
\text { WMOD-AD- 119/R3, Section } 7\end{array}$ & $\mathrm{AvG}$ & JK \\
\hline A.5 & $\begin{array}{l}\text { Training program is performance } \\
\text { based. }\end{array}$ & Same as A.4 (PUEs \& PDC) & $\overline{\text { Same }}$ as A.4 & \multirow{2}{*}{$\begin{array}{l}A v G \\
A v G\end{array}$} & \multirow{2}{*}{$\begin{array}{l}\mathrm{JK} \\
\mathrm{JK}\end{array}$} \\
\hline A.6 & $\begin{array}{l}\text { Training records are complete for } \\
\text { all staff required for safe operations. }\end{array}$ & 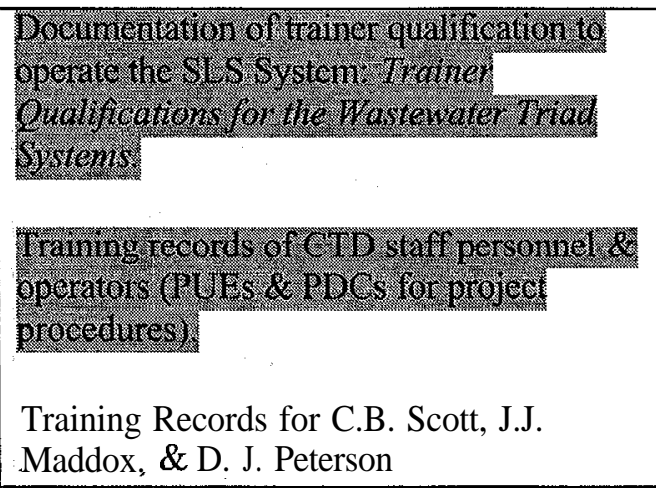 & $\begin{array}{l}\text { ORNL Triad Project Training } \\
\text { Program Manual (separate } 3 \text { ring } \\
\text { binder) }\end{array}$ & & \\
\hline A.7 & $\begin{array}{l}\text { A sufficient number of trained } \\
\text { backup staff is available. }\end{array}$ & Training Records. & $\begin{array}{l}\text { ORNL Triad Project Training } \\
\text { Program Manual (separate } 3 \text { ring } \\
\text { binder) }\end{array}$ & \multirow{2}{*}{$\begin{array}{l}\text { TK } \\
\text { N/A }\end{array}$} & \multirow{2}{*}{$\begin{array}{l}\mathrm{cs} \\
\mathrm{JK}\end{array}$} \\
\hline A.8 & $\begin{array}{l}\text { Interviews with operations and } \\
\text { matrix support staff indicate that } \\
\text { they are fully knowledgeable of } \\
\text { their assigned tasks and can conduct } \\
\text { the operation in a safe and effective } \\
\text { manner (staff appear to know and } \\
\text { respect the safety related hazards of } \\
\text { the job). }\end{array}$ & To be aksessed by the Independedt Team & Checklist A proisal Form & & \\
\hline
\end{tabular}

* MT - Management Team Presenter

** ERB - Independent/Internal ERB Reviewer 


\begin{tabular}{|l|l|l|l|l|}
\hline A.9 & $\begin{array}{l}\text { Emergency staff readiness has been } \\
\text { verified through site drills. }\end{array}$ & $\begin{array}{l}\text { Emergency Drill Program will not change. } \\
\text { The recently conducted MVST-CIP RA (an } \\
\text { adjacent facility to TRIAD operations) } \\
\text { assessed the Emergency Drill Program, see } \\
\text { MVST CR09. }\end{array}$ & $\begin{array}{l}\text { MVST-CIP (MVST.CR09) } \\
\text { Local Emergency Manual, Rev. 3, } \\
\text { January 1999. }\end{array}$ & TK \\
Wastewater Triad Emergency Drill. & Module \# 10024, 5/12/99. & CS \\
\hline A.10 & $\begin{array}{l}\text { The contractor readiness evaluation } \\
\text { has adequately covered items (1) to } \\
\text { (9) above. }\end{array}$ & & Checklist Appraisal Form. & TK \\
\hline
\end{tabular}

B. Procedures and Management Controls

\begin{tabular}{|c|c|c|c|c|c|}
\hline \# & Criteria & Evidence (Document Title) & Document No. & MT*- & $\overline{\text { ERB }}$ \\
\hline B.1 & $\begin{array}{l}\text { Safety and Health responsibilities } \\
\text { are defined, understood, and } \\
\text { accepted by all levels. An } \\
\text { appropriate level of safety and } \\
\text { health support and oversight is } \\
\text { being provided to the project. }\end{array}$ & $\begin{array}{ll}\text { c. } & \text { MOUs define responsibilities: } \\
\text { WT Project MOU } \\
\text { d } \\
\text { The site wide safety and environmental } \\
\text { awareness culture programs will not } \\
\text { change. Seethe recently conducted RA } \\
\text { for the MVST-CIP for support } \\
\text { organizational to LGWOP facilities. }\end{array}$ & $\begin{array}{l}\text { (WT Project) MOU, January 22, } \\
1999 . \\
\text { MVST-CIP RA (MVST.CR08) }\end{array}$ & $\mathrm{TH}^{-}$ & $\overline{J J M}$ \\
\hline B. 2 & $\begin{array}{l}\text { The activities that constitute routine } \\
\text { and emergency operations have } \\
\text { been defined and written procedures } \\
\text { have been approved and issued to } \\
\text { cover these activities. }\end{array}$ & 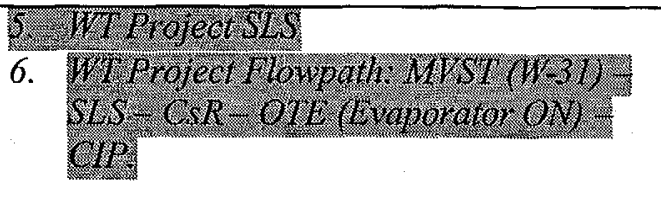 & 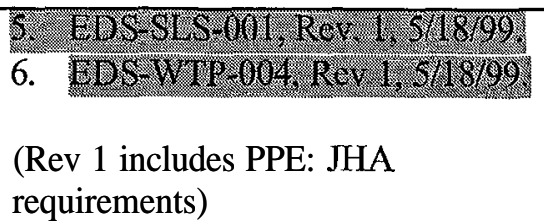 & ${ }^{-} \mathrm{JWW}^{-}$ & $\overline{\mathrm{JJM}}$ \\
\hline B. 3 & $\begin{array}{l}\text { Written procedures contain the } \\
\text { appropriate level of detail for safe } \\
\text { operations and have been prepared } \\
\text { in a step-wise manner that is readily } \\
\text { usable by the intended operator. }\end{array}$ & 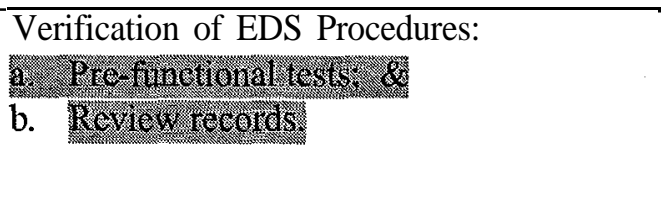 & 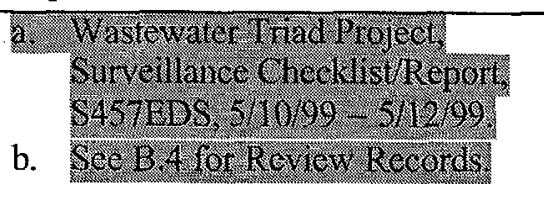 & $\mathrm{JFW}^{-}$ & $\overline{J J M}$ \\
\hline
\end{tabular}

* MT - Management Team Presenter

** ERB - Independent/Internal ERB Reviewer 
WT PROJECT EVIDENCE FILE INDEX

Phase 2 - SLS

\begin{tabular}{|c|c|c|c|c|c|}
\hline B. 4 & $\begin{array}{l}\text { The project has verified by } \\
\text { walkdown that the procedures } \\
\text { match the actual working conditions } \\
\text { and match the required actions to be } \\
\text { performed. }\end{array}$ & $\begin{array}{l}\text { Example of a marked-up/review comments } \\
\text { to the drafted procedures. }\end{array}$ & 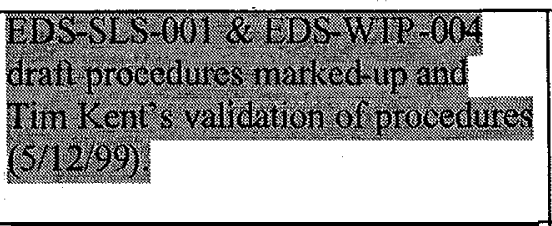 & JFW & JJM 7 \\
\hline B.5 & $\begin{array}{l}\text { The project has developed a Health } \\
\text { and Safety Plan, a Waste } \\
\text { Management Plan, and a QA Plan. }\end{array}$ & $\begin{array}{ll}\text { h. } & \begin{array}{l}\text { Site Specific Health \& Safety Plan Matrix } \\
\text { Implementing Documents/References }\end{array} \\
\text { i. } & \begin{array}{l}\text { See previous MVST-CIP RA for the OS!! } \\
\text { support program. } \\
\text { j. }\end{array} \\
\text { See previous MVST-CIP RA for the RPI } \\
\text { ALARA support program. } \\
\text { k } & \text { WT Project ALARA Plan. } \\
\text { l. } & \text { Waste Management Plan } \\
\text { m. } & \text { LGWOP QA Plan. } \\
\text { n. } & \text { The PSS addresses project specific QA. }\end{array}$ & \begin{tabular}{ll|} 
h. & Matrix title (no document \\
& number): Required Sections of \\
& Health and Safety Plan from \\
& DOE Health and Safety Plan \\
& Guidelines \\
i. & MVST-CIP RA (MVST.CR08) \\
j. & MVST-CIP RA (MVST.CR08) \\
k & Wastewater Triad ALARA \\
& Plan, 4/20/99. \\
1. & Legacy Waste Project \\
& Management Plan, 3/31/99, \\
& Rev 1. \\
m. & MVST-CIP RA (MVST.CR08) \\
n. & EDS 99-02-23, Rev 2. \\
\end{tabular} & TK & $\mathrm{JJM}$ \\
\hline B.6 & $\begin{array}{l}\text { A Job Hazards Analysis has been } \\
\text { completed to ensure an adequate } \\
\text { review of planned operations for } \\
\text { any safety related hazards and } \\
\text { required hazard mitigating } \\
\text { measures; this review must be } \\
\text { documented in the Health and } \\
\text { Safety Plan or by itself. }\end{array}$ & $\begin{array}{l}\text { a. CsR/OTE/SLS Systems JHA. } \\
\text { b. FROTELSTS JHA for Maintenaned } \\
\text { ard Calibration Activitios }\end{array}$ & $\begin{array}{l}\text { a. JHA No. EDS-WTP-JHA-01, } \\
\text { R1,5/21/99. } \\
\text { b. EDS-WIIPIHA } 02 \text { 520199. }\end{array}$ & $\mathrm{TH}^{-}$ & $\mathrm{JK}$ \\
\hline B.7 & $\begin{array}{l}\text { Operating instructions and/or } \\
\text { procedures ensure that staff use the } \\
\text { appropriate protective measures to } \\
\text { mitigate any work related hazards } \\
\text { that have been identified in the Job } \\
\text { Hazard Analysis and the Safety }\end{array}$ & $\begin{array}{l}\text { e. EDS operating procedures } \\
\text { f. JHA } \\
\text { g. RWPs } \\
\text { h. ES\&H Surveillance Checklist }\end{array}$ & $\begin{array}{l}\text { e. See B.2 } \\
\text { f. See B.6 } \\
\text { g. See B. } 10(d) \\
\text { h. See C.1 (d) }\end{array}$ & $\mathrm{TH}^{-}$ & JJM[ \\
\hline
\end{tabular}

* MT - Management Team Presenter

** ERB - Independent/Internal ERB Reviewer 
WT PROJECT EVIDENCE FILE INDEX

Phase 2 - SLS

\begin{tabular}{|c|c|c|c|c|c|}
\hline & $\begin{array}{l}\text { Authorization Basis document (BIO } \\
\text { or SAR) e.g. if PPE are required the } \\
\text { operating procedures spell out PPE } \\
\text { requirements. }\end{array}$ & & & & \\
\hline$\overline{\text { B.8 }}$ & $\begin{array}{l}\text { A document control system is in } \\
\text { place to ensure that staff has the } \\
\text { most recent versions of plans and } \\
\text { procedures. }\end{array}$ & $\begin{array}{l}\text { EDS Development, Review, and Control of } \\
\text { Procedures. (References LGWOP Conduct } \\
\text { of Operations Manual.) }\end{array}$ & EDS-WTP-01, Rev 1, 5/11/99. & $-\mathrm{GC}$ & $\mathrm{JJM}^{-}$ \\
\hline$\overline{\mathrm{B} .9}$ & $\begin{array}{l}\text { A routine program of assessments is } \\
\text { planned including surveillance and } \\
\text { inspections of routine operations; } \\
\text { these assessments are geared } \\
\text { towards verifying that the job is } \\
\text { being conducted per procedures and } \\
\text { that all required safety controls are } \\
\text { being met. }\end{array}$ & $\begin{array}{ll}\text { c. } & \text { The WMOD WSS Self-Assessment } \\
\text { Program has been reviewed previously } \\
\text { during the C-Tanks RA. } \\
\text { d } \\
\text { Schedule of ES\&H surveillance for } \\
\text { EDS. }\end{array}$ & $\begin{array}{l}\text { c. C-Tanks RA (File 7.1) } \\
\begin{array}{ll}\text { d } & \text { WT Project - } 1999 \text { Assessment } \\
\text { Schedule - Rev } 1 .\end{array}\end{array}$ & $\begin{array}{l}\mathrm{GC} \\
\mathrm{AvG}\end{array}$ & गJM \\
\hline B.10 & $\begin{array}{l}\text { All required operating permits and } \\
\text { approvals have been issued. } \\
\text { Examples include: Radiation Work } \\
\text { Permits (RWPs), Nuclear Criticality } \\
\text { Safety Approvals (NCSAs), Safety } \\
\text { Work Permits, Drilling Permits, } \\
\text { Regulatory Approvals, Lift Plans, } \\
\text { Labor Standards Determinations, } \\
\text { Environmental Permits (Clean Air } \\
\text { Act, NESHAPS, NPDES, etc.), } \\
\text { NEPA and NEPA related statutes, } \\
\text { Hot Work Permits. }\end{array}$ & 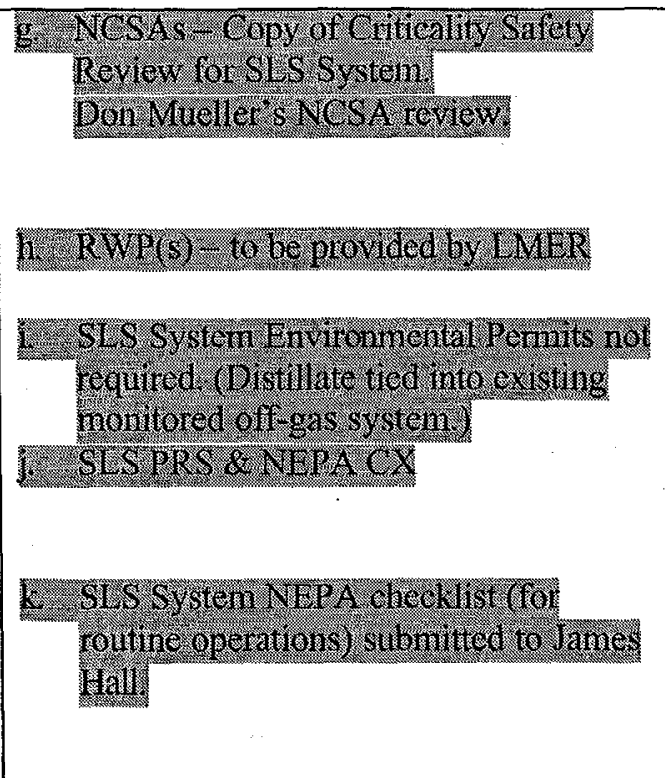 & 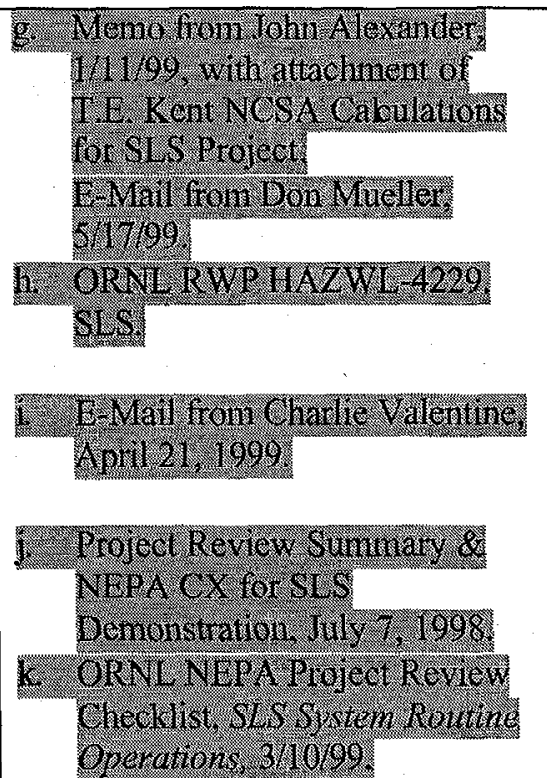 & TK & $\overline{\mathrm{CS}}$ \\
\hline
\end{tabular}

* $\quad$ MT - Management Team Presenter

** ERB - Independent/Internal ERB Reviewer 
Phase 2 - SLS

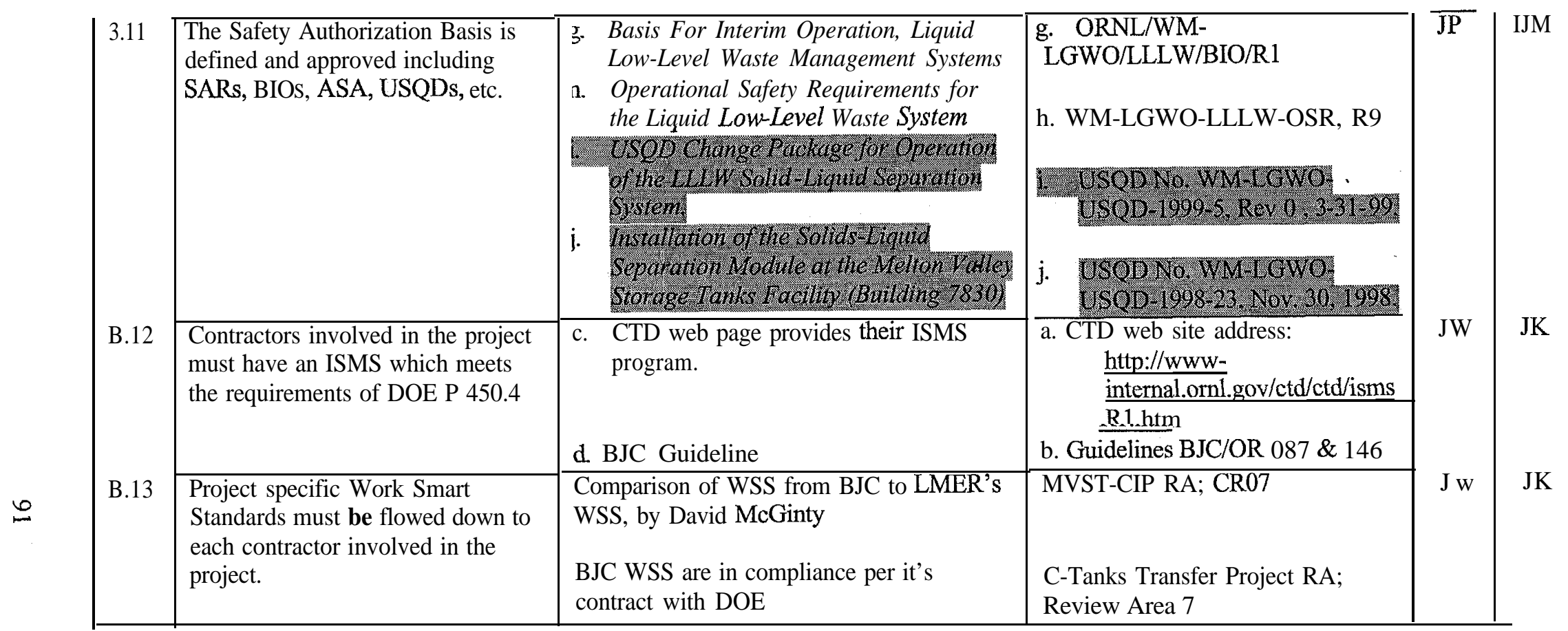

* $\quad$ MT - Management Team Presenter

** ERB - Independent/Internal ERB Reviewer 
WT PROJECT EVIDENCE FILE INDEX

Phase 2 - SLS

\section{Facilities and Equipment}

\begin{tabular}{|c|c|c|c|c|c|}
\hline \# & Criteria & Evidence (Document Title) & Document No. & $\mathbf{M T}^{*}$ & $\underset{* *}{\mathbf{E R B}}$ \\
\hline C.1 & $\begin{array}{l}\text { The project meets all applicable } \\
\text { structural and safety code } \\
\text { requirements. } \\
\text { Walkdowns shall verify that } \\
\text { required personnel protective } \\
\text { equipment has been provided and is } \\
\text { available on-site. }\end{array}$ & 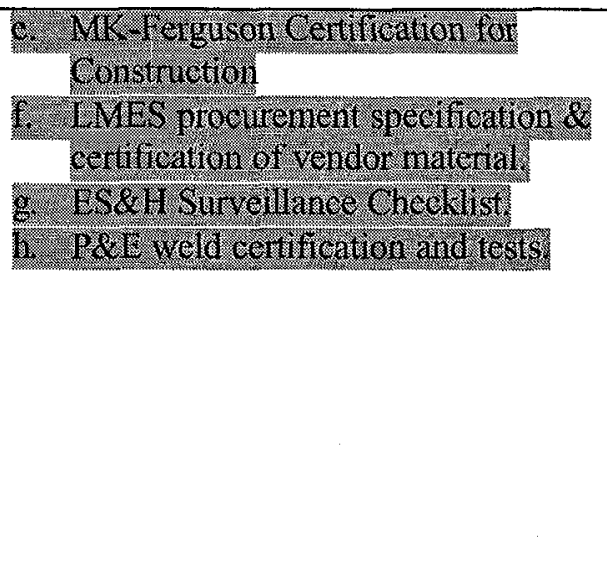 & 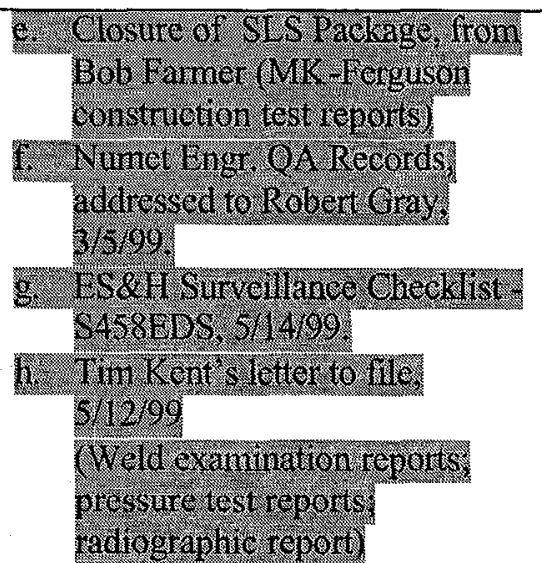 & TH & JK \\
\hline$\overline{C .2}$ & $\begin{array}{l}\text { The facility and site meet all } \\
\text { applicable signage, posting, and } \\
\text { boundary control requirements for } \\
\text { Radiological Control per } 10 \mathrm{CFR} \\
835 \text {. }\end{array}$ & ES\&H Surveillance Checklist. & 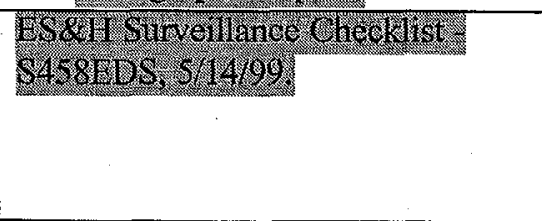 & $\overline{\mathrm{TH}}$ & JK \\
\hline C.3 & $\begin{array}{l}\text { The site is adequately equipped } \\
\text { with personnel monitoring } \\
\text { equipment (e.g. frisk stations, } \\
\text { continuous air monitors, volatile } \\
\text { organics emissions monitors, LEL } \\
\text { monitors, etc.). }\end{array}$ & ES\&H Surveillance Checklist. & 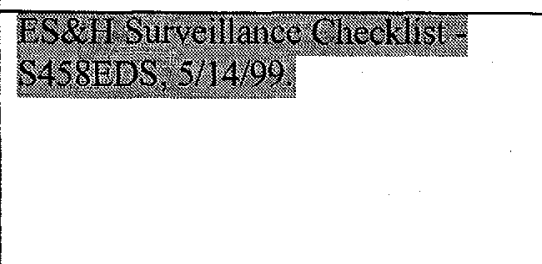 & TH & JJM \\
\hline C.4 & $\begin{array}{l}\text { Adequate eye wash and safety } \\
\text { showers are set-up in areas where } \\
\text { they are needed for their intended } \\
\text { purpose. }\end{array}$ & $\begin{array}{l}\text { a. ES\&H Surveillance Checklist. } \\
\text { b. Documented closure of open items. }\end{array}$ & 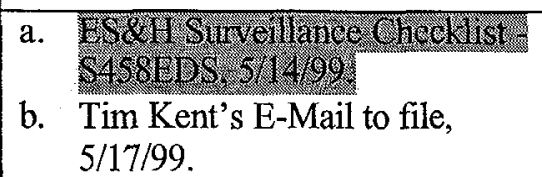 & $\overline{\mathrm{TH}}$ & JJM \\
\hline
\end{tabular}

* MT - Management Team Presenter

** ERB - Independent/Internal ERB Reviewer 
WT PROJECT EVIDENCE FILE INDEX

Phase 2 - SLS

\begin{tabular}{|c|c|c|c|c|c|}
\hline C. .5 & $\begin{array}{l}\text { Jazards labeling is complete for } \\
\text { shemicals, physical hazards, and } \\
\text { zxplosion potential (e.g. NO } \\
\text { Smoking Signs around ignitable } \\
\text { shemicals). Material Safety Data } \\
\text { Sheets are available. }\end{array}$ & $\begin{array}{l}\therefore \text { ES\&H Surveillance Checklist. } \\
1 \text { MSDS for the WT operations }\end{array}$ & 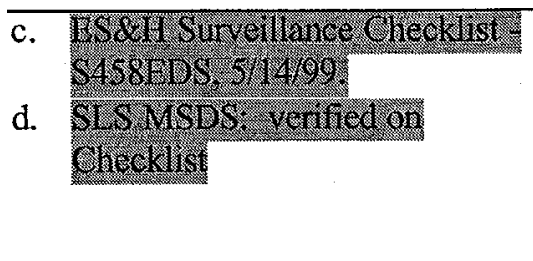 & $\mathrm{TH}$ & JJM \\
\hline С. 6 & $\begin{array}{l}\text { Key process piping, equipment } \\
\text { components, and valves are labeled } \\
\text { to provide easy location and } \\
\text { adequate implementation of } \\
\text { operating procedures. }\end{array}$ & $\begin{array}{l}\text { Verified during procedure validation. } \\
\text { Facility walk down and documented on the } \\
\text { ES\&H Surveillance Checklist. }\end{array}$ & 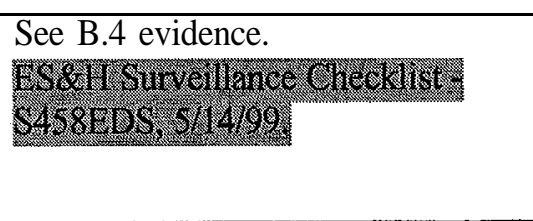 & $\mathrm{TH}$ & JJM \\
\hline C. 7 & $\begin{array}{l}\text { All process and safety related } \\
\text { instrumentation, monitoring } \\
\text { equipment, and gages are calibrated } \\
\text { with a certified and traceable source } \\
\text { (e.g. NIST), and building/site } \\
\text { emergency contacts have been } \\
\text { contacted and coordinated with } \\
\text { concerning the project and } \\
\text { Site/building Lock Out/Tag Out } \\
\text { Procedures. }\end{array}$ & 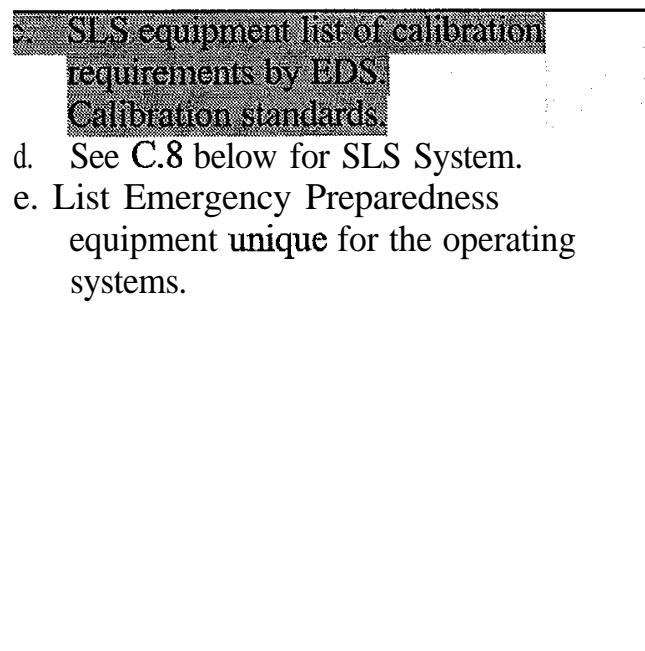 & 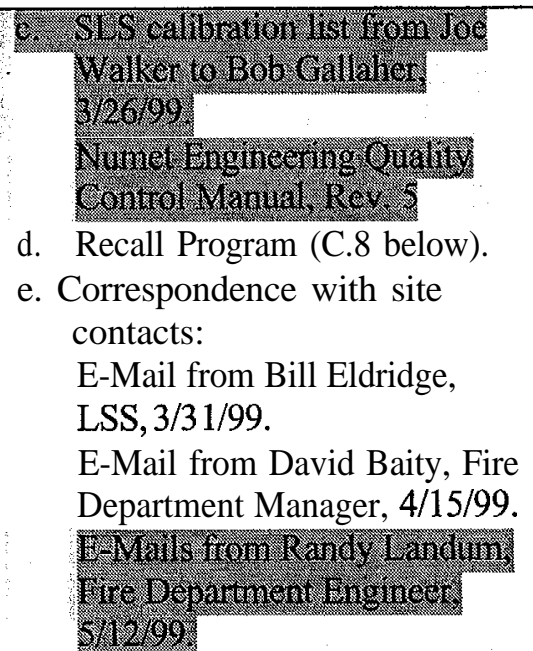 & TK & JJM \\
\hline
\end{tabular}

\footnotetext{
* MT - Management Team Presenter

** ERB - Independent/Internal ERB Reviewer
} 
WT PROJECT EVIDENCE FILE INDEX

Phase 2 - SLS

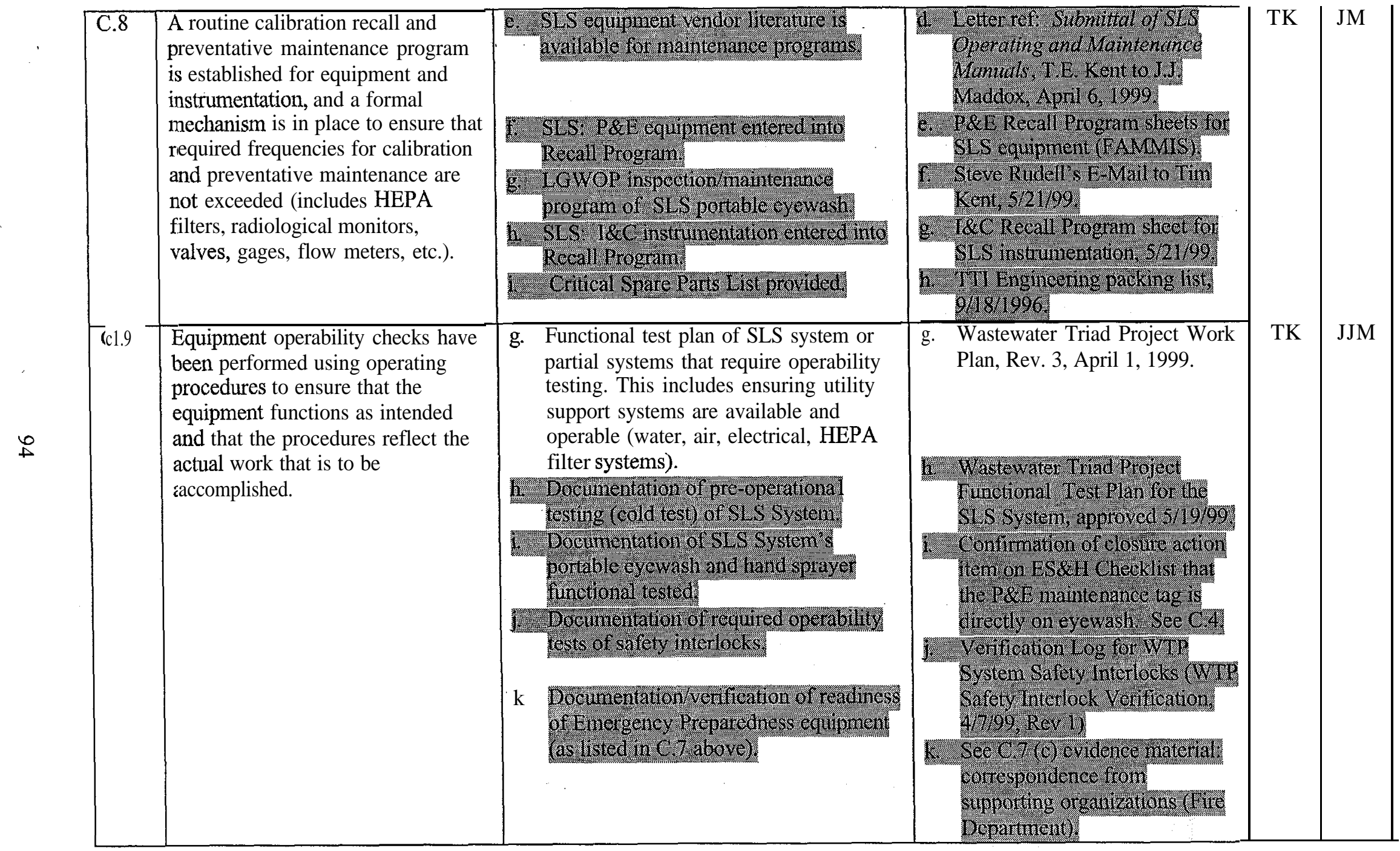

* MT - Management Team Presenter

** ERB - Independent/Internal ERB Reviewer 
WT PROJECT EVIDENCE FILE INDEX

$5 / 17 / 99$

Phase 2 - SLS

\begin{tabular}{|l|l|}
\hline C.10 & $\begin{array}{l}\text { As built or redlined drawings have } \\
\text { been prepared and coordinated with } \\
\text { building/site personnel to reflect the } \\
\text { actual site conditions, location of } \\
\text { equipment, piping layout, and any } \\
\text { safety related system that could } \\
\text { potentially be involved or affect the } \\
\text { project. }\end{array}$ \\
\hline
\end{tabular}

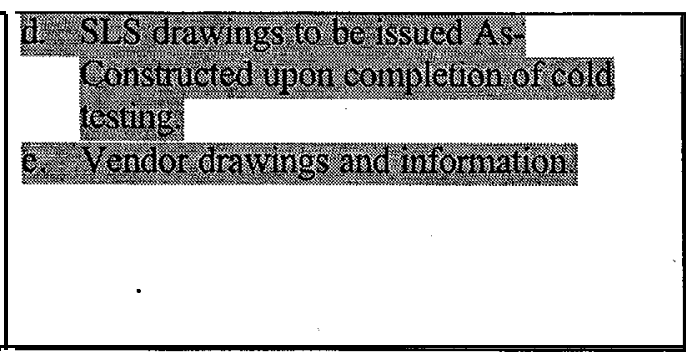

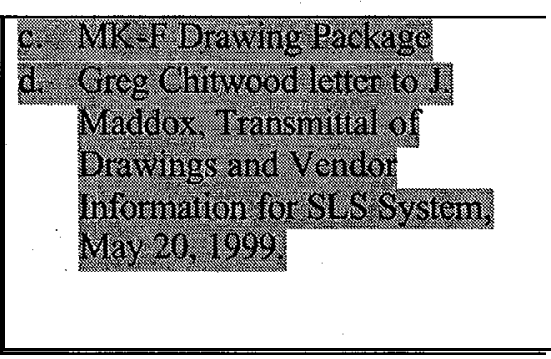

\begin{tabular}{|l|l|}
\hline TK & JJM \\
& \\
\hline
\end{tabular}




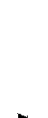


APPENDIX B

DETAILS OF RADIOLOGICAL SURVEYS 
Survey 32662, page 1 of 4 .

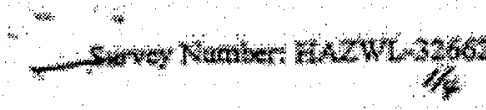

What

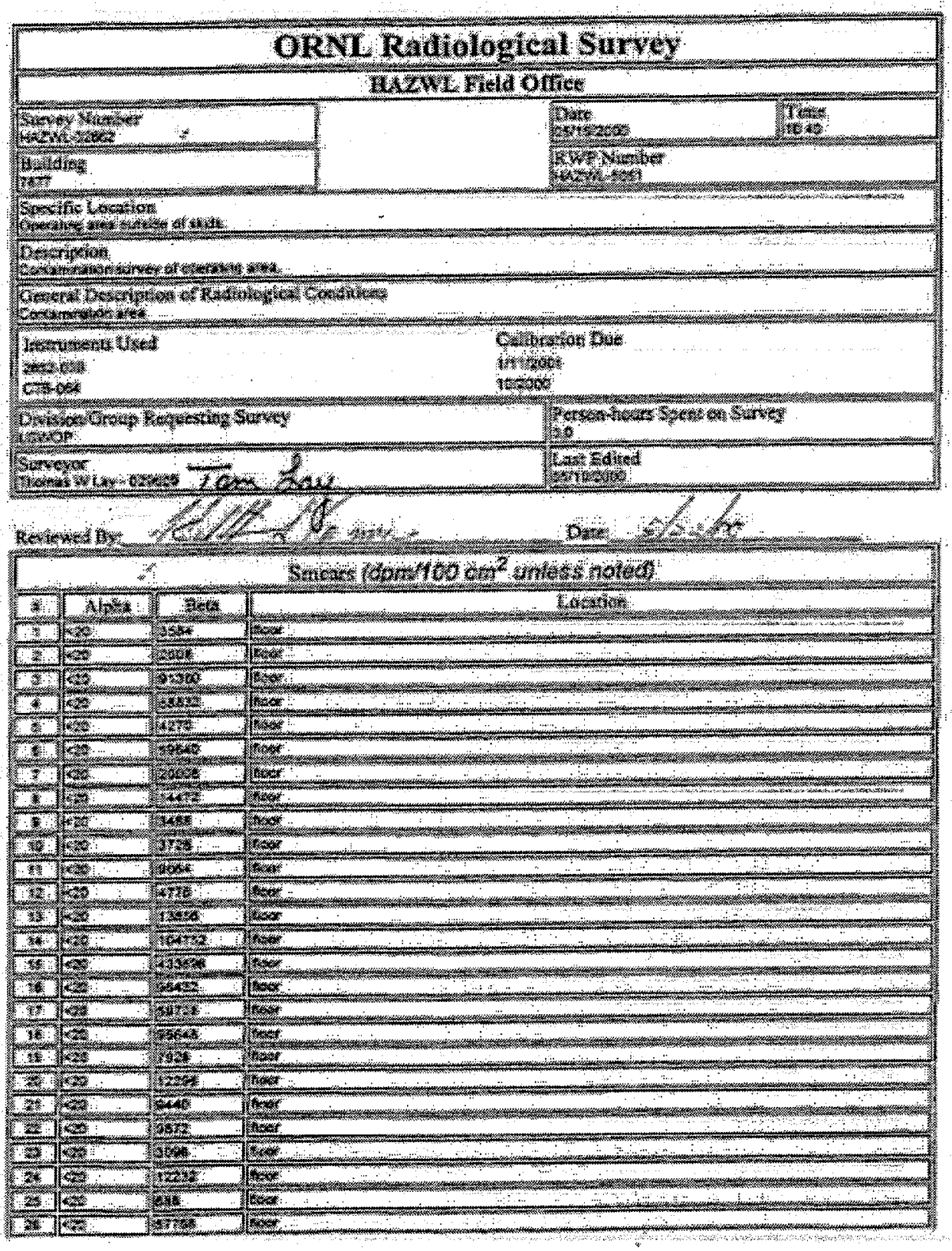

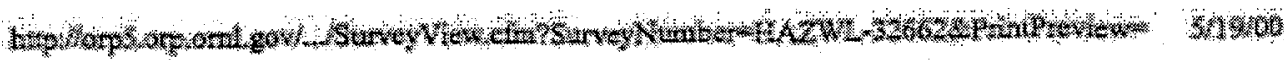


Survey 32662, page 2 of 4 .

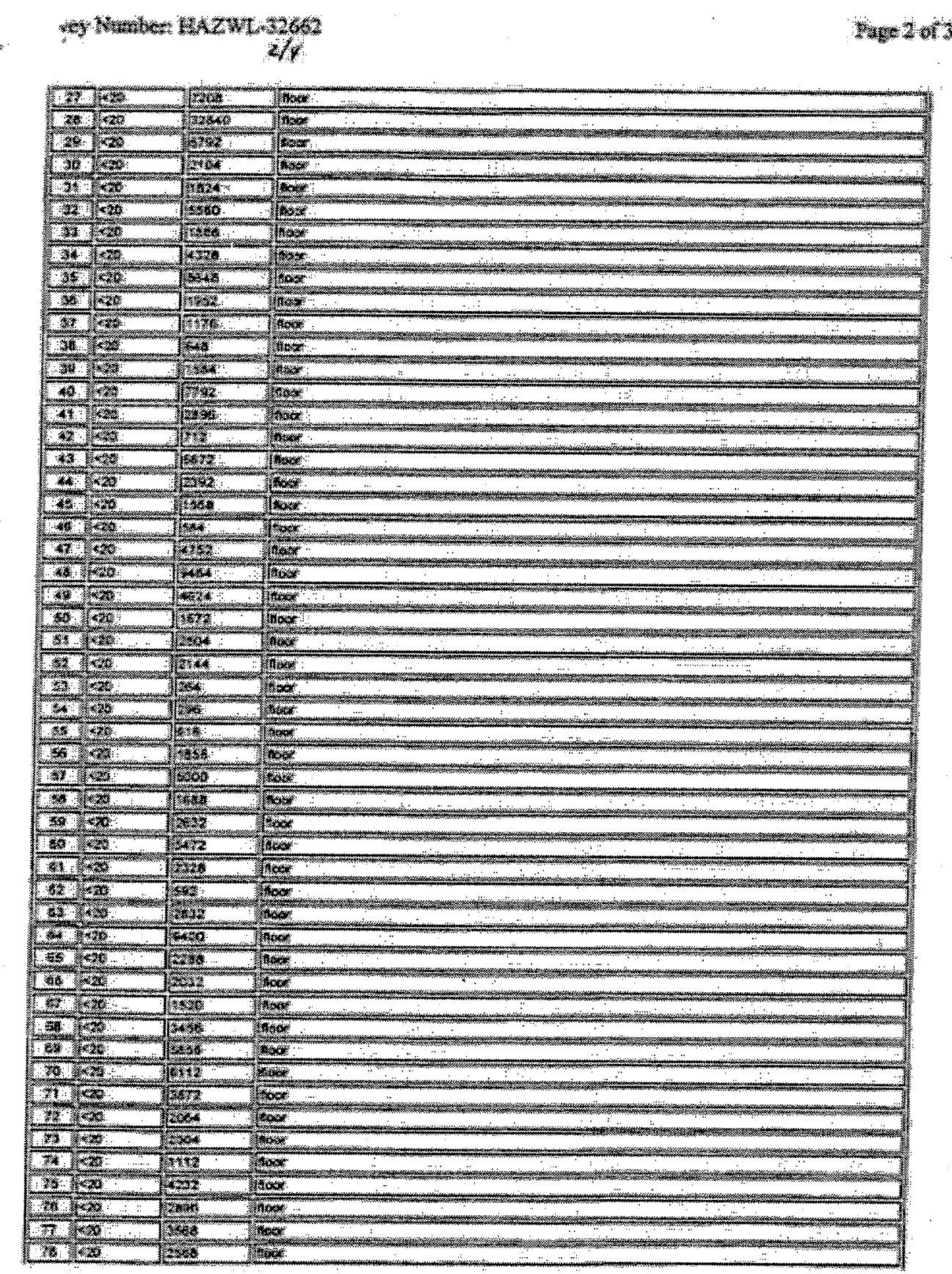

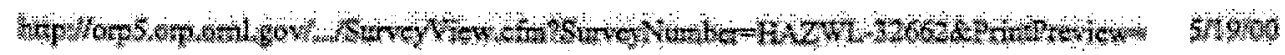


Survey 32662, page 3 of 4 .

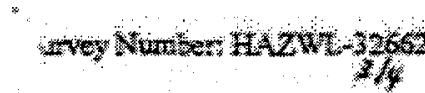

page 3 ats

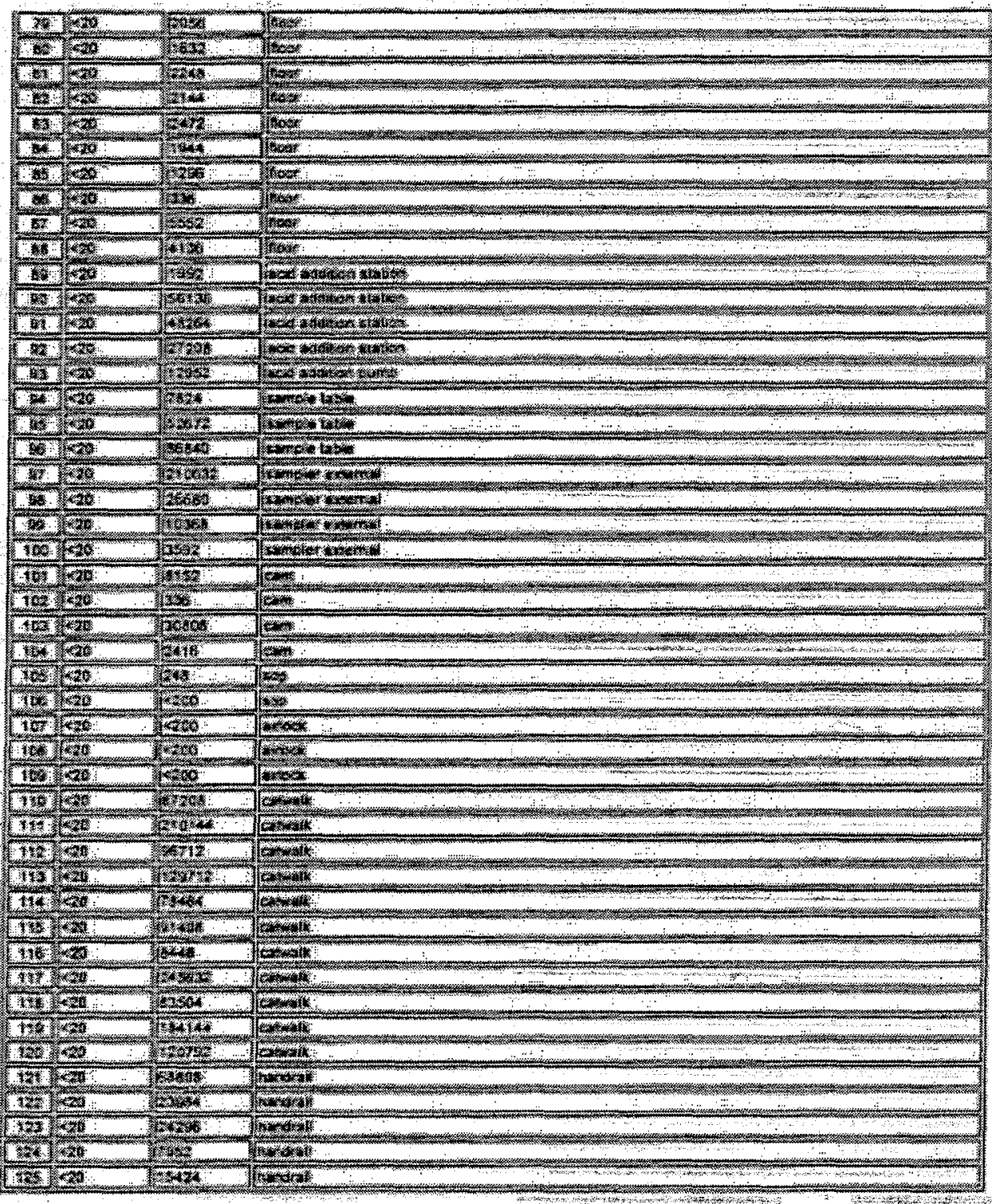

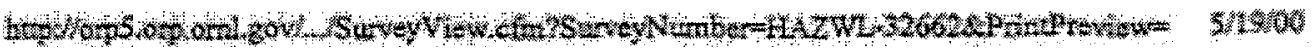


Survey 32662, page 4 of 4 .

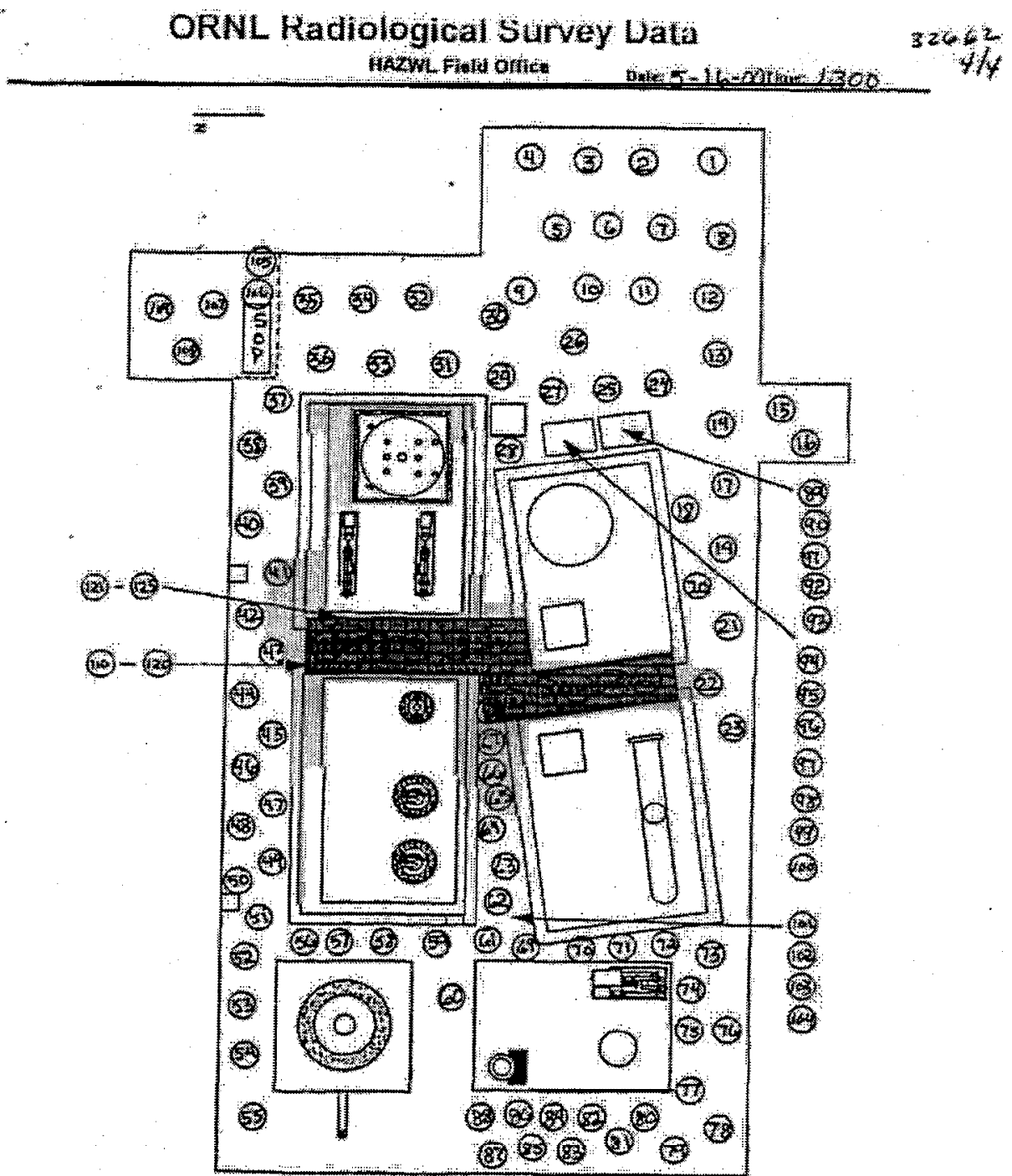

\begin{tabular}{|c|c|c|c|}
\hline 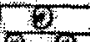 & sinvelest 194 & \multicolumn{2}{|c|}{ 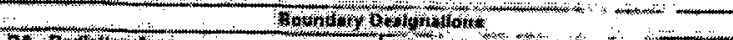 } \\
\hline$\alpha-0$ & Hogs sinto & 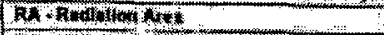 & 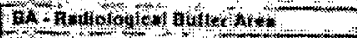 \\
\hline 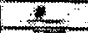 & 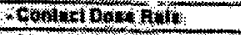 & 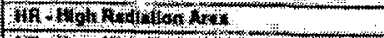 & 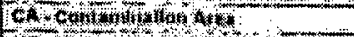 \\
\hline 7 & 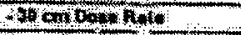 & 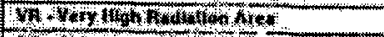 & 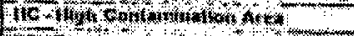 \\
\hline 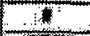 & 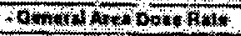 & 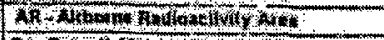 & 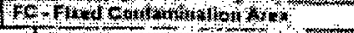 \\
\hline EOS & 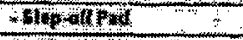 & 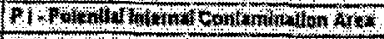 & 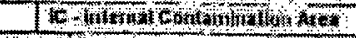 \\
\hline X: & Ars smph Luerion & 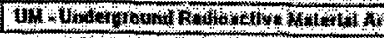 & 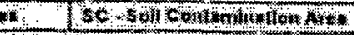 \\
\hline
\end{tabular}


Survey 32664, page 1 of 3 .

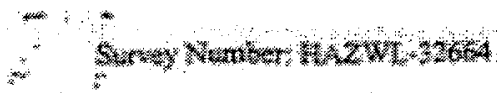

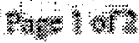

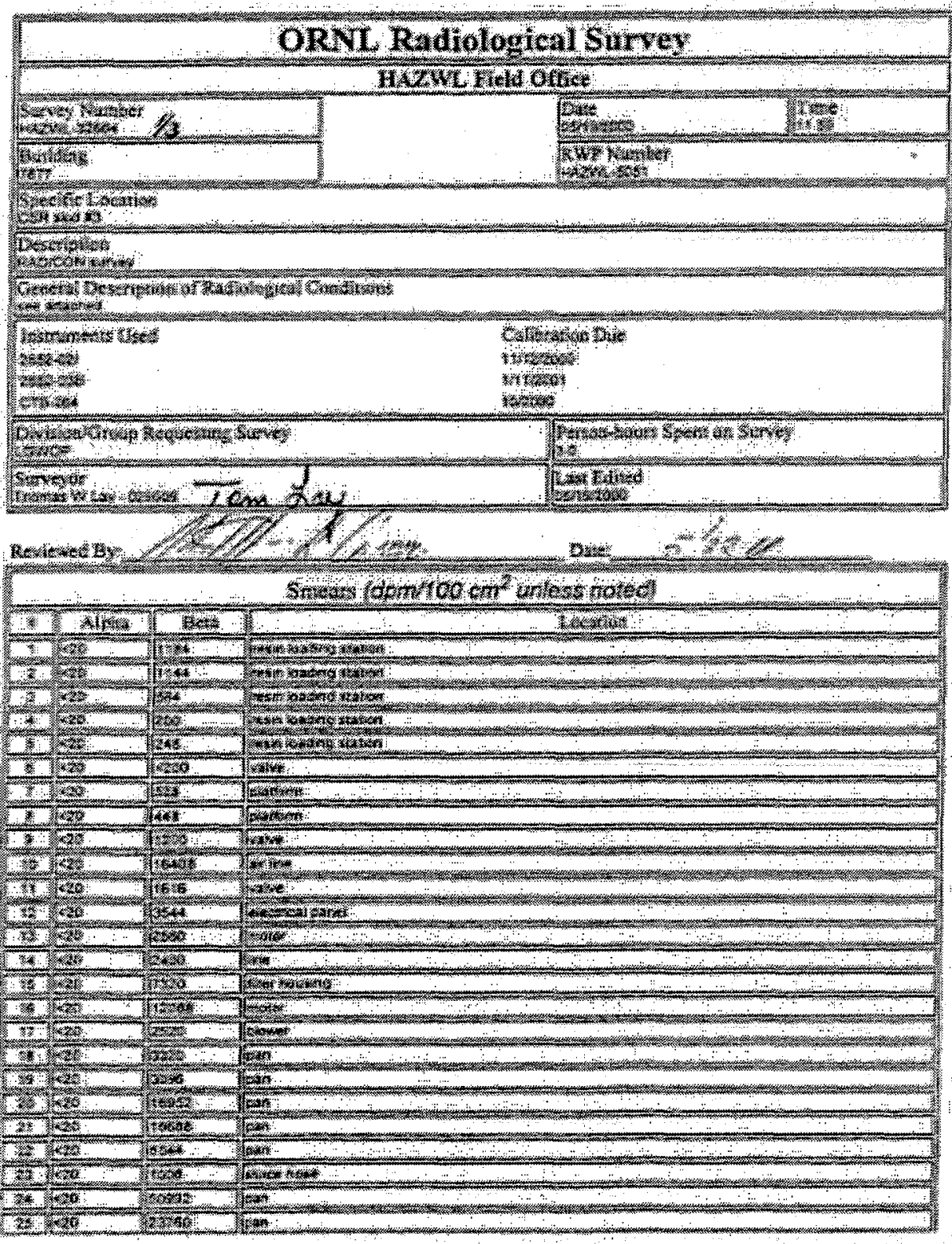

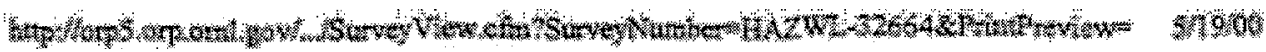


Survey 32664, page 2 of 3.

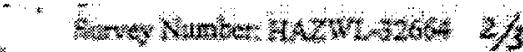

2urat 2

\begin{tabular}{|c|c|c|c|}
\hline 8. & 6 & 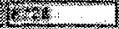 & $14 x 87>07=$ \\
\hline (3) & 3428: & 6 & 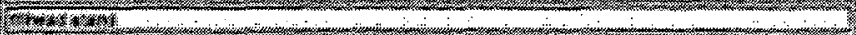 \\
\hline 4 & 1) & (280 & 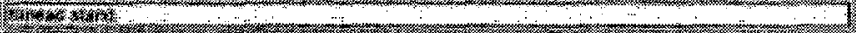 \\
\hline 4 & Ke & 47 & 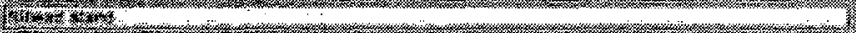 \\
\hline $3=$ & xis & 48 & 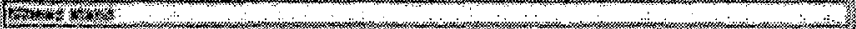 \\
\hline 3) & $8 \%$ & 6 & r. \\
\hline 1 & $6 \%$ & 36 & 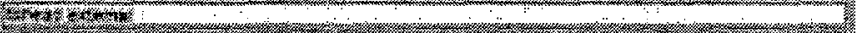 \\
\hline 3. & tet. & (29) & 1. \\
\hline
\end{tabular}

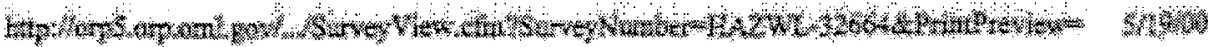



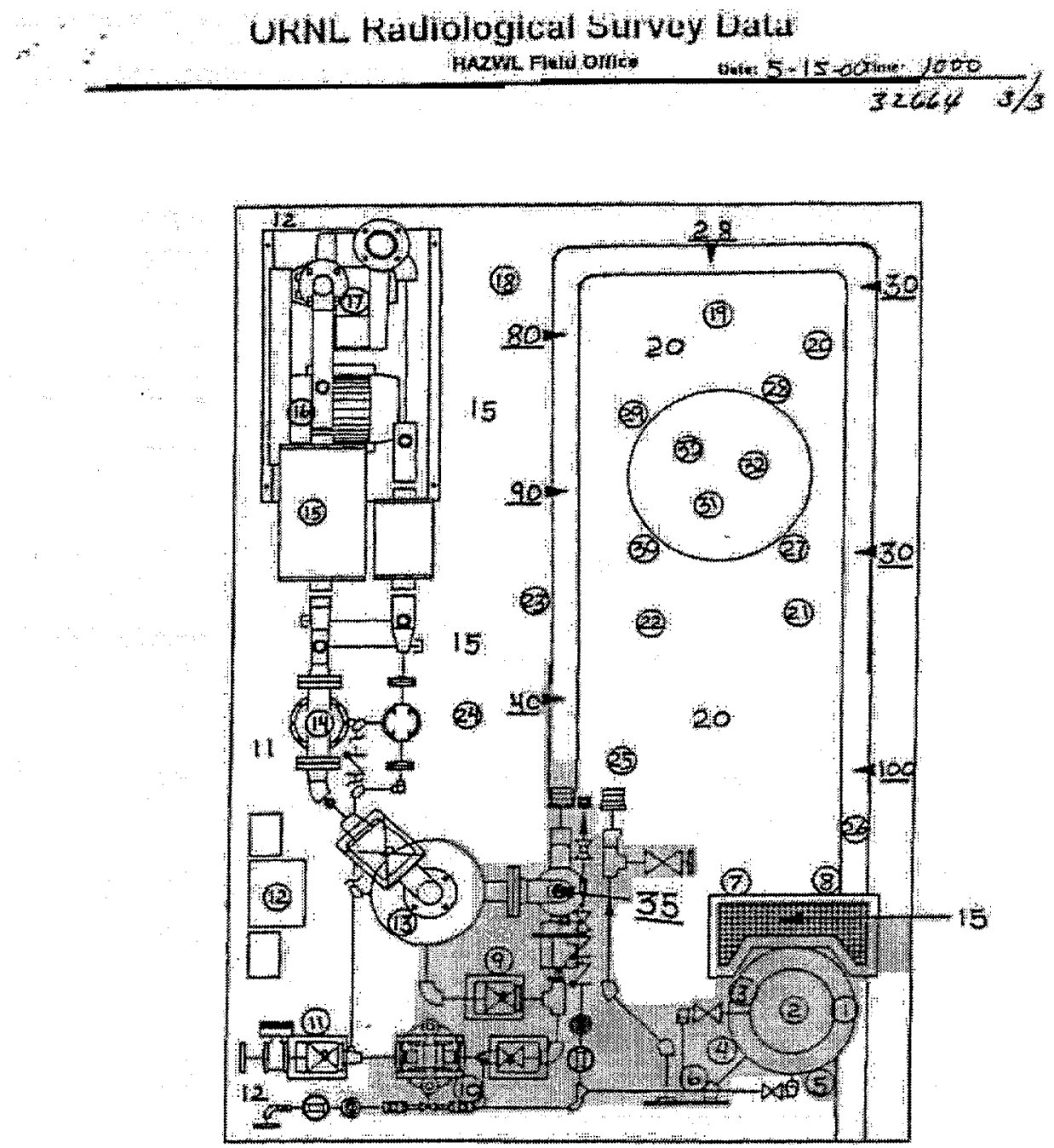

\begin{tabular}{|c|c|c|c|}
\hline t. & Sonver Loculan & Bowndy 0 & Houthos: \\
\hline $0 \div$ & - Wuaturustrot & 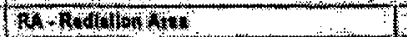 & 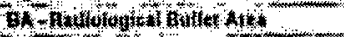 \\
\hline 1 & Tanthologondy & 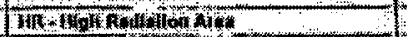 & 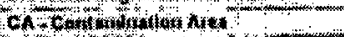 \\
\hline 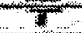 & 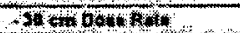 & 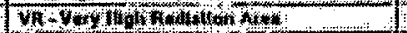 & 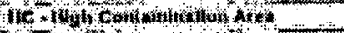 \\
\hline in & 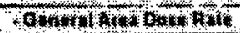 & 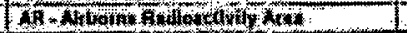 & 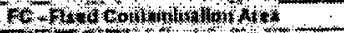 \\
\hline Son & 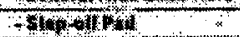 & 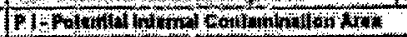 & 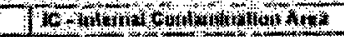 \\
\hline As & Af simple corifor & 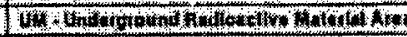 & 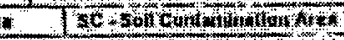 \\
\hline
\end{tabular}


Survey 32670; page 1 of 2 .

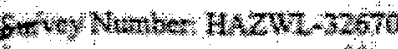

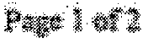

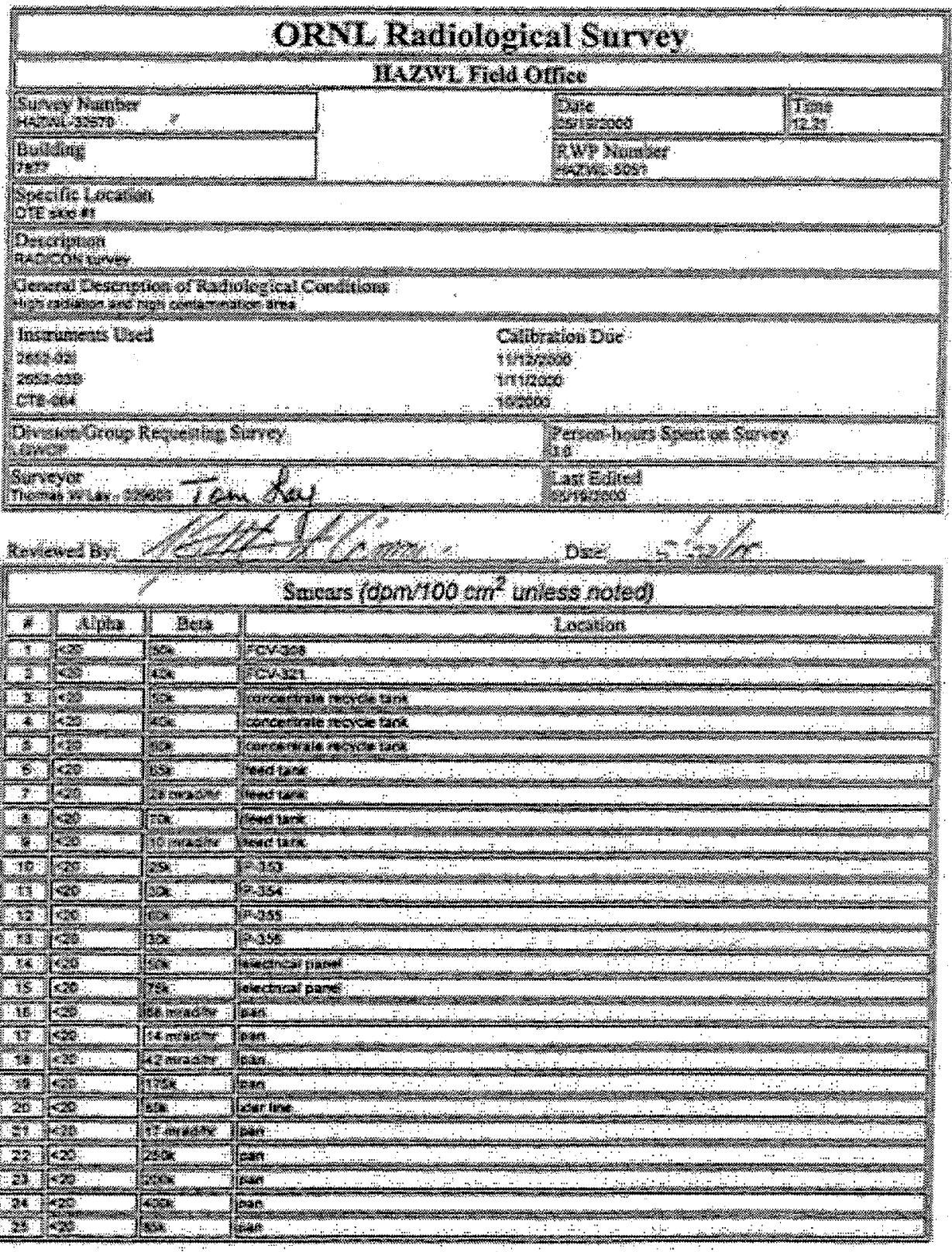

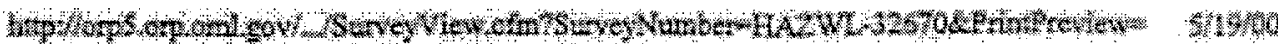


Survey 32670, page 2 of 2 .

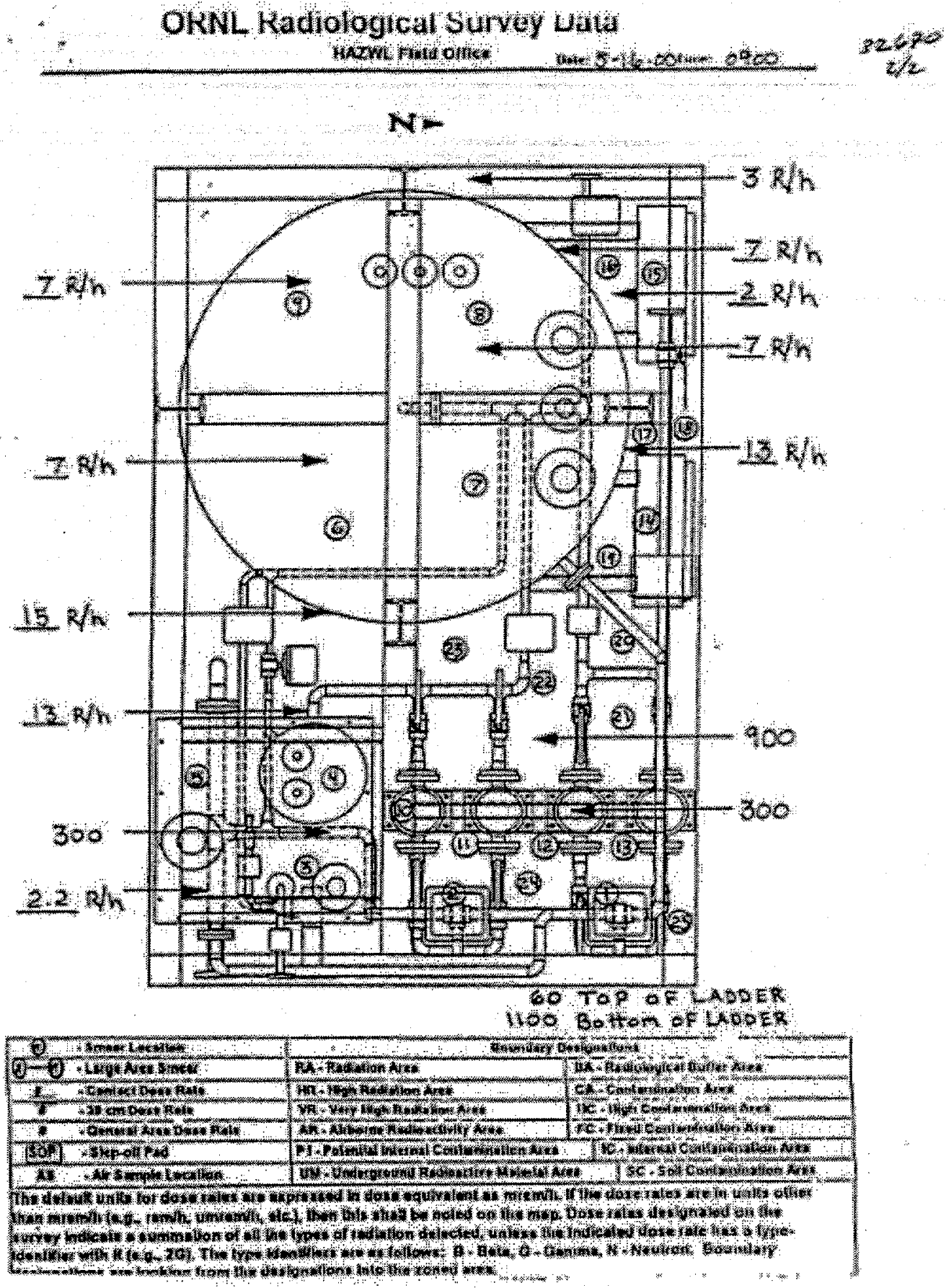


Survey 32714, page 1 of 2 .

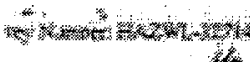

How How

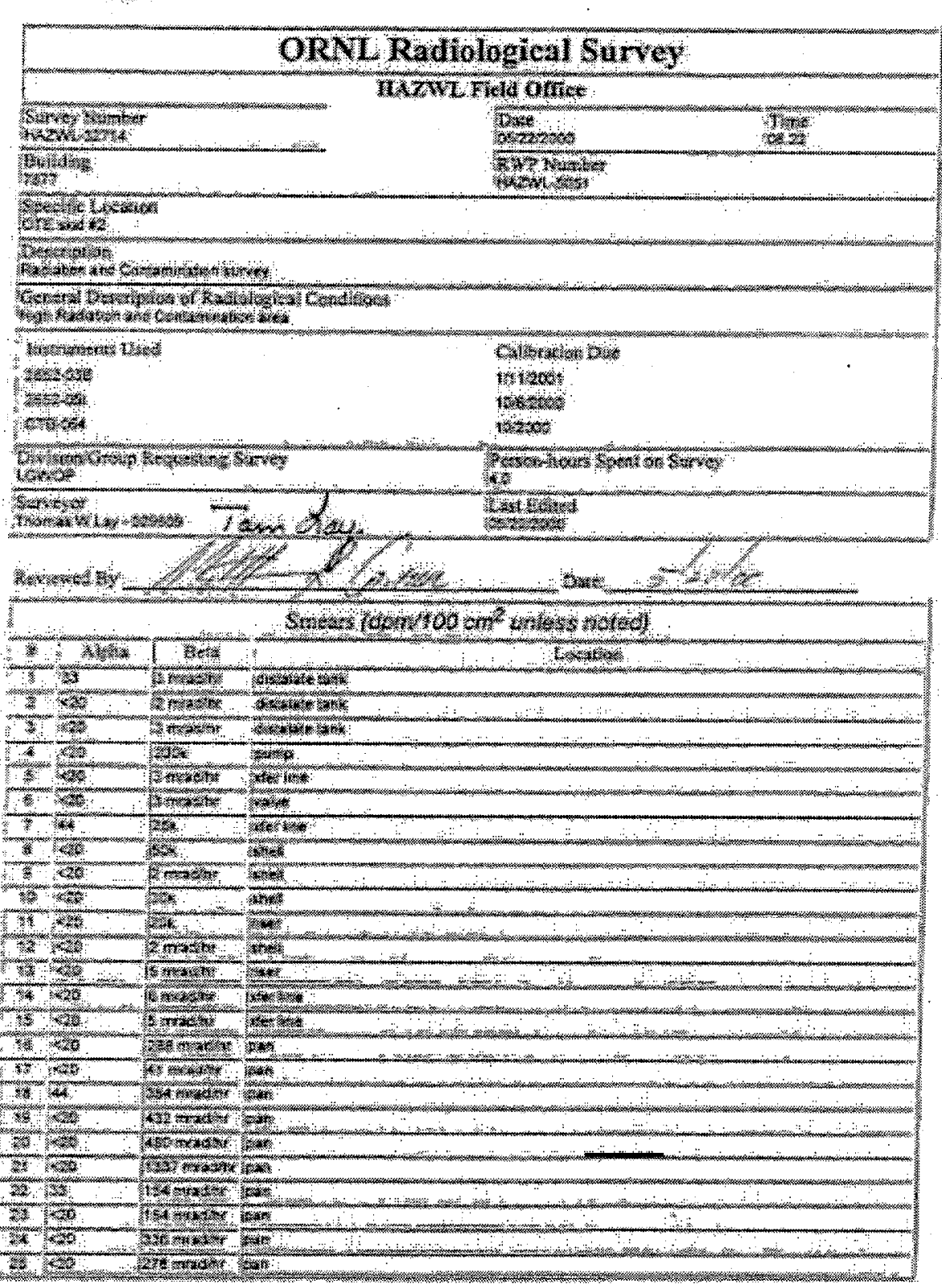


Survey 32714, page 2 of 2 .

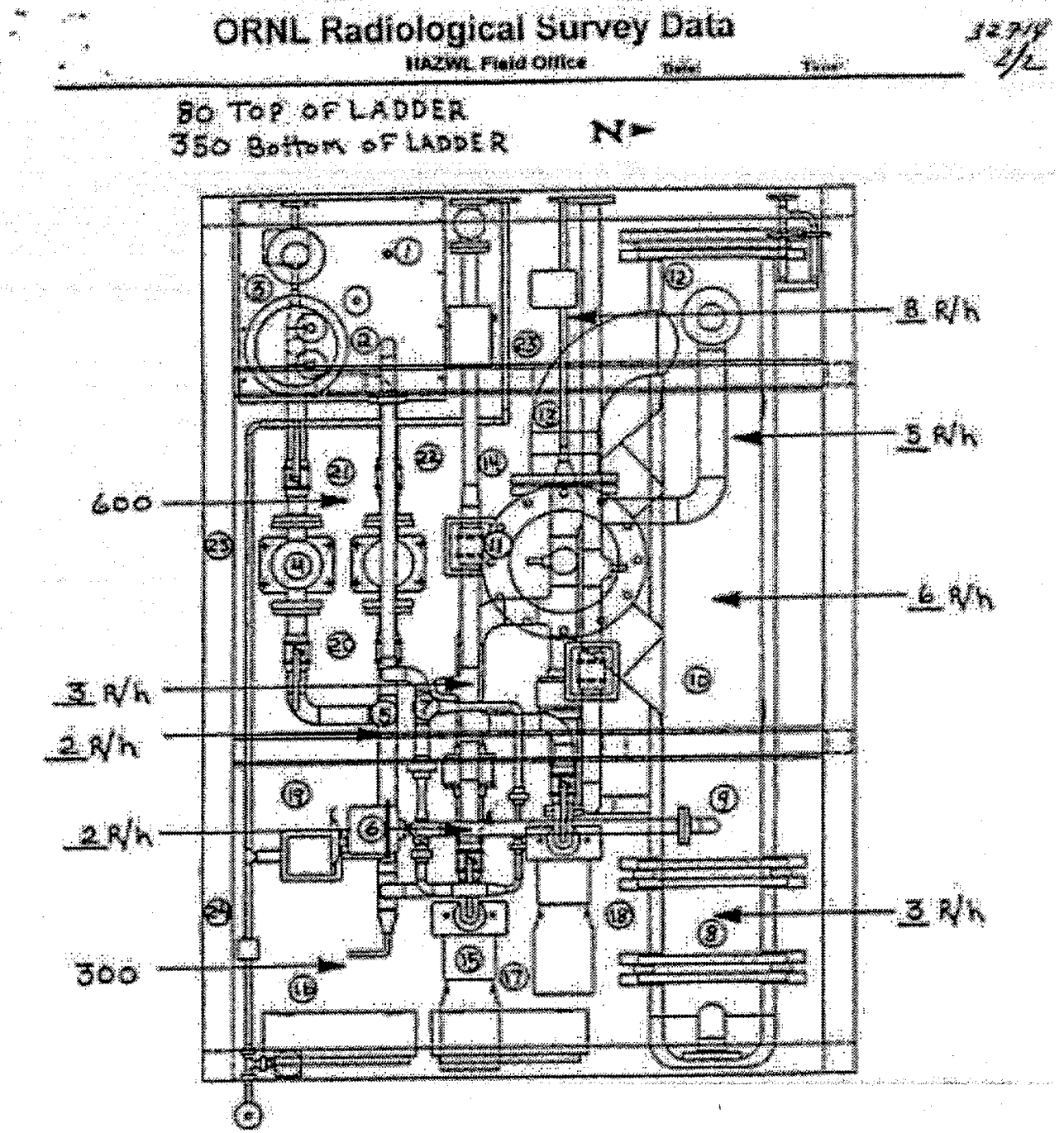

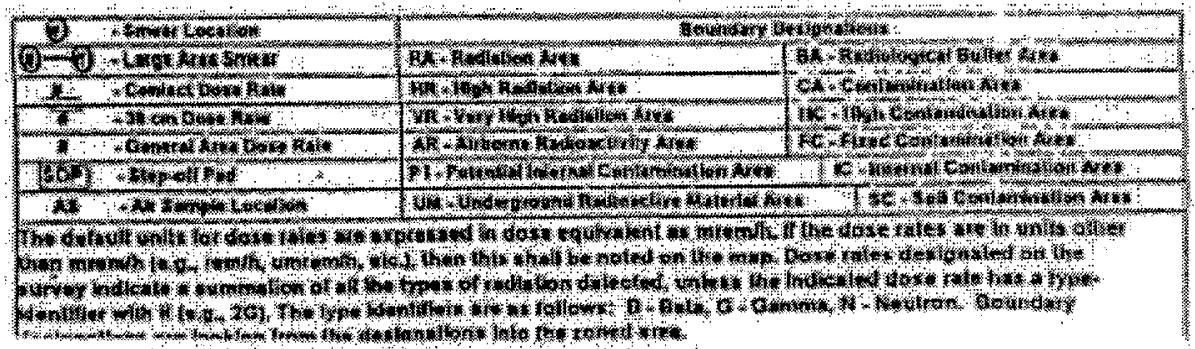

Survey 32717, page 1 of 3 . 


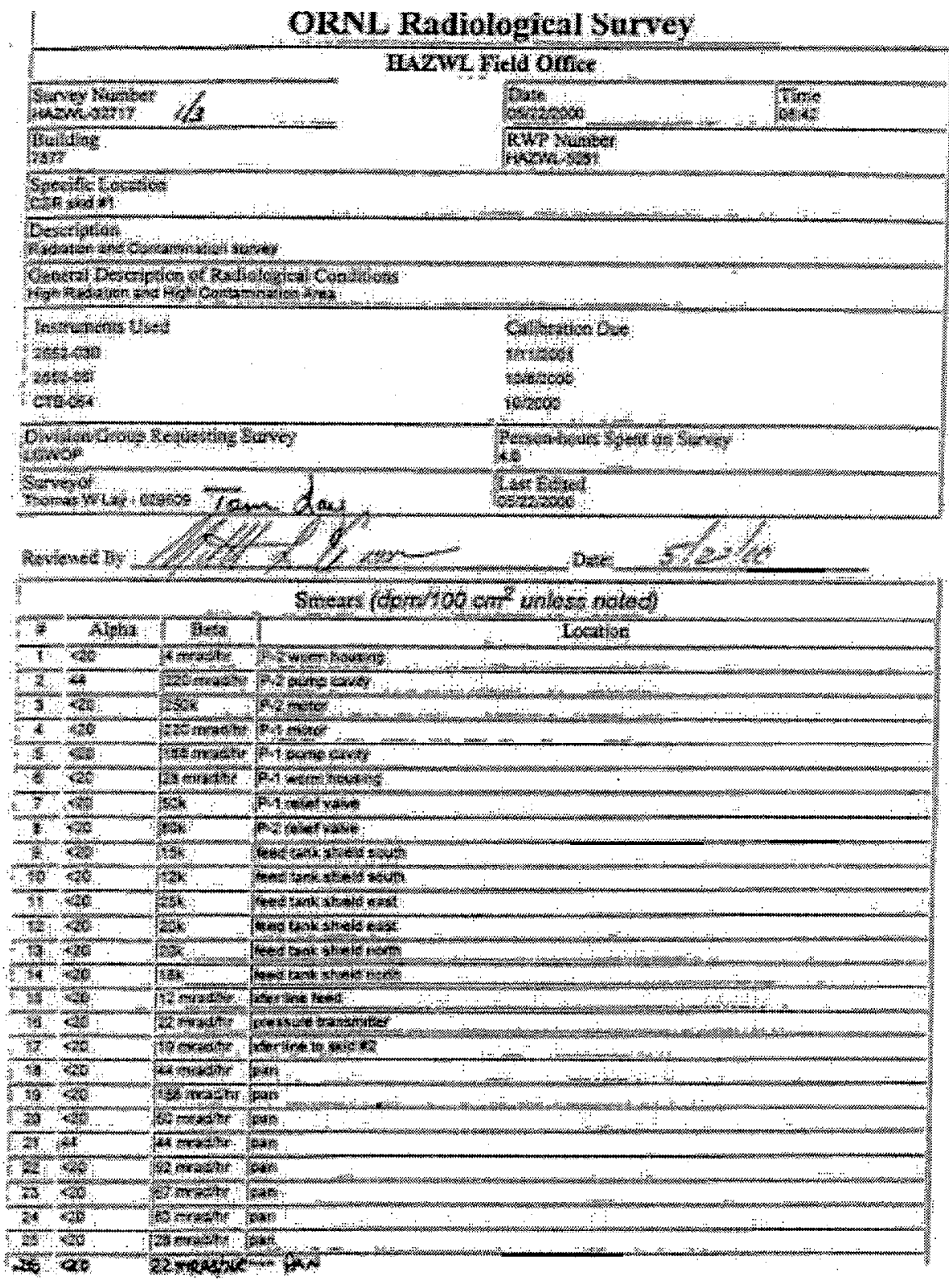


Survey 32717 , page 2 of 3 .

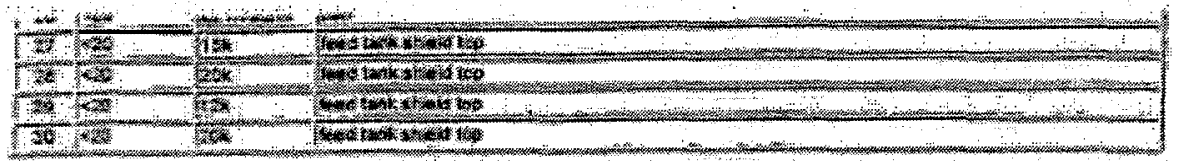

$2+7$

$1 / 3$

-

\begin{tabular}{|c|c|c|c|}
\hline$x$ & 28 & (1) & Wen soystos \\
\hline 2 & ratar & 4 & 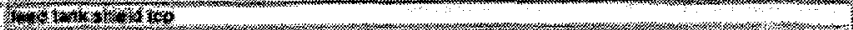 \\
\hline 4 & tres? & क्ष. & 4 \\
\hline$\pi$ & K & \% & 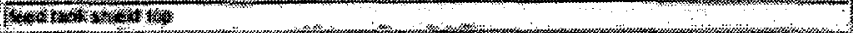 \\
\hline
\end{tabular}




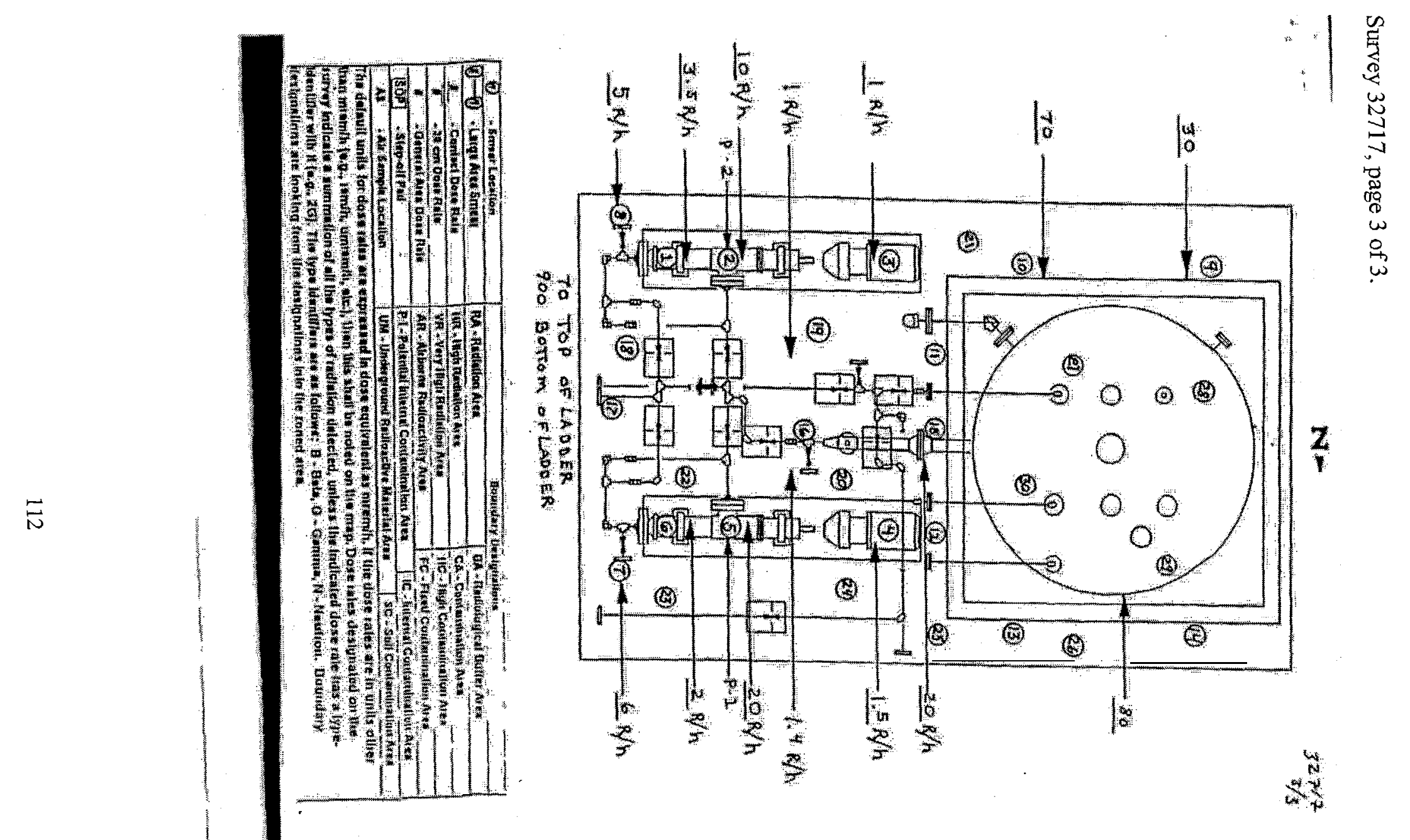


Survey 327 19, page 1 of 3 .

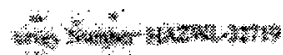

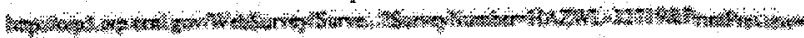

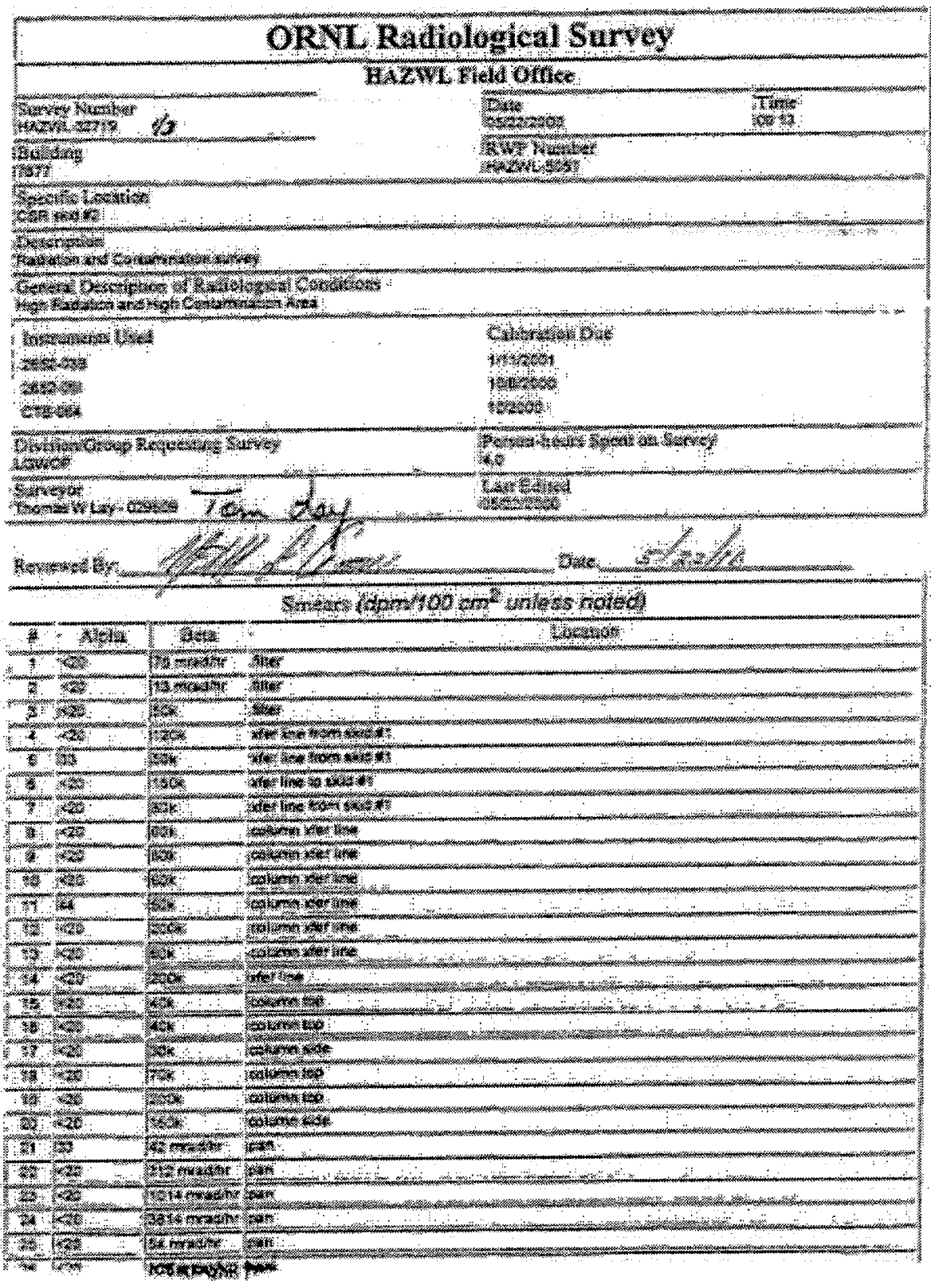

(r)

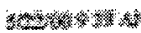


Survey 32719, page 2 of 3 .

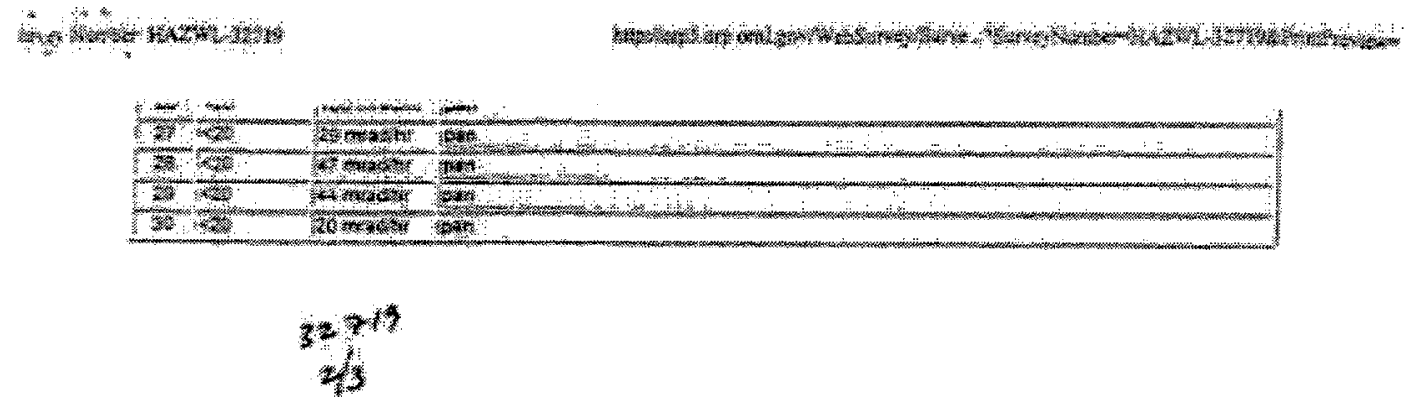


Survey 32719, page 3 of 3 .

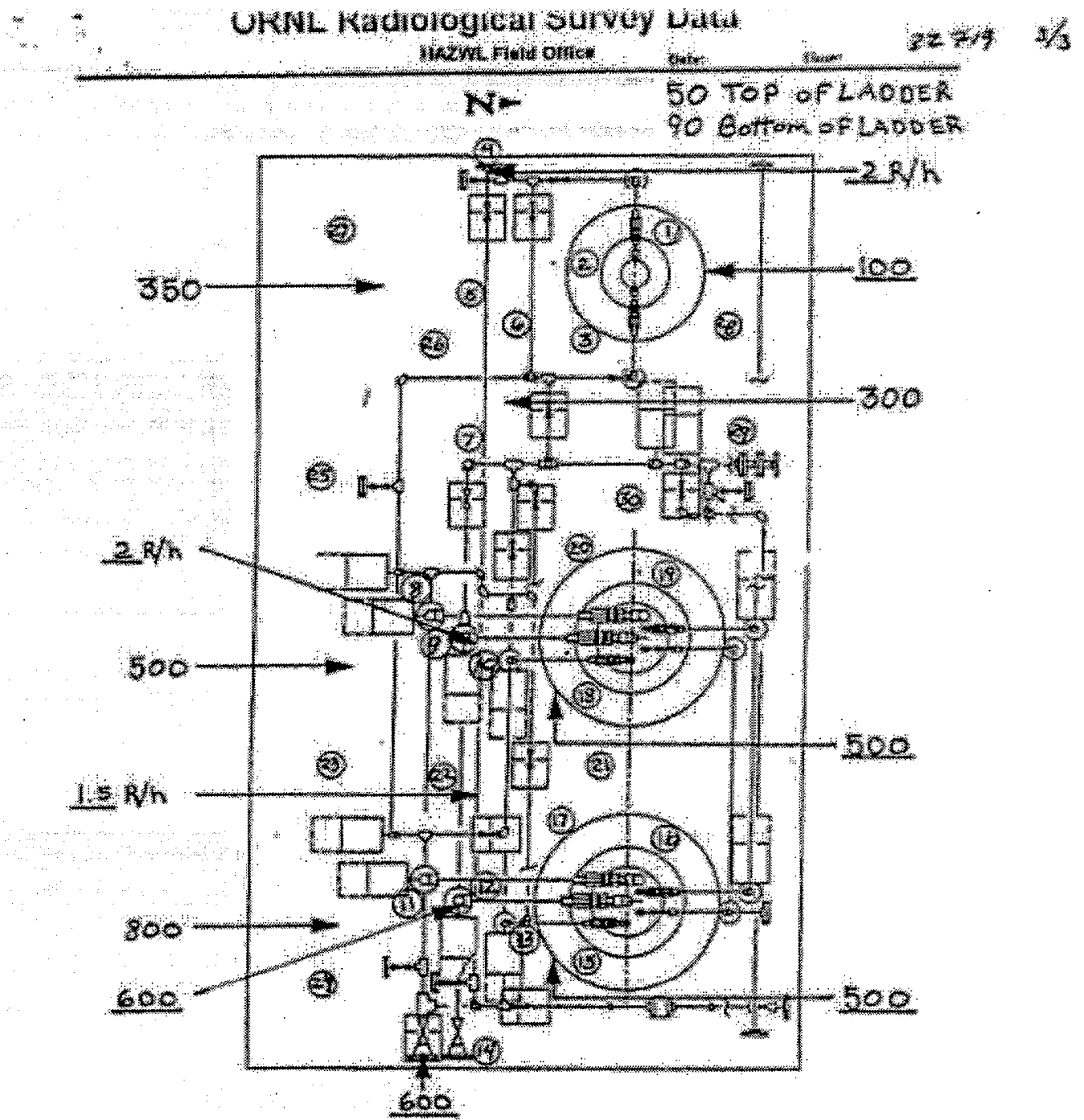

\begin{tabular}{|c|c|c|c|}
\hline 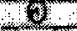 & 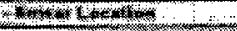 & \multicolumn{2}{|c|}{ 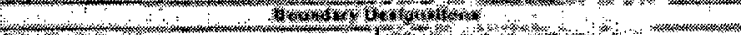 } \\
\hline $3=3$ & Hntwhrom & $34+1134$ & 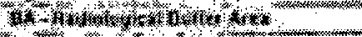 \\
\hline Ts: & 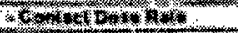 & 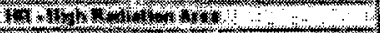 & 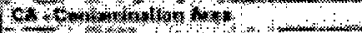 \\
\hline & 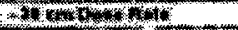 & 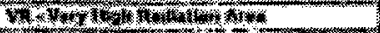 & 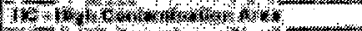 \\
\hline 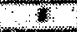 & 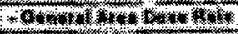 & 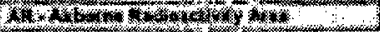 & 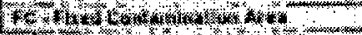 \\
\hline (1) & 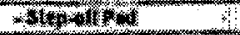 & 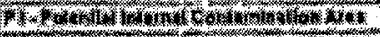 & 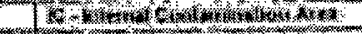 \\
\hline 3: & 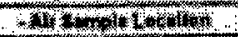 & 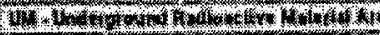 & 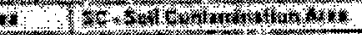 \\
\hline
\end{tabular}


Survey 32783, page 1 of 2 .

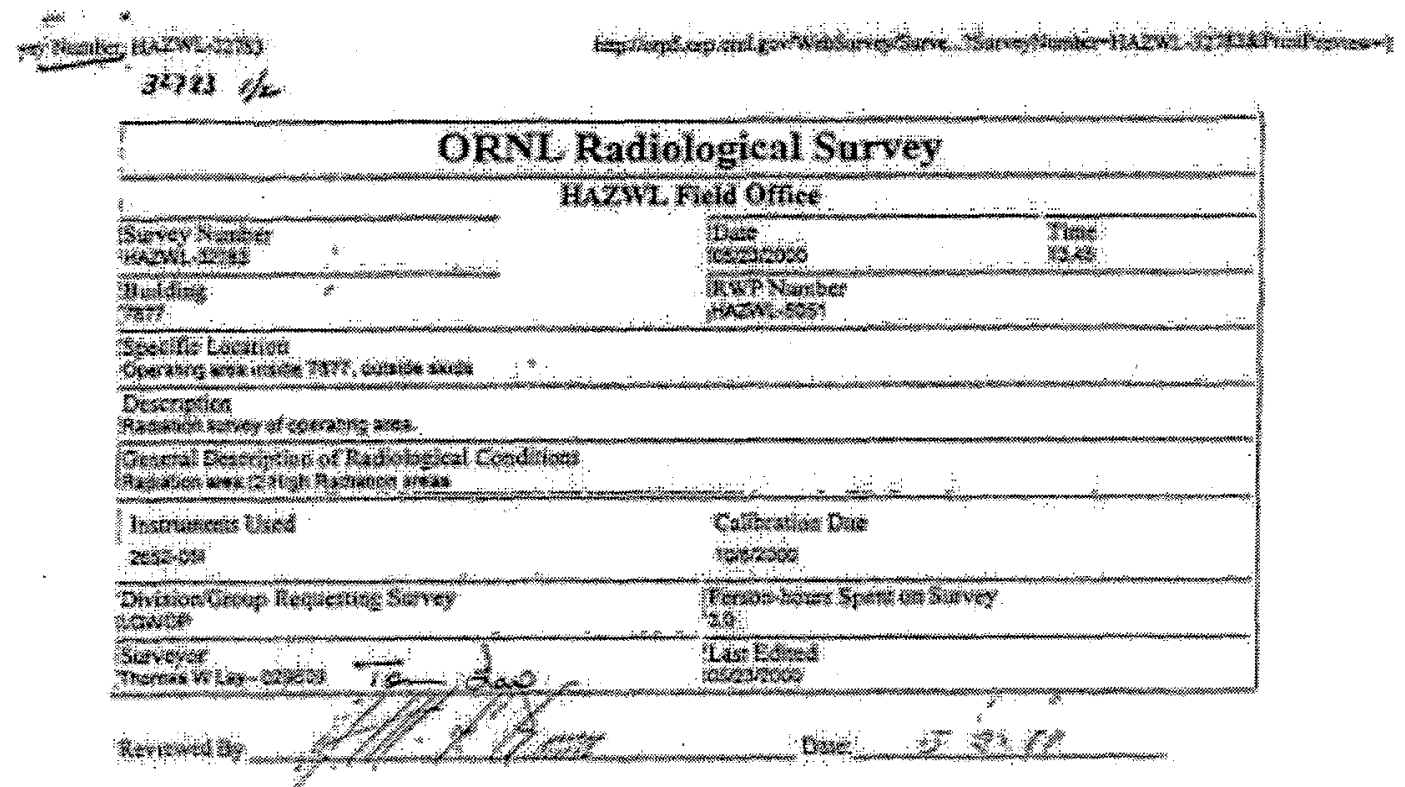




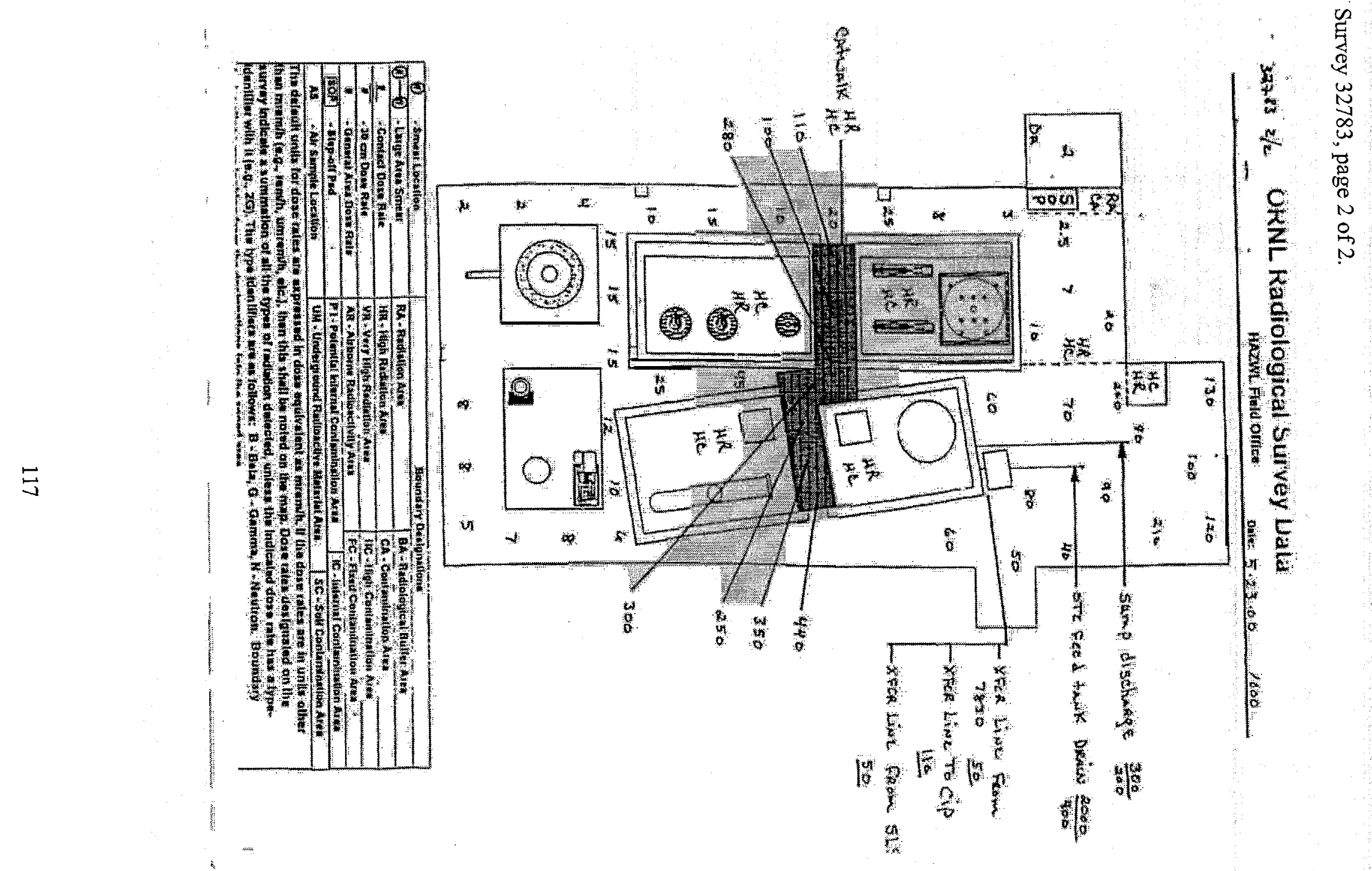


Survey 32784, page 1 of 2 .

...

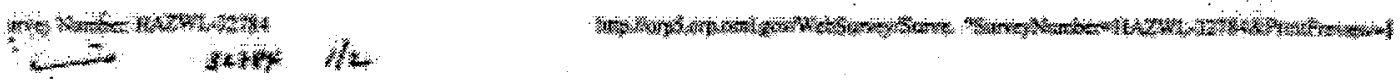

\begin{tabular}{|c|c|}
\hline OR & gatedsursy \\
\hline \multicolumn{2}{|c|}{ NKZWL Kivid OTfe: } \\
\hline 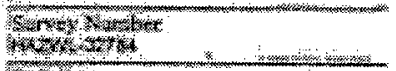 & 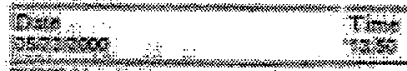 \\
\hline 6y & menters? \\
\hline \multicolumn{2}{|l|}{$64+476$} \\
\hline \multicolumn{2}{|c|}{ 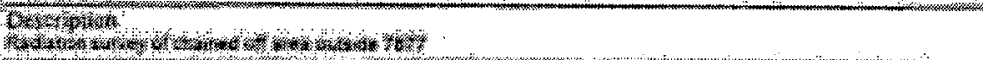 } \\
\hline \multicolumn{2}{|c|}{ 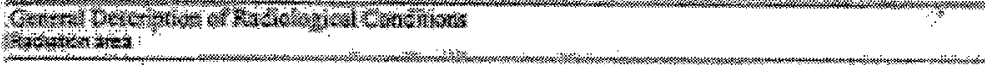 } \\
\hline 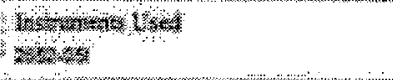 & wilksias 6 \\
\hline 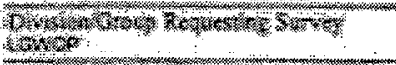 & 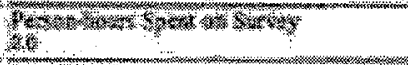 \\
\hline 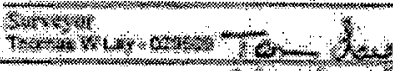 & 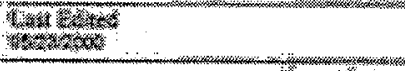 \\
\hline
\end{tabular}


Survey 32784, page 2 of 2 .

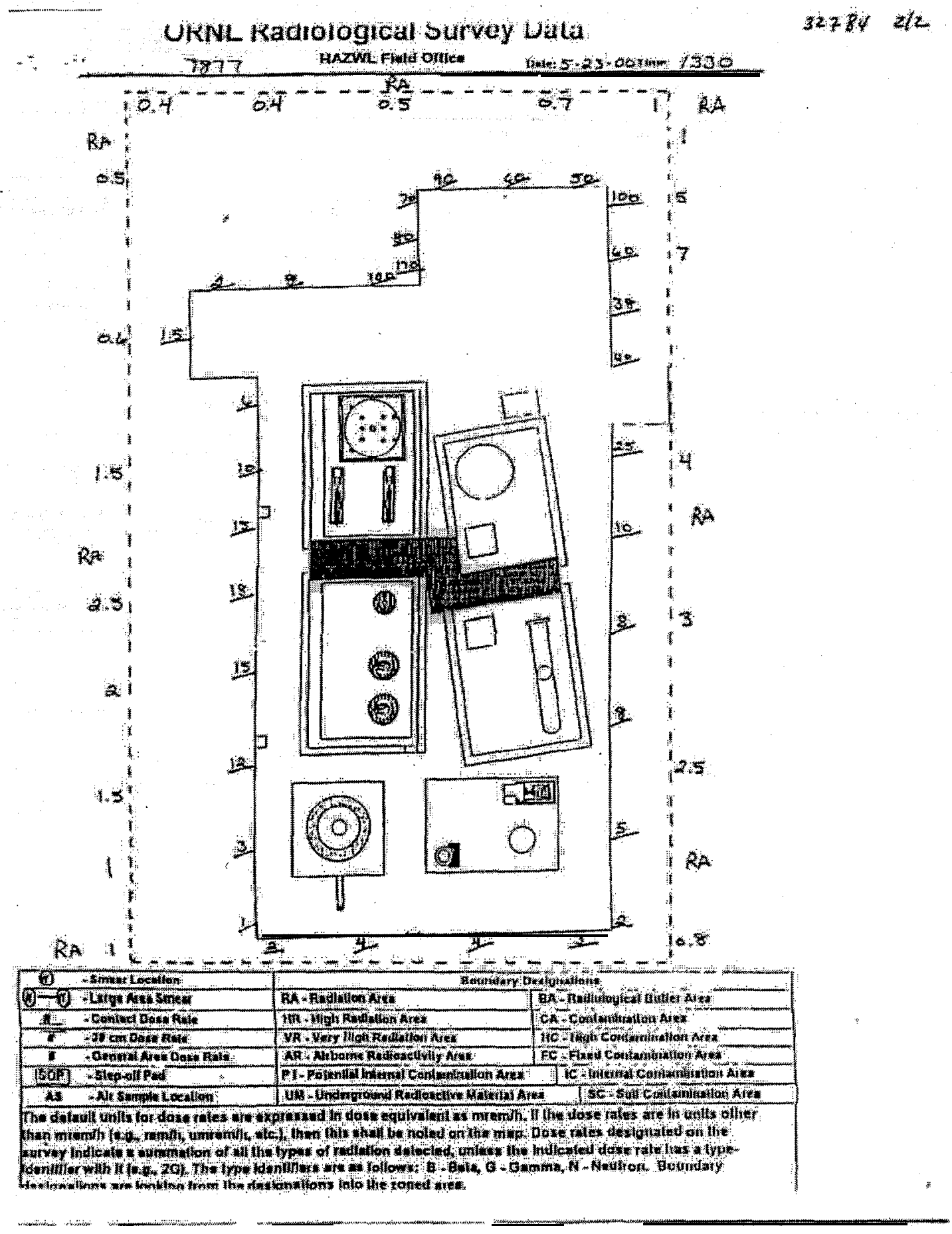


Survey 32876, page 1 of 2 .

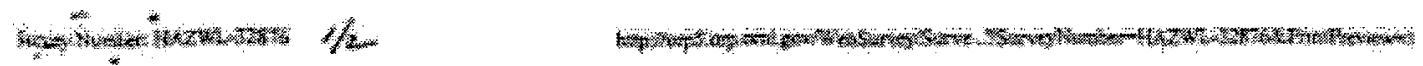

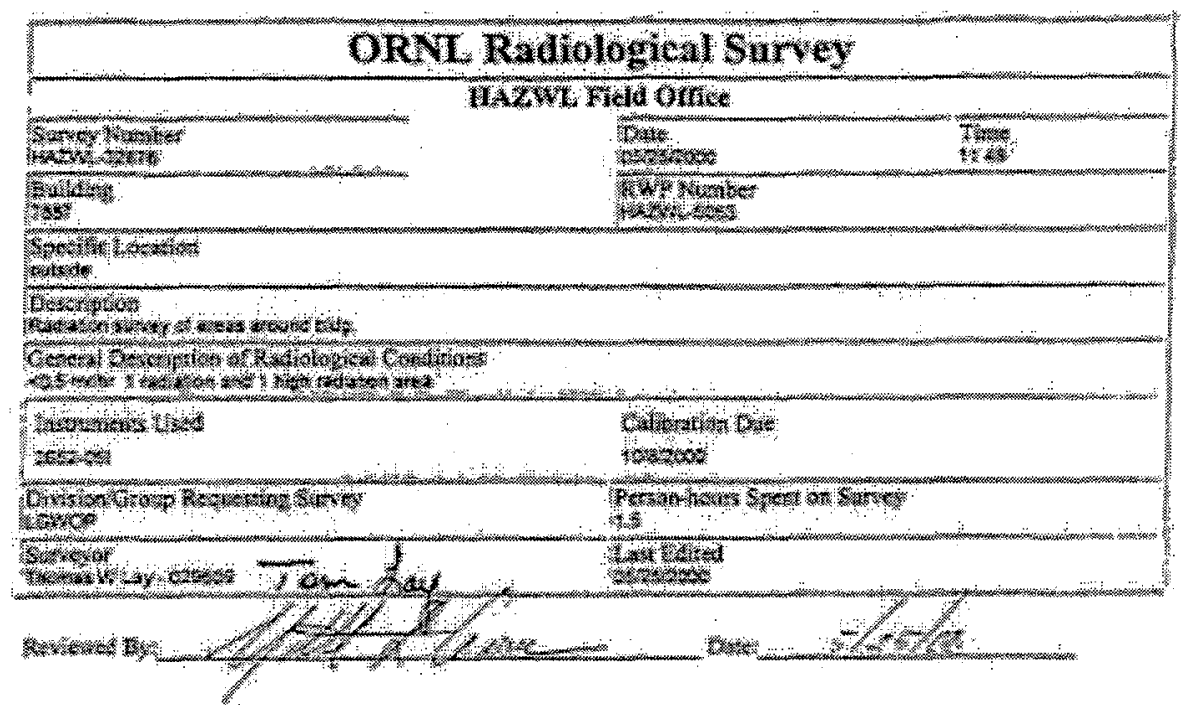



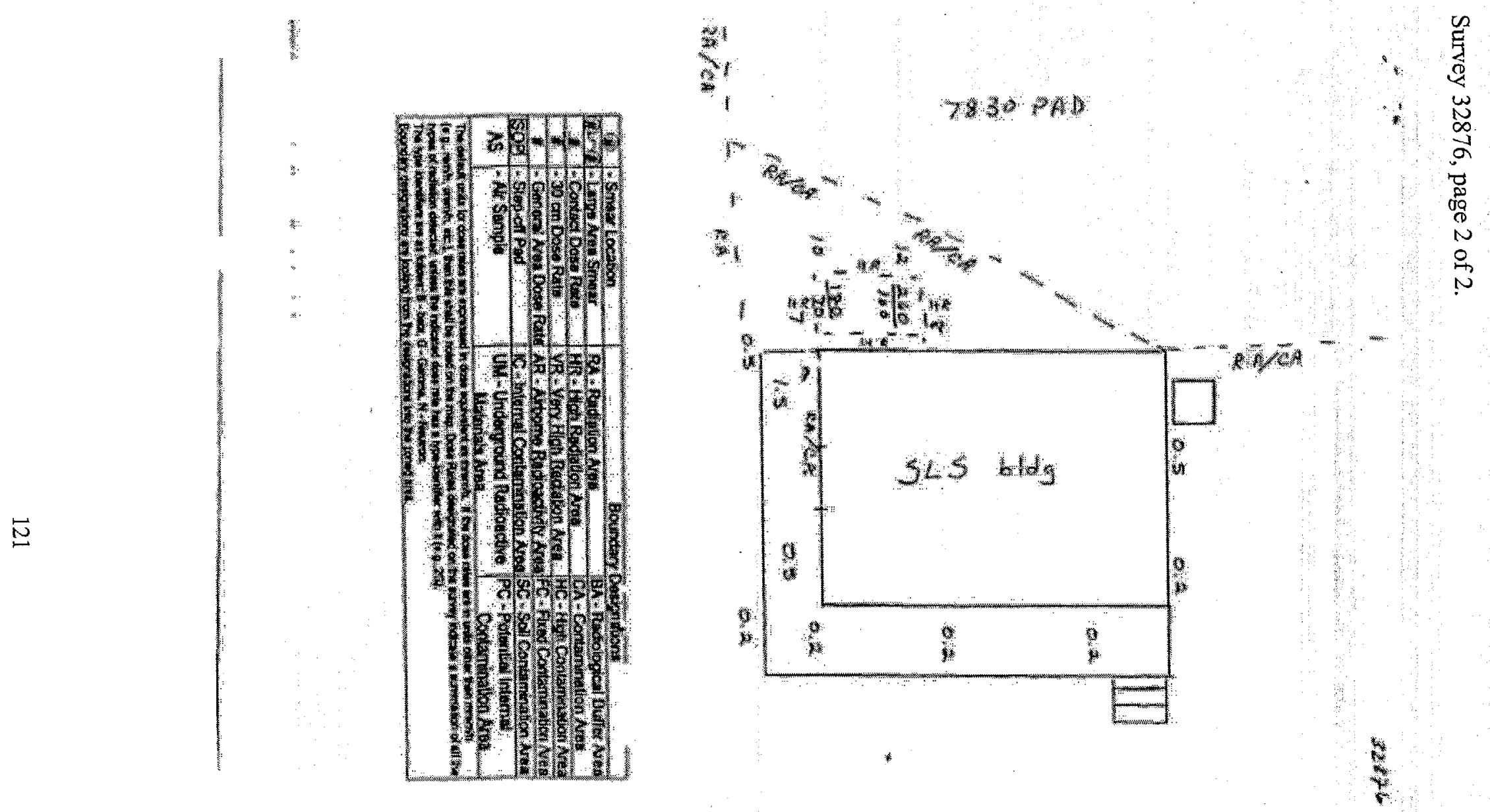

f 
Survey 32879 , page 1 of 3 .

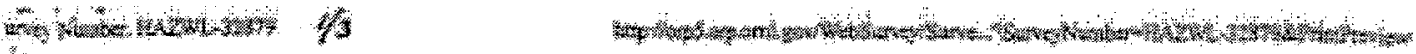

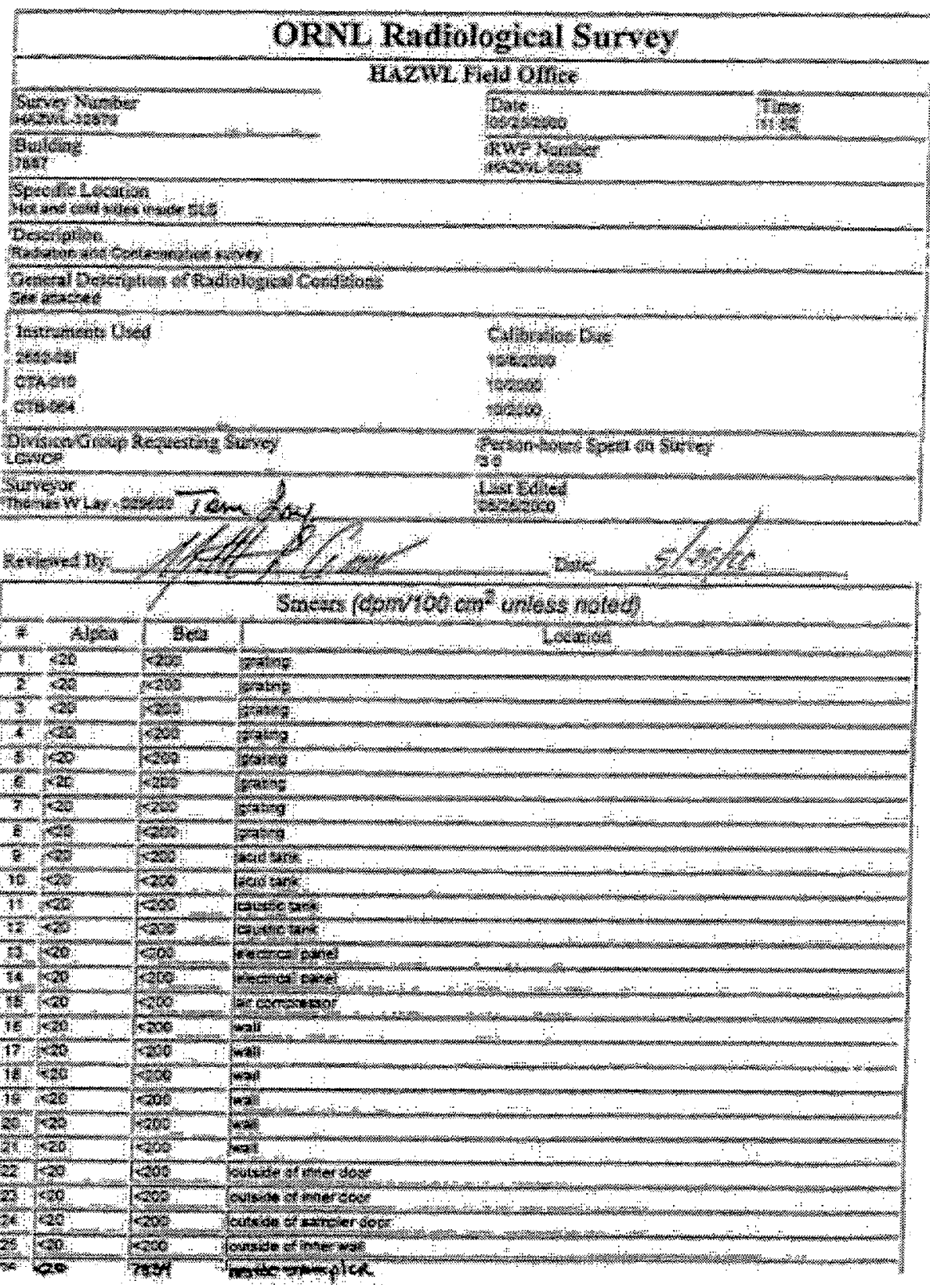


Survey 32879, page 2 of 3 .

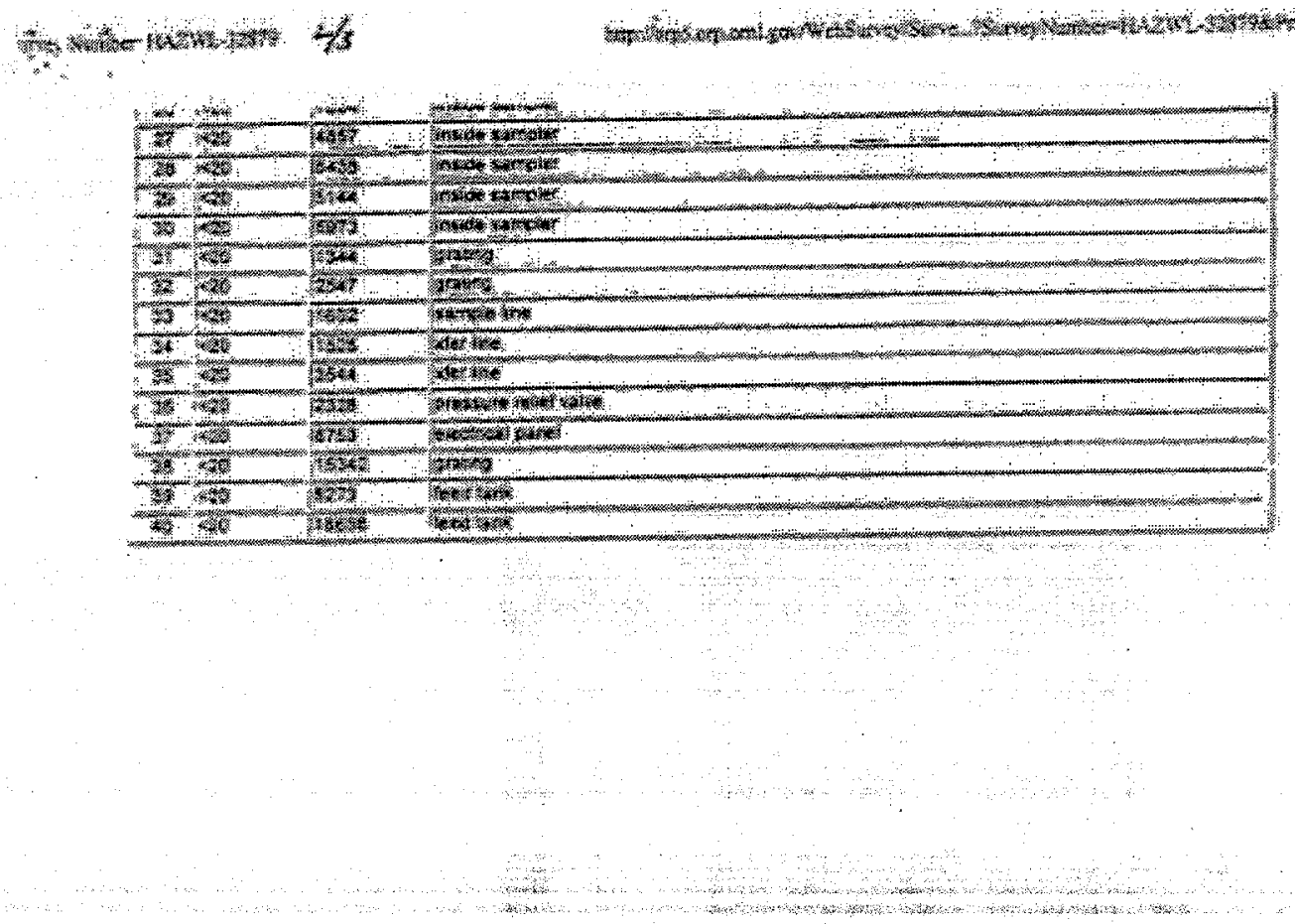


Survey 32879, page 3 of 3 .
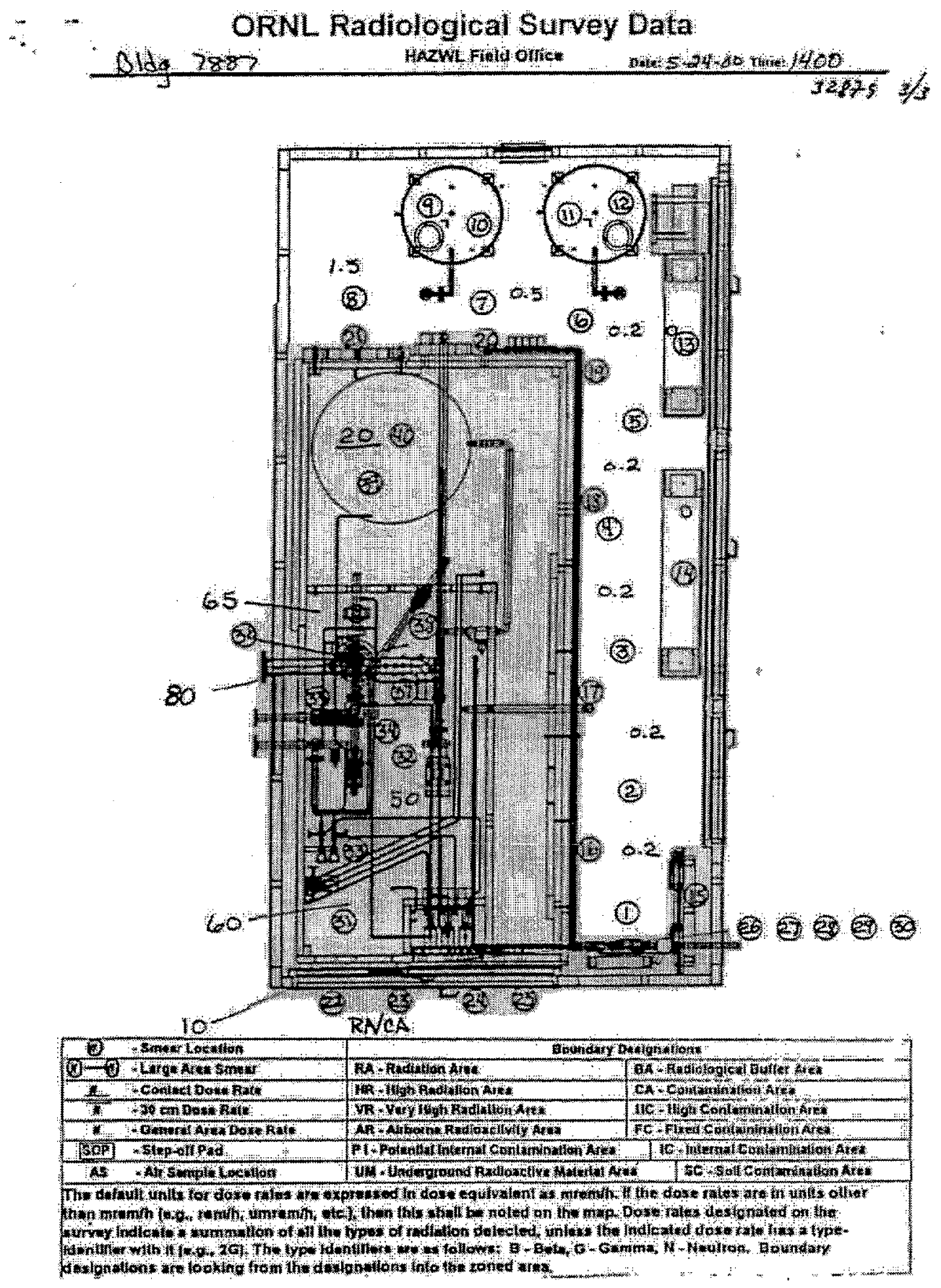
Survey 32880, page 1 of 6 .

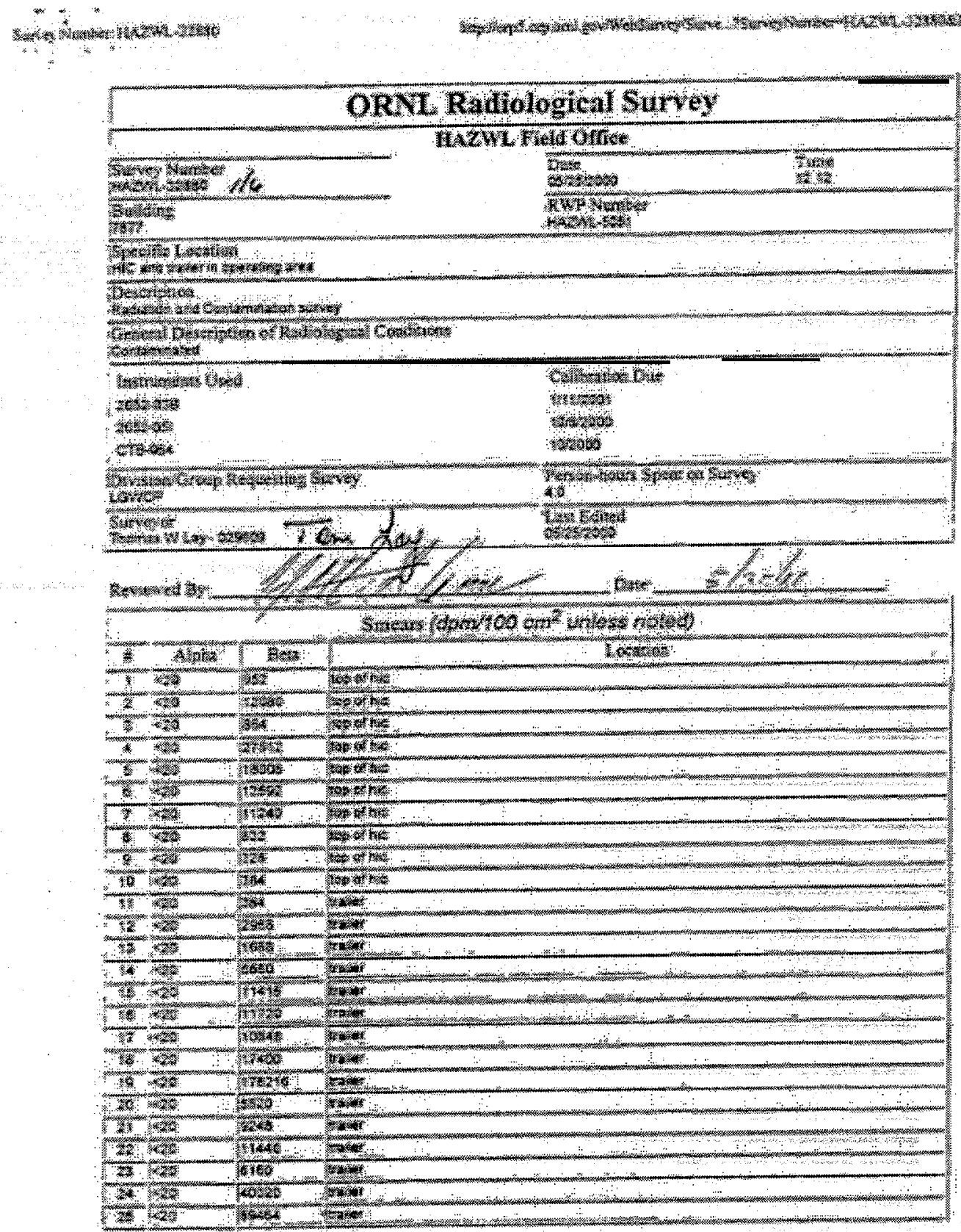


Survey 32880, page 2 of 6 .

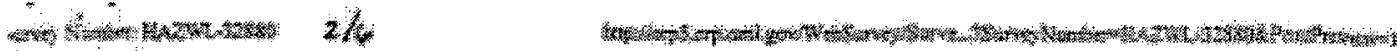

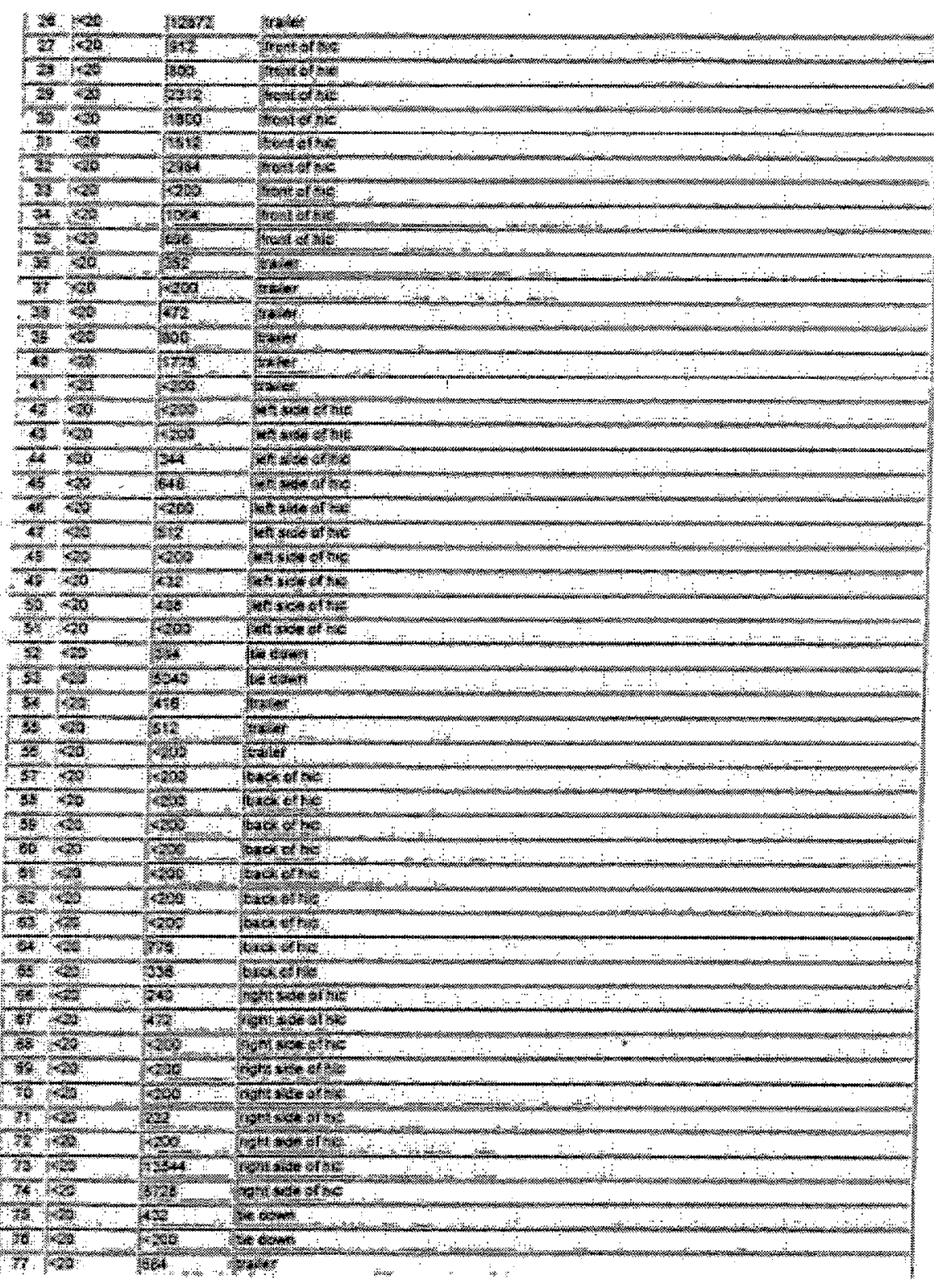

in

serese 
Survey 32880, page 3 of 6 .

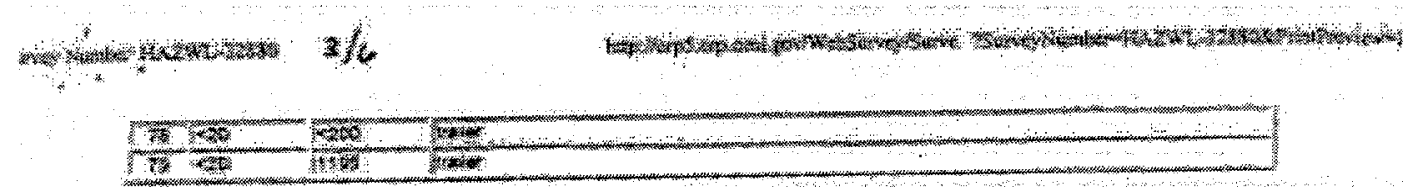



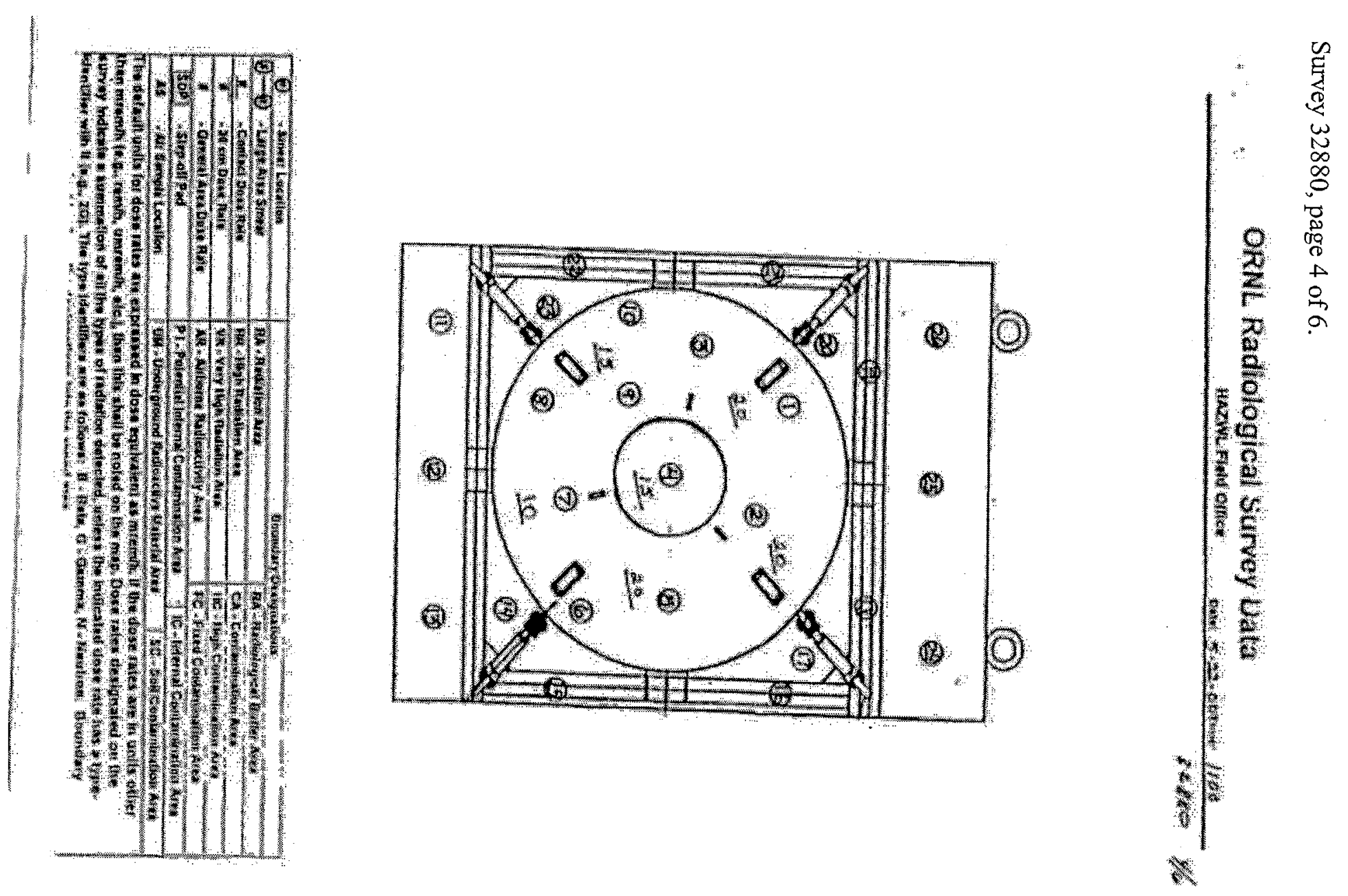
Survey 32880, page 5 of 6 .

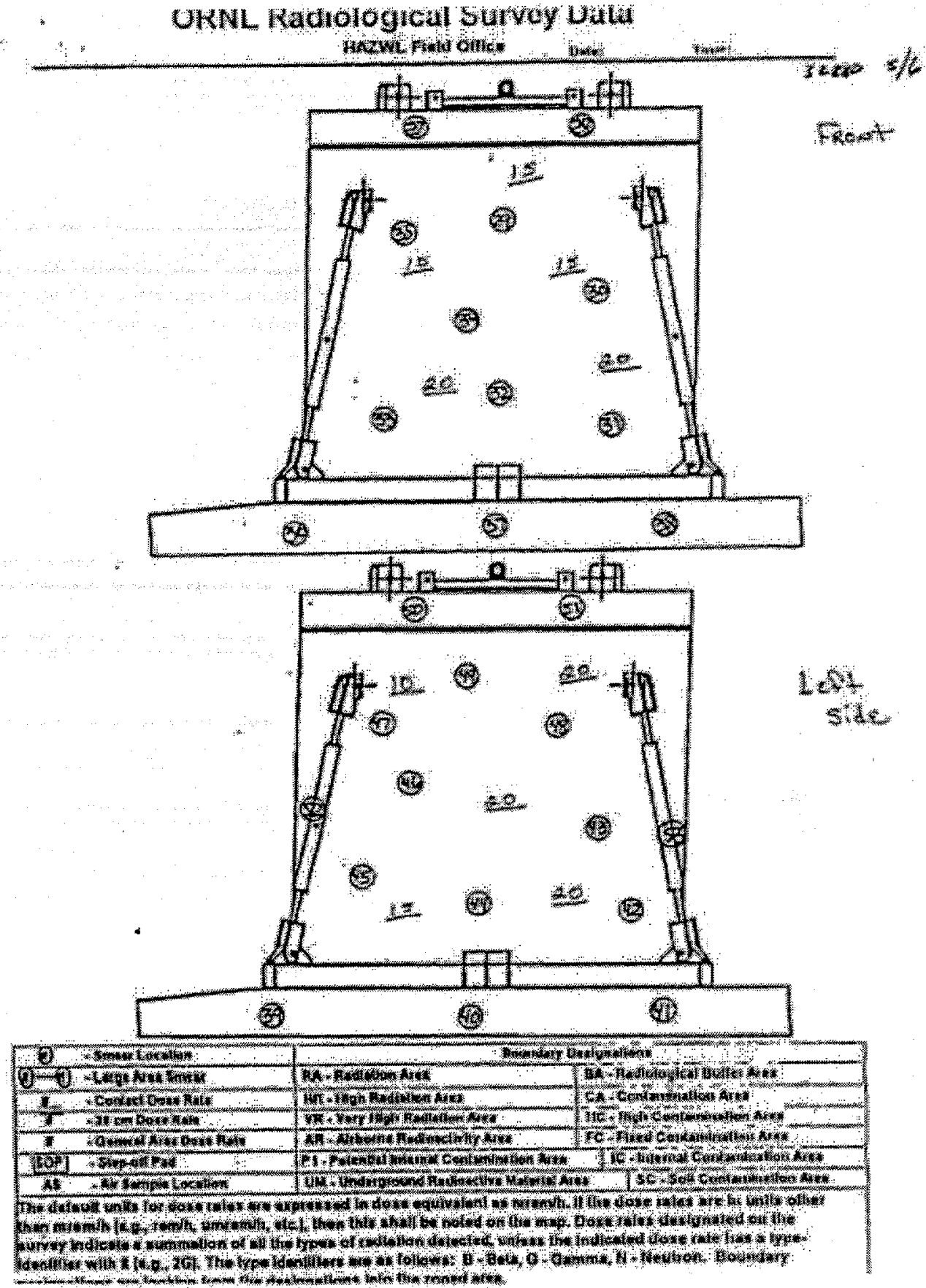


Survey 32880, page 6 of 6 .

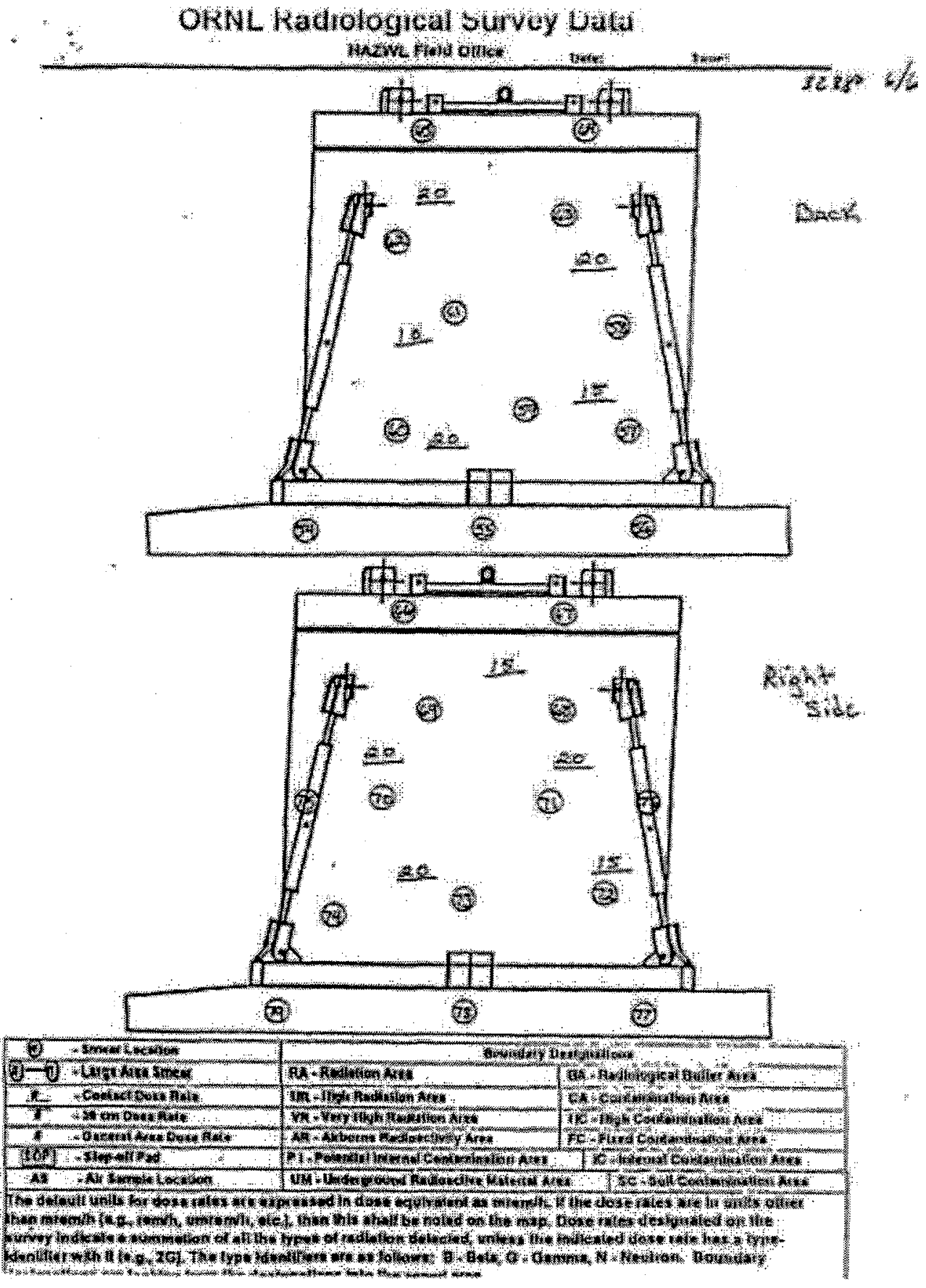


ORNL/TM-2001/129

\section{INTERNAL DISTRIBUTION}

1. R. L. Cummins

2. B. S. Evans

3. L. L. Farr

4. J. N. Herndon

5. T. D. Hylton

6. H. L. Jennings

7. R. T. Jubin

8. C. M Kendrick

9. M. J. Lanterbach

10. T. Lay

11. D. D. Lee

12. B. E. Lewis
13. J. J. Maddox

14. C. P. McGinnis

15. B. D. Oakley

16. S. A. Richardson

17. S. M. Robinson

18. C. B. Scott

19. P. A. Taylor

20. J. F. Walker, Jr.

21. ORNL Central Research Library

22. ORNL Laboratory Records, RC

23. ORNL Laboratory Records, OSTI

\section{EXTERNAL DISTRIBUTION}

24. J. T. Carter, Westinghouse Savannah River Company, P.O. Box 616, 704-3N, Room S151, Aiken, SC 29808 .

25. Samuel D. Fink, Westinghouse Savannah River Company, P.O. Box 616, 773-A, Room B112, Aiken, SC 29808

26. Roger L Gilchrist, Pacific Northwest National Laboratory, P.O. Box 999, MS:K9-91, Richland, WA 99352

27. H. D. Harmon, TFA Salt Waste Processing Program, Westinghouse, Savannah River Company, Building 704-3N, Room N1 11, Aiken, SC 29808

28. N. R. Mann, Idaho National Engineering and Environmental Laboratory P.O. Box 1625, Idaho Falls, ID 83415-5218

29. D. J. McCabe, Westinghouse Savannah River Company, P.O. Box 616, 773-42A, Room 152, Aiken, SC 29808

30. C. A. Nash, Westinghouse Savannah River Company, P.O. Box 616, 773-42A, Room 182, Aiken, SC 29808

31. J. R. Noble-Dial, U.S. Department of Energy, Oak Ridge Operations Office, P.O. Box 2001, Oak Ridge, TN 37831-8620

32. W. L. Tamosaitis, Westinghouse Savannah River Company, P.O. Box 616, 773-A, Room A-231, Aiken, SC 29808

33. T. A. Todd, Idaho National Engineering and Environmental Laboratory, Building 637, MS-5218, Idaho Falls, ID 83415-5218

34. Tanks Focus Headquarters Program Manager, c/o K. D. Gerdes, DOE Office of Science and Technology, 9901 Germantown Road, 1154 Cloverleaf Building, Germantown, MD 20874- 1290

35. Tanks Focus Area Technical Team, c/o B. J. Williams, Pacific Northwest National Laboratory, P.O. Box 999, MSIN K9-69, Richland, WA 99352

36. Tanks Focus Area Program Lead, c/o T. P. Pietrok, U.S. Department of Energy, Richland Operations Office, P.O. Box 550, MS:K8-50, Richland, WA 99352 
. 